Andreia Santos do Nascimento / Cerilene Santiago Machado Geni da Silva Sodré / Carlos Alfredo Lopes de Carvalho

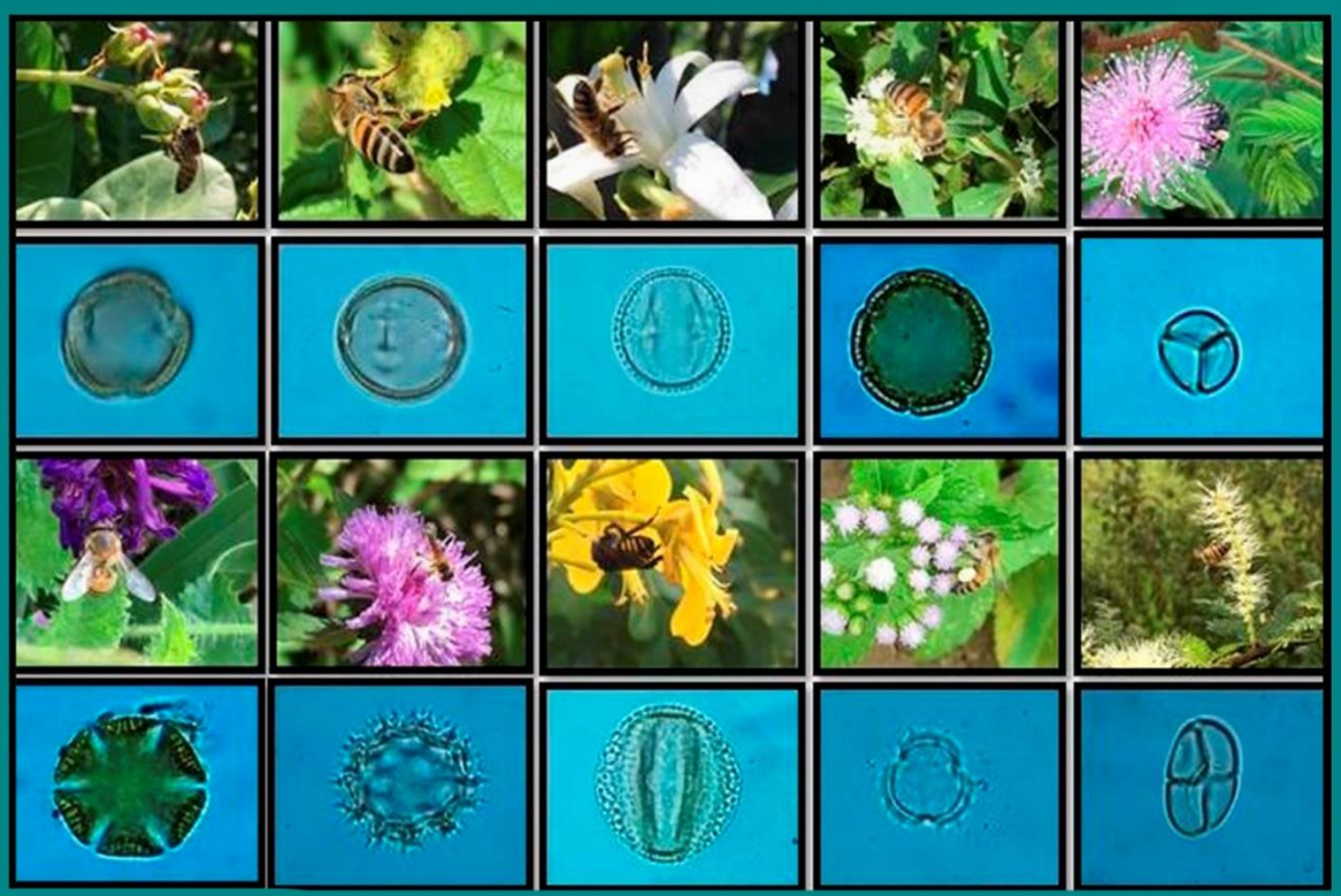

\title{
ATLAS POLÍNICO DE PLANTAS DE INTERESSE APICOLA/MELIPONICOLA PARA O RECÔNCAVO BAIANO
}

$1^{\circ}$ Edição

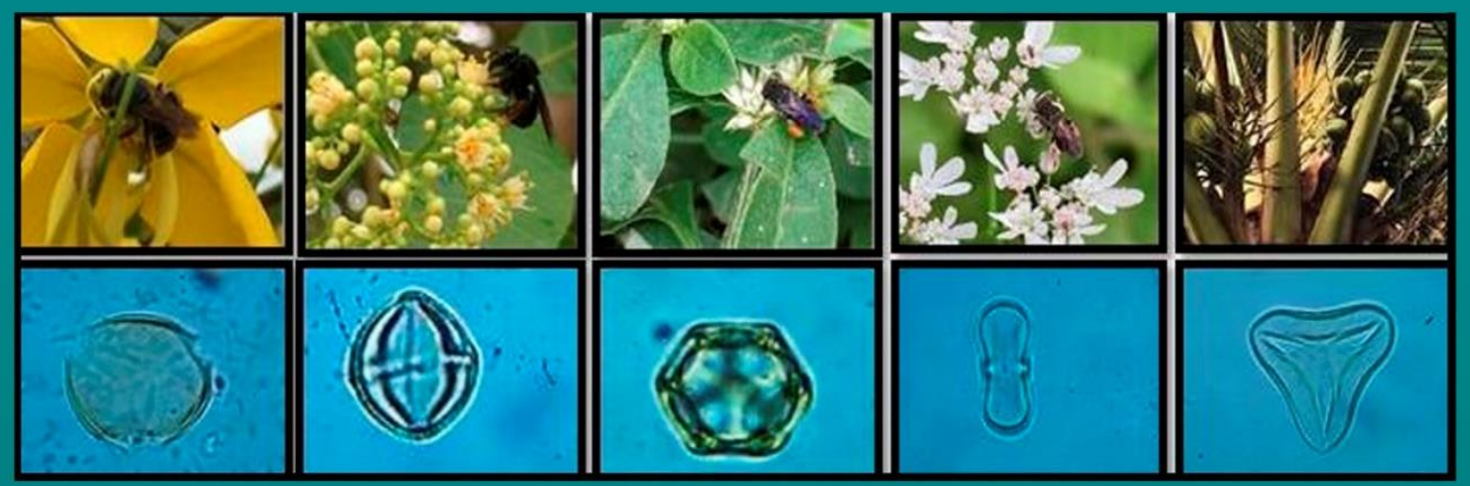

São José dos Pinhais

BRAZILIAN JOURNALS PUBLICAÇÕES DE PERIÓDICOS E EDITORA 2021 
Andreia Santos do Nascimento / Cerilene Santiago Machado Geni da Silva Sodré / Carlos Alfredo Lopes de Carvalho

\section{Atlas polínico de plantas de interesse apícola/meliponícola para o Recôncavo Baiano}

$1^{\circ}$ Edição

São José dos Pinhais 2021 


\author{
2021 by Brazilian Journals Editora \\ Copyright (C) Brazilian Journals Editora \\ Copyright do Texto (C) 2021 Os Autores \\ Copyright da Edição @ 2021 Brazilian Journals Editora \\ Diagramação: Sabrina Binotti \\ Edição de Arte: Andreia S. do Nascimento \\ Revisão: Os autores
}

\begin{abstract}
O conteúdo do livro e seus dados em sua forma, correção e confiabilidade são de responsabilidade exclusiva dos autores. Permitido o download da obra e o compartilhamento desde que sejam atribuídos créditos aos autores, mas sem a possibilidade de alterá-la de nenhuma forma ou utilizá-la para fins comerciais.
\end{abstract}

Conselho Editorial:

Prof ${ }^{a}$. Dra . Fátima Cibele Soares - Universidade Federal do Pampa, Brasil.

Prof. Dr. Gilson Silva Filho - Centro Universitário São Camilo, Brasil.

Prof. Msc. Júlio Nonato Silva Nascimento - Instituto Federal de Educação, Ciência e Tecnologia do Pará, Brasil.

Prof ${ }^{a}$. Msc. Adriana Karin Goelzer Leining - Universidade Federal do Paraná, Brasil.

Prof. Msc. Ricardo Sérgio da Silva - Universidade Federal de Pernambuco, Brasil.

Prof. Esp. Haroldo Wilson da Silva - Universidade Estadual Paulista Júlio de Mesquita Filho, Brasil.

Prof. Dr. Orlando Silvestre Fragata - Universidade Fernando Pessoa, Portugal.

Prof. Dr. Orlando Ramos do Nascimento Júnior - Universidade Estadual de Alagoas, Brasil.

Prof ${ }^{a}$. Drạ. Angela Maria Pires Caniato - Universidade Estadual de Maringá, Brasil.

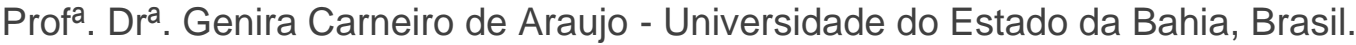

Prof. Dr. José Arilson de Souza - Universidade Federal de Rondônia, Brasil.

Profá. Msc. Maria Elena Nascimento de Lima - Universidade do Estado do Pará, Brasil.

Prof. Caio Henrique Ungarato Fiorese - Universidade Federal do Espírito Santo, Brasil.

Prof a . Drá. Silvana Saionara Gollo - Instituto Federal de Educação, Ciência e Tecnologia do

Rio Grande do Sul, Brasil.

Prof ${ }^{a}$. Drª . Mariza Ferreira da Silva - Universidade Federal do Paraná, Brasil.

Prof. Msc. Daniel Molina Botache - Universidad del Tolima, Colômbia.

Prof. Dr. Armando Carlos de Pina Filho- Universidade Federal do Rio de Janeiro, Brasil.

Prof. Dr. Hudson do Vale de Oliveira- Instituto Federal de Educação, Ciência e Tecnologia de Roraima, Brasil.

Prof ${ }^{a}$. Msc. Juliana Barbosa de Faria - Universidade Federal do Triângulo Mineiro, Brasil.

Prof ${ }^{a}$. Esp. Marília Emanuela Ferreira de Jesus - Universidade Federal da Bahia, Brasil.

Prof. Msc. Jadson Justi - Universidade Federal do Amazonas, Brasil.

Prof ${ }^{a}$. Dr ${ }^{\underline{a}}$. Alexandra Ferronato Beatrici - Instituto Federal de Educação, Ciência e

Tecnologia do Rio Grande do Sul, Brasil.

Profa . Msc. Caroline Gomes Mâcedo - Universidade Federal do Pará, Brasil.

Prof. Dr. Dilson Henrique Ramos Evangelista - Universidade Federal do Sul e Sudeste do

Pará, Brasil.

Prof. Dr. Edmilson Cesar Bortoletto - Universidade Estadual de Maringá, Brasil.

Prof. Msc. Raphael Magalhães Hoed - Instituto Federal do Norte de Minas Gerais, Brasil.

Prof ${ }^{a}$. Msc. Eulália Cristina Costa de Carvalho - Universidade Federal do Maranhão, Brasil.

Prof. Msc. Fabiano Roberto Santos de Lima - Centro Universitário Geraldo di Biase, Brasil.

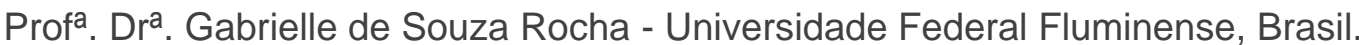

Prof. Dr. Helder Antônio da Silva, Instituto Federal de Educação do Sudeste de Minas

Gerais, Brasil. 
Prof ${ }^{a}$. Esp. Lida Graciela Valenzuela de Brull - Universidad Nacional de Pilar, Paraguai.

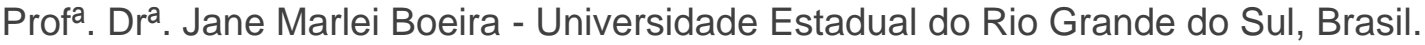
Prof ${ }^{a}$. Dra . Carolina de Castro Nadaf Leal - Universidade Estácio de Sá, Brasil.

Prof. Dr. Carlos Alberto Mendes Morais - Universidade do Vale do Rio do Sino, Brasil.

Prof. Dr. Richard Silva Martins - Instituto Federal de Educação, Ciência e Tecnologia Sul Rio Grandense, Brasil.

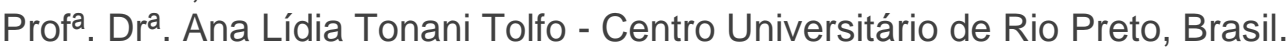

Prof. Dr. André Luís Ribeiro Lacerda - Universidade Federal de Mato Grosso, Brasil.

Prof. Dr. Wagner Corsino Enedino - Universidade Federal de Mato Grosso, Brasil.

Profa . Msc. Scheila Daiana Severo Hollveg - Universidade Franciscana, Brasil.

Prof. Dr. José Alberto Yemal - Universidade Paulista, Brasil.

Prof ${ }^{a}$. Dr ${ }^{\mathrm{a}}$. Adriana Estela Sanjuan Montebello - Universidade Federal de São Carlos, Brasil. Profa . Msc. Onofre Vargas Júnior - Instituto Federal de Educação, Ciência e Tecnologia Goiano, Brasil.

Prof ${ }^{a}$. Dra . Rita de Cássia da Silva Oliveira - Universidade Estadual de Ponta Grossa, Brasil. Prof ${ }^{a}$. Dr ${ }^{a}$. Leticia Dias Lima Jedlicka - Universidade Federal do Sul e Sudeste do Pará, Brasil.

Prof ${ }^{\text {a }}$. Dr ${ }^{\mathrm{a}}$. Joseina Moutinho Tavares - Instituto Federal da Bahia, Brasil

Prof. Dr. Paulo Henrique de Miranda Montenegro - Universidade Federal da Paraíba, Brasil. Prof. Dr. Claudinei de Souza Guimarães - Universidade Federal do Rio de Janeiro, Brasil.

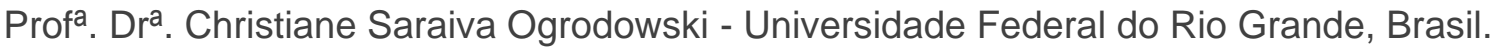
Prof ${ }^{a}$. Dr . Celeide Pereira - Universidade Tecnológica Federal do Paraná, Brasil. Prof ${ }^{a}$. Msc. Alexandra da Rocha Gomes - Centro Universitário Unifacvest, Brasil. Prof ${ }^{a}$. Dr ${ }^{a}$. Djanavia Azevêdo da Luz - Universidade Federal do Maranhão, Brasil. Prof. Dr. Eduardo Dória Silva - Universidade Federal de Pernambuco, Brasil. Profa. Msc. Juliane de Almeida Lira - Faculdade de Itaituba, Brasil.

Prof. Dr. Luiz Antonio Souza de Araujo - Universidade Federal Fluminense, Brasil.

Prof. Dr. Rafael de Almeida Schiavon - Universidade Estadual de Maringá, Brasil.

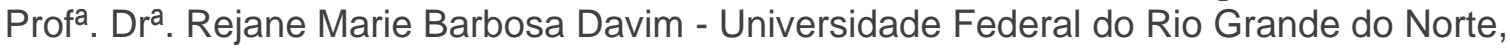
Brasil.

Prof. Msc. Salvador Viana Gomes Junior - Universidade Potiguar, Brasil.

Prof. Dr. Caio Marcio Barros de Oliveira - Universidade Federal do Maranhão, Brasil.

Prof. Dr. Cleiseano Emanuel da Silva Paniagua - Instituto Federal de Educação, Ciência e Tecnologia de Goiás, Brasil.

Prof ${ }^{a}$. Dr ${ }^{\mathrm{a}}$. Ercilia de Stefano - Universidade Federal Fluminense, Brasil. 


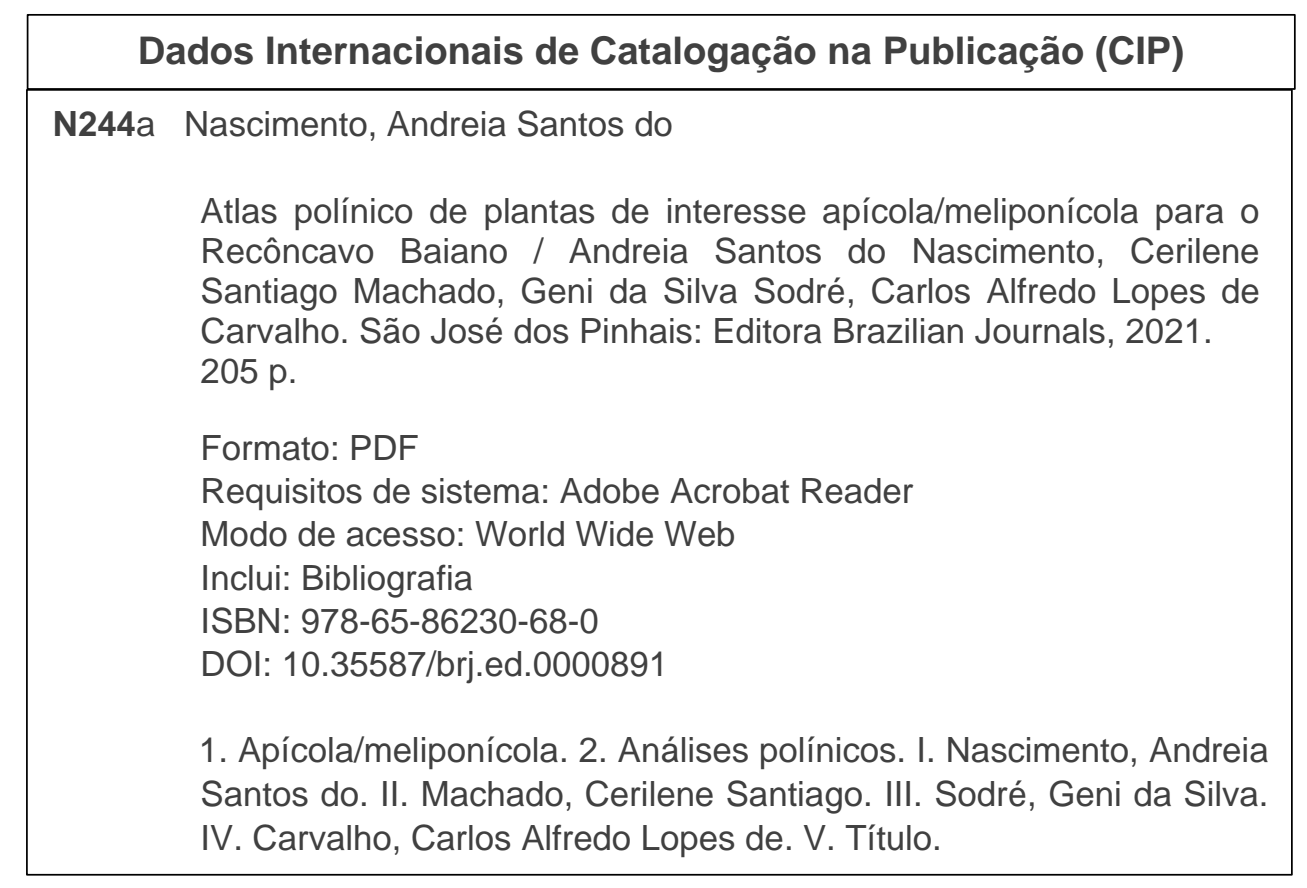

\section{Equipe de realização}

Redação e formatação da obra: Andreia S. do Nascimento Revisão do texto: Cerilene S. Machado; Geni da S. Sodré e Carlos Alfredo L. de Carvalho

Revisão da Normas da ABNT: Cerilene S. Machado

Correção dos termos técnicos: Andreia S. do Nascimento; Cerilene S. Machado e Geni da S. Sodré

Capa: Andreia S. do Nascimento Fotomicrografias: Andreia S. do Nascimento Fotografias: Andreia S. do Nascimento; Carlos Alfredo L. de Carvalho e Leandro S. de Jesus Arte final: Andreia S. do Nascimento

Brazilian Journals Editora São José dos Pinhais - Paraná - Brasil www.brazilianjournals.com.br editora@brazilianjournals.com.br 


\section{OS AUTORES}

Andreia Santos do Nascimento

Universidade Federal do Recôncavo da Bahia (CCAAB/UFRB)

Grupo de Pesquisa Insecta: asndea@gmail.com

Cerilene Santiago Machado

Universidade Federal do Recôncavo da Bahia

(CCAAB/UFRB)

Grupo de Pesquisa Insecta: cerilenes7@gmail.com

Geni da Silva Sodré

Universidade Federal do Recôncavo da Bahia (CCAAB/UFRB)

Grupo de Pesquisa Insecta: geni@ufrb.edu.br

Carlos Alfredo Lopes de Carvalho

Universidade Federal do Recôncavo da Bahia (CCAAB/UFRB)

Grupo de Pesquisa Insecta: calfredo@ufrb.edu.br 


\section{AGRADECIMENTOS}

Agradecemos ao professor Paulo Cesar Lemos de Carvalho, pelo auxílio na identificação das espécies vegetais.

A toda equipe do Herbário (Casa da Botânica) da Universidade Federal do Recôncavo da Bahia - UFRB em especial ao Prof. Márcio Lacerda Lopes Martins, pelo apoio e auxílio nas identificações do material vegetal.

À Universidade Federal do Recôncavo da Bahia (UFRB).

Ao CNPq (Conselho Nacional de Desenvolvimento Científico e Tecnológico) pela bolsa de Iniciação cientifica (PIBIC/UFRB) e a CAPES (Coordenação de Aperfeiçoamento de Pessoal de Nível Superior) pela bolsa de mestrado de A. S. do Nascimento, as quais permitiram maior dedicação na execução da pesquisa.

Ao Grupo de Pesquisa Insecta (CCAAB/UFRB).

Ao Eng. Agrônomo Leandro Silva de Jesus e Msc. Luzimário Lima Pereira pela ajuda na coleta do material vegetal.

Ao Dr. Wyratan da Silva Santos e Msc. Luzimário Lima Pereira pelo auxílio na manipulação do software para medição dos grãos de pólen. 


\section{PREFÁCIO}

A análise polínica de produtos da colmeia é uma das linhas de atuação do Grupo de Pesquisa Insecta desde o ano 2000, com resultados promissores e inserindo na pesquisa científica relacionada à melissopalinologia alunos de iniciação científica, mestrado e doutorado, além de pós-doutorandos. O grupo conta com publicação em periódicos nacionais e internacionais, onde são divulgados resultados de estudos de fontes poliníferas e nectaríferas exploradas por abelhas sociais como Apis mellifera Linnaeus, 1758 e Meliponini (Melipona spp.), sendo a identificação da flora explorada por estas abelhas, realizada em sua maioria por meio de estudos palinológico dos produtos da colmeia.

O livro "Atlas polínico de plantas de interesse apícola/meliponícola para o Recôncavo Baiano" é resultado de um amplo espectro de estudos relacionados à análise polínica de produtos da colmeia de abelhas sociais realizado pelos autores, especialmente os projetos de iniciação cientifica e mestrado desenvolvidos no período de 2005 a 2009, que contribuíram de forma expressiva para coleção de referências de grãos de pólen (palinoteca) de plantas de interesse apícola e meliponícola do Núcleo de Estudo dos Insetos da Universidade Federal do Recôncavo da Bahia.

A apresentação da descrição polínica de táxons das principais famílias apontadas como potenciais para apicultura e meliponicultura na região do Recôncavo Baiano, contribuirá na identificação de tipos polínicos em produtos da colmeia em estudos futuros.

Comumente, estudos relacionados à identificação da flora visitada pela abelha a partir de seus produtos (mel, pólen apícola, samburá, própolis e geoprópolis) utilizam a análise polínica. Porém, a identificação dos tipos polínicos (conjunto de grãos pólen) é um trabalho que requer treinamento, conhecimento e dedicação, sendo necessário consultas a palinoteca (coleção de grão pólen de referências), atlas e catálogos polínicos, bem como outras publicações pertinentes. Nesse sentido, este livro apresenta um conteúdo relevante e que pode auxiliar muitos trabalhos de pesquisa, contribuindo para identificação da flora visitada por abelhas sociais, especialmente no Recôncavo Baiano.

Os Autores. 
SUMÁRIO

1. INTRODUÇÃO

2. REVISÃO DE LITERATURA

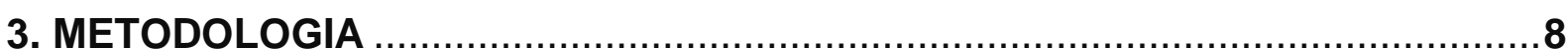

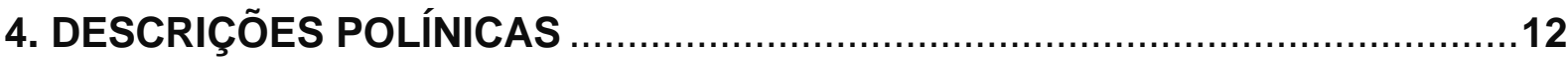

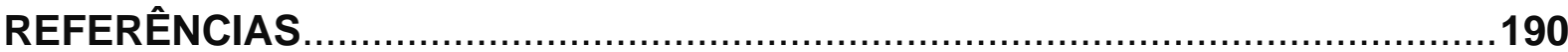




\section{INTRODUÇÃO}

A flora visitada por abelhas é objeto de estudo de muitos pesquisadores em espectro global (ADAMCHUK, 2020; MAJEWSKA; DRUŻYŃSKA; WOŁOSIAK, 2019; SANTOS et al., 2020; SNIDERMAN et al., 2018). Dentre as técnicas empregadas para identificação das fontes de recursos tróficos utilizadas por abelhas sociais, o uso da palinologia é frequente (PAREDES; BRYANT, 2020). A palinologia é a ciência que estuda o grão de pólen, sendo esta subdividida em aeropalinologia, entomopalinologia, iatropalinologia, paleoecologia, paleopalinologia, palinologia forense, melissopalinologia, entre outras com aplicações diversas (ALOTAIBI et al., 2020; BARTH, 2013). A melissopalinologia é o estudo do grão de pólen em produtos da colmeia, que auxilia na identificação da flora visitada pelas abelhas para coletas de recursos tróficos (MATOS; SANTOS, 2017; SILVA; SANTOS, 2014).

Em estudos que utilizaram a melissopalinologia, os tipos polínicos das famílias Asteraceae, Anacardiaceae, Euphorbiaceae, Fabaceae, Myrtaceae, Rubiaceae, Rutaceae, Solanaceae e Sapindaceae são citados como pólen dominante, indicando a importância de materiais bibliográficos que auxiliem na identificação de táxons dessa família botânica em produtos das colmeias (ANDRADE et al., 2019; MATOS; SANTOS, 2017; SANTOS et al., 2020).

A melissopalinologia pode contribuir para o rastreamento da origem geográfica de um determinado tipo de mel, uma vez que seu espectro polínico reflete a gama de recurso floral do local onde este mel específico foi produzido (EBENEZER; OLUGBENGA, 2010; SANTOS, 2011; SNIDERMAN, et al., 2018). Diferentes áreas geográficas apresentam associações florais particulares e quanto maior a diferença climática, mais notável é a variação na associação floral e ainda mais complexa é avaliação para determinação da sua origem botânica e geográfica (RICCIARDELLI; GALARINI; RICCIARDELLI, 2020; SNIDERMAN, et al., 2018).

Os caracteres morfológicos dos grãos de pólen são utilizados para a análise polínica, sendo apresentados por meio de descrições, com o uso de terminologia própria, além disso, as representações gráficas como desenhos e fotomicrografias auxiliam na identificação dos tipos polínicos (BARTH, 1989). Nesse sentido, as descrições polínicas e fotomicrografias, bem como as imagens das espécies vegetais apresentadas neste livro, podem contribuir para estudos relacionados com a identificação da flora visitada pelas abelhas, utilizando a técnica da análise polínica. 


\section{REVISÃO DE LITERATURA}

\subsection{MELISSOPALINOLOGIA}

A melissopalinologia é uma ciência que contribui para o controle de qualidade do mel, produto da colmeia mais amplamente conhecido e comercializado, bem como de outros produtos das abelhas (ÇELEMLİ et al., 2018; ESTEVINHO et al., 2016). O conteúdo polínico presente no mel, pólen apícola, samburá ou na própolis auxiliam também na identificação da flora visitada pelas abelhas, assim como no conhecimento de aspectos ecológicos como a origem geográfica deste produto e interação inseto planta.

Com a aplicação da análise polínica é possível à classificação do mel quanto à fonte nectarífera explorada pela abelha como monofloral (originário de uma única espécie vegetal) ou multifloral também chamando de mel silvestre (originário de um complexo de espécies vegetais) (BARTH, 1989). Para tanto, a melissopalinologia é realizada em etapas, cujas subdivisões são: a) processamento das amostras; b) preparo de lâminas com material polinífero comumente adotando as metodologias descritas por Erdtman (1960), Jones e Bryant (2004) e Louveaux; Maurizio e Vorwohl (1978); e c) posterior análise qualitativa e quantitativa.

\subsection{ANÁLISE MELISSOPALINOLÓGICA QUALITATIVA}

A análise qualitativa consiste em reconhecer os diferentes tipos polínicos e esporos de fungos no sedimento de determinado produto da colmeia (RICCIARDELLI; GALARINI; RICCIARDELLI, 2020). Geralmente, a análise qualitativa é relatada em estudos polínicos como a identificação dos grãos de pólen utilizando para tanto, catálogos com descrições polínicas, consultas a coleção de pólen de referência (palinoteca) (BRYANT, 2018; CORREIA et al., 2017; OSTERKAMP; JASPE, 2013; ROUBIK; MORENO, 1991; SILVA et al., 2020).

A identificação dos tipos polínicos encontrados nas amostras é baseada em caracteres morfológicos dos grãos de pólen como tipo de abertura do grão, ornamentação da exina, simetria, âmbito, número de unidades polínicas, forma e tamanho do grão (ERDTMAN, 1952; LABOURIAU, 1973).

\subsection{ANÁLISE MELISSOPALINOLÓGICA QUANTITATIVA}

A análise quantitativa é baseada na contagem dos grãos de pólen que compõem o espectro polínico amostral de determinando produto da colmeia. Recentemente, em estudos realizados com a análise polínica de mel adota-se a 
contagem de um número maior que 200 grãos de pólen por amostra (ANDRADE et al., 2019; MATOS; SANTOS, 2017; SANTOS et al., 2020). Este procedimento permite a determinação das classes de frequência estabelecida por Louveaux; Maurizio e Vorwohl (1978), que são as seguintes: pólen dominante ( $>45 \%$ do total de grãos do conjunto amostral), pólen acessório (de $16 \%$ a $45 \%$ ), pólen isolado importante (de $3 \%$ a $15 \%$ ) e pólen isolado ocasional ( $\leq 3 \%$ ). E também a frequência de ocorrência de cada tipo polínico na amostra, como: muito frequente $>50 \%$ das amostras; frequente $=20-50 \%$; esporádico $=10-20 \%$ e raro $<10 \%$ (FELLER-DEMALSY; PARENT; STRACHAN, 1987).

\subsection{PALINOTECA}

A análise palinológica requer uma boa coleção de materiais de referência. Para tanto, amostras de pólen retiradas de diferentes espécies botânicas e o equipamento de laboratório necessário para realizar análises qualitativas e quantitativas são fundamentais (RICCIARDELLI; GALARINI; RICCIARDELLI, 2020).

A coleção de lâminas de grãos de pólen de referência requer a coleta do material polinífero das espécies vegetais da região ou área de estudo, estes constituem a palinoteca (RICCIARDELLI; GALARINI; RICCIARDELLI, 2020). As palinotecas são coleções de lâminas permanentes para microscopia com material polinífero de espécies vegetais, fungos e esporos, bem como bancos de dados contendo imagens (fotomicrografias) dos grãos de pólen (CORREIA et al., 2017; EVALDT; PAZ; BAUERMANN, 2014).

Além da consulta a coleção de referência, existe a possibilidade de busca em palinotecas virtuais (on-line), como as disponibilizadas nos sites da Australasian Pollen and Spore Atlas (http://apsa.anu.edu.au/search) e RCPol-Rede de Catálogos Polínicos Online (http://rcpol.org.br/pt/home/).

Para obter os materiais preliminares é preciso coletar flores não abertas (botões florais) preferencialmente; a antese deve ser realizada em ambiente fechado para que outros grãos de pólen presentes no ar, principalmente os provenientes de plantas anemófilas, não contaminem as amostras de pólen. Portanto, as anteras maduras ou a flor inteira, se muito pequena, devem ser colhidas (RICCIARDELLI; GALARINI; RICCIARDELLI, 2020). Estes procedimentos auxiliam para formar uma palinoteca de acordo com o interesse do pesquisador. A coleção de referência base para elaboração deste atlas polínico foi produzida com a finalidade de auxiliar na identificação da flora fornecedora de recursos tróficos para abelhas sociais. 


\subsection{PLANTAS FORNECEDORAS DE RECURSOS TRÓFICOS}

O sucesso na criação de abelhas, apicultura e meliponicultura, está relacionado à disponibilidade da flora explorada por estes insetos, a qual fornece alimento (pólen e néctar), abrigo (ambiente para nidificação) e material para proteção das colônias (resinas) (Figura 1). O conjunto de plantas visitadas por abelhas para coleta de néctar, pólen e resina é definido como flora apícola/meliponícola (NORDI; BARRETO, 2016).

Algumas espécies vegetais são boas produtoras de pólen, sendo estas denominadas plantas poliníferas, estas produzem maior quantidade de grão de pólen em relação ao volume de néctar (BARTH, 1989; SANTOS et al., 2018), como Cocos nucifera L. e Mimosa caesalpiniifolia Benth. Por outro lado, são consideradas plantas nectaríferas aquelas que ofertam maior volume de néctar e menor produção de pólen (ALMEIDA et al., 2003; SANTOS et al., 2018), como Citrus spp. e Eucalyptus spp. Existem também plantas consideradas resiníferas, comumente exploradas para produção da própolis, como as espécies dos gêneros Dalbergia e Baccharis (MAGALHÃES et al., 2011; SANTOS et al., 2018).

Figura 1. Abelhas e plantas apícolas/meliponícolas. $\mathbf{A}=$ Ninho de Trigona spinipes em Anacardium occidentale, B= Ninho de Nannotrigona testaceicornis em tronco de Artocarpus heterophyllus, $\mathbf{C}=$ Ninho de Tetragonisca angustula em Artocarpus heterophyllus, $\mathrm{D}=$ Ninho de Scaptotrigona sp. em Azadirachta indica, E= Apis mellifera coletando pólen em Centratherum punctatum, $\mathbf{F}=$ Melipona scutellaris coletando pólen em Eugenia uniflora, $\mathrm{G}=$ Apis mellifera coletando néctar em Citrus sinensis, $\mathbf{H}=$ Apis mellifera coletando néctar em Richardia grandiflora, $\mathbf{I}=$ Trigona spinipes coletando resina em Blainvillea biaristata.

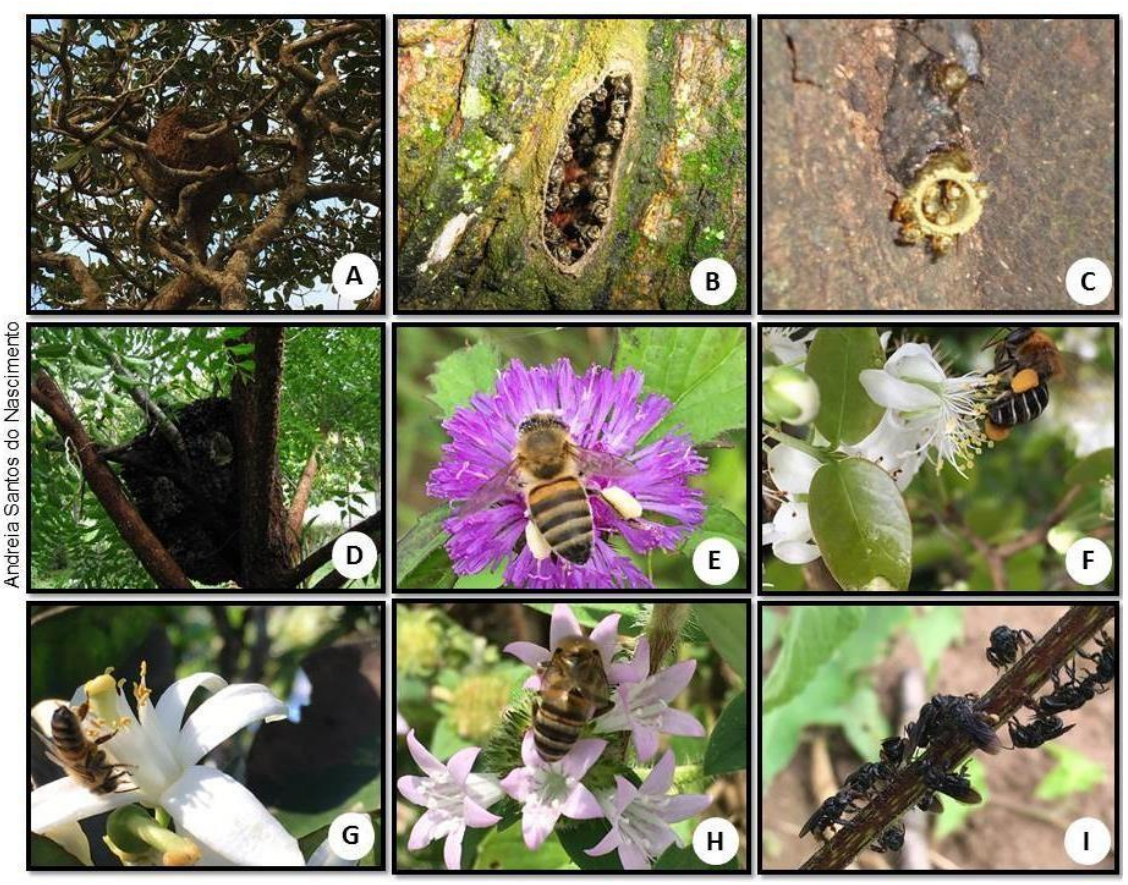

Fonte: Os Autores. 
Constituem-se plantas importantes para apicultura e meliponicultura, àquelas que são visitadas pelas abelhas para coleta de recursos tróficos, englobando as plantas cultivadas, plantas espontâneas, plantas ornamentais, plantas medicinais e espécies florestais.

O número de espécies vegetais visitadas por abelhas é muito diversificado e dependente da abundância destas plantas na região e ou em áreas próximas das colônias (ANDRADE et al., 2019; MATOS; SANTOS, 2017; SANTOS et al., 2020). Dentre as plantas cultivadas, comumente são citados em estudos de identificação da flora visitada pelas abelhas as espécies Anacardium occidentale L., Citrus spp., Helianthus annuus L., Eucalyptus spp. (BOSCO; LUZ, 2018; MACHADO; CARVALHO, 2006; NASCIMENTO; CARVALHO; SODRÉ, 2015; RIBEIRO et al., 2017; SILVA et al., 2020). Plantas medicinais e condimentares também são citadas como visitadas pelas abelhas no Recôncavo Baiano, como Pimpinella anisum L. (BARROS et al., 2002). Da mesma forma, espécies de interesse forrageiro para a pecuária, como Cajanus cajan (L. Millsp.) (AZEVEDO et al., 2007) e Gliricidia sepium (Jacq.) Stend. (CARVALHO et al., 2009).

As plantas espontâneas apresentam uma riqueza de espécie, podendo ser citado alguns exemplos importantes para região do Recôncavo Baiano: Borreria verticillata L., Cardiospermum corindum L. f. parviflorum (A. St.-Hil., A. Juss. \& Cambess.) Radlk., Centratherum punctatum Cass., Croton moritibensis Baill., Mimosa pudica L., Richardia grandiflora (Cham. \& Schtdl.) Steud. e Serjania pernambucensis Radlk (BOSCO; LUZ, 2018; NASCIMENTO; CARVALHO; SODRÉ, 2015; OLIVEIRA et al., 2013; SILVA et al., 2020).

A flora representada pela arborização urbana e espécies ornamentais também são fontes de recursos relevantes para sobrevivência das colônias (SILVA; SANTOS, 2014), particularmente para as abelhas sociais sem ferrão (Meliponini), que muitas vezes mantem suas colônias próximas das residências localizadas em perímetro urbano (NASCIMENTO et al., 2018). A palmeira-de-Manila (Veitchia merrillii (Becc.) H. E. Moore. é uma planta ornamental muito utilizada nos jardins residenciais na região do Recôncavo Baiano, suas flores branca-creme são visitadas por Meliponini como Plebeia sp., Scaptotrigona sp. e Trigona spinipes (LINS, 2020). Outros exemplos, são as espécies Cassia fistula L. (chuva-de-ouro) e Tibouchina granulosa (Desr.) Cogn., (quaresmeira) apontadas como plantas importantes para abelhas sociais (AGOSTINI; SAZIMA, 2003; BRIZOLA-BONACINA et al., 2012). 
Estudos sobre a identidade botânica das espécies visitadas pelas abelhas no Recôncavo Baiano e seu entorno, tem sido realizado por diversos autores e para diferentes espécies de abelhas (CARVALHO; MARCHINI, 1999; SANTANA et al., 2009; NASCIMENTO; CARVALHO, 2019). Para Apis mellifera pode ser citados os trabalhos de Moreti et al., (2000), Ramalho et al., (2007) e Santos et al., (2019); Melipona quadrifasciata anthidioides as pesquisas de Carvalho et al., (2006) e Nascimento et al. (2009); Melipona scutellaris os estudos de Andrade et al., (2009), Andrade et al. (2019), Carvalho et al., (2001), Costa et al., (2009), Oliveira et al., (2020) e Ramalho et al. (2007); e de Tetrapedia diversipes o trabalho de Neves et al., (2014). Contudo, o presente estudo é o primeiro catálogo que aborda a técnica e apresenta os tipos polínicos de diversas plantas visitadas por abelhas sociais nesta região.

\subsection{APICULTURA E MELIPONICULTURA}

A criação de abelhas sociais pertencentes ao gênero Apis (Apidae: Apini) caracteriza a apicultura (SANFORD; TEW, 2004). Apis mellifera é a espécie manejada para produção de mel em esfera global (NASCIMENTO; NASCIMENTO; CARVALHO, 2020). No Brasil a subespécie A. mellifera scutellata, denominada de abelha africanizada (SILVA et al., 2012), é manejada desde a década de 50, garantindo o sucesso da atividade apícola no país, que ocupou em 2019 o 6º lugar no ranking mundial dos principais exportadores de mel, com contribuição expressiva da região Nordeste (ABEMEL, 2020). Além da produção de mel, outros produtos apícolas também são de grande interesse para o mercado consumidor como a própolis, geleia real, cera, apitoxina, e o pólen apícola.

Meliponicultura é a terminologia utilizada para definir a criação de abelhas sociais sem ferrão (Apidae: Meliponini) (QUEZADA-EUÁN, 2018; VILLAS-BÔAS, 2018). As espécies do gênero Melipona são comumente criadas para produção do mel no Nordeste brasileiro (NASCIMENTO et al., 2018). O mel destas abelhas possui características diferenciadas do mel de $A$. mellifera, com valor de mercado mais elevado (SANT'ANA et al., 2020; SANTOS et al., 2018; SILVA et al., 2020).

Para exploração eficaz dos produtos da apicultura ou da meliponicultura é necessário o manejo correto das colônias. Dentre os aspectos com relevância nestas práticas de manejo é essencial que as abelhas tenham acesso a alimentos com os requerimentos nutricionais importantes para seu desenvolvimento. Dessa forma, o conhecimento das plantas úteis como fonte de alimento (poliníferas e ou nectaríferas) para as abelhas é fundamental para uma produção apícola/meliponícola rentável, 
vantajosa para o meio ambiente e para o apicultor/meliponicultor. Nesse contexto, a análise polínica de produtos da colmeia é uma ferramenta com relevância para disponibilização de lista de plantas visitadas por abelhas em uma determinada região. 


\section{METODOLOGIA}

\subsection{LOCAL DE AMOSTRAGEM}

As espécies vegetais $(n=176)$ de interesse apícola e meliponícola foram coletadas em áreas de entorno de apiários e meliponários na região do Recôncavo Baiano, nos municípios de Cachoeira (12³7'06"S; 3857'21"W), Castro Alves (1245'56"S; 39²5'42"W), Cruz das Almas (1240'12"S; 3906'07"W), Governador

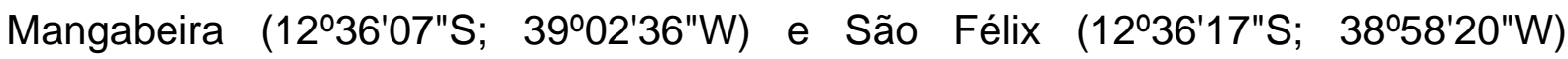
(Figura 2).

Figura 2. Mapa de Localização da amostragem de plantas apícolas e meliponícolas no Recôncavo Baiano. Dados do mapa @2020.

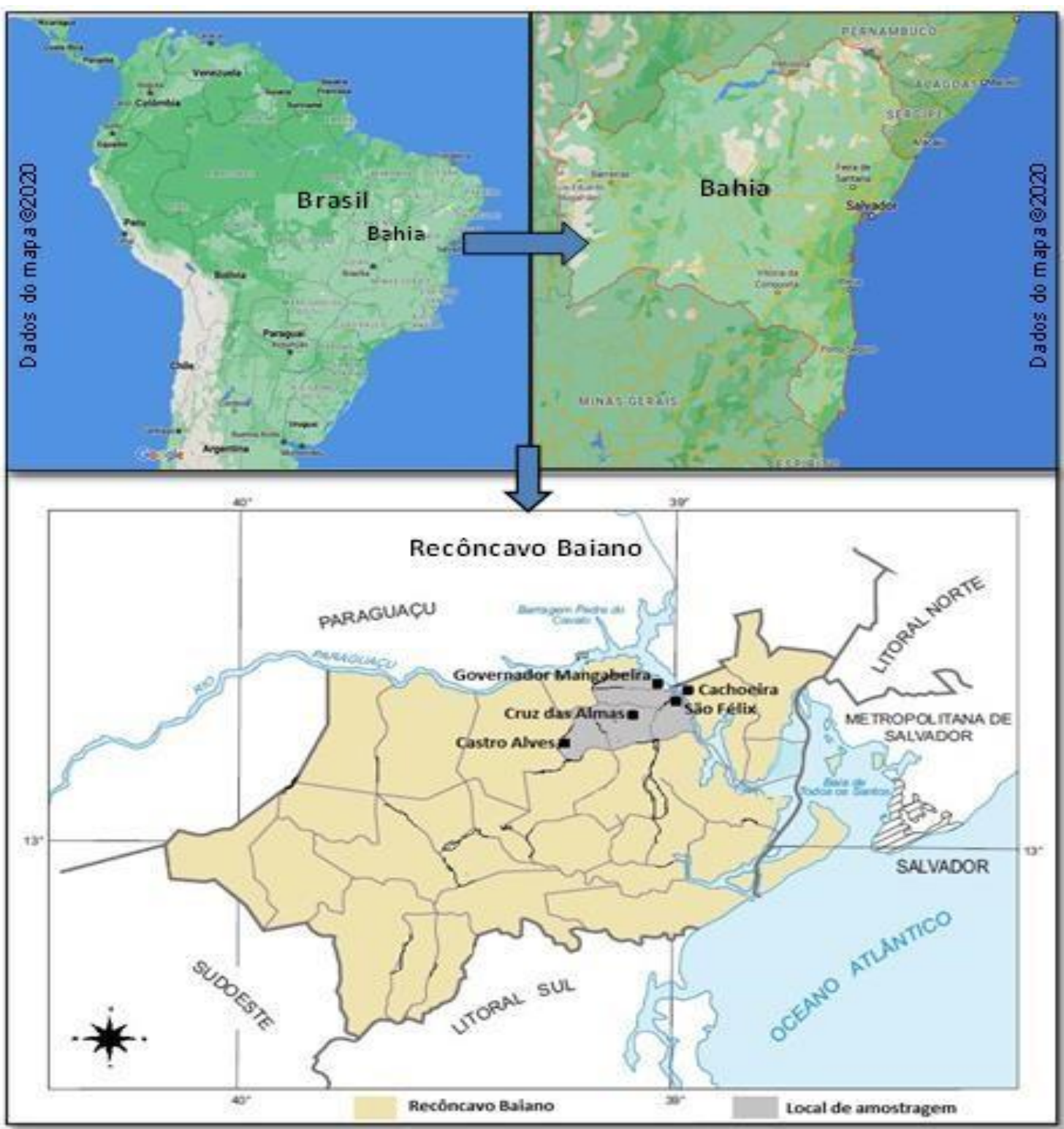

Fonte: Os Autores. 
O Território de Identidade do Recôncavo Baiano é composto por vinte municípios, sendo que esta região geográfica está localizada em torno da Baía de Todos os Santos (SEI, 2020; UFRB, 2020). Esta região possui solo fértil, conhecido como massapê baiano e apresenta relevo diverso, consequentemente, o clima é bastante variado. Em municípios situados ao longo do litoral a temperatura média anual é de aproximadamente $23^{\circ} \mathrm{C}$ e precipitação pluviométrica superiores a $1.500 \mathrm{~mm}$. Para municípios, mais afastados do litoral a temperatura média anual varia entre 18 a $22^{\circ} \mathrm{C}$ e precipitação pluviométrica equivalente a 1.000mm (UFRB, 2020).

A vegetação predominante no Recôncavo Baiano é do bioma Mata Atlântica, com áreas onde ocorrem incursões de exemplares característicos de Caatinga e até de Cerrado. Esta região possui uma riqueza de espécies vegetais (biodiversidade) potenciais para atividade apícola (NASCIMENTO; CARVALHO; MARTINS, 2014; SANTANA et al., 2009; SANTOS et al., 2019).

\subsection{COLETA DO MATERIAL VEGETAL}

Para cada espécime coletada $(n=176)$ foram confeccionadas exsicatas para posterior identificação botânica, bem como coletou-se o material polinífero (botões florais). O material vegetal (as exsicatas com partes reprodutivas) foi encaminhado para a identificação taxonômica por especialistas em sistemática vegetal. O hábito de crescimento de cada espécie foi registrado conforme Bell (1991) e Ferri (1983). Adicionalmente, foi realizado o registro de imagens da espécie.

Os botões florais coletados foram utilizados para preparação das lâminas com os respectivos materiais poliníferos. Para tanto, adotou-se o método de acetólise de Erdtman (1960). As lâminas de pólen foram depositadas na Palinoteca de plantas apícolas/meliponícolas do Núcleo de Estudo dos Insetos - Grupo de Pesquisa Insecta no Centro de Ciências Agrárias, Ambientais e Biológicas da Universidade Federal do Recôncavo da Bahia.

\subsection{PROTOCOLO DE PREPARAÇÃO DO MATERIAL POLINÍFERO (ERDTMAN,} 1960)

O material polinífero (antera) foi retirado com auxílio de pinças ou estiletes previamente esterilizados ao rubro e colocados em tubo de ensaio contendo $2 \mathrm{~mL}$ de ácido acético glacial e identificados com código da palinoteca. O material polinífero permaneceu no ácido acético por no mínimo $24 \mathrm{~h}$. Posteriormente, o material foi centrifugado a $3000 \mathrm{rpm}$ por 5 min e em seguida o sobrenadante foi descartado. 
Na etapa seguinte, realizou-se o descarte do sobrenadante e foi adicionado 2 $\mathrm{mL}$ da mistura acetolítica (9 partes de anidrido acético e 1 parte de ácido sulfúrico) e em seguida os tubos de ensaio contendo o material polinífero foram levados ao banhomaria programado com temperatura de $100^{\circ} \mathrm{C}$, por 2 minutos. Em sequência, as amostras foram retiradas do banho-maria e centrifugadas a $3000 \mathrm{rpm}$ por 5 min e o sobrenadante descartado. Após este procedimento adicionou-se $2 \mathrm{~mL}$ de água destilada e duas gotas de álcool etílico, homogeneizou-se a amostra e então procedeu-se a centrifugação a 3000 rpm por 5 min e descarte o sobrenadante.

$\mathrm{Na}$ sequência da etapa anterior em cada tubo de ensaio contendo a amostra foi adicionado $2 \mathrm{~mL}$ de uma solução de glicerina a 50 \% (mistura de glicerina e água destilada). As amostras foram mantidas nesta solução por $12 \mathrm{~h}$, sendo após este período centrifugadas a $3000 \mathrm{rpm}$ por $5 \mathrm{~min}$ e o sobrenadante descartado. Posteriormente, os tubos contendo as amostras foram invertidos para escorrimento da solução e montagem das lâminas para microscopia com material polinífero.

Para a montagem das lâminas para microscopia com os grãos de pólen foi utilizado a gelatina glicerinada impregnado com material polinífero da espécie, sendo este depositado sobre uma lâmina e selado com uma lamínula. As lâminas permanentes foram seladas com parafina, a fim de evitar a ocorrência de fungos.

\subsection{MORFOLOGIA POLÍNICA}

As lâminas para microscopia preparadas com material polinífero de cada espécie vegetal foram utilizadas para captura de imagens (fotomicrografias) dos grãos de pólen em vista polar e equatorial, sendo as mesmas obtidas em um prazo máximo de sete dias após montagem da lâmina. Para tanto, utilizou-se um microscópio Olympus (CH30) com uma câmera digital (Moticam-2300) acoplada. Foram mensurados, aleatoriamente, 25 grãos de pólen de cada espécie. Calculou-se a média aritmética $(\bar{x})$ e a relação $P / E$. Os parâmetros mensurados foram: em vista polar (VP), diâmetro da área polar (DAP), diâmetro do eixo equatorial em vista polar (DEVP), diâmetro do eixo polar (DEP), diâmetro do eixo equatorial (DEE), eixo maior (EMA) e eixo menor (EME). Em vista equatorial (VE) o eixo polar (EP) e Eixo equatorial (EQ) (Tabela 1) (LABOURIAU, 1973; SILVA et al., 2014).

Com a determinação da relação P/E obteve-se a classificação quanto a forma do grão de pólen, conforme descrito na Tabela 2. As descrições morfológicas basearam-se no Glossário llustrado de Palinologia de Barth e Barbosa (1972), Barth e Melhem (1988), Labouriau (1973) e Punt et al., (2007). Os resultados produzidos 
são apresentados a seguir nas descrições polínicas de cada espécie vegetal e organizados por família botânica.

Tabela 1. Mensuração de grão de pólen em vista polar e equatorial.

\begin{tabular}{|c|c|}
\hline \multicolumn{2}{|c|}{ Parâmetros para medição $(\boldsymbol{\mu m})$} \\
\hline Âmbito & Vista Polar (VP) \\
\hline Circular, subcircular & Diâmetro do eixo polar (DEP) \\
\hline & Diâmetro do eixo equatorial (DEE) \\
\hline & Eixo maior (EMA) \\
\hline Triangular, subtriangular menor (EME) & Diâmetro da área polar (DAP) \\
\hline & Diâmetro do eixo equatorial em vista polar (DEVP) \\
\hline Âmbito & Vista Equatorial (VE) \\
\hline Circular, subcircular & Eixo polar (EP) \\
\hline & Eixo equatorial (EQ) \\
\hline
\end{tabular}

Fonte: Os Autores.

Tabela 2. Parâmetros morfológicos para classificação dos grãos de pólen.

\begin{tabular}{|c|c|c|c|}
\hline \multirow{2}{*}{ Classe de tamanho } & \multicolumn{2}{c|}{$\begin{array}{c}\text { Classe de Forma baseado na } \\
\text { relação P/E }\end{array}$} \\
\cline { 3 - 4 } \multicolumn{2}{|c|}{} & P/E & Forma \\
\hline Muito pequeno & $<10 \mu \mathrm{m}$ & $\leq 0,50$ & Peroblata \\
\hline Pequeno & $10-24 \mu \mathrm{m}$ & $0,51-0,75$ & Oblata \\
\hline Médio & $25-49 \mu \mathrm{m}$ & $0,76-0,88$ & Suboblata \\
\hline Grande & $50-99 \mu \mathrm{m}$ & $0,89-0,99$ & Oblata esferoidal \\
\hline Muito grande & $100-200 \mu \mathrm{m}$ & 1,00 & Esferoidal \\
\hline Gigante & $\geq 200 \mu \mathrm{m}$ & $1,01-1,14$ & Prolata esferoidal \\
\hline--- & --- & $1,15-1,33$ & Subprolata \\
\hline--- & --- & $1,34-1,99$ & Prolata \\
\hline--- & --- & $\geq 2,00$ & Perprolata \\
\hline
\end{tabular}

Fonte: Erdtman (1952). $\mathrm{P}=$ medida do eixo polar e $\mathrm{E}=$ medida do eixo equatorial. 


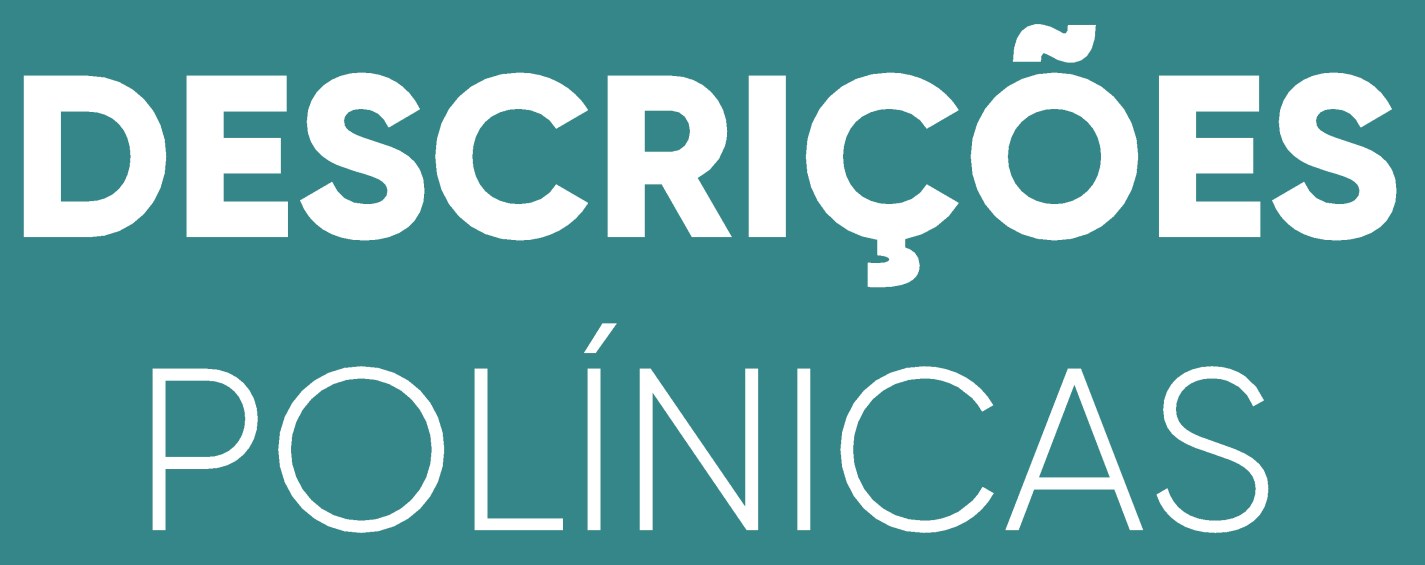




\section{Adoxaceae}

Espécie: Sambucus australis Cham \& Schlecht.

Nome comum: Sabugueiro

Hábito de crescimento: arbustivo

Fonte de recurso trófico: néctar

Período de Floração: fevereiro a março

№ Palinoteca: PA 126
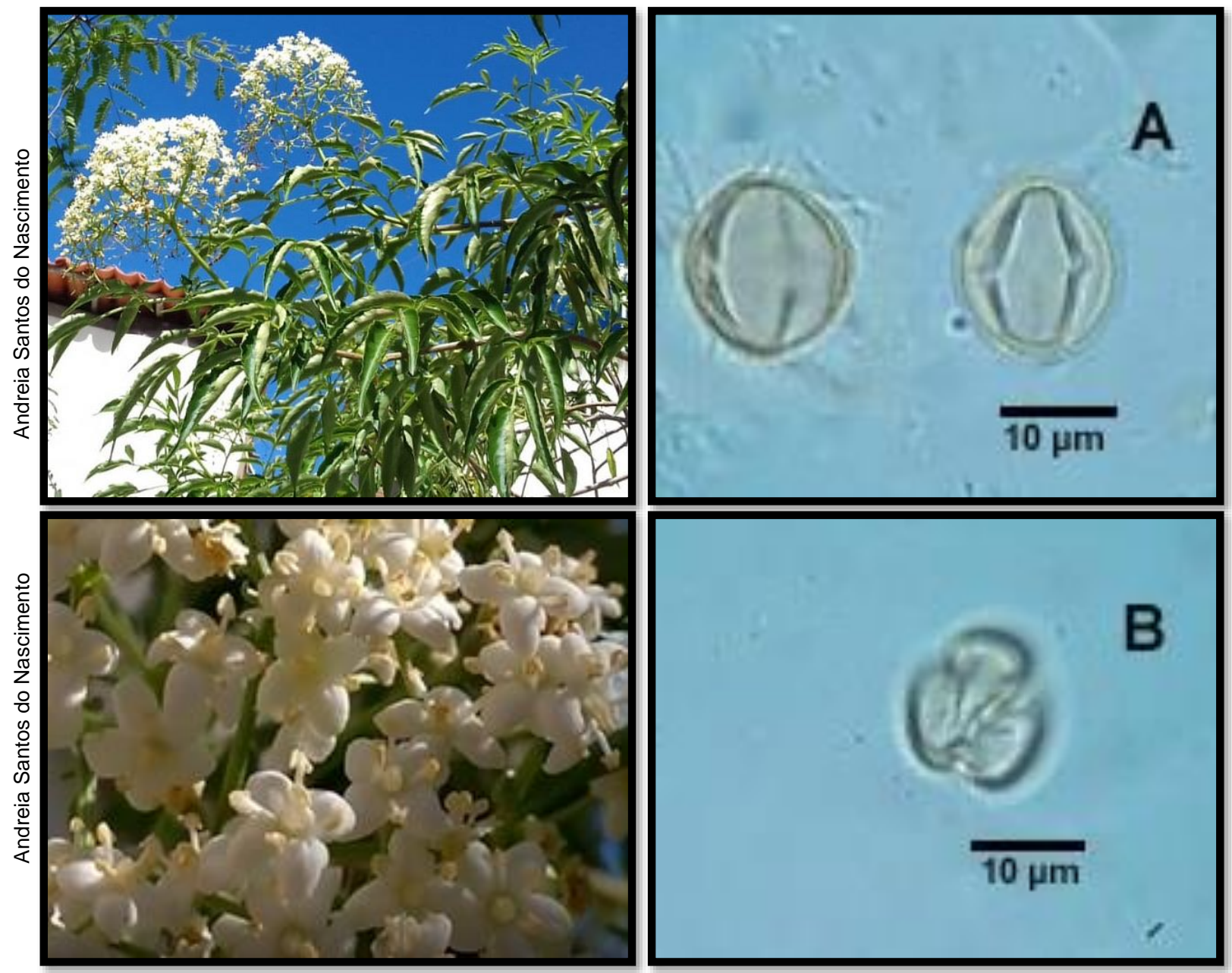

Descrição polínica: $A$ = vista equatorial e $B$ = vista polar, grão de pólen com simetria radial, isopolar, nômade, âmbito subtriangular, abertura polínica do tipo colporo, exina microrreticulada, tamanho pequeno, forma subprolata, eixo polar $=16,66 \mu \mathrm{m}$, eixo equatorial $=14,24 \mu \mathrm{m}, \mathrm{P} / \mathrm{E}=1,16 \mu \mathrm{m}$. 


\section{Amaranthaceae}

Espécie: Amaranthus spinosus L.

Nome comum: Caruru-de-espinho

Hábito de crescimento: herbáceo

Fonte de recurso trófico: pólen

Período de Floração: maio a agosto

№ Palinoteca: PA 153

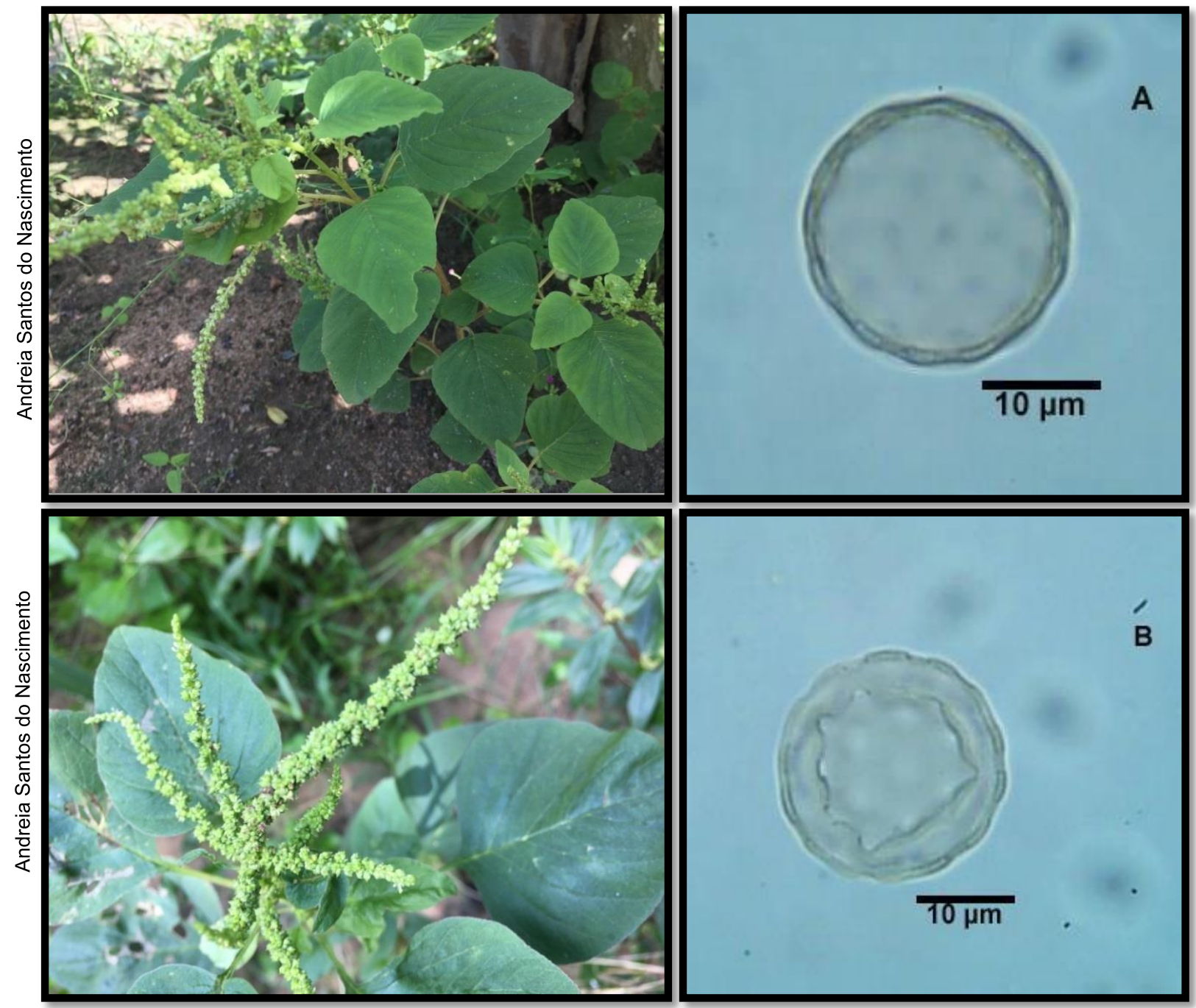

Descrição polínica: A-B = grão de pólen com simetria radial, apolar, nômade, âmbito circular, abertura polínica do tipo poro, forma esferoidal, exina microrreticulada, tamanho pequeno, diâmetro do eixo polar $=24,24 \mu \mathrm{m}$; diâmetro do eixo equatorial $=$ $22,72 \mu \mathrm{m} ; \mathrm{P} / \mathrm{E}=1,06 \mu \mathrm{m}$. 


\section{Amaranthaceae}

Espécie: Alternanthera brasiliana (L.) Kuntze

Nome comum: Apaga-fofo

Hábito de crescimento: herbáceo

Fonte de recurso trófico: néctar/pólen

Período de Floração: maio

No Palinoteca: PA 43
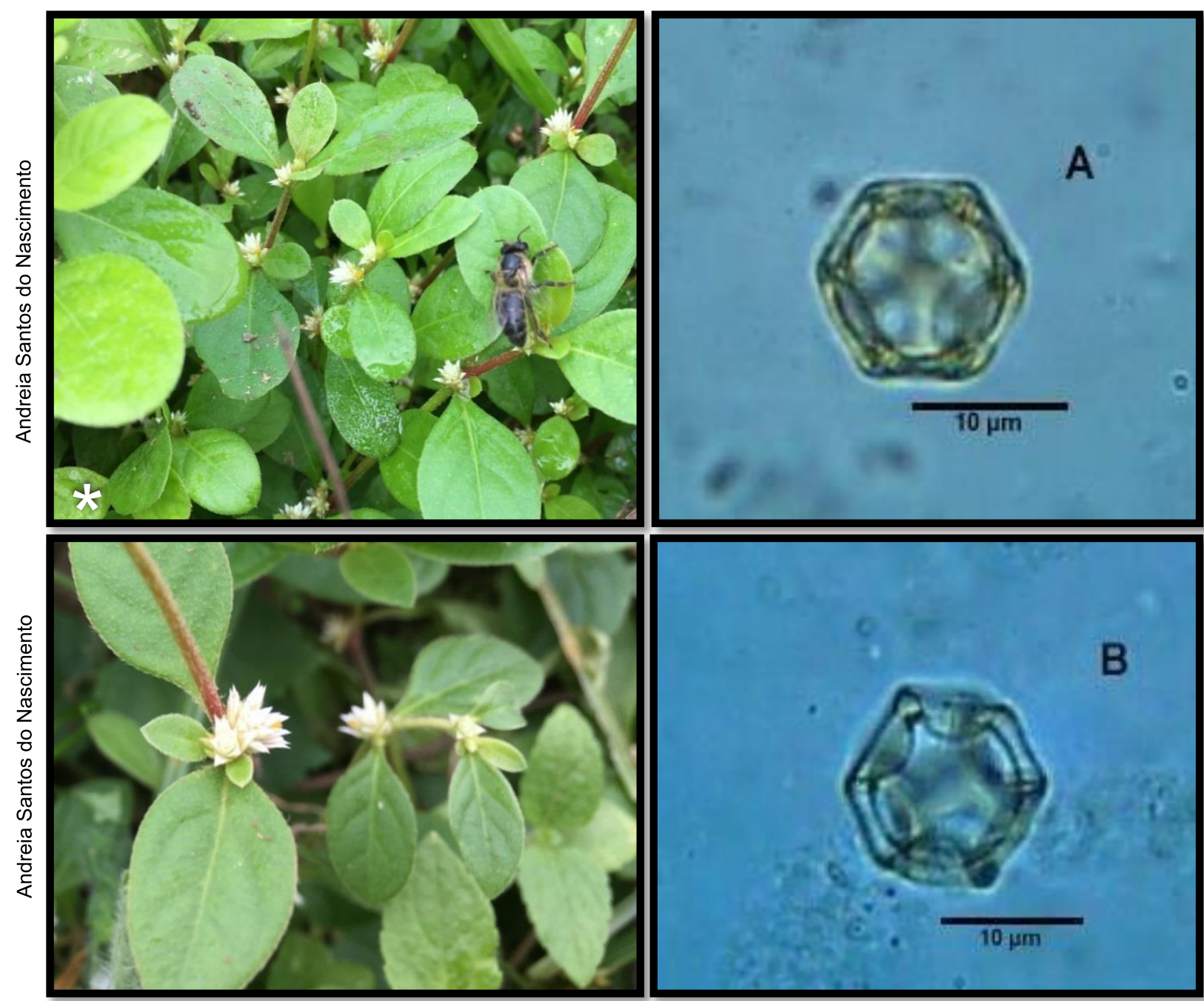

Descrição polínica: $A-B$ = grão de pólen com simetria radial, apolar, nômade, âmbito circular, abertura polínica do tipo poro, forma esferoidal, tamanho pequeno, diâmetro do eixo polar $=10,90 \mu \mathrm{m}$; diâmetro do eixo equatorial $=10,30 \mu \mathrm{m} ; \mathrm{P} / \mathrm{E}=1,05 \mu \mathrm{m}$. *Abelha visitante floral: Apis mellifera Linnaeus, 1758. 


\section{Amaranthaceae}

Espécie: Alternanthera philoxeroides (Mart.) Griseb.

Nome comum: Perpetua; bredo-d'água

Hábito de crescimento: herbáceo

Fonte de recurso trófico: néctar

Período de Floração: abril a maio

№ Palinoteca: NAS01
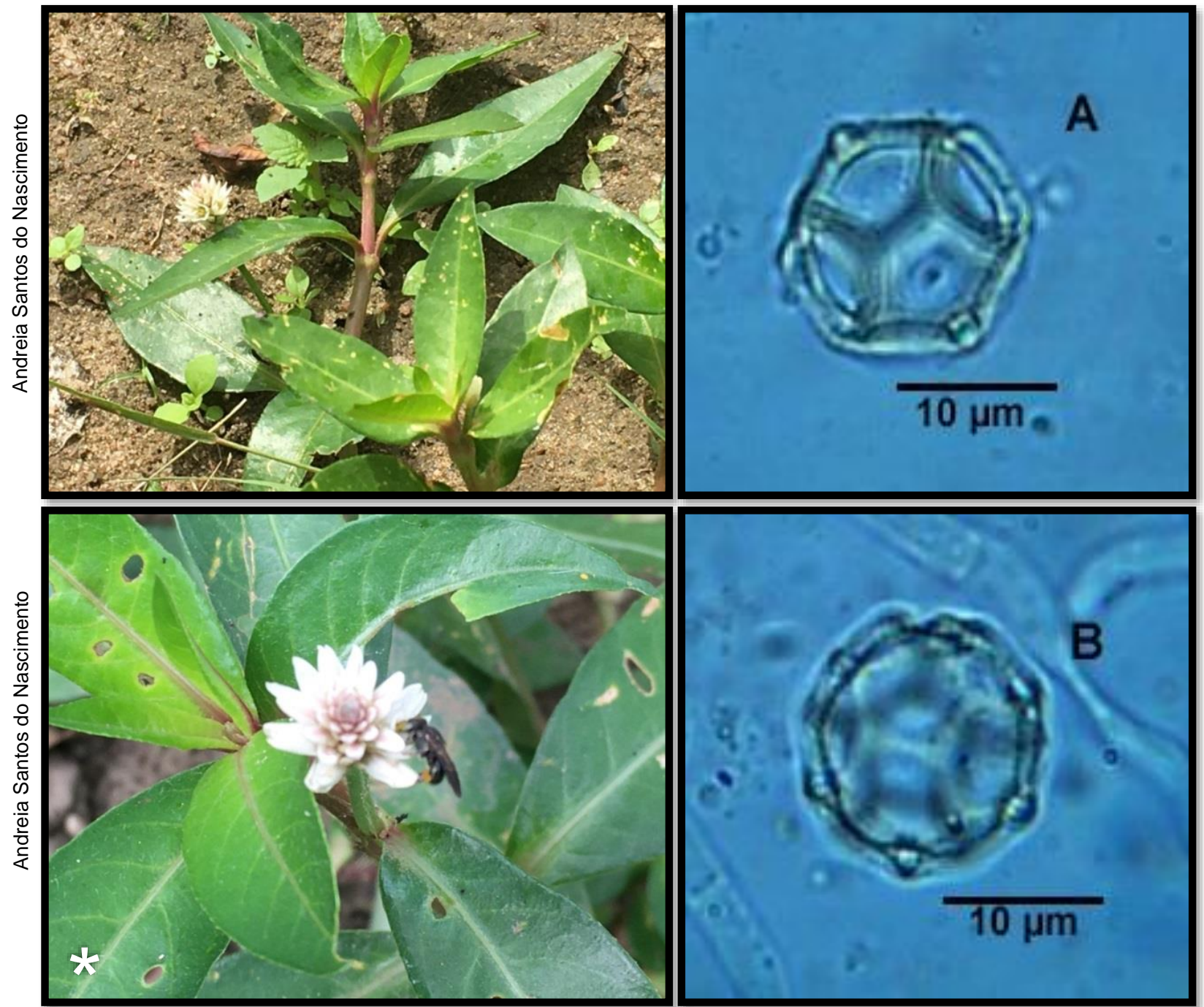

Descrição polínica: A-B = grão de pólen com simetria radial, apolar, nômade, âmbito circular, tamanho pequeno, abertura polínica do tipo poro, forma esferoidal, diâmetro do eixo polar $=12,12 \mu \mathrm{m}$; diâmetro do eixo equatorial $=11,81 \mu \mathrm{m} ; \mathrm{P} / \mathrm{E}=1,02 \mu \mathrm{m}$.

*Abelha visitante floral: Nannotrigona testaceicornis Lepeletier, 1836. 


\section{Amaranthaceae}

Espécie: Alternanthera tenella Colla Nome comum: Perpetua-do-campo Hábito de crescimento: herbáceo Fonte de recurso trófico: néctar/pólen Período de Floração: abril a maio № Palinoteca: PC 189
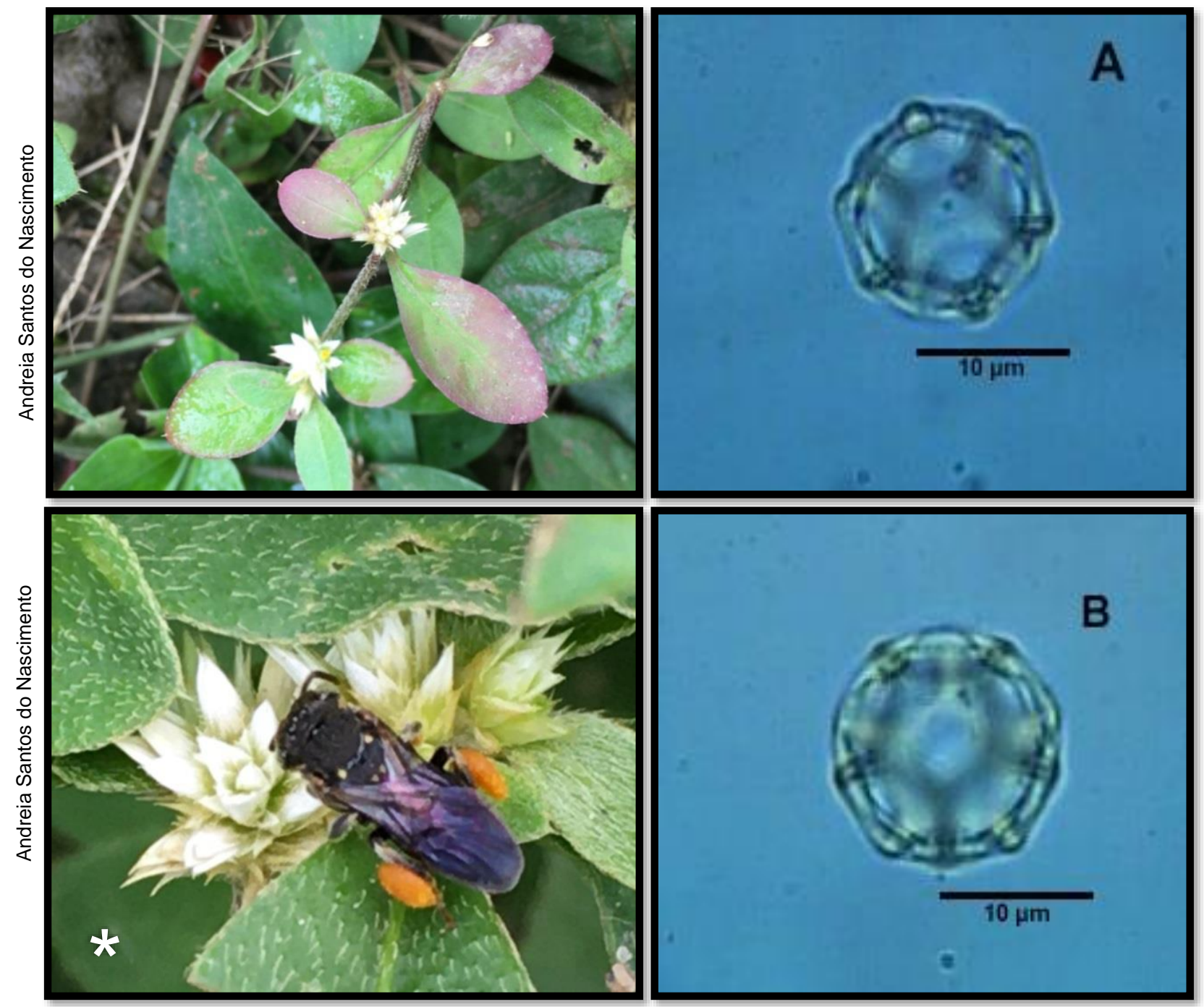

Descrição polínica: A-B = grão de pólen com simetria radial, apolar, nômade, âmbito circular, tamanho pequeno, abertura polínica do tipo poro, forma esferoidal, diâmetro do eixo polar $=11,51 \mu \mathrm{m}$; diâmetro do eixo equatorial $=11,21 \mu \mathrm{m} ; \mathrm{P} / \mathrm{E}=1,02 \mu \mathrm{m}$.

*Abelha visitante floral: Nannotrigona testaceicornis Lepeletier, 1836. 


\section{Amaranthaceae}

Espécie: Gomphrena celosioides Mart.

Nome comum: Perpetua-brava

Hábito de crescimento: herbáceo

Fonte de recurso trófico: néctar/pólen

Período de Floração: abril a maio

№ Palinoteca: NASO2

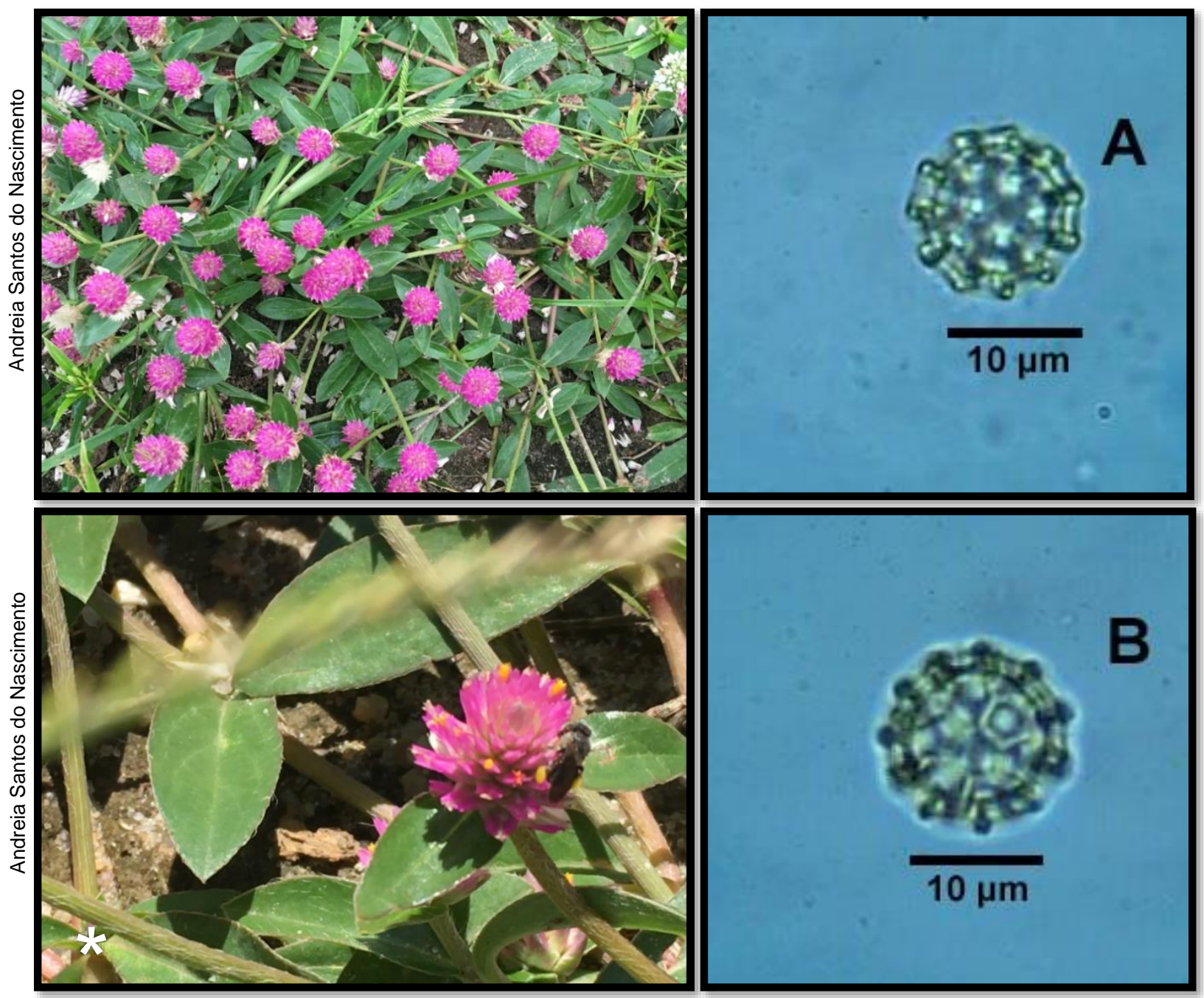

Descrição polínica: A-B = vista polar, grão de pólen com simetria radial, isopolar, nômade, âmbito circular, abertura polínica do tipo poro, forma esferoidal, tamanho pequeno, diâmetro do eixo polar $=10,30 \mu \mathrm{m}$; diâmetro do eixo equatorial $=10,30 \mu \mathrm{m}$; $\mathrm{P} / \mathrm{E}=1,00 \mu \mathrm{m}$.

*Abelha visitante floral: Nannotrigona testaceicornis Lepeletier, 1836. 


\section{Anacardiaceae}

Espécie: Anacardium occidentale L.

Nome comum: Cajueiro

Hábito de crescimento: arbóreo

Fonte de recurso trófico: néctar/pólen

Período de Floração: setembro

№ Palinoteca: PA 92
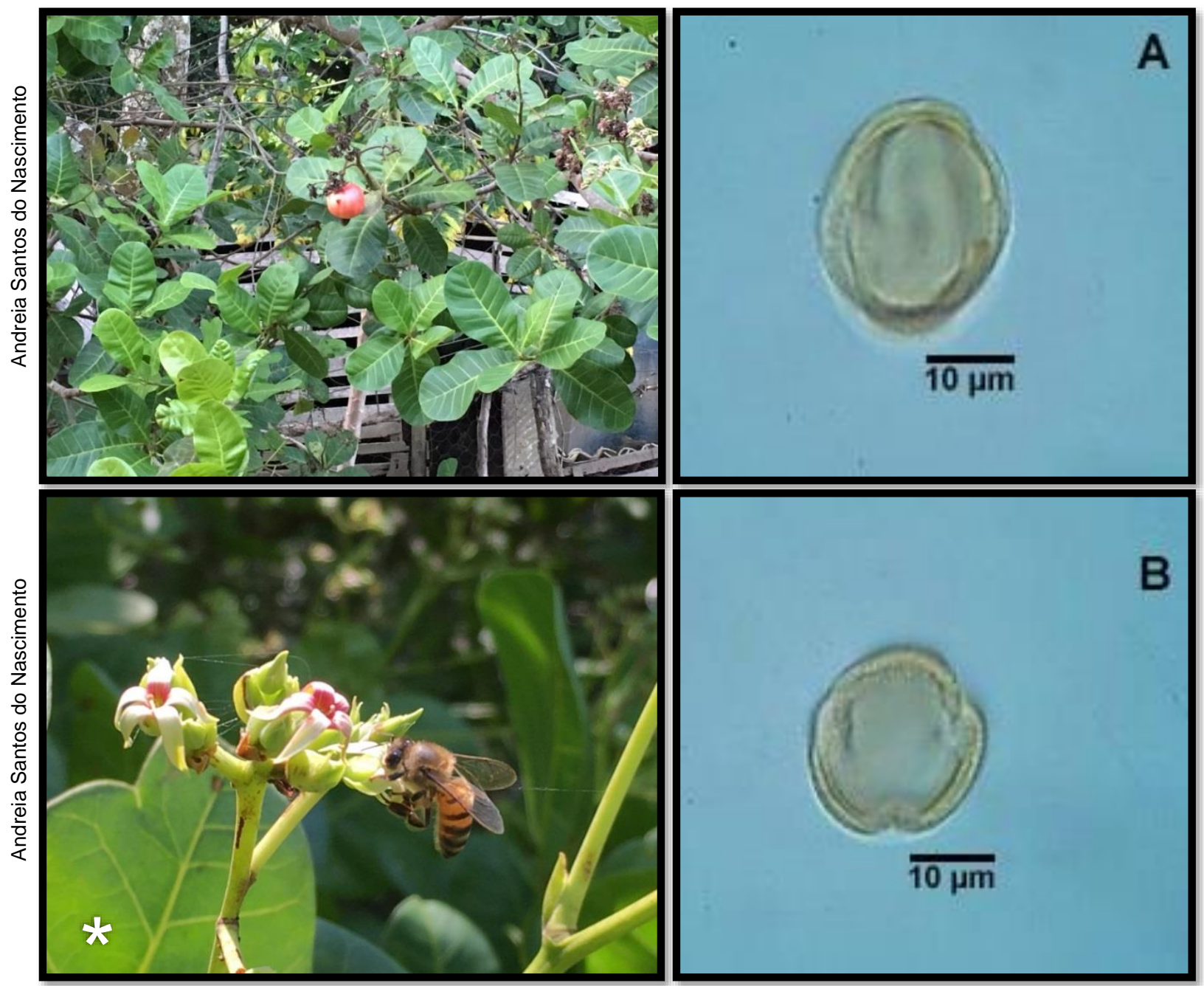

Descrição polínica: $A$ = vista equatorial, $B=$ vista polar, grão de pólen com simetria radial, nômade, âmbito subtriangular, abertura polínica do tipo colporo, exina microrreticulada, tamanho médio, forma subprolata, eixo polar $=25,45 \mu \mathrm{m}$; eixo equatorial $=23,03 \mu \mathrm{m} ; \mathrm{P} / \mathrm{E}=1,10 \mu \mathrm{m}$.

*Abelha visitante floral: Apis mellifera Linnaeus, 1758. 


\section{Anacardiaceae}

Espécie: Mangifera indica L.

Nome comum: Mangueira

Hábito de crescimento: arbóreo

Fonte de recurso trófico: néctar/pólen

Período de Floração: setembro

№ Palinoteca: PA 91

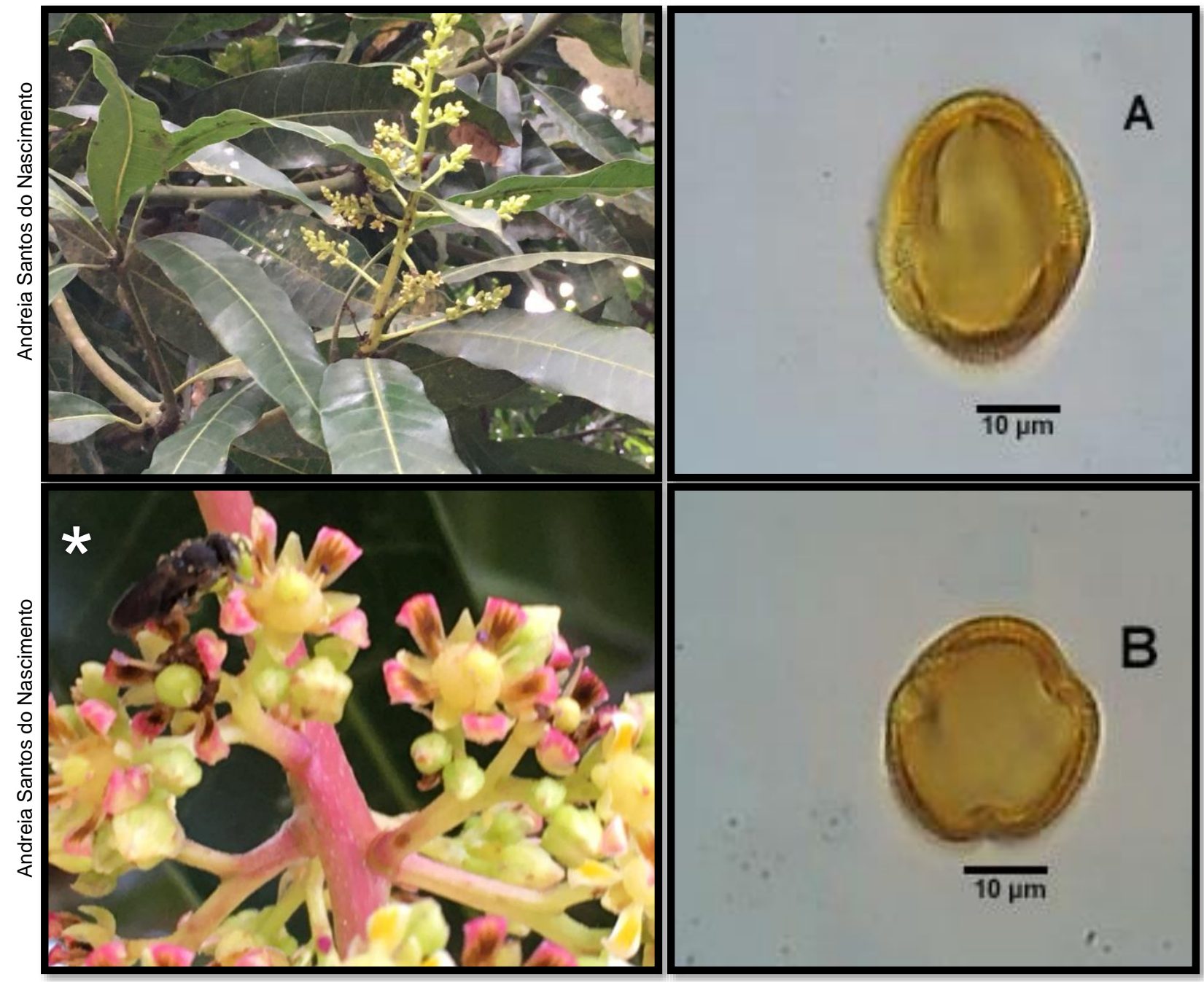

Descrição polínica: $A$ = vista equatorial, $B$ = vista polar, grão de pólen com simetria radial, nômade, âmbito subtriangular, abertura polínica do tipo colporo, exina microrreticulada, tamanho pequeno, forma subprolata, eixo polar $=23,33 \mu \mathrm{m}$; eixo equatorial $=20,60 \mu \mathrm{m} ; \mathrm{P} / \mathrm{E}=1,13 \mu \mathrm{m}$.

*Abelha visitante floral: Nannotrigona testaceicornis Lepeletier, 1836. 


\section{Anacardiaceae}

Espécie: Schinus terebinthifolius Raddi

Nome comum: Aroeira-branca

Hábito de crescimento: arbóreo

Fonte de recurso trófico: néctar

Período de Floração: fevereiro a maio

№ Palinoteca: PA 17
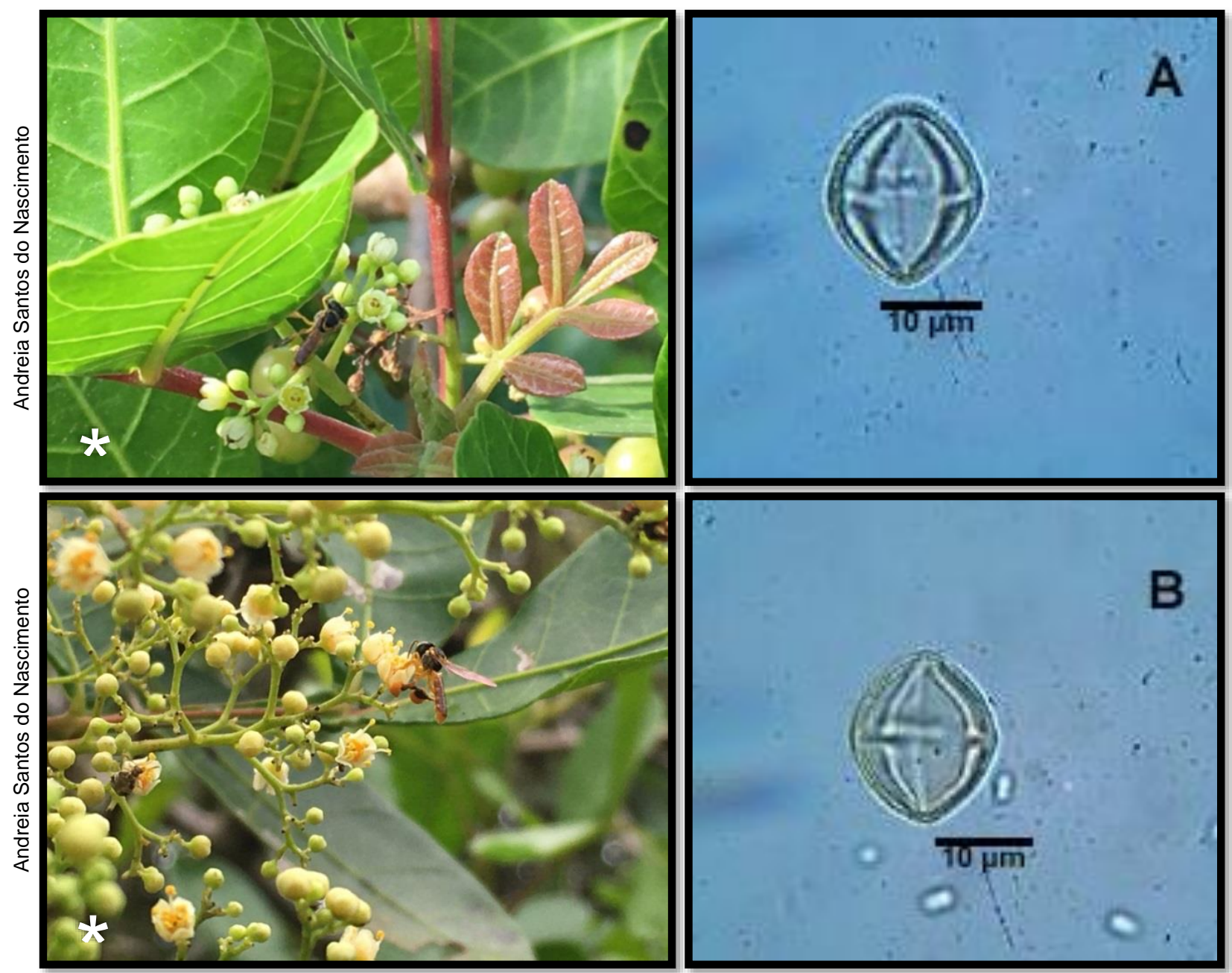

Descrição polínica: $A-B$ = vista equatorial, grão de pólen com simetria radial, isopolar, nômade, âmbito subtriangular, abertura polínica do tipo colporo, exina reticulada, tamanho pequeno, forma subprolata, eixo polar $=18,78 \mu \mathrm{m}$; eixo equatorial $=15,45 \mu \mathrm{m} ; \mathrm{P} / \mathrm{E}=1,21 \mu \mathrm{m}$.

*Abelha visitante floral: Tetragonisca angustula Latreille, 1811. 


\section{Anacardiaceae}

Espécie: Spondia tuberosa Arruda Cam.

Nome comum: Umbuzeiro

Hábito de crescimento: arbóreo

Fonte de recurso trófico: néctar/pólen

Período de Floração: dezembro

№ Palinoteca: PA 121
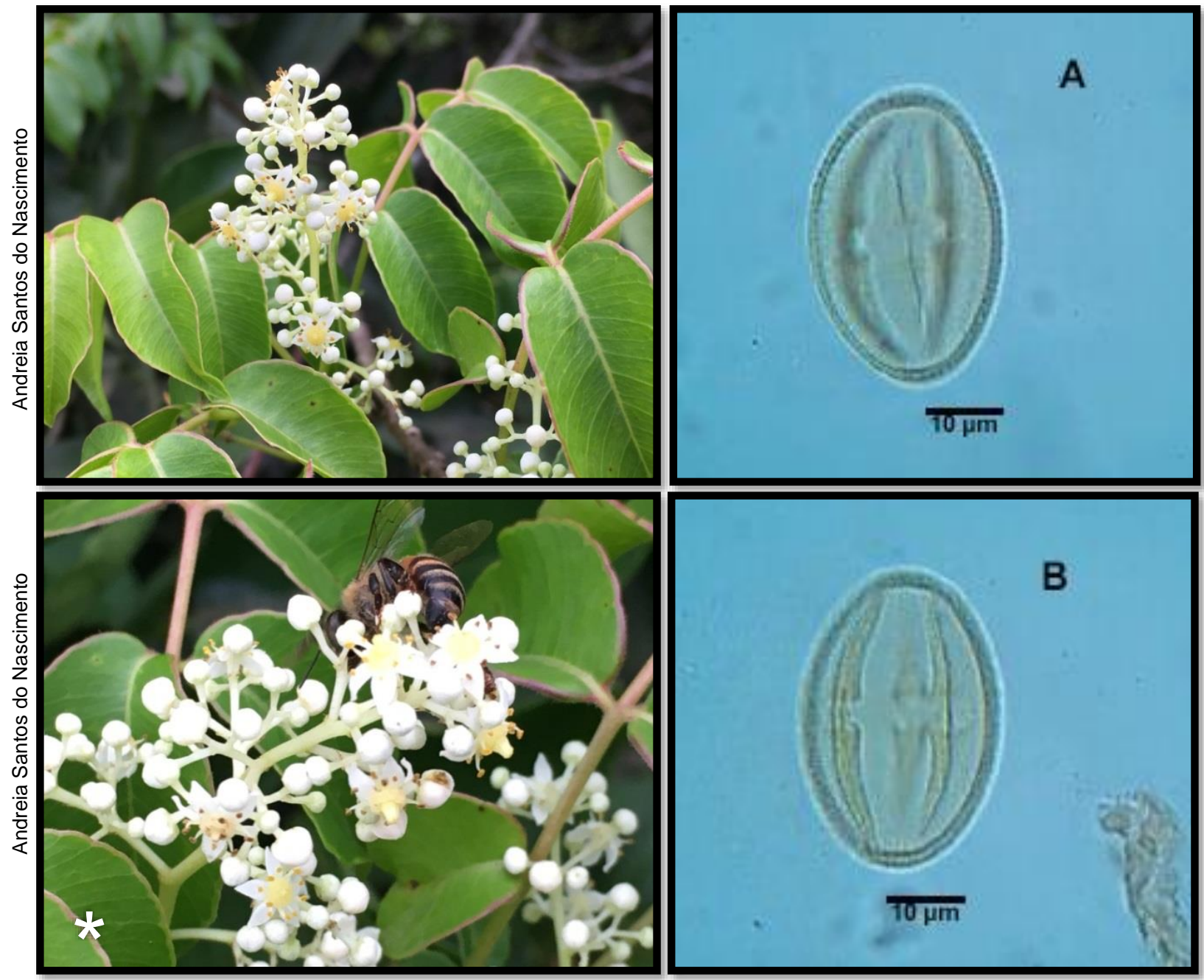

Descrição polínica: $A-B$ = vista equatorial, grão de pólen com simetria radial, isopolar, nômade, âmbito subtriangular, abertura polínica do tipo colporo, exina microrreticulada, tamanho médio, forma prolata, eixo polar $=35,45 \mu \mathrm{m}$; eixo equatorial $=23,93 \mu \mathrm{m} ; \mathrm{P} / \mathrm{E}=1,48 \mu \mathrm{m}$.

*Abelha visitante floral: Apis mellifera Linnaeus, 1758. 


\section{Apiaceae}

Espécie: Coriandrum sativum L.

Nome comum: Coentro

Hábito de crescimento: herbáceo

Fonte de recurso trófico: pólen/néctar

Período de Floração: janeiro a dezembro

№ Palinoteca: PA 50
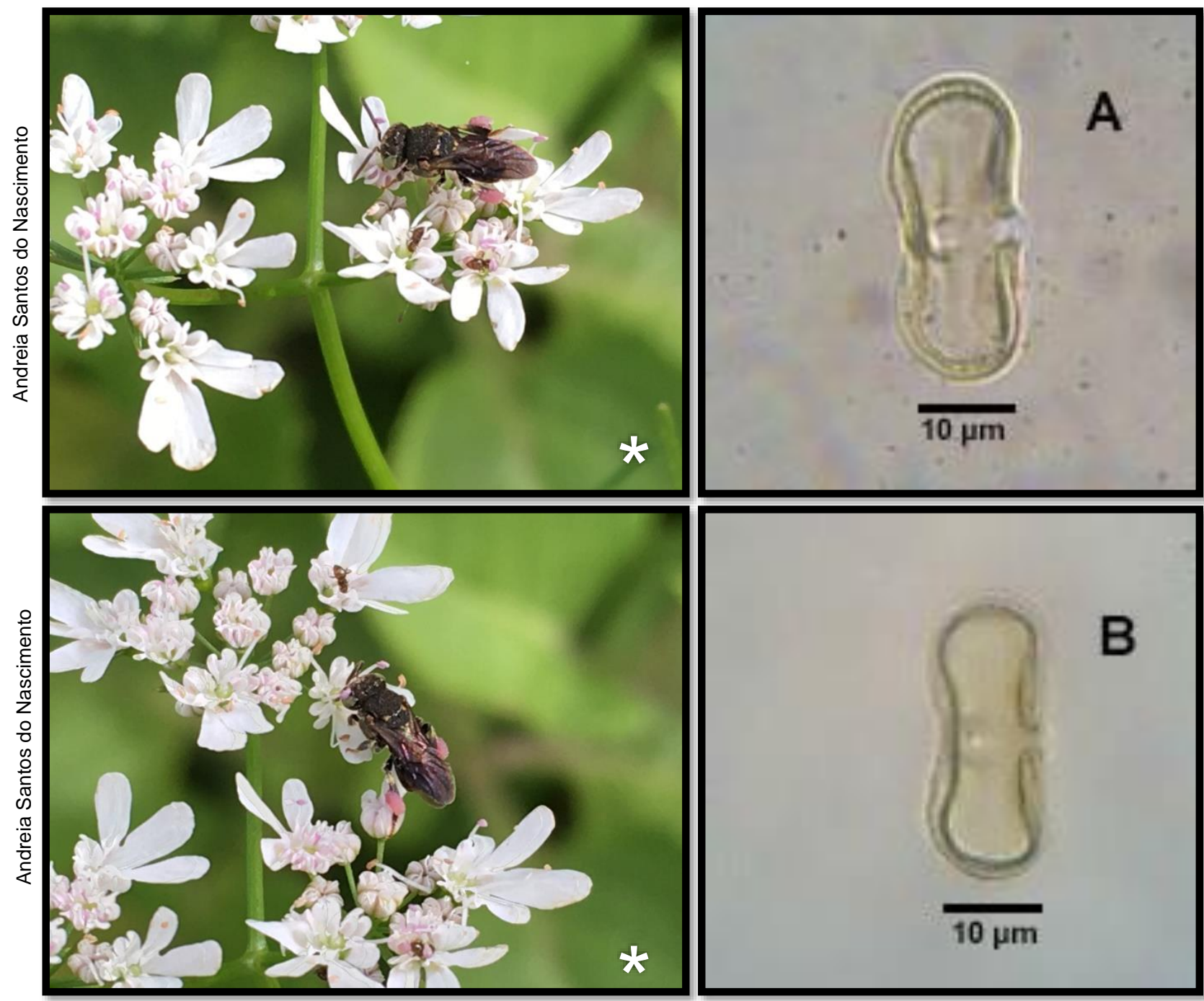

Descrição polínica: $A-B$ = vista equatorial, grão de pólen nômade isopolar, abertura polínica do tipo colporo, exina microrreticulada, tamanho pequeno, forma perprolata, eixo maior $=23,93 \mu \mathrm{m}$; eixo menor $=9,69 \mu \mathrm{m} ; \mathrm{P} / \mathrm{E}=2,46 \mu \mathrm{m}$.

*Abelha visitante floral: Nannotrigona testaceicornis Lepeletier, 1836 


\section{Arecaceae}

Espécie: Cocos nucifera L.

Nome comum: Coco

Hábito de crescimento: palmeira

Fonte de recurso trófico: pólen

Período de Floração: abril a junho e outubro a janeiro

№ Palinoteca: PA 103
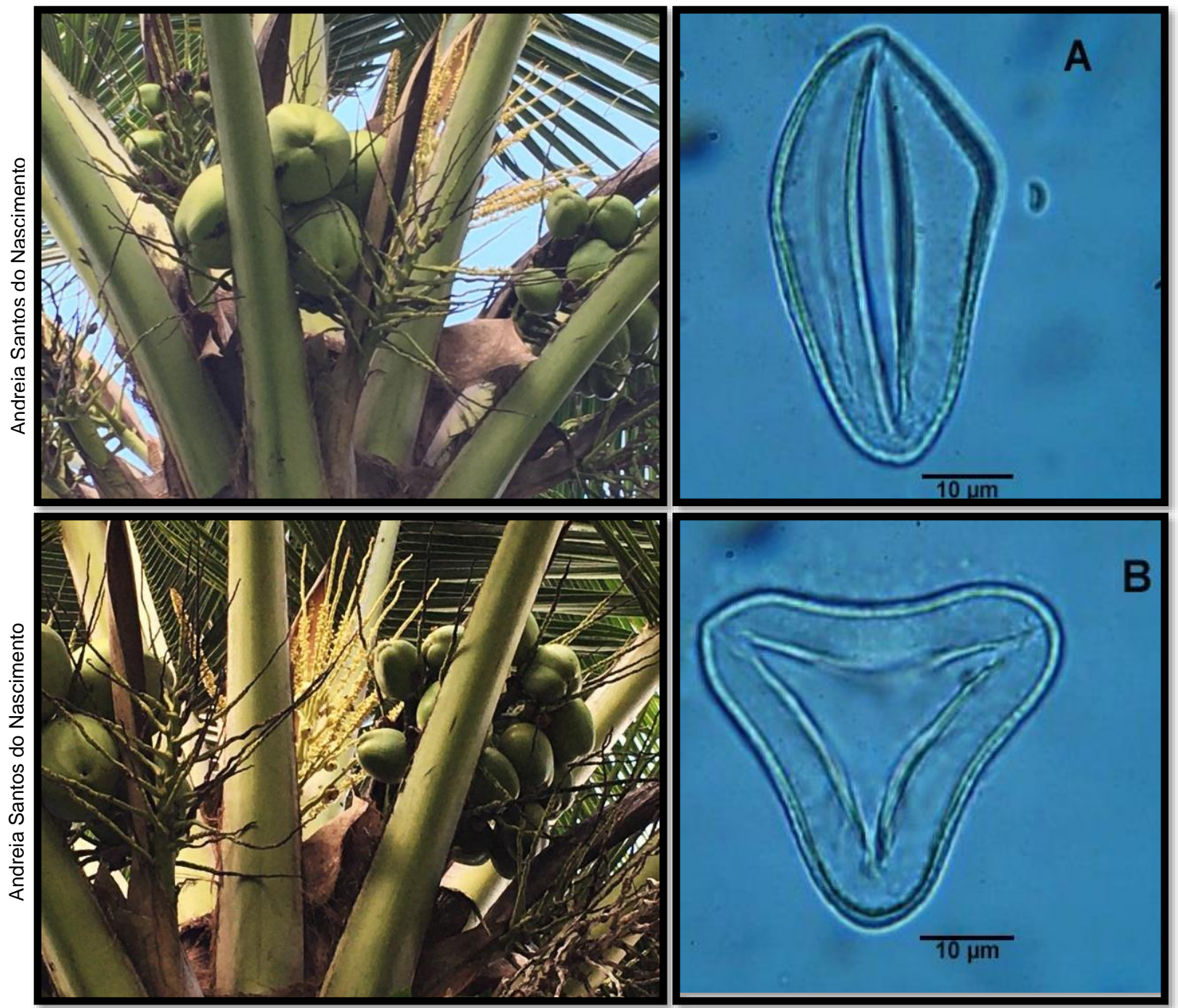

Descrição polínica: $A$ = vista equatorial, $B$ = vista polar, grão de pólen com simetria bilateral, heteropolar, nômade, âmbito triangular, abertura polínica do tipo sulco, exina microrreticulada, tamanho médio, forma subprolata, eixo maior $=37,27 \mu \mathrm{m}$; eixo menor $=30,60 \mu \mathrm{m} ; \mathrm{P} / E=1,21 \mu \mathrm{m}$. 


\section{Arecaceae}

Espécie: Elaeis guineensis Jacq.

Nome comum: Dendezeiro

Hábito de crescimento: palmeira

Fonte de recurso trófico: pólen

Período de Floração: abril a junho e outubro a janeiro

№ Palinoteca: NAS03
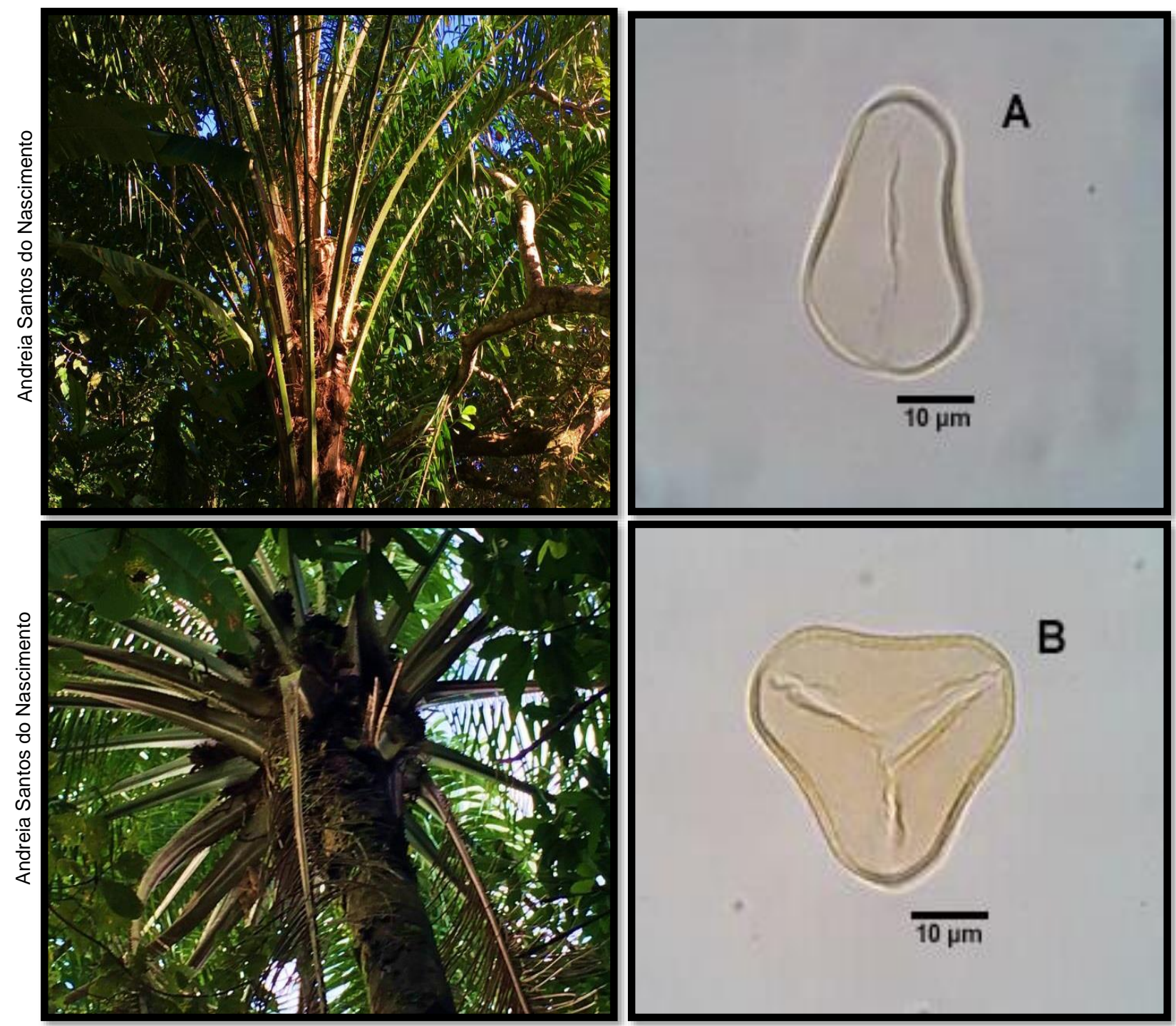

Descrição polínica: $\mathrm{A}$ = vista equatorial, $\mathrm{B}=$ vista polar, grão de pólen com simetria bilateral, heteropolar, nômade, âmbito triangular, abertura polínica do tipo sulco, exina microrreticulada, tamanho médio, forma prolata esferoidal, eixo maior $=43,03 \mu \mathrm{m}$; eixo menor $=39,39 \mu \mathrm{m} ; \mathrm{P} / \mathrm{E}=1,09 \mu \mathrm{m}$. 


\section{Arecaceae}

Espécie: Syagrus coronata (Mart.) Becc.

Nome comum: Licurizeiro

Hábito de crescimento: palmeira

Fonte de recurso trófico: pólen

Período de Floração: outubro a dezembro

№ Palinoteca: PA 104
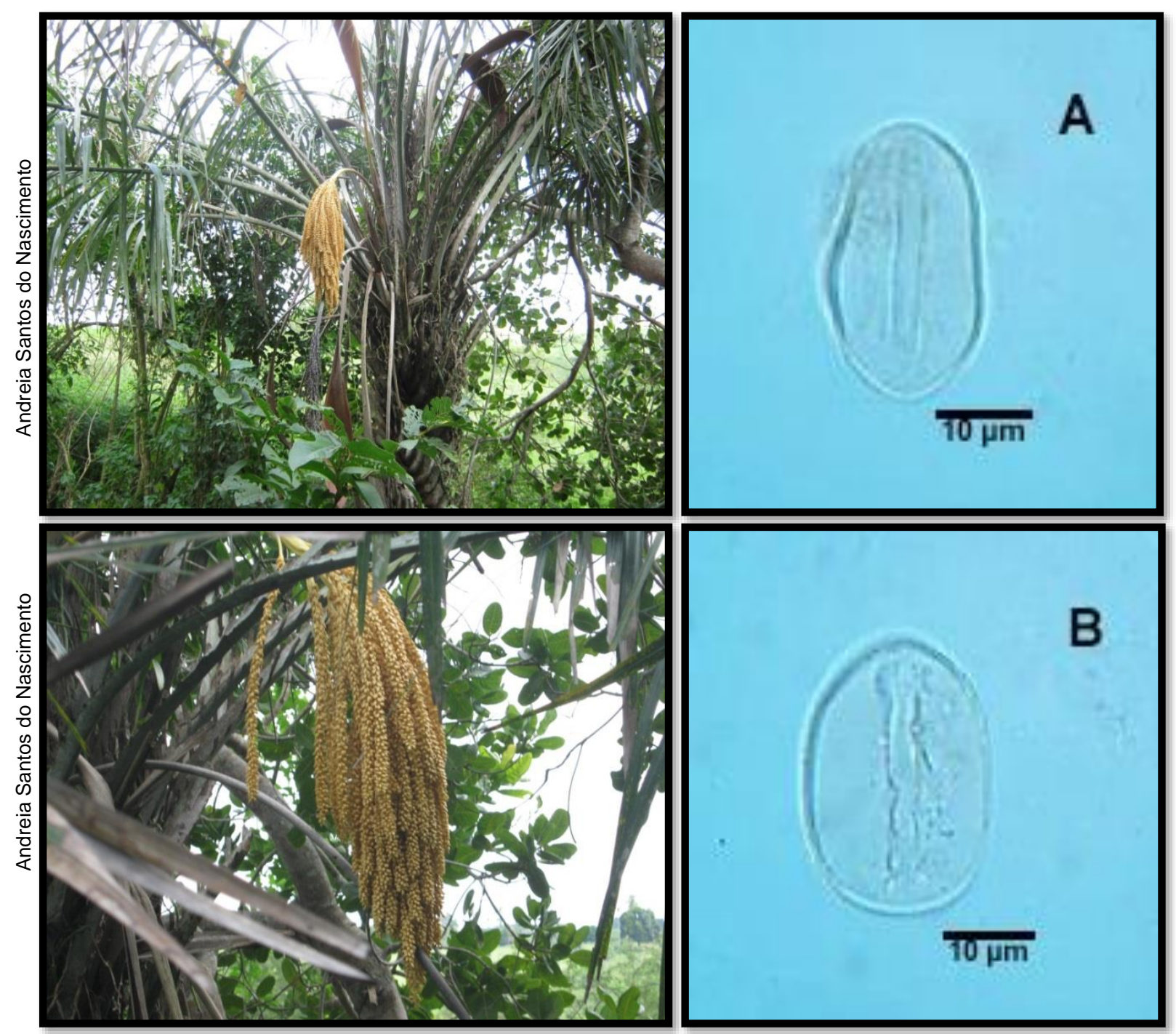

Descrição polínica: $A-B$ = vista equatorial, grão de pólen com simetria bilateral, heteropolar, nômade, âmbito triangular, abertura polínica do tipo sulco, exina microrreticulada, tamanho médio, forma prolata, eixo maior $=31,81 \mu \mathrm{m}$; eixo menor $=$ $18,18 \mu \mathrm{m} ; \mathrm{P} / \mathrm{E}=1,74 \mu \mathrm{m}$. 


\section{Arecaceae}

Espécie: Veitchia merrillii (Becc.) H. E. Moore.

Nome comum: palmeira-de-manila

Hábito de crescimento: Palmeira

Fonte de recurso trófico: pólen

Período de Floração: março a maio

№ Palinoteca: NAS04
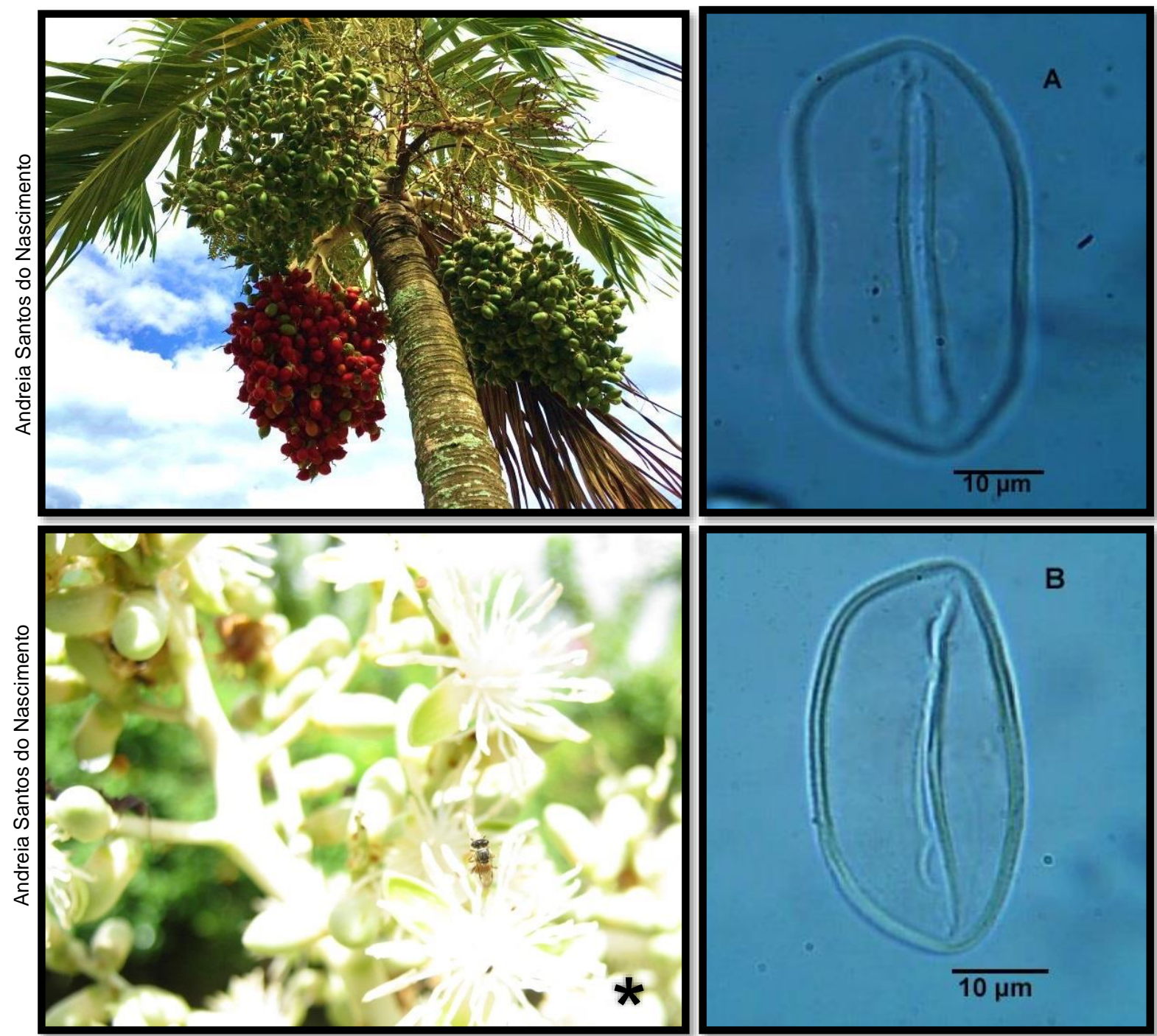

Descrição polínica: $A-B$ = vista equatorial, grão de pólen com simetria bilateral, heteropolar, nômade, âmbito triangular, abertura polínica do tipo sulco, exina microrreticulada, tamanho médio, forma prolata, eixo maior $=43,33 \mu \mathrm{m}$; eixo menor $=$ $39,69 \mu \mathrm{m} ; \mathrm{P} / \mathrm{E}=1,09 \mu \mathrm{m}$.

*Abelha visitante floral: Plebeia sp. 


\section{Asphodelaceae}

Espécie: Bulbine frutescens L.

Nome comum: Bulbine

Hábito de crescimento: herbáceo

Fonte de recurso trófico: pólen

Período de Floração: maio a agosto

№ Palinoteca: PA 41

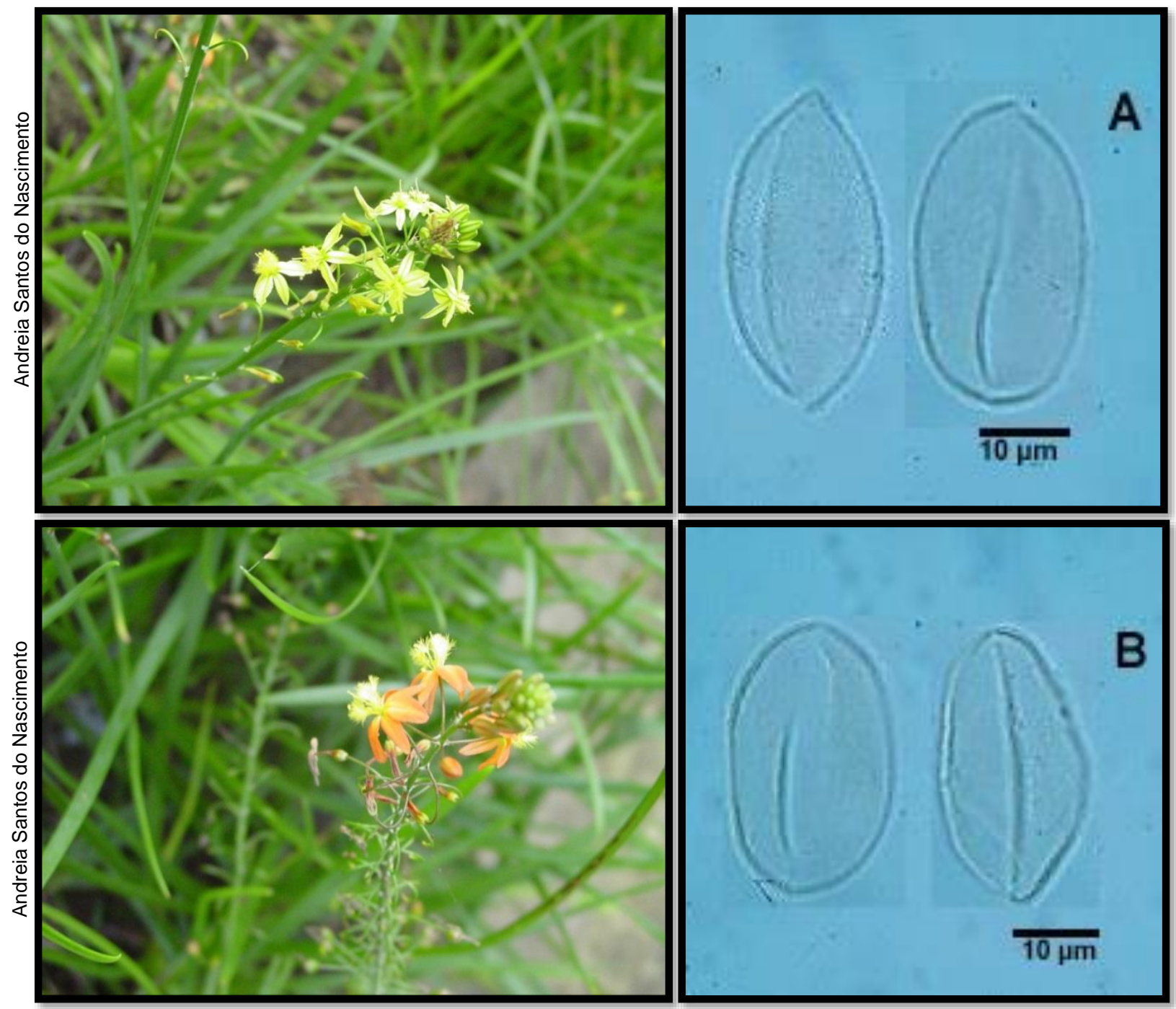

Descrição polínica: $A-B$ = vista equatorial, grão de pólen com simetria bilateral, heteropolar, nômade, âmbito elíptico, abertura polínica do tipo sulco, exina microrreticulada, tamanho médio, forma prolata, eixo maior $=31,81 \mu \mathrm{m}$; eixo menor $=$ $18,48 \mu \mathrm{m} ; \mathrm{P} / \mathrm{E}=1,72 \mu \mathrm{m}$. 


\section{Asteraceae}

Espécie: Acanthospermum australe (Loefl.) Kuntze

Nome comum: Carrapichinho

Hábito de crescimento: herbáceo

Fonte de recurso trófico: néctar

Período de Floração: março a julho

№ Palinoteca: PA 150
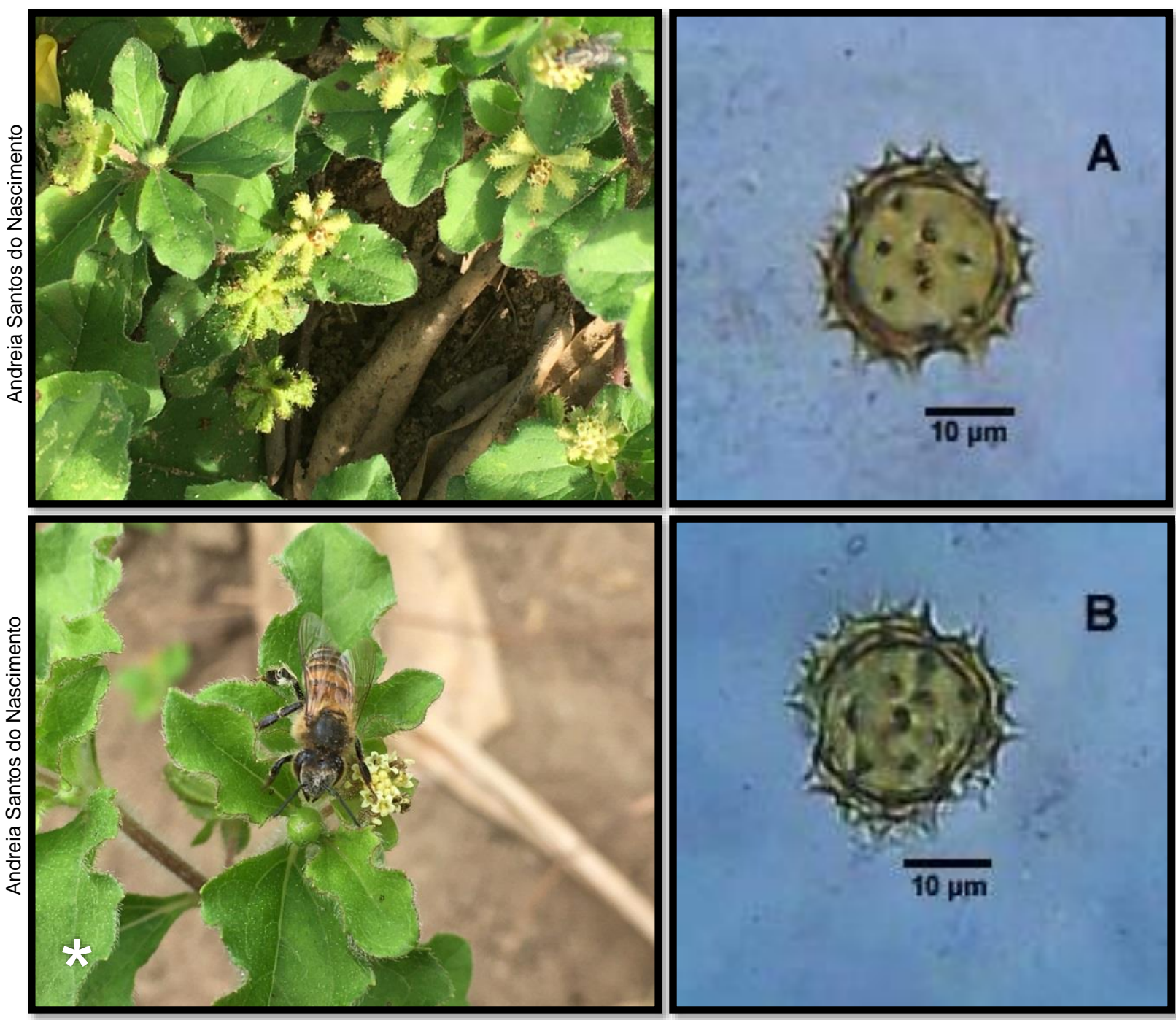

Descrição polínica: $A-B=$ vista polar, grão de pólen com simetria radial, isopolar, nômade, âmbito subtriangular, abertura polínica do tipo colporo, exina equinada, tamanho médio, forma prolata esferoidal, diâmetro do eixo polar $=25,45 \mu \mathrm{m}$; diâmetro do eixo equatorial $=24,84 \mu \mathrm{m} ; \mathrm{P} / \mathrm{E}=1,02 \mu \mathrm{m}$.

*Abelha visitante floral: Apis mellifera Linnaeus, 1758. 


\section{Asteraceae}

Espécie: Acanthospermum hispidum DC.

Nome comum: Carrapicho-cabeça-de-boi

Hábito de crescimento: herbáceo

Fonte de recurso trófico: néctar

Período de Floração: março a julho

No Palinoteca: PA 74

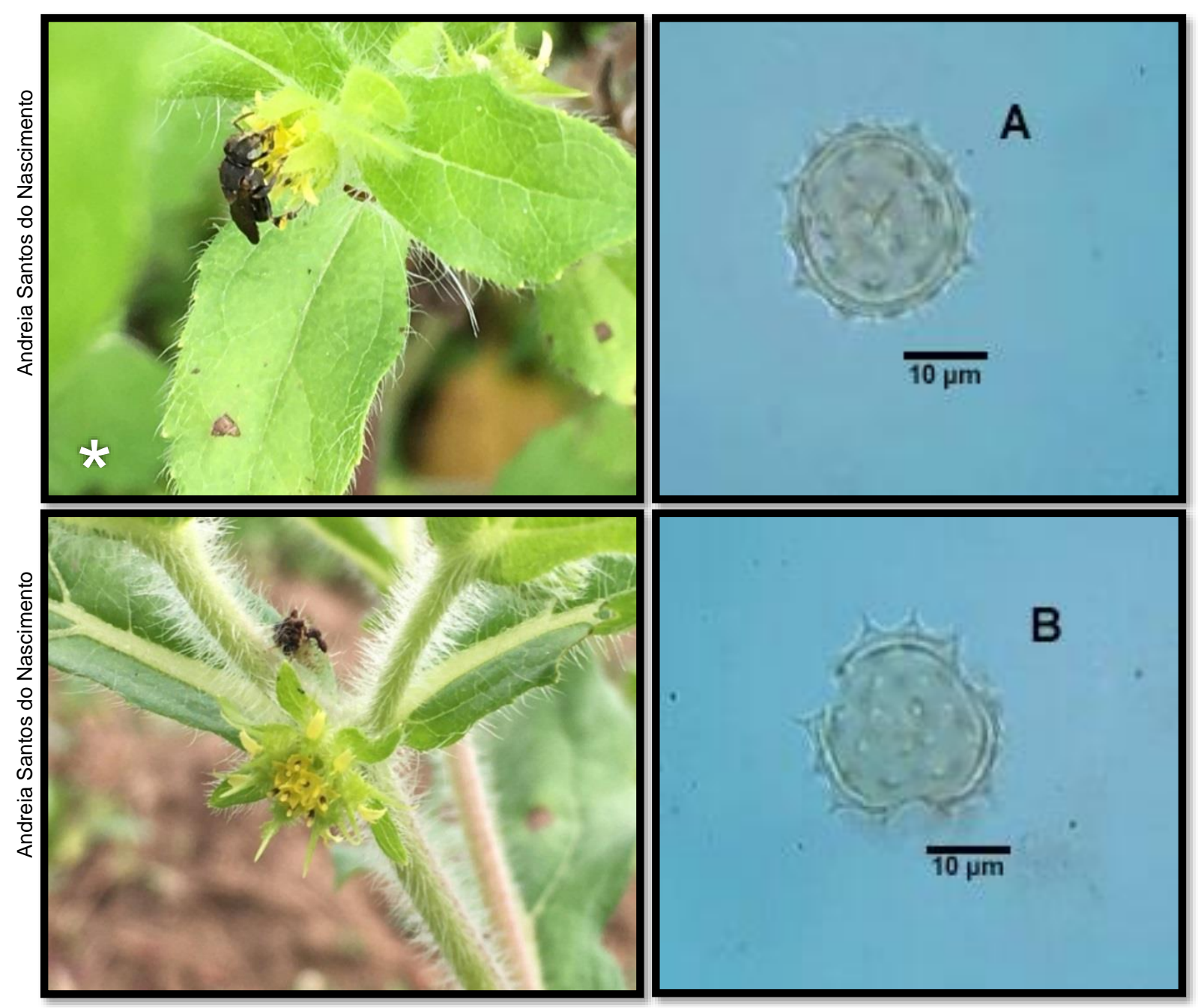

Descrição polínica: A-B = vista polar, grão de pólen com simetria radial, isopolar, nômade, âmbito subtriangular, abertura polínica do tipo colporo, exina equinada, tamanho médio, forma prolata esferoidal, diâmetro do eixo polar $=25,75 \mu \mathrm{m}$; diâmetro do eixo equatorial $=24,54 \mu \mathrm{m} ; \mathrm{P} / \mathrm{E}=1,04 \mu \mathrm{m}$.

*Abelha visitante floral: Nannotrigona testaceicornis Lepeletier, 1836. 


\section{Asteraceae}

Espécie: Acmella uliginosa (Sw.) Cass.

Nome comum: agrião-bravo

Hábito de crescimento: herbáceo

Fonte de recurso trófico: néctar/pólen

Período de Floração: julho a agosto

No Palinoteca: NAS28
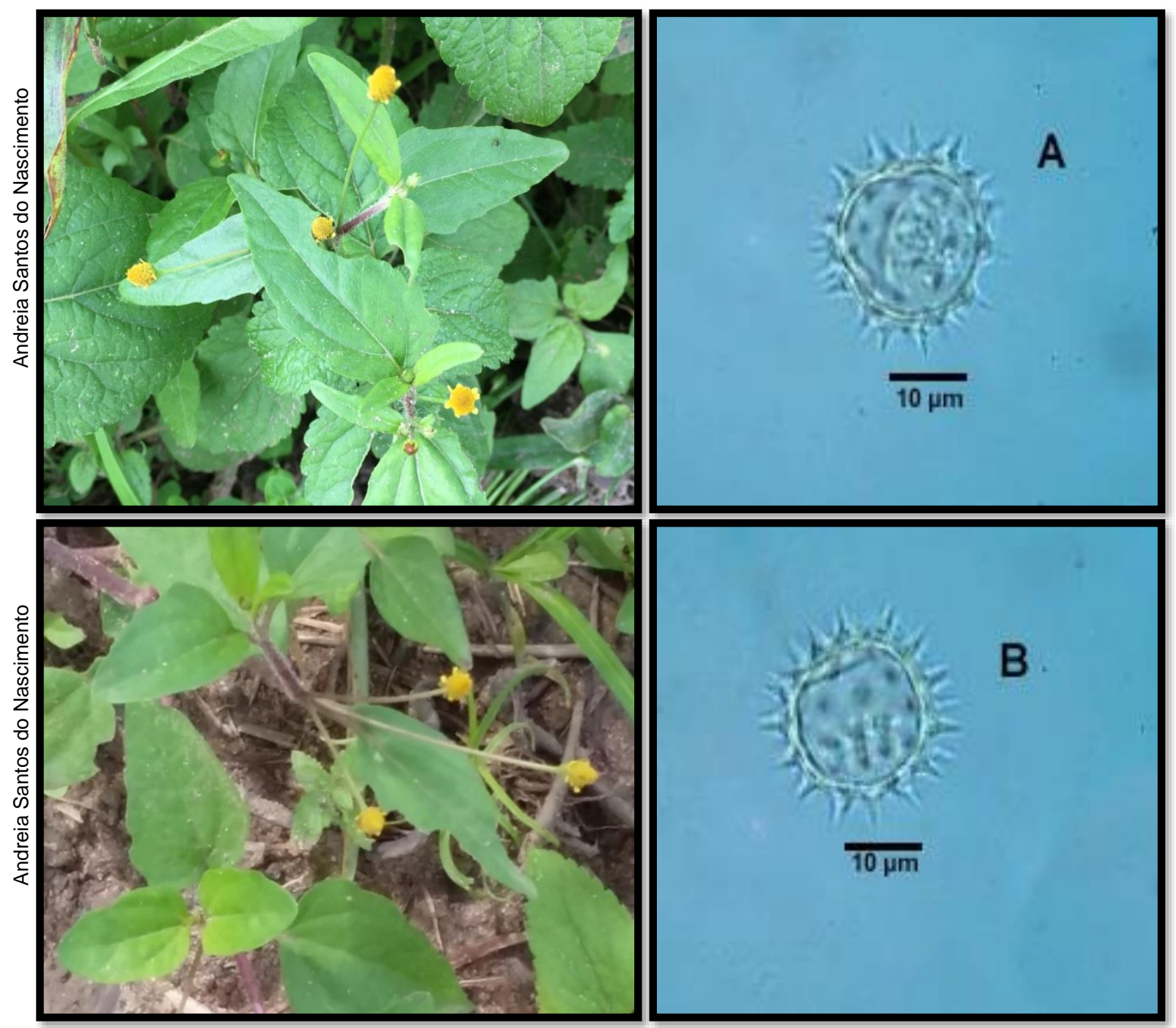

Descrição polínica: A-B = vista polar, grão de pólen com simetria radial, isopolar, nômade, âmbito subtriangular, abertura polínica do tipo colporo, exina equinada, tamanho médio, forma prolata esferoidal, diâmetro do eixo polar $=26,06 \mu \mathrm{m}$; diâmetro do eixo equatorial $=25,15 \mu \mathrm{m} ; \mathrm{P} / \mathrm{E}=1,03 \mu \mathrm{m}$. 


\section{Asteraceae}

Espécie: Adenostemma brasilianum (Pers.) Cass.

Nome comum: Cravinho-do-mato

Hábito de crescimento: herbáceo

Fonte de recurso trófico: néctar

Período de Floração: março a julho

No Palinoteca: PA 65
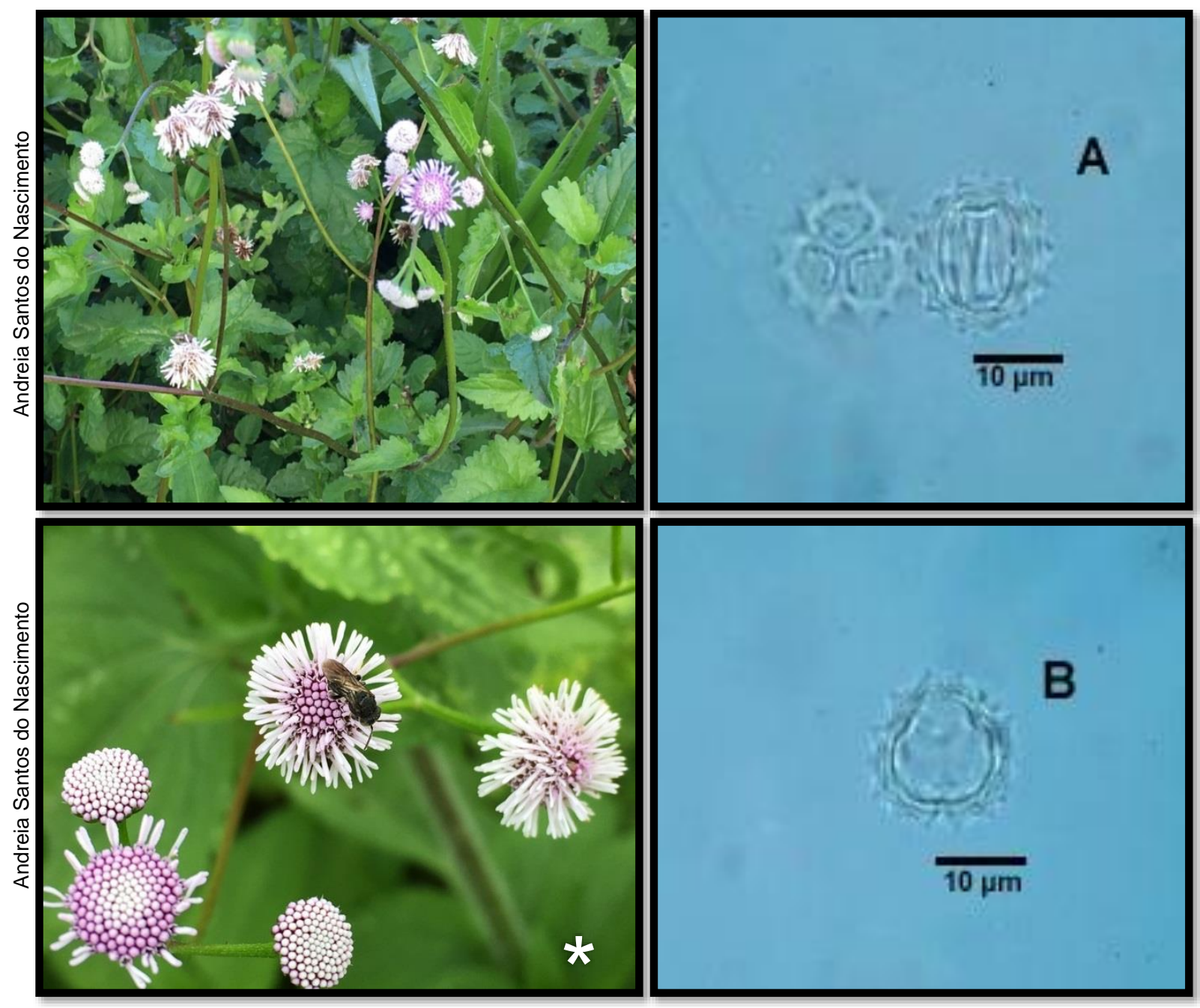

Descrição polínica: A-B = vista polar, grão de pólen com simetria radial, isopolar, nômade, âmbito subtriangular, abertura polínica do tipo colporo, exina equinada, tamanho pequeno, forma prolata esferoidal, diâmetro do eixo polar $=16,66 \mu \mathrm{m}$; diâmetro do eixo equatorial $=16,06 \mu \mathrm{m} ; \mathrm{P} / \mathrm{E}=1,03 \mu \mathrm{m}$.

*Abelha visitante floral: Nannotrigona testaceicornis Lepeletier, 1836. 


\section{Asteraceae}

Espécie: Ageratum conyzoides L.

Nome comum: Mentrasto

Hábito de crescimento: herbáceo

Fonte de recurso trófico: néctar

Período de Floração: maio a julho № Palinoteca: PA 48
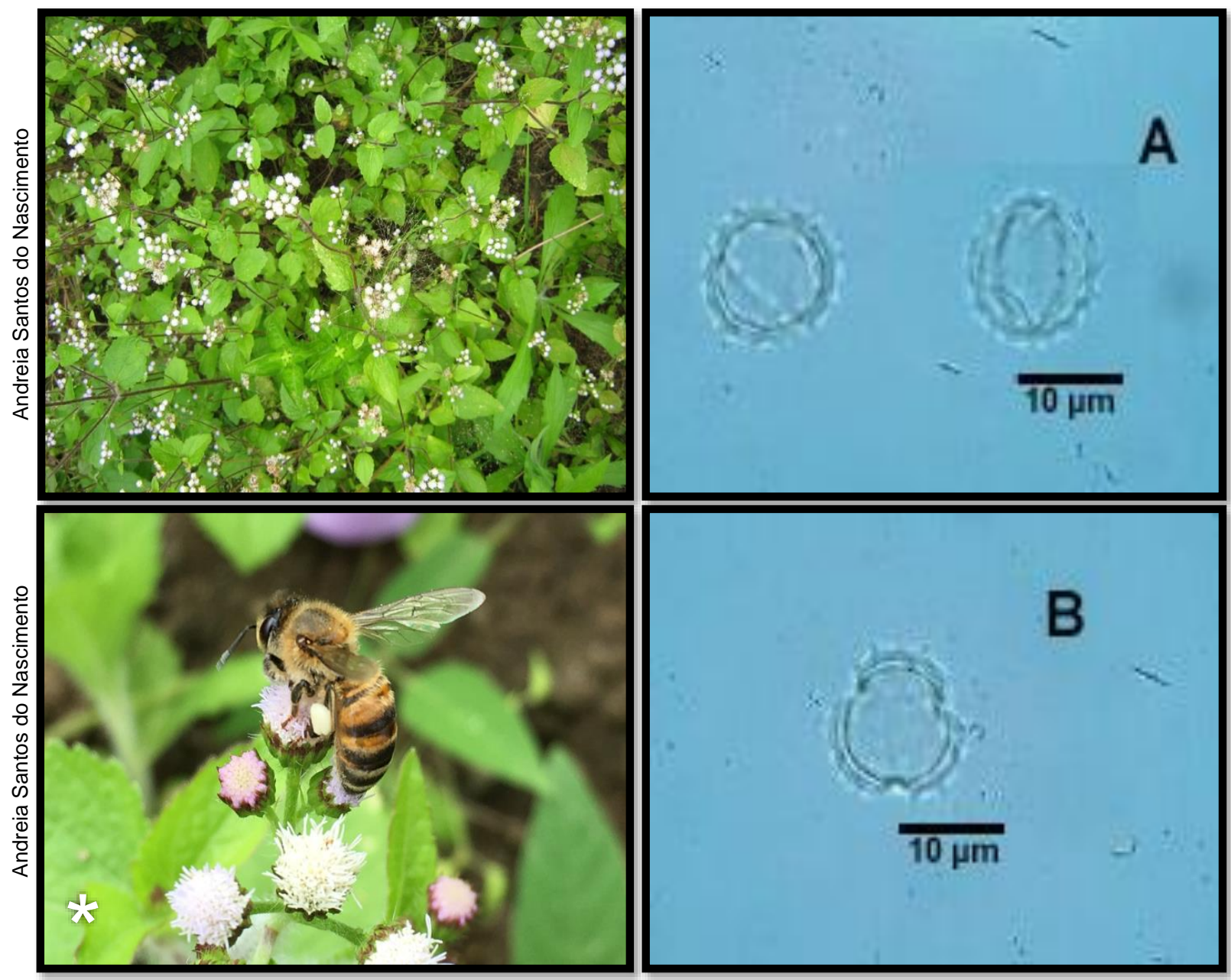

Descrição polínica: A-B = vista polar, grão de pólen com simetria radial, isopolar, nômade, âmbito subtriangular, abertura polínica do tipo colporo, exina equinada, tamanho pequeno, forma prolata esferoidal, diâmetro do eixo polar $=12,12 \mu \mathrm{m}$; diâmetro do eixo equatorial $=11,51 \mu \mathrm{m} ; \mathrm{P} / \mathrm{E}=1,05 \mu \mathrm{m}$.

*Abelha visitante floral: Apis mellifera Linnaeus, 1758. 


\section{Asteraceae}

Espécie: Bidens pilosa L.

Nome comum: Picão

Hábito de crescimento: herbáceo

Fonte de recurso trófico: néctar/pólen

Período de Floração: maio a junho

№ Palinoteca: PA 52
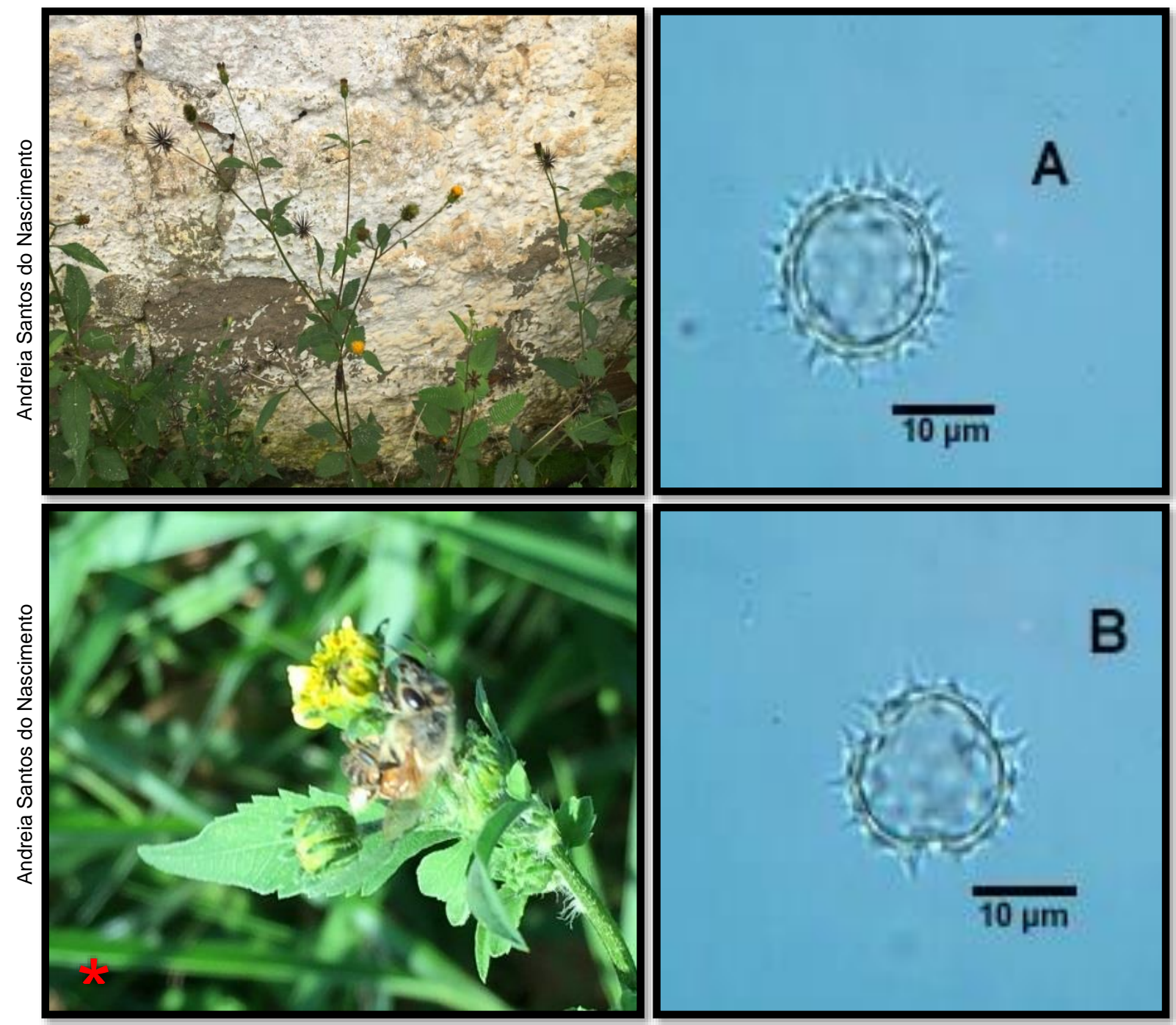

Descrição polínica: A-B = vista polar, grão de pólen com simetria radial, isopolar, nômade, âmbito subtriangular, abertura polínica do tipo colporo, exina equinada, tamanho pequeno, forma prolata esferoidal, diâmetro do eixo polar $=19,69 \mu \mathrm{m}$; diâmetro do eixo equatorial $=17,87 \mu \mathrm{m} ; \mathrm{P} / \mathrm{E}=1,10 \mu \mathrm{m}$.

*Abelha visitante floral: Apis mellifera Linnaeus, 1758. 


\section{Asteraceae}

Espécie: Bidens sulphurea (Cav.) Sch.Bip.

Nome comum: Cosmos

Hábito de crescimento: herbáceo

Fonte de recurso trófico: néctar/pólen

Período de Floração: janeiro a agosto

№ Palinoteca: PA 38
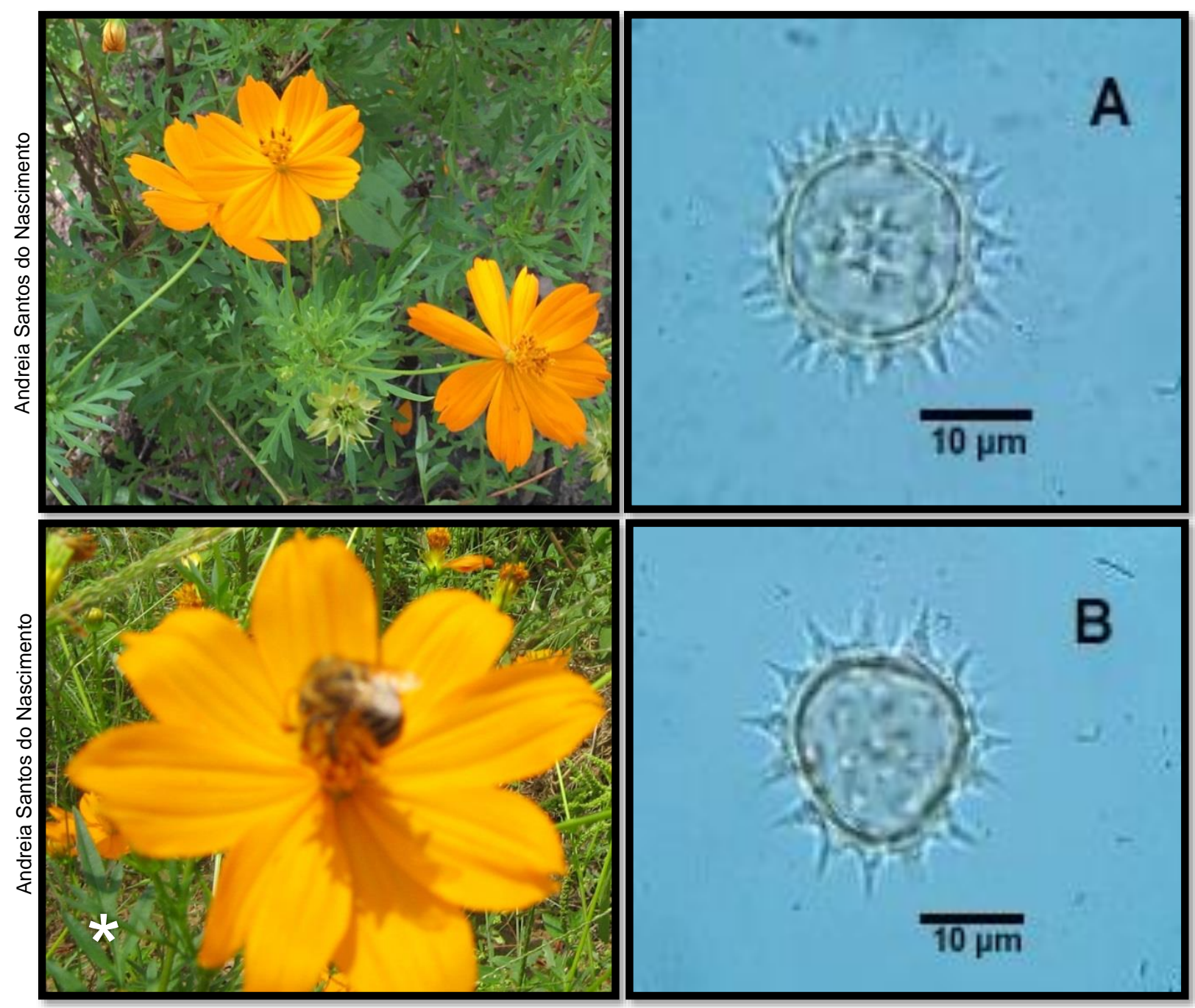

Descrição polínica: $A-B$ = vista polar, grão de pólen com simetria radial, isopolar, nômade, âmbito subtriangular, abertura polínica do tipo colporo, exina equinada, tamanho médio, forma prolata esferoidal, diâmetro do eixo polar $=26,96 \mu \mathrm{m}$; diâmetro do eixo equatorial $=24,84 \mu \mathrm{m} ; \mathrm{P} / \mathrm{E}=1,08 \mu \mathrm{m}$.

*Abelha visitante floral: Melipona scutellaris Latreille, 1811. 


\section{Asteraceae}

Espécie: Blainvillea biaristata DC.

Nome comum: Erva-palha; canela-de-urubu

Hábito de crescimento: herbáceo

Fonte de recurso trófico: néctar/pólen

Período de Floração: maio a agosto

№ Palinoteca: PA 144
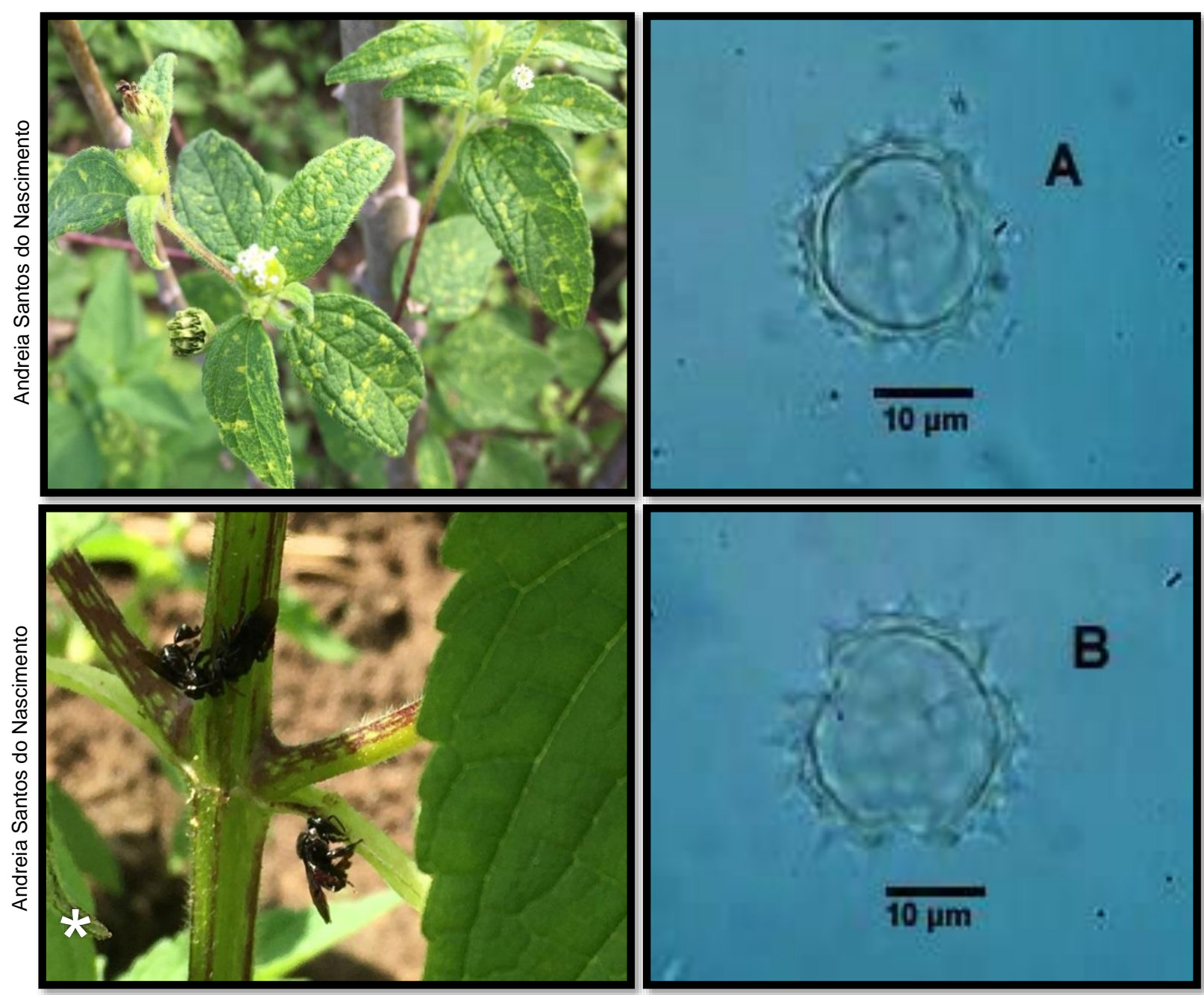

Descrição polínica: A-B = vista polar, grão de pólen com simetria radial, isopolar, nômade, âmbito subtriangular, abertura polínica do tipo colporo, exina equinada, tamanho médio, forma prolata esferoidal, diâmetro do eixo polar $=26,96 \mu \mathrm{m}$; diâmetro do eixo equatorial $=25,15 \mu \mathrm{m} ; \mathrm{P} / \mathrm{E}=1,07 \mu \mathrm{m}$.

*Abelha coletando resina: Trigona spinipes Fabricius, 1793. 


\section{Asteraceae}

Espécie: Centratherum punctatum Cass.

Nome comum: Balainho-de-velho

Hábito de crescimento: herbáceo

Fonte de recurso trófico: néctar/pólen

Período de Floração: maio a agosto

№ Palinoteca: PA 56

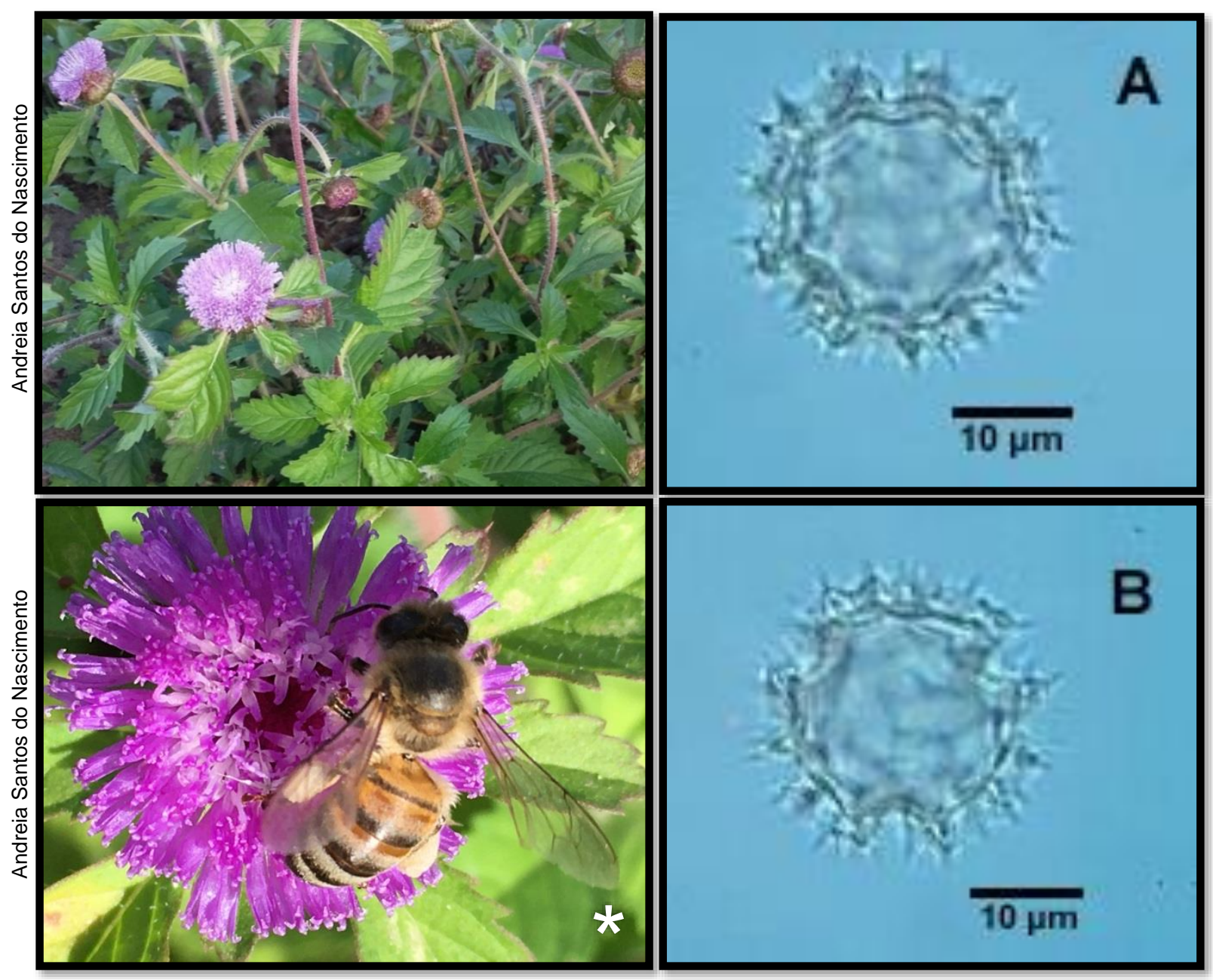

Descrição polínica: $A-B$ = vista polar, grão de pólen com simetria radial, isopolar, nômade, âmbito subtriangular, abertura polínica do tipo poro, exina equinolofada, tamanho médio, forma prolata esferoidal, diâmetro do eixo polar $=28,48 \mu \mathrm{m}$; diâmetro do eixo equatorial $=27,27 \mu \mathrm{m} ; \mathrm{P} / \mathrm{E}=1,04 \mu \mathrm{m}$.

*Abelha visitante floral: Apis mellifera Linnaeus, 1758. 


\section{Asteraceae}

Espécie: Eclipta alba (L.) Hassk.

Nome comum: Agrião-do-brejo; erva-botão

Hábito de crescimento: herbáceo

Fonte de recurso trófico: néctar/pólen

Período de Floração: maio a agosto

№ Palinoteca: PA 78
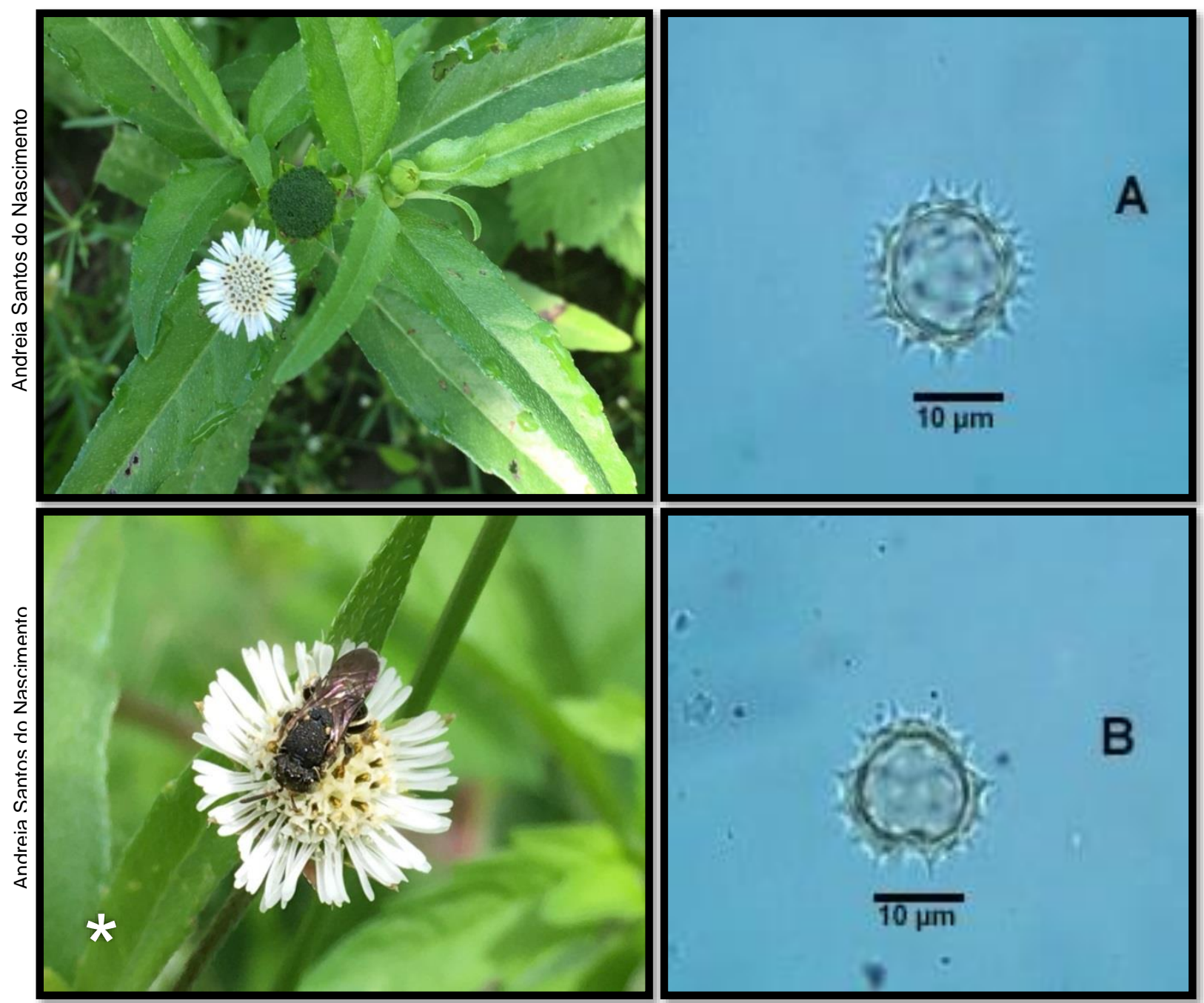

Descrição polínica: A-B = vista polar, grão de pólen com simetria radial, isopolar, nômade, âmbito subtriangular, abertura polínica do tipo colporo, exina equinada, tamanho pequeno, forma prolata esferoidal, diâmetro do eixo polar $=14,15 \mu \mathrm{m}$; diâmetro do eixo equatorial $=12,72 \mu \mathrm{m} ; \mathrm{P} / \mathrm{E}=1,11 \mu \mathrm{m}$.

*Abelha visitante floral: Nannotrigona testaceicornis Lepeletier, 1836. 


\section{Asteraceae}

Espécie: Elephantopus mollis Kunth.

Nome comum: Erva-de-colégio

Hábito de crescimento: herbáceo

Fonte de recurso trófico: néctar/pólen

Período de Floração: maio a agosto

№ Palinoteca: PA 134

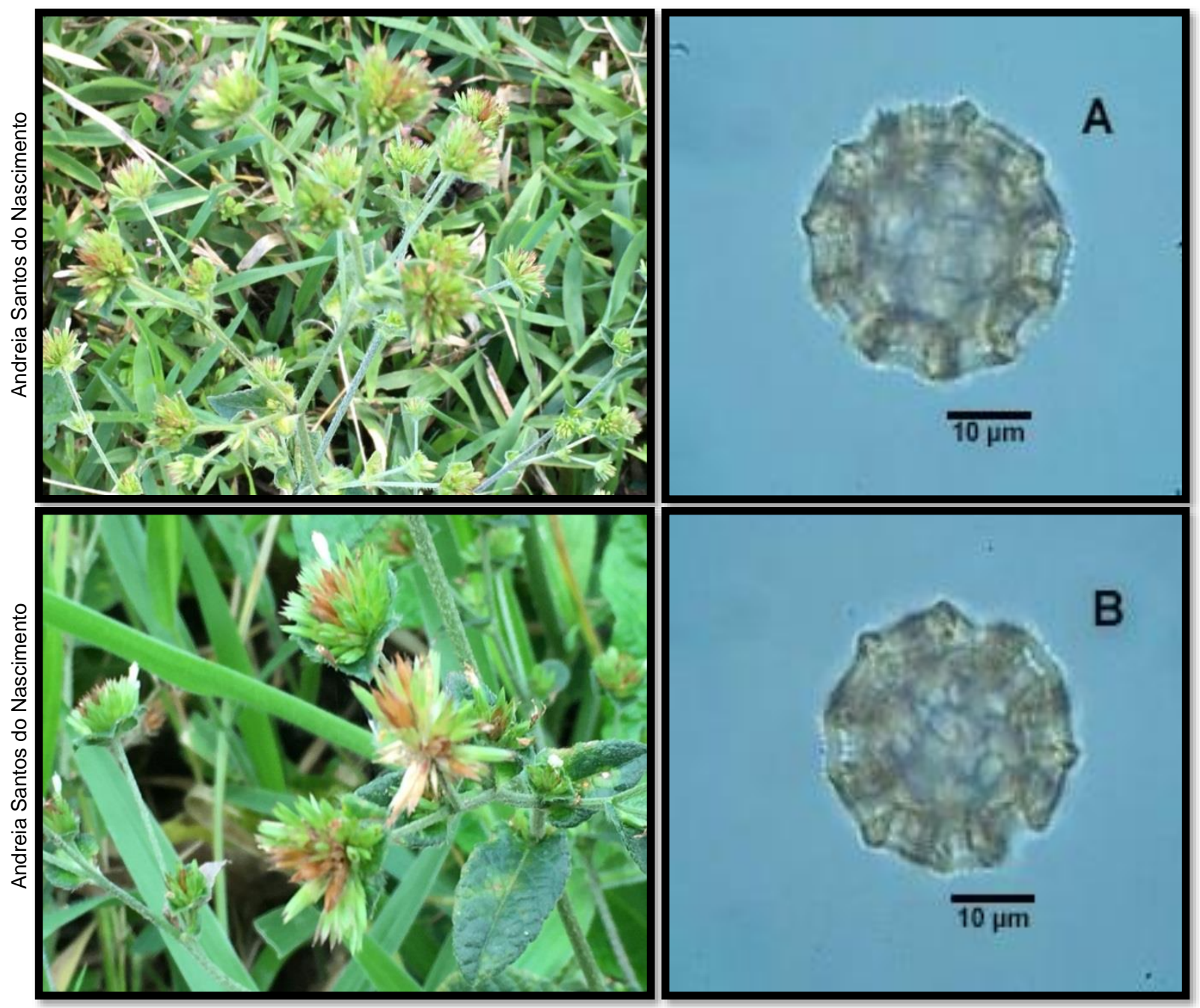

Descrição polínica: $A-B$ = vista polar, grão de pólen com simetria radial, isopolar, nômade, âmbito subtriangular, abertura polínica do tipo poro, exina equinolofada, tamanho médio, forma prolata esferoidal, diâmetro do eixo polar $=31,81 \mu \mathrm{m}$; diâmetro do eixo equatorial $=30,90 \mu \mathrm{m} ; \mathrm{P} / \mathrm{E}=1,02 \mu \mathrm{m}$. 


\section{Asteraceae}

Espécie: Emilia sonchifolia (L.) DC. ex Wight

Nome comum: Flor-de-pincel; serralhinha

Hábito de crescimento: herbáceo

Fonte de recurso trófico: néctar/pólen

Período de Floração: maio a agosto

№ Palinoteca: PA 61

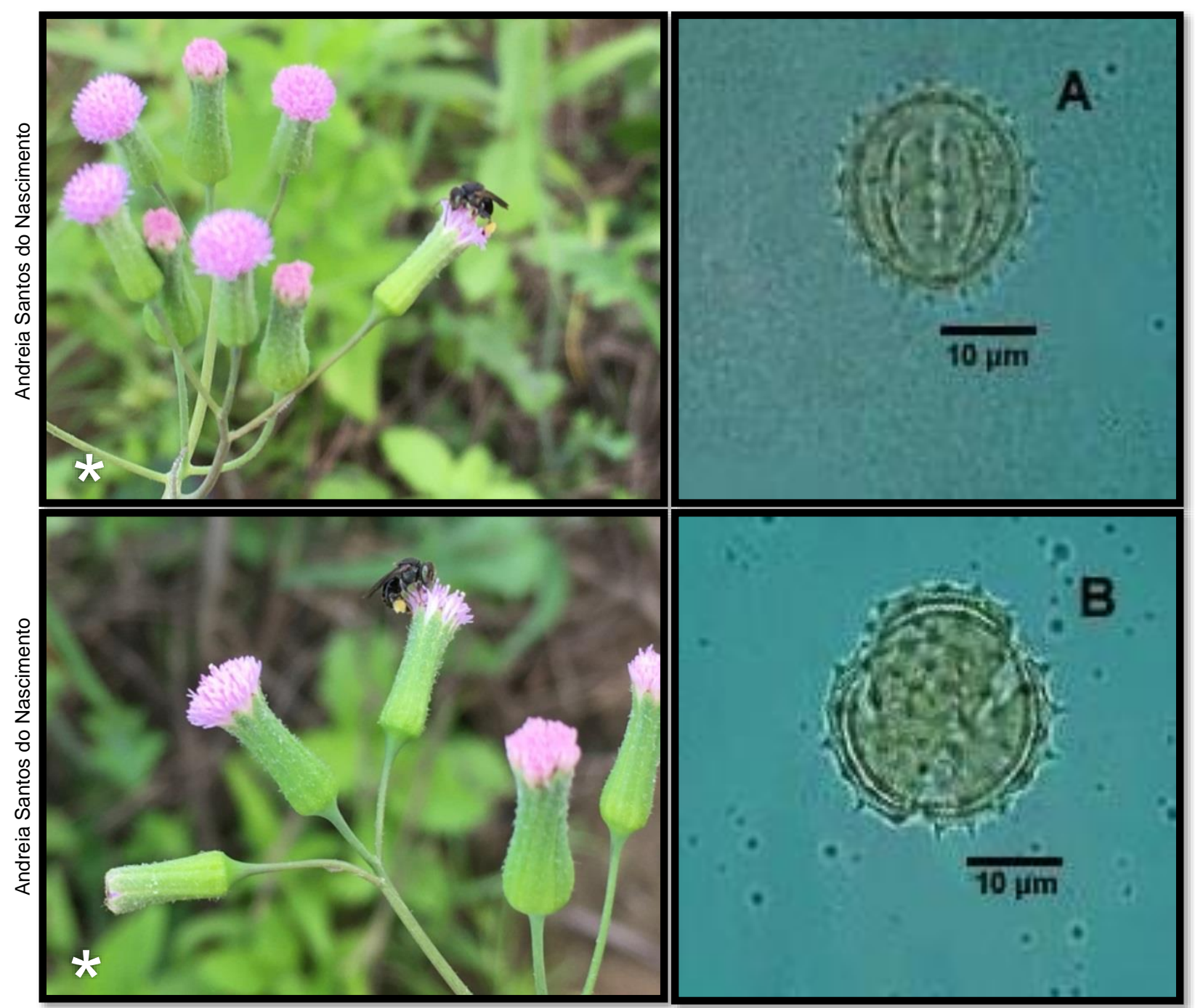

Descrição polínica: $A$ = equatorial e $B$ = vista polar, grão de pólen com simetria radial, isopolar, nômade, âmbito subtriangular, abertura polínica do tipo colporo, exina equinada, tamanho médio, forma prolata esferoidal, diâmetro do eixo polar $=34,24$ $\mu \mathrm{m}$; diâmetro do eixo equatorial = 32,42 $\mu \mathrm{m} ; \mathrm{P} / \mathrm{E}=1,05 \mu \mathrm{m}$.

*Abelha visitante floral: Nannotrigona testaceicornis Lepeletier, 1836 


\section{Asteraceae}

Espécie: Helianthus annuus L.

Nome comum: Girassol

Hábito de crescimento: herbáceo

Fonte de recurso trófico: néctar/pólen

Período de Floração: agosto a dezembro

№ Palinoteca: PA 90
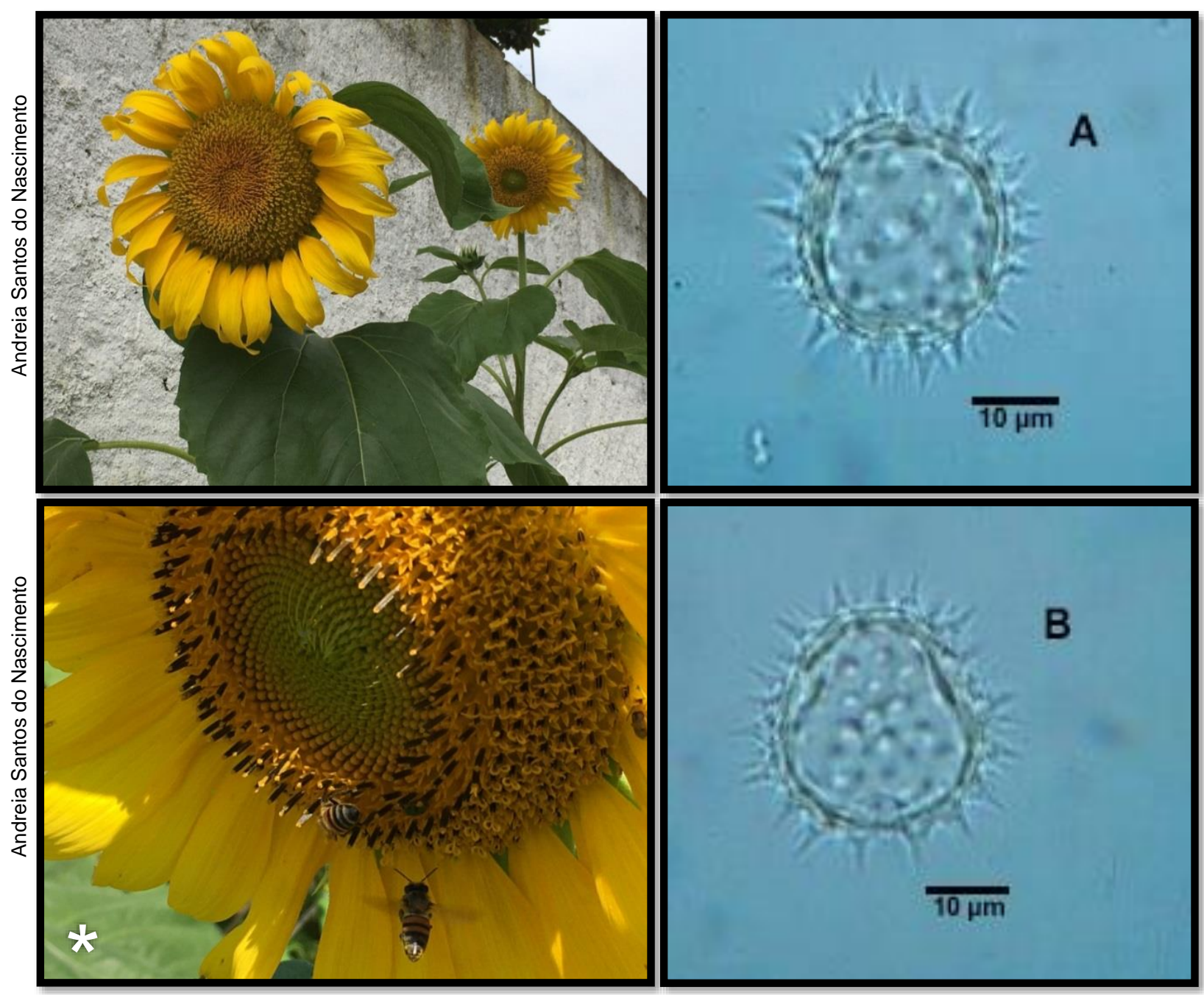

Descrição polínica: A-B = vista polar, grão de pólen com simetria radial, isopolar, nômade, âmbito subtriangular, abertura polínica do tipo colporo, exina equinada, tamanho médio, forma prolata esferoidal, diâmetro do eixo polar $=34,84 \mu \mathrm{m}$; diâmetro do eixo equatorial $=33,93 \mu \mathrm{m} ; \mathrm{P} / \mathrm{E}=1,02 \mu \mathrm{m}$.

*Abelha visitante floral: Apis mellifera Linnaeus, 1758. 


\section{Asteraceae}

Espécie: Lourteigia ballotifolia Kunth

Nome comum: Picão-roxo

Hábito de crescimento: herbáceo

Fonte de recurso trófico: néctar

Período de Floração: julho a outubro

№ Palinoteca: PA 149
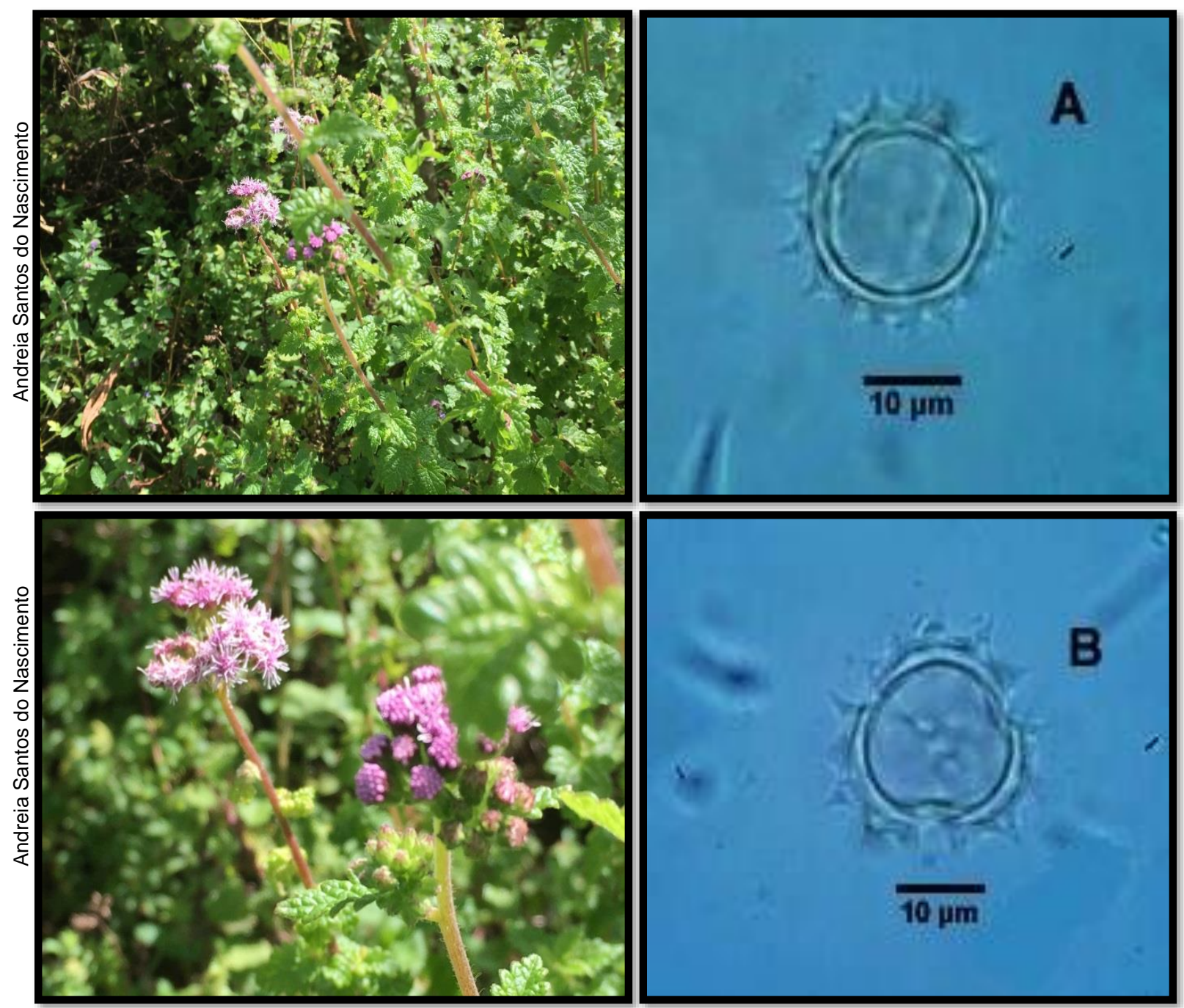

Descrição polínica: A-B = vista polar, grão de pólen com simetria radial, isopolar, nômade, âmbito subtriangular, abertura polínica do tipo colporo, exina equinada, tamanho médio, forma prolata esferoidal, diâmetro do eixo polar $=26,06 \mu \mathrm{m}$; diâmetro do eixo equatorial $=23,63 \mu \mathrm{m} ; \mathrm{P} / \mathrm{E}=1,10 \mu \mathrm{m}$. 


\section{Asteraceae}

Espécie: Melampodium paniculatum Gardner

Nome comum: Botão-de-ouro

Hábito de crescimento: herbáceo

Fonte de recurso trófico: néctar/pólen

Período de Floração: março a julho

№ Palinoteca: PA 142
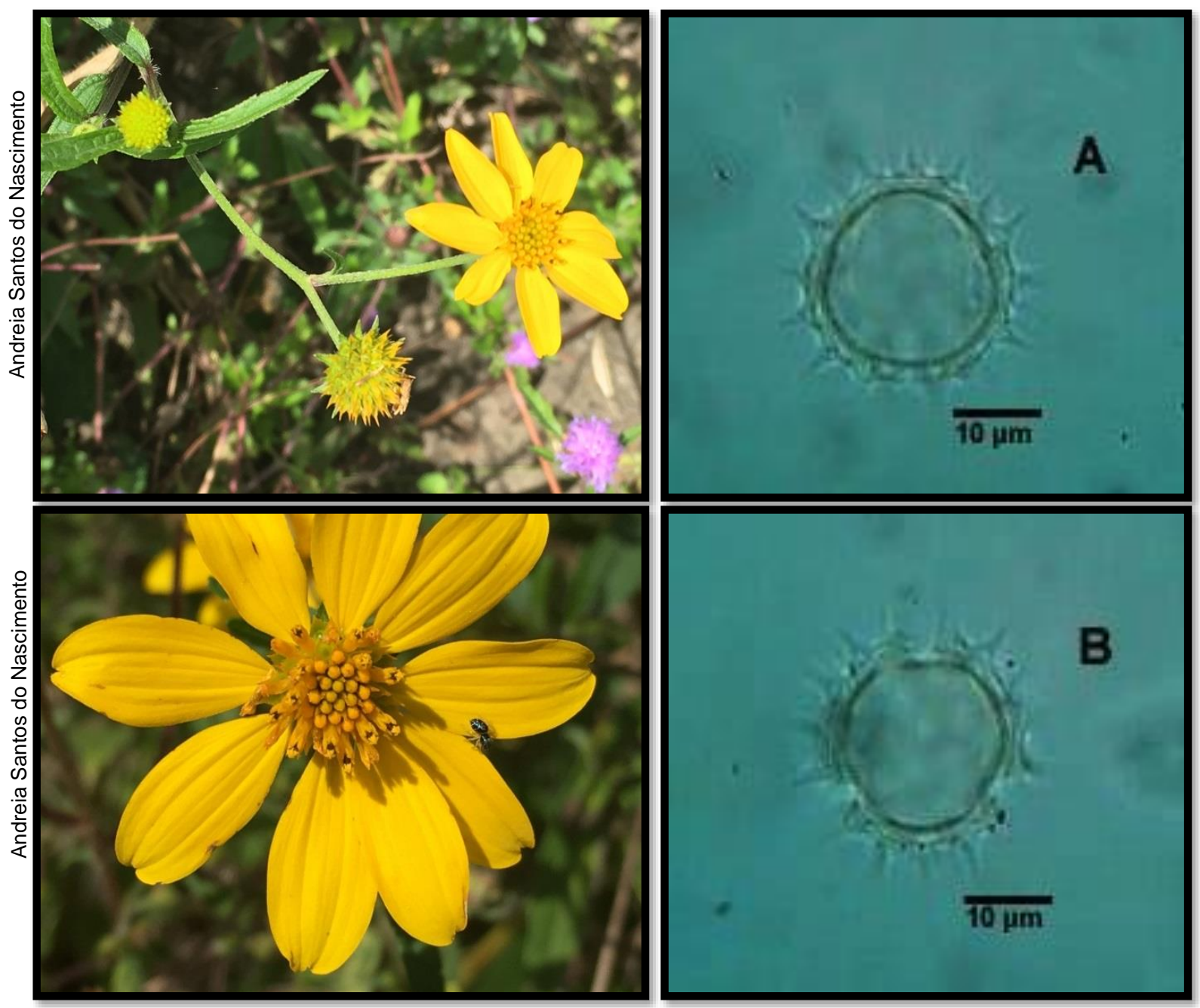

Descrição polínica: A-B = vista polar, grão de pólen com simetria radial, isopolar, nômade, âmbito subtriangular, abertura polínica do tipo colporo, exina equinada, tamanho médio, forma prolata esferoidal, diâmetro do eixo polar $=25,15 \mu \mathrm{m}$; diâmetro do eixo equatorial $=24,54 \mu \mathrm{m} ; \mathrm{P} / \mathrm{E}=1,02 \mu \mathrm{m}$. 


\section{Asteraceae}

Espécie: Montanoa bipinnatifida (Kunth) K. Koch

Nome comum: Margaridão-branco

Hábito de crescimento: herbáceo

Fonte de recurso trófico: néctar

Período de Floração: julho a outubro

№ Palinoteca: PA 58
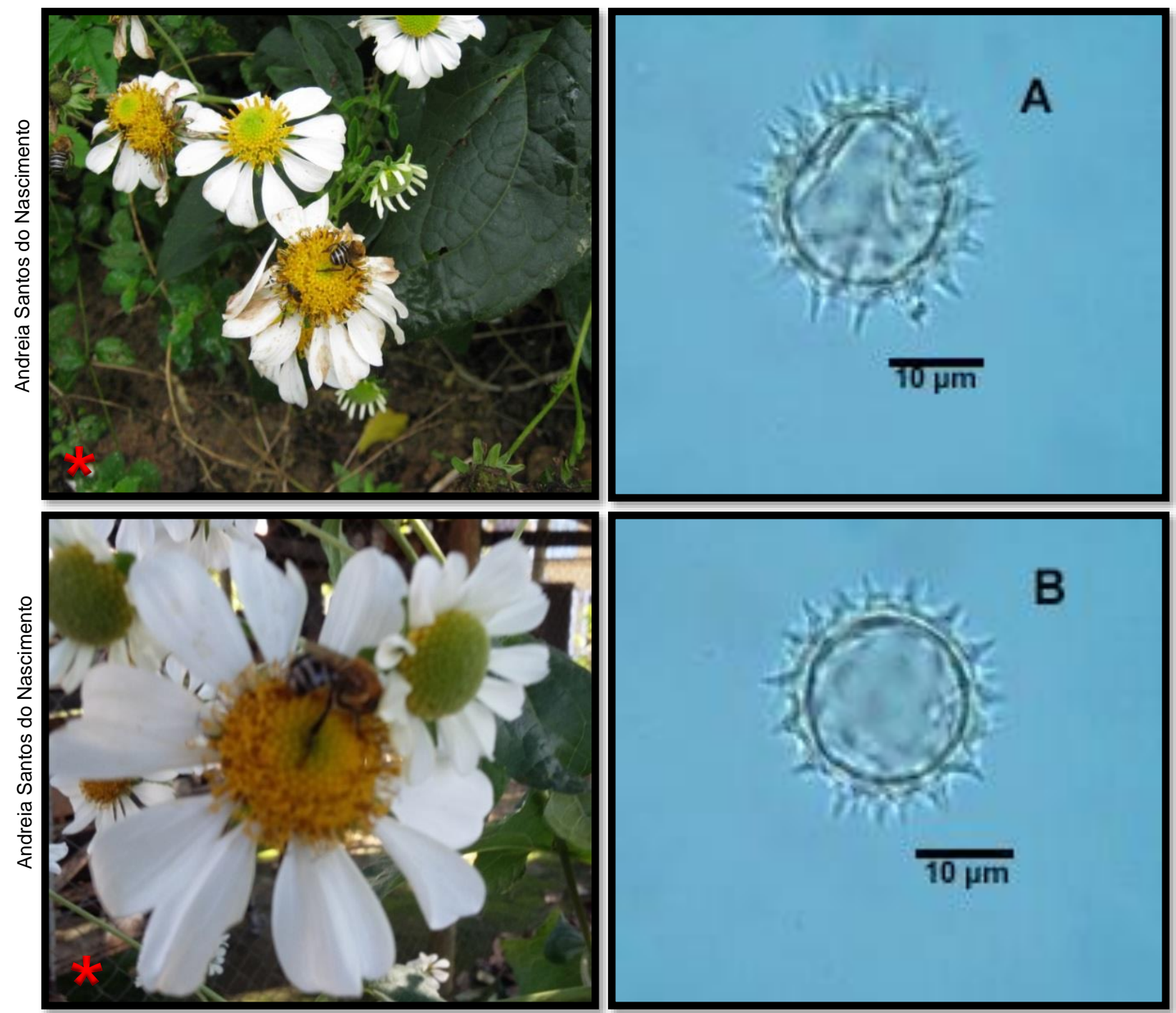

Descrição polínica: A-B = vista polar, grão de pólen com simetria radial, isopolar, nômade, âmbito subtriangular, abertura polínica do tipo colporo, exina equinada, tamanho médio, forma prolata esferoidal diâmetro do eixo polar $=26,06 \mu \mathrm{m}$; diâmetro do eixo equatorial $=25,15 \mu \mathrm{m} ; \mathrm{P} / \mathrm{E}=1,03 \mu \mathrm{m}$.

*Abelha visitante floral: Melipona scutellaris Latreille, 1811. 


\section{Asteraceae}

Espécie: Synedrella nodiflora (L.) Gaertn.

Nome comum: Corredeira

Hábito de crescimento: herbáceo

Fonte de recurso trófico: néctar/pólen

Período de Floração: março a julho

№ Palinoteca: PA 181
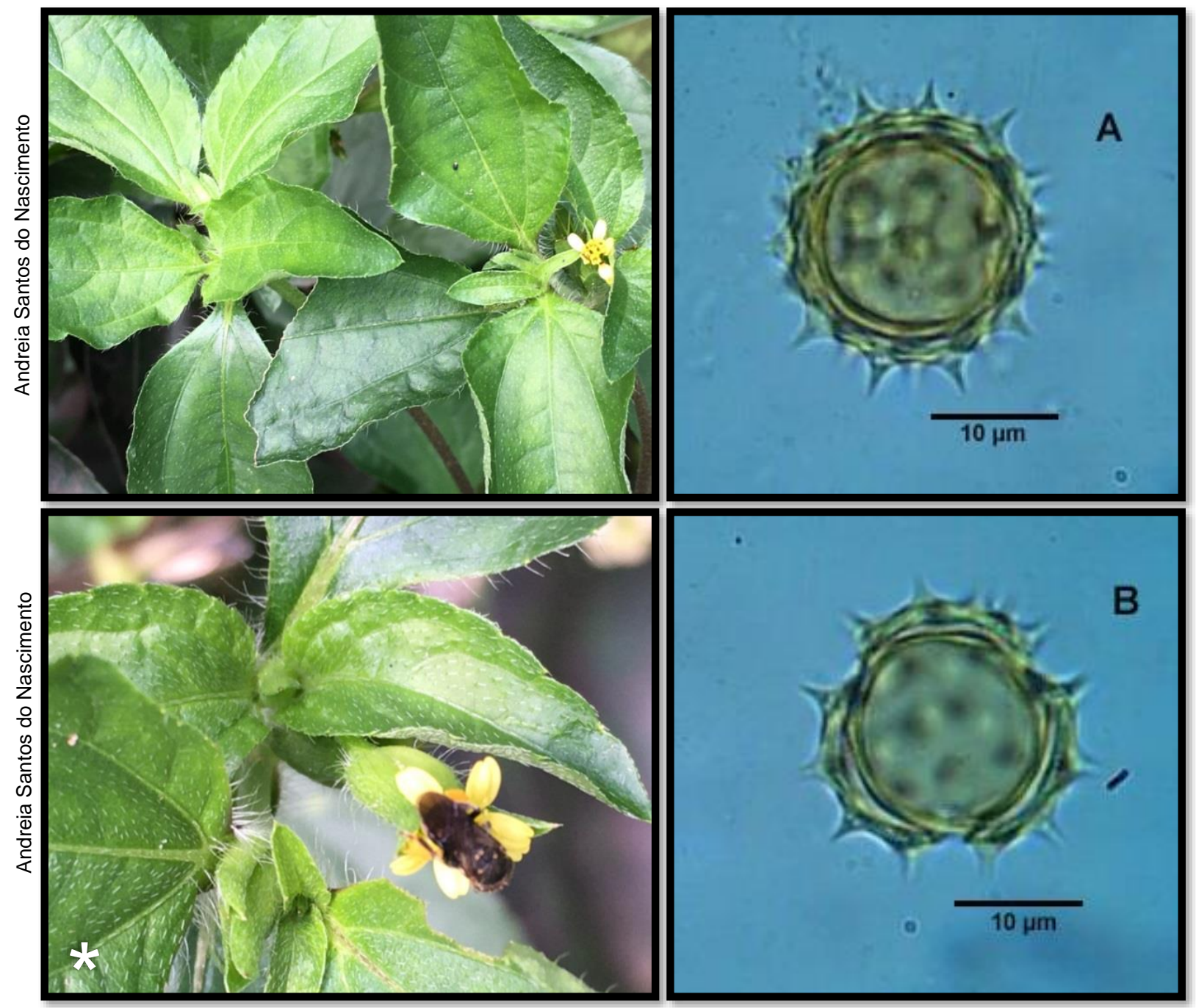

Descrição polínica: A-B = vista polar, grão de pólen com simetria radial, isopolar, nômade, âmbito subtriangular, abertura polínica do tipo colporo, exina equinada, tamanho médio, forma prolata esferoidal diâmetro do eixo polar $=29,69 \mu \mathrm{m}$; diâmetro do eixo equatorial $=28,48 \mu \mathrm{m} ; \mathrm{P} / \mathrm{E}=1,04 \mu \mathrm{m}$.

*Abelha visitante floral: Nannotrigona testaceicornis Lepeletier, 1836. 


\section{Asteraceae}

Espécie: Tithonia diversifolia (Hemsl.) A.Gray

Nome comum: Margaridão-amarelo

Hábito de crescimento: arbustivo

Fonte de recurso trófico: néctar/pólen

Período de Floração: janeiro a outubro

№ Palinoteca: PA 60
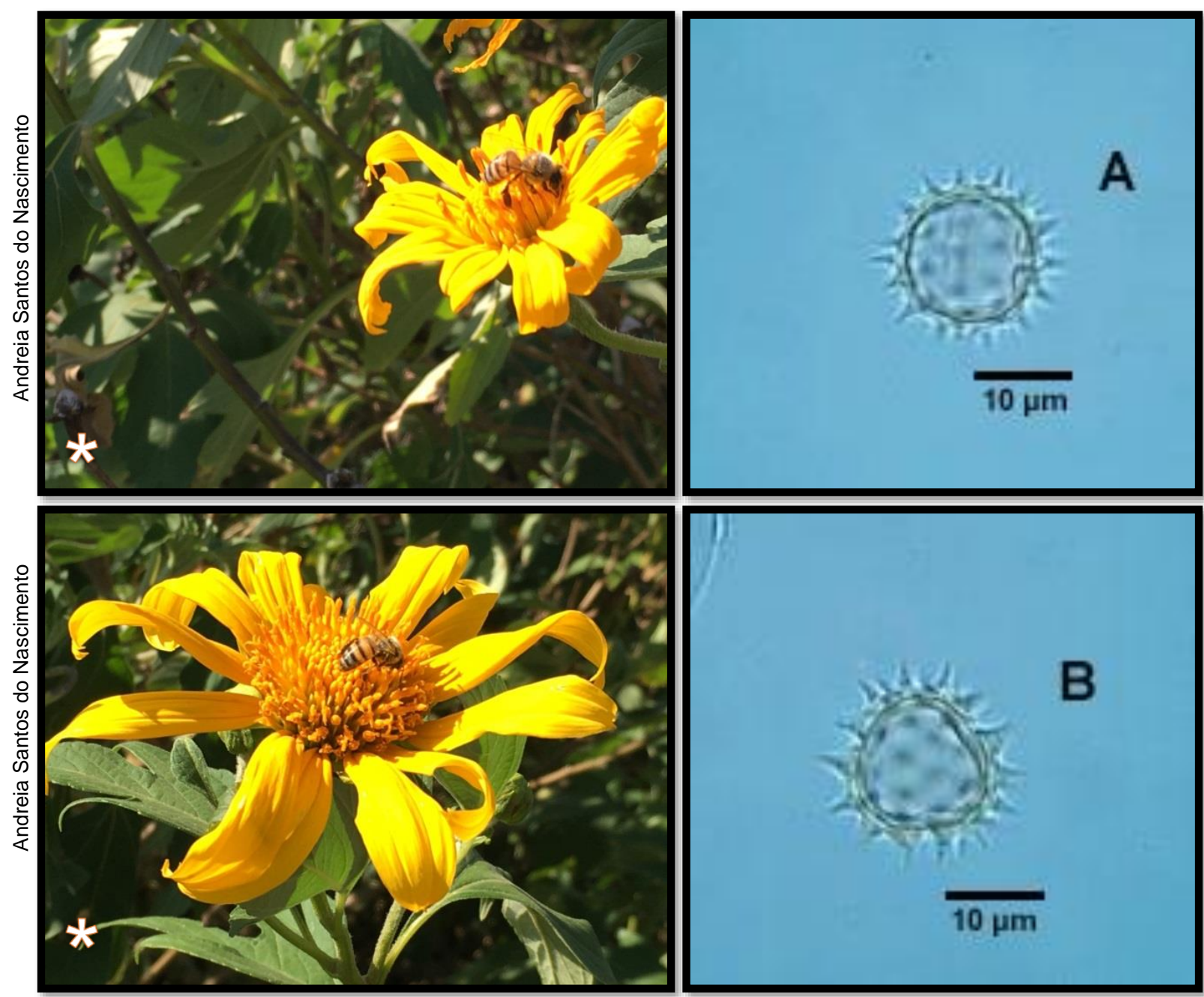

Descrição polínica: $A-B=$ vista polar, grão de pólen com simetria radial, isopolar, nômade, âmbito subtriangular, abertura polínica do tipo colporo, exina equinada, tamanho pequeno, forma prolata esferoidal, diâmetro do eixo polar $=16,96 \mu \mathrm{m}$; diâmetro do eixo equatorial $=16,36 \mu \mathrm{m} ; \mathrm{P} / \mathrm{E}=1,03 \mu \mathrm{m}$.

*Abelha visitante floral: Apis mellifera Linnaeus, 1758. 


\section{Asteraceae}

Espécie: Tridax procumbens L.

Nome comum: Picão-branco

Hábito de crescimento: herbáceo

Fonte de recurso trófico: pólen

Período de Floração: maio a agosto

№ Palinoteca: PA 53
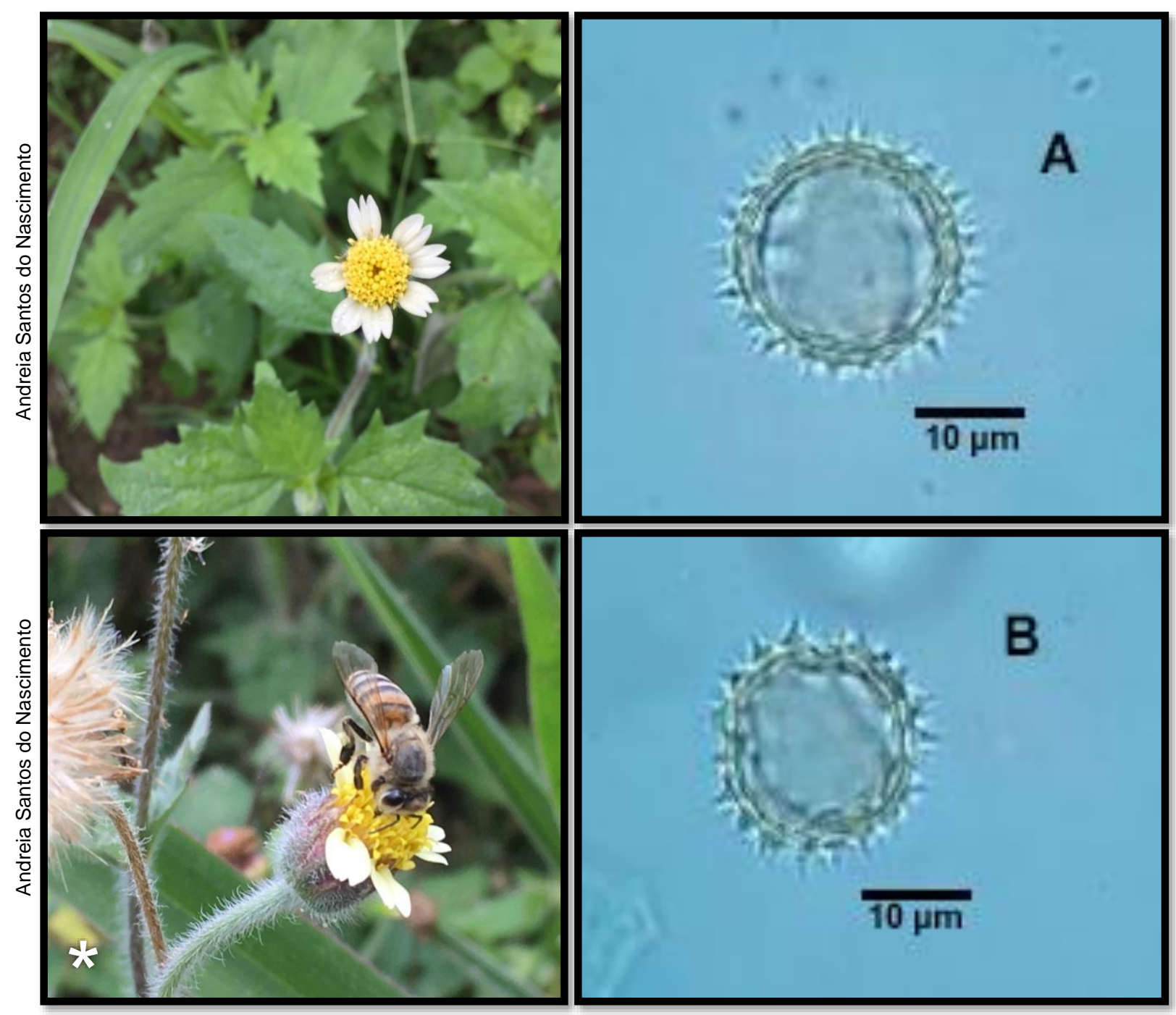

Descrição polínica: A-B = vista polar, grão de pólen com simetria radial, isopolar, nômade, âmbito Quadrangular/subtriangular, abertura polínica do tipo colporo, exina equinada, tamanho médio, forma prolata esferoidal, diâmetro do eixo polar $=30,00$ $\mu \mathrm{m}$; diâmetro do eixo equatorial = 29,09 $\mu \mathrm{m} ; \mathrm{P} / \mathrm{E}=1,03 \mu \mathrm{m}$.

*Abelha visitante floral: Apis mellifera Linnaeus, 1758. 


\section{Asteraceae}

Espécie: Vernonanthura phosphorica (Vell.) H.Rob.

Nome comum: Assa-peixe

Hábito de crescimento: arbustivo

Fonte de recurso trófico: néctar

Período de Floração: agosto a setembro

№ Palinoteca: PA 166

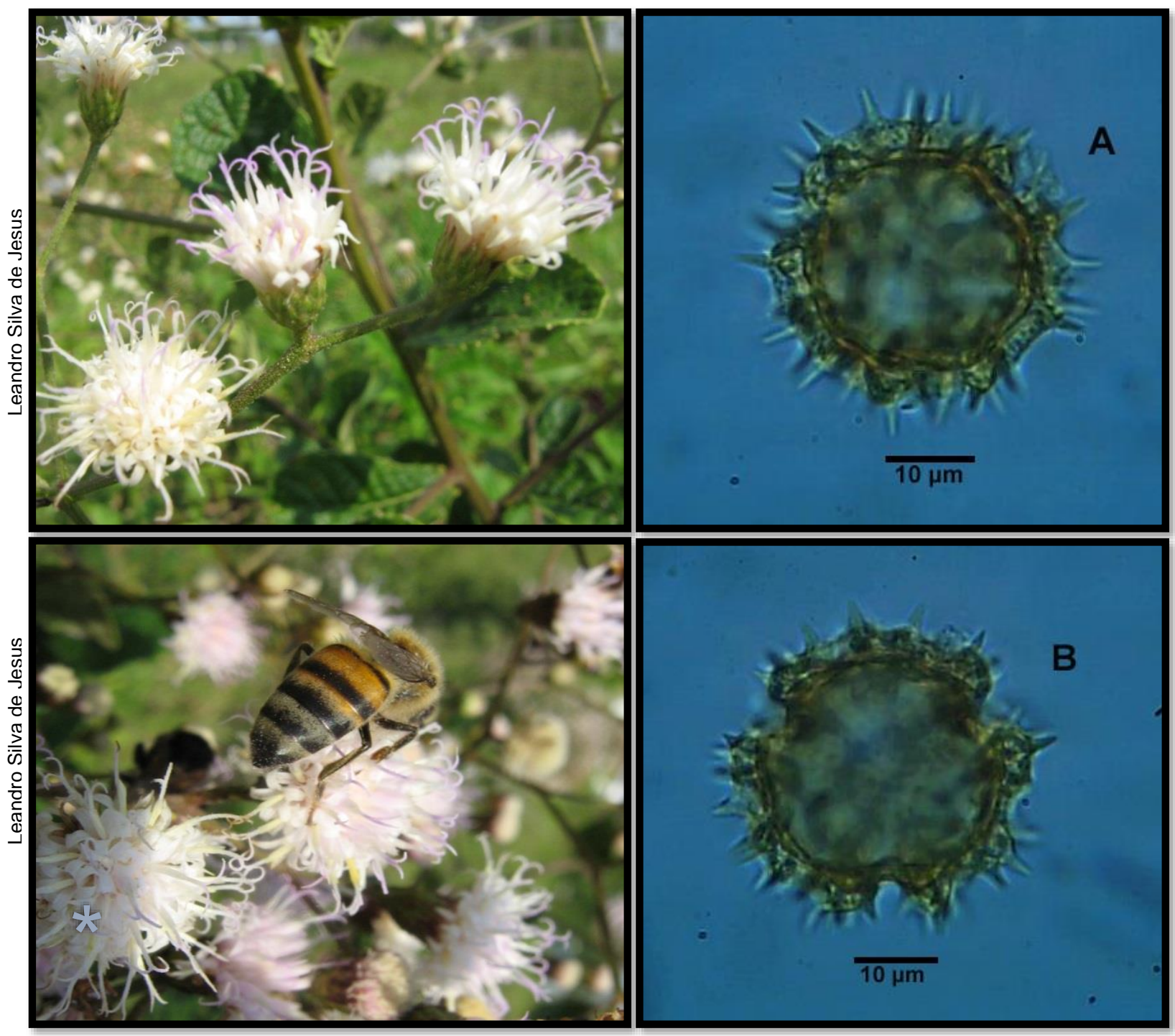

Descrição polínica: A-B = vista polar, grão de pólen com simetria radial, isopolar, nômade, âmbito subtriangular, abertura polínica do tipo poro, exina equinolofada, tamanho médio, forma prolata esferoidal, diâmetro do eixo polar $=36,06 \mu \mathrm{m}$; diâmetro do eixo equatorial $=35,15 \mu \mathrm{m} ; \mathrm{P} / \mathrm{E}=1,02 \mu \mathrm{m}$.

*Abelha visitante floral: Apis mellifera Linnaeus, 1758. 


\section{Asteraceae}

Espécie: Vernonia condensata Baker.

Nome comum: Alumã

Hábito de crescimento: arbustivo

Fonte de recurso trófico: néctar

Período de Floração: junho a novembro

№ Palinoteca: PA 72
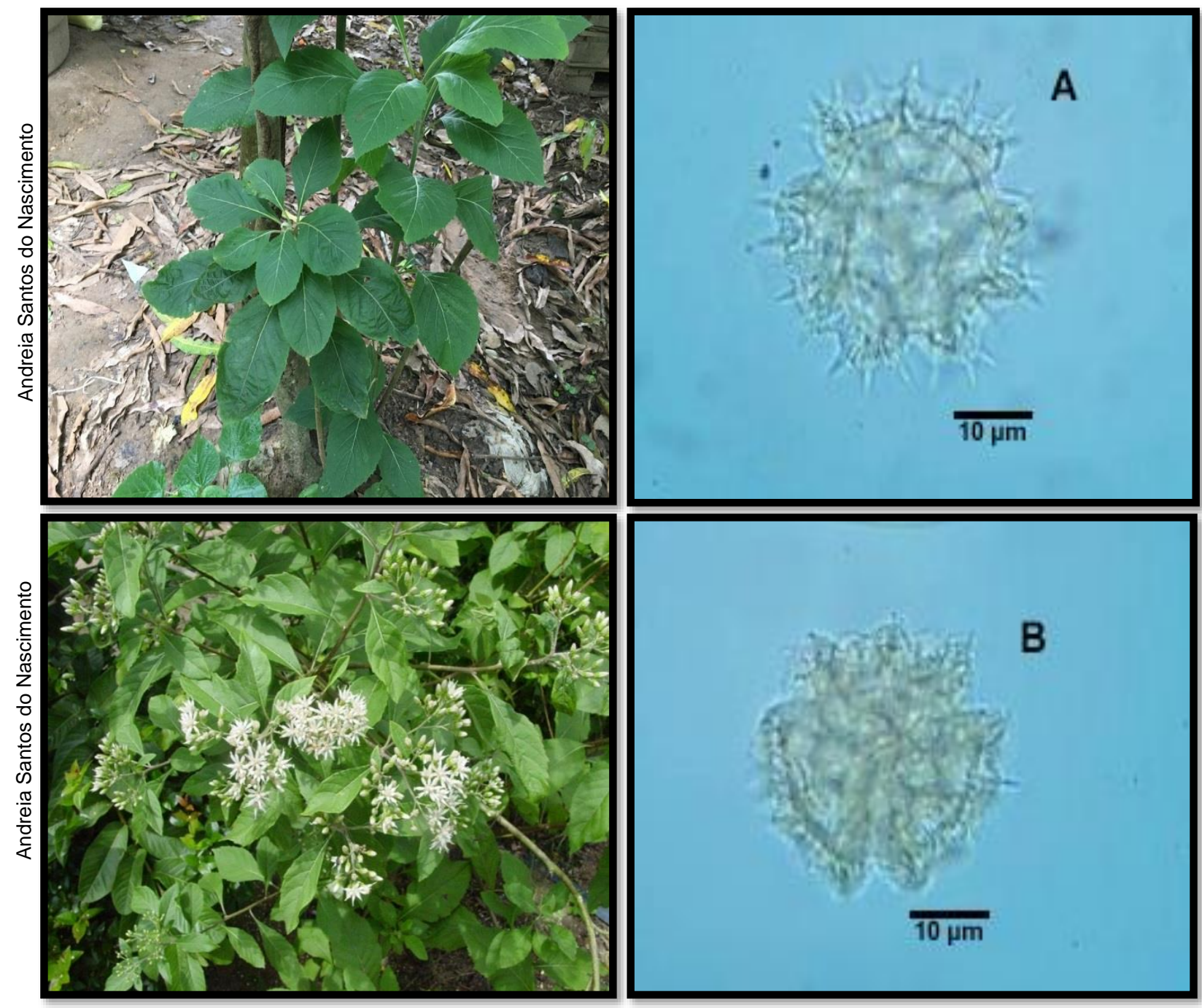

Descrição polínica: A-B = vista polar, grão de pólen com simetria radial, isopolar, nômade, âmbito subtriangular, abertura polínica do tipo poro, exina equinada/reticulada, tamanho médio, forma prolata esferoidal, diâmetro do eixo polar $=37,87 \mu \mathrm{m}$; diâmetro do eixo equatorial $=36,96 \mu \mathrm{m} ; \mathrm{P} / \mathrm{E}=1,02 \mu \mathrm{m}$. 


\section{Asteraceae}

Espécie: Vernonia sp.

Nome comum: Assa-peixe

Hábito de crescimento: arbustivo

Fonte de recurso trófico: néctar

Período de Floração: agosto a setembro

№ Palinoteca: PA 146
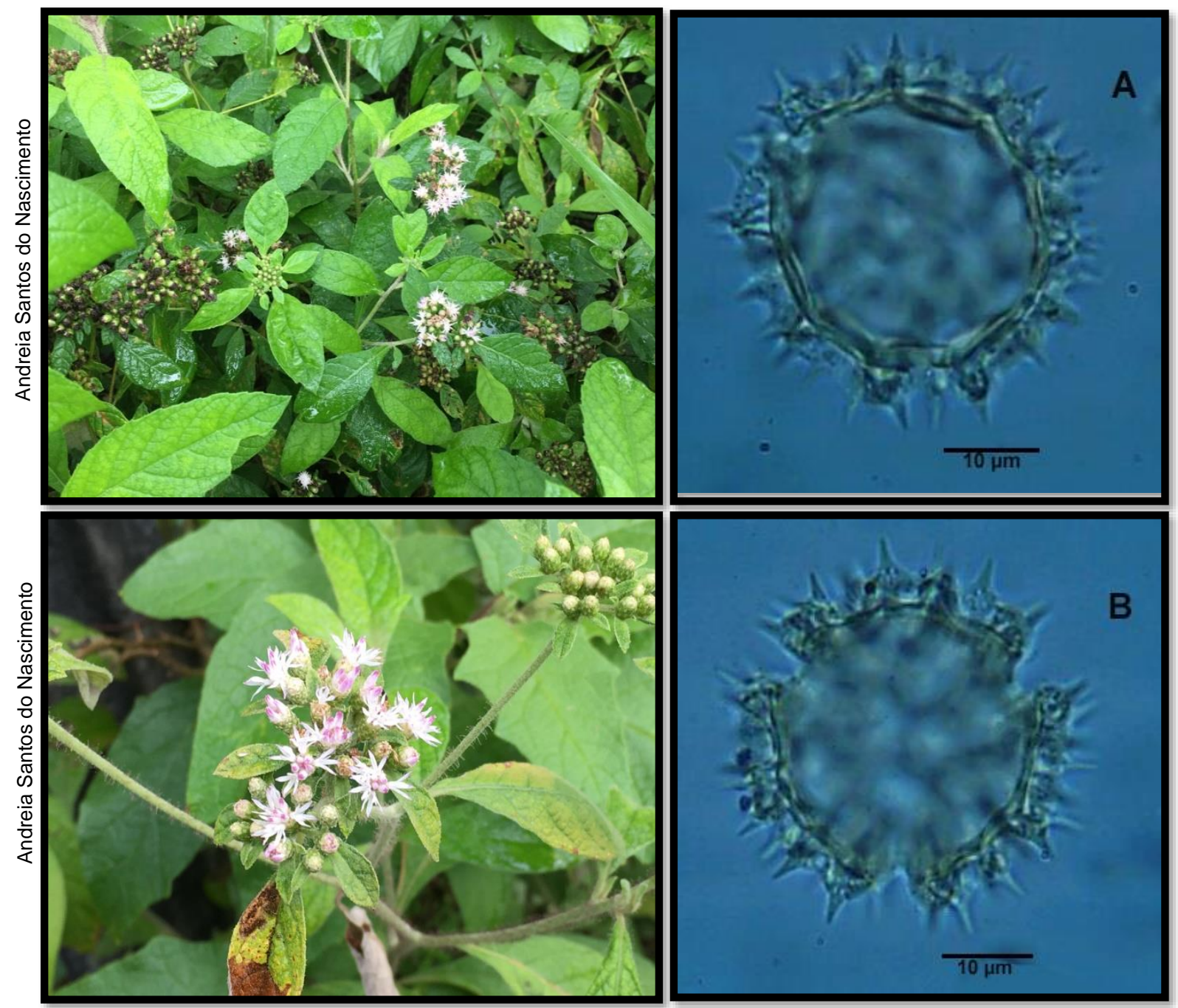

Descrição polínica: A-B = vista polar, grão de pólen com simetria radial, isopolar, nômade, âmbito subtriangular, abertura polínica do tipo poro, exina equinada/reticulada, tamanho médio, forma prolata esferoidal, diâmetro do eixo polar $=38,78 \mu \mathrm{m}$; diâmetro do eixo equatorial $=38,18 \mu \mathrm{m} ; \mathrm{P} / \mathrm{E}=1,01 \mu \mathrm{m}$. 


\section{Bignoniaceae}

Espécie: Tecoma stans (L.) Juss. ex Kunth

Nome comum: Ipê-de-jardim

Hábito de crescimento: arbustivo

Fonte de recurso trófico: pólen

Período de Floração: maio a outubro

№ Palinoteca: PA 51

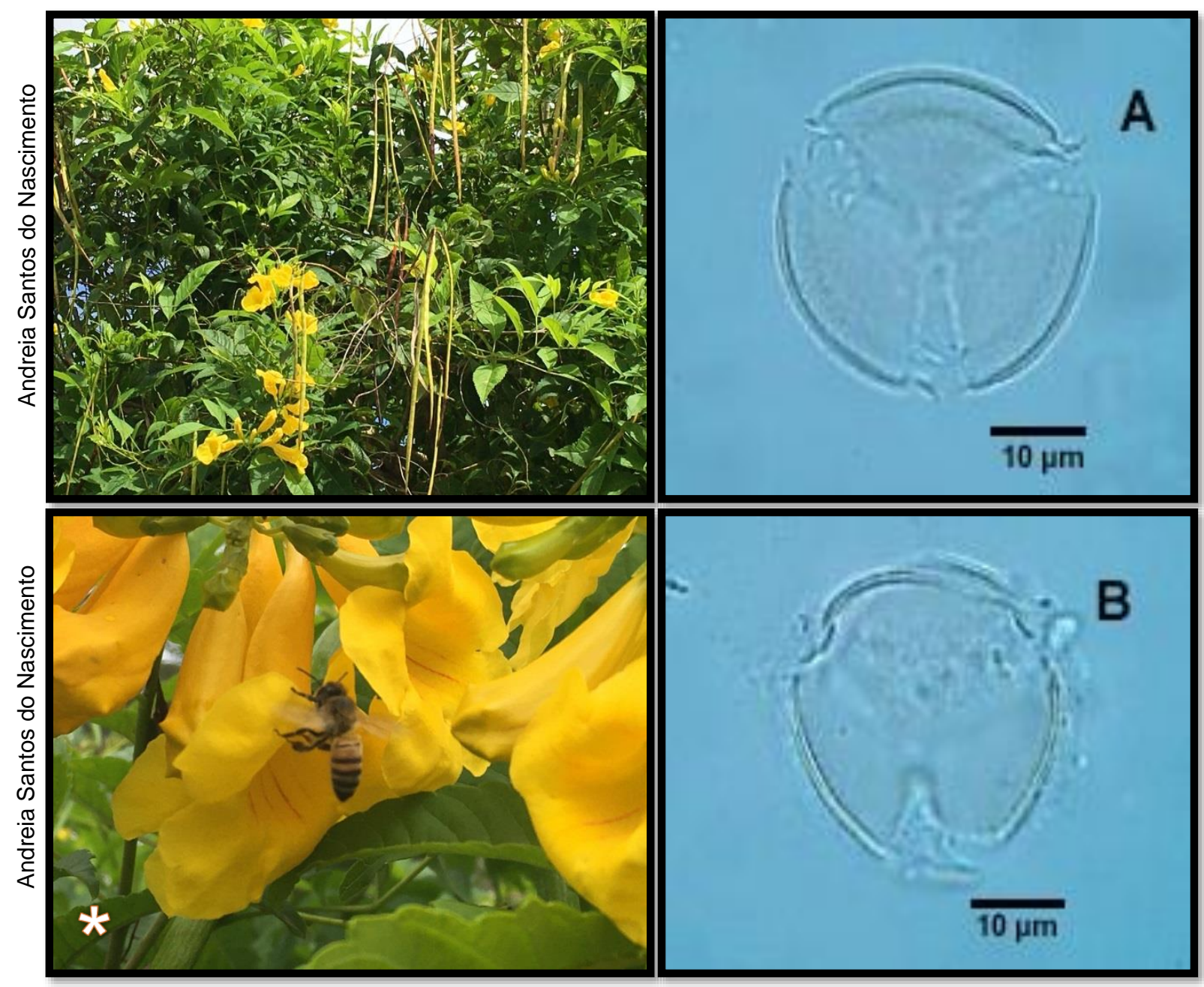

Descrição polínica: A-B = vista polar, grão de pólen com simetria radial, isopolar, nômade, âmbito triangular, abertura polínica do tipo colporo, exina microrreticulada, tamanho médio, forma subprolata, eixo polar $=31,51 \mu \mathrm{m}$; eixo equatorial $=30,30 \mu \mathrm{m}$; $\mathrm{P} / \mathrm{E}=1,03 \mu \mathrm{m}$.

*Abelha visitante floral: Apis mellifera Linnaeus, 1758. 


\section{Bixaceae}

Espécie: Bixa orellana L.

Nome comum: Urucum

Hábito de crescimento: arbóreo

Fonte de recurso trófico: pólen

Período de Floração: setembro a novembro

№ Palinoteca: PA 12
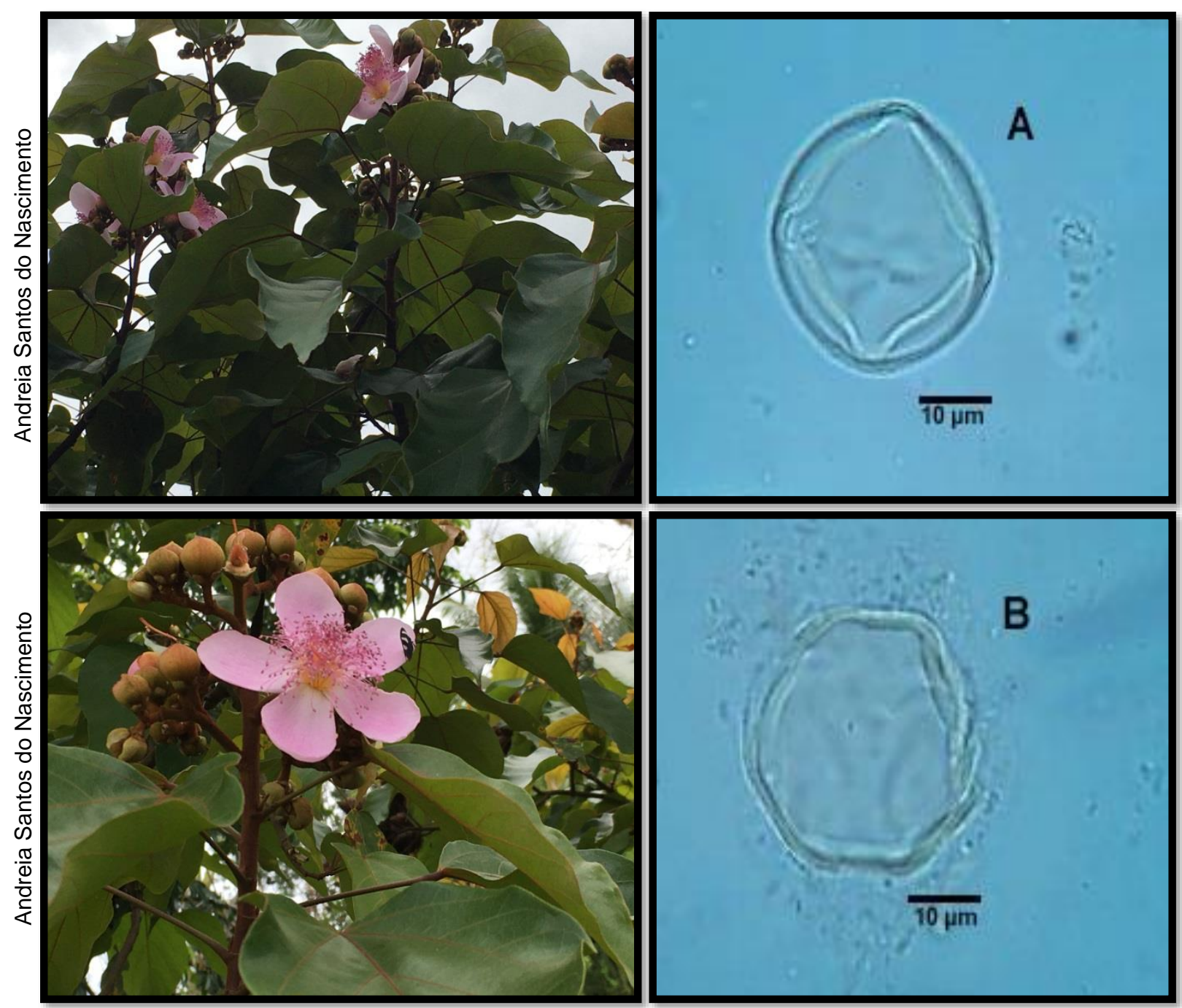

Descrição polínica: $A$ = vista equatorial e $B$ = vista polar, grão de pólen com simetria radial, isopolar, nômade, âmbito subtriangular, abertura polínica do tipo colporo, exina microrreticulada, tamanho médio, forma subprolata, eixo polar $=35,45 \mu \mathrm{m}$; eixo equatorial $=32,42 \mu \mathrm{m} ; \mathrm{P} / \mathrm{E}=1,09 \mu \mathrm{m}$. 


\section{Boraginaceae}

Espécie: Cordia verbenacea DC.

Nome comum: Maria-milagrosa

Hábito de crescimento: arbustivo

Fonte de recurso trófico: néctar/pólen

Período de Floração: fevereiro e junho

№ Palinoteca: PA 19
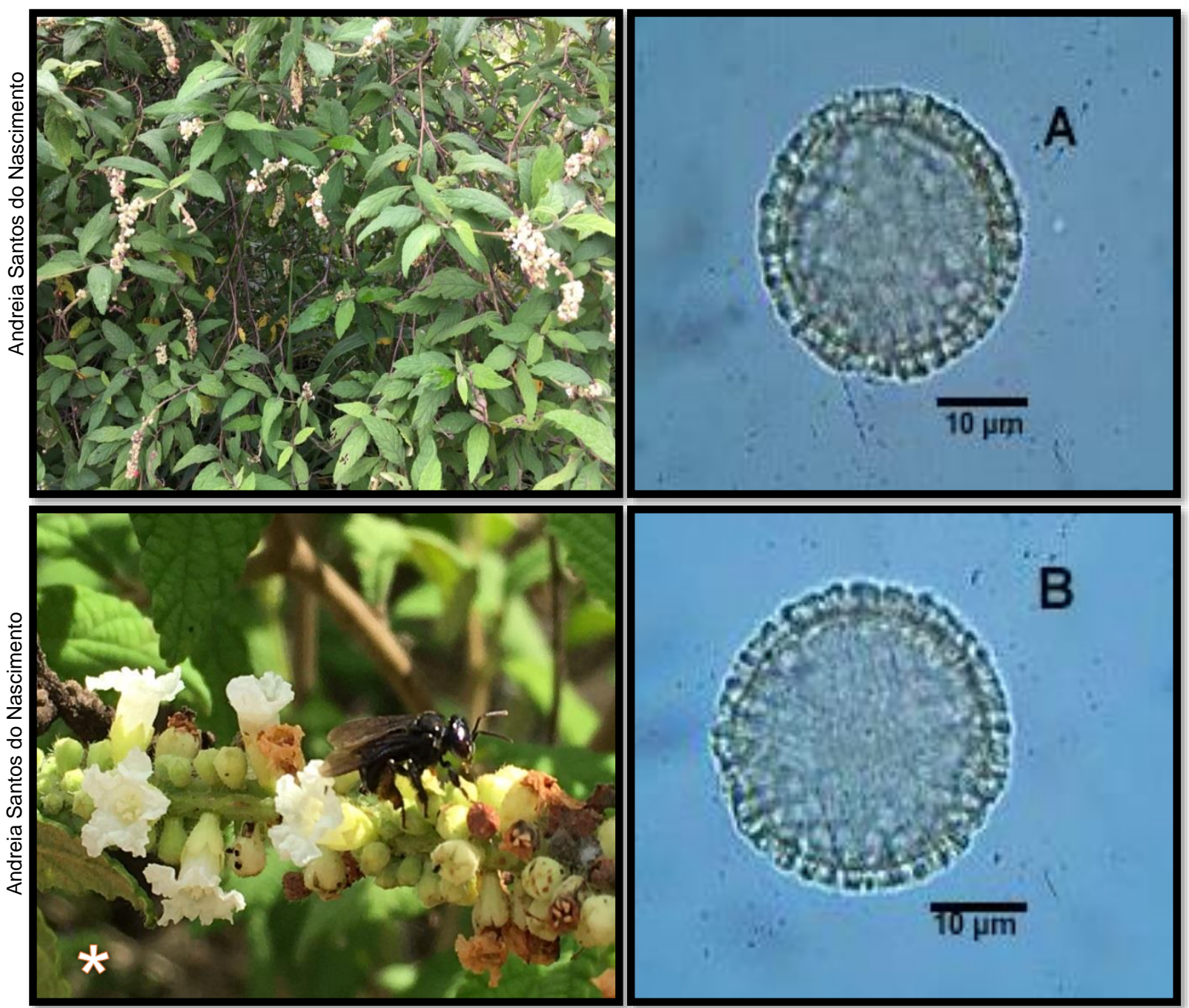

Descrição polínica: $A-B$ = vista polar, grão de pólen com simetria radial, isopolar, nômade, âmbito circular, abertura polínica do tipo poro, exina reticulada, tamanho médio, forma oblata esferoidal, diâmetro do eixo polar $=29,39 \mu \mathrm{m}$, diâmetro do eixo equatorial $=31,81 \mu \mathrm{m}, \mathrm{P} / \mathrm{E}=0,92 \mu \mathrm{m}$.

*Abelha visitante floral: Trigona spinipes Fabricius, 1793. 


\section{Boraginaceae}

Espécie: Heliotropium indicum L.

Nome comum: Crista-de-galo

Hábito de crescimento: herbáceo

Fonte de recurso trófico: néctar

Período de Floração: maio a agosto

№ Palinoteca: PA 67
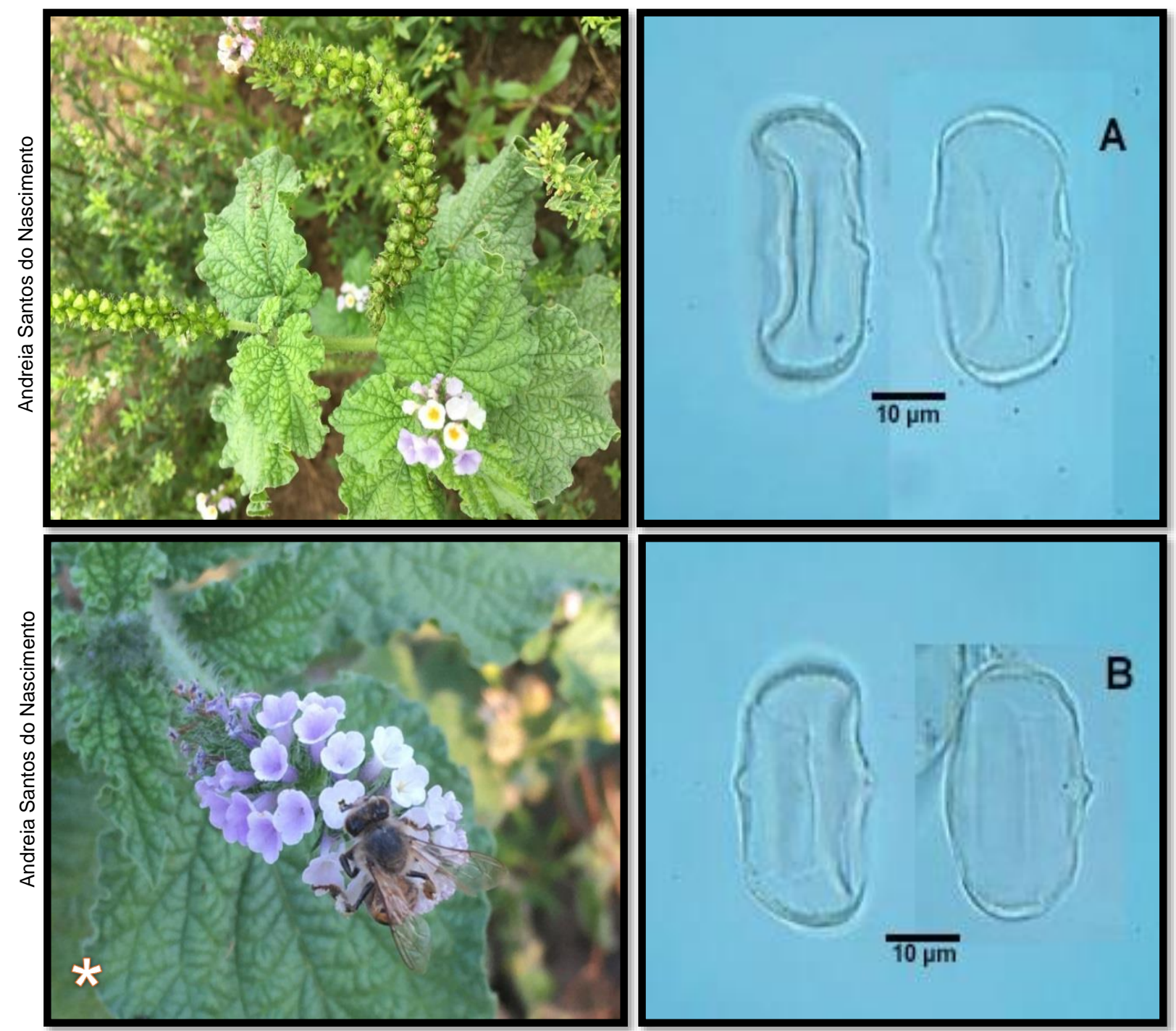

Descrição polínica: $A-B$ = vista equatorial, grão de pólen com simetria radial, isopolar, nômade, âmbito subcircular, abertura polínica do tipo colporo, exina microrreticulada, tamanho médio, forma subprolata, eixo maior $=30,90 \mu \mathrm{m}$, eixo menor $=25,51 \mu \mathrm{m}, \mathrm{P} / \mathrm{E}=1,21 \mu \mathrm{m}$.

*Abelha visitante floral: Apis mellifera Linnaeus, 1758. 


\section{Combretaceae}

Espécie: Terminalia catappa L.

Nome comum: Amendoeira

Hábito de crescimento: arbóreo

Fonte de recurso trófico: néctar

Período de Floração: setembro

№ Palinoteca: PA 87
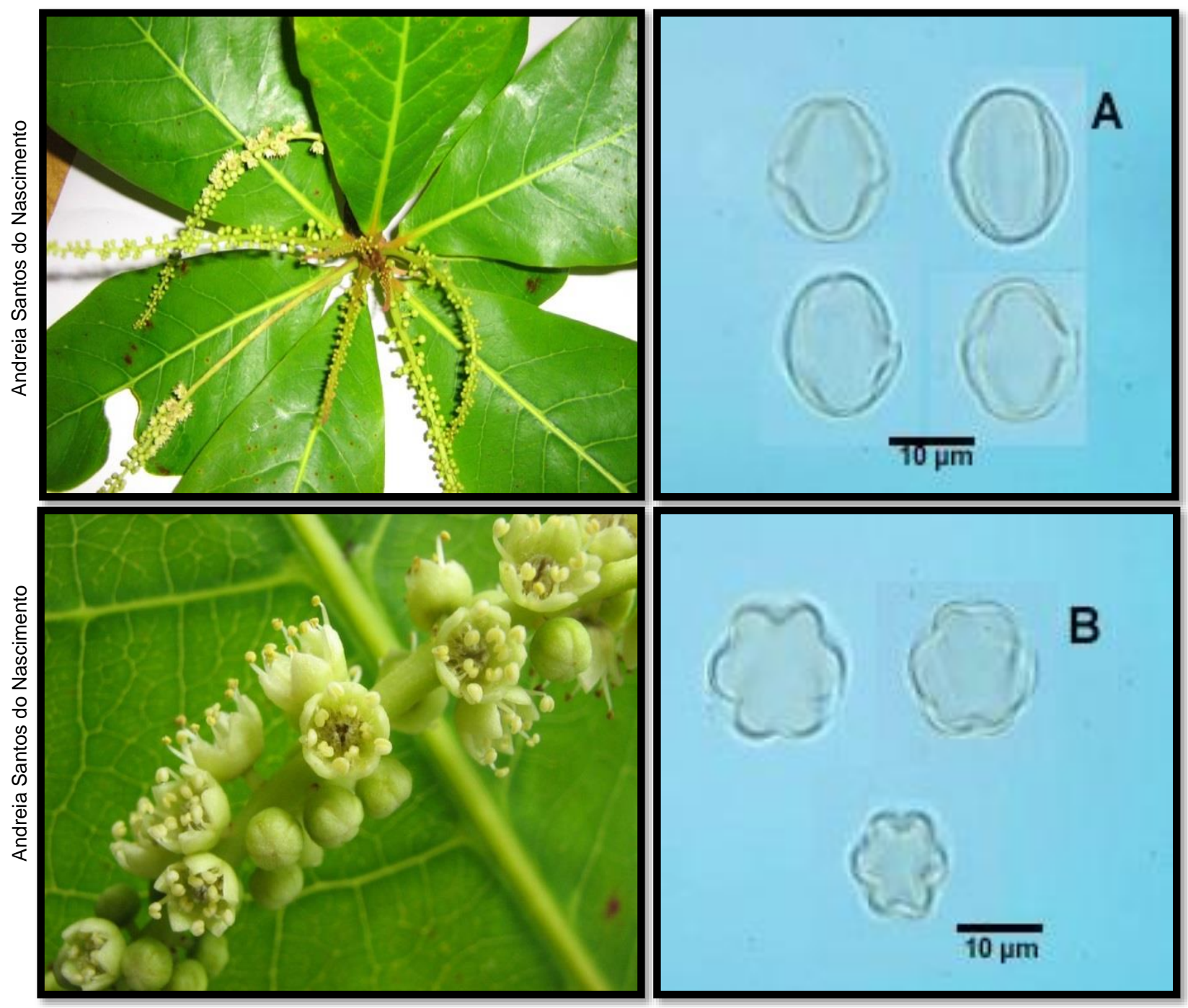

Descrição polínica: $A$ = vista equatorial e $B$ = vista polar, grão de pólen com simetria radial, isopolar, nômade, âmbito circular, abertura polínica do tipo colporo, exina microrreticulada, tamanho pequeno, forma subprolata, eixo polar $=16,36 \mu \mathrm{m}$, eixo equatorial $=13,63 \mu \mathrm{m}, \mathrm{P} / \mathrm{E}=1,20 \mu \mathrm{m}$. 


\section{Commelinaceae}

Espécie: Commelina benghalensis L.

Nome comum: Belemília

Hábito de crescimento: herbáceo

Fonte de recurso trófico: néctar

Período de Floração: março a junho

No Palinoteca: PA 24

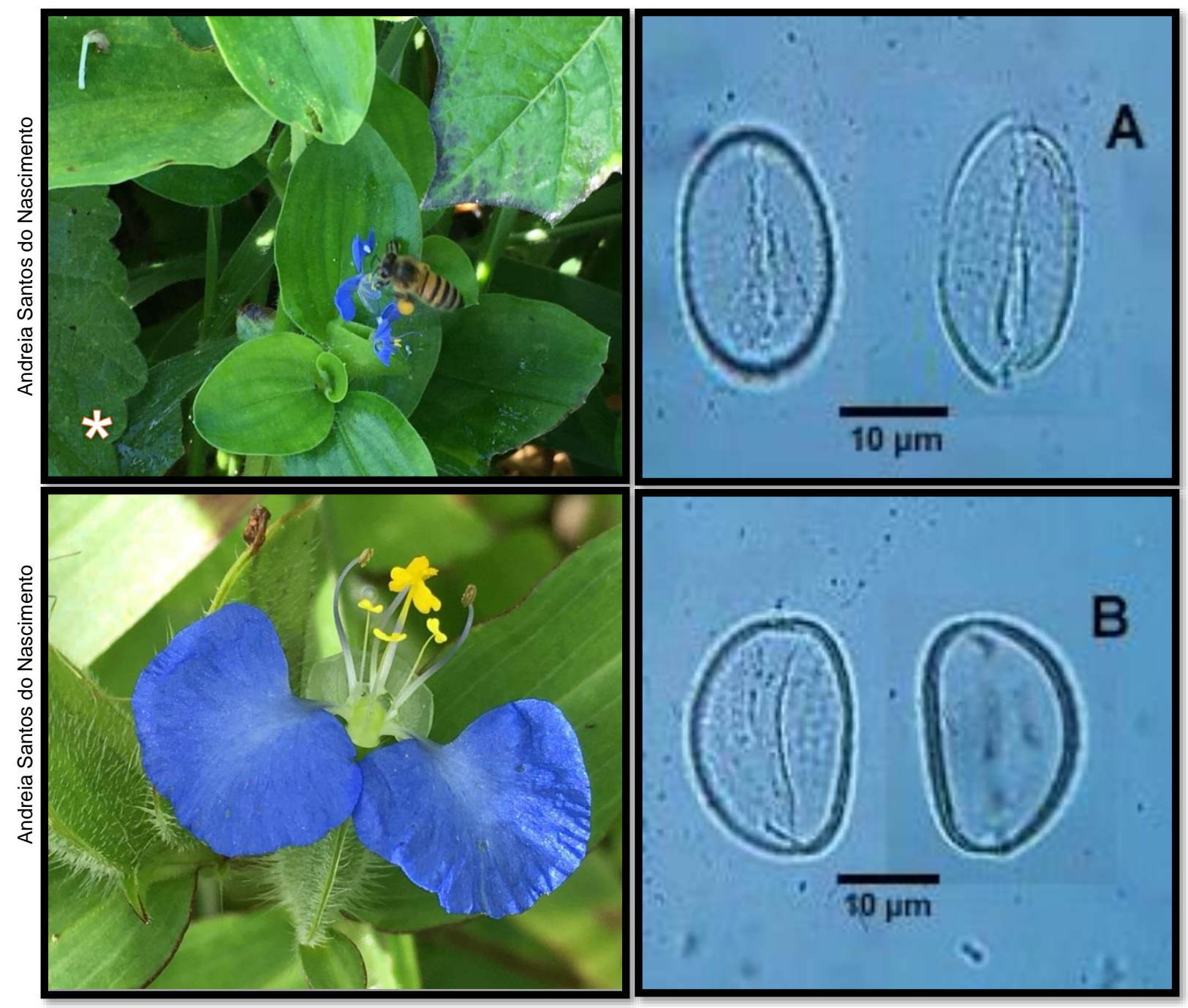

Descrição polínica: $A-B$ = vista equatorial, grão de pólen com simetria bilateral, heteropolar, nômade, âmbito elíptico, abertura polínica do tipo sulco, exina microequinada, tamanho pequeno, forma prolata, eixo maior $=22,12 \mu \mathrm{m}$, eixo menor $=14,84 \mu \mathrm{m}, \mathrm{P} / \mathrm{E}=1,49 \mu \mathrm{m}$.

*Abelha visitante floral: Apis mellifera Linnaeus, 1758. 


\section{Convolvulaceae}

Espécie: Ipomoea asarifolia (Desr.) Roem. \& Schult.

Nome comum: Salsa-roxa; rama-azul; trombeta

Hábito de crescimento: liana

Fonte de recurso trófico: néctar

Período de Floração: janeiro a dezembro

No Palinoteca: PA 04
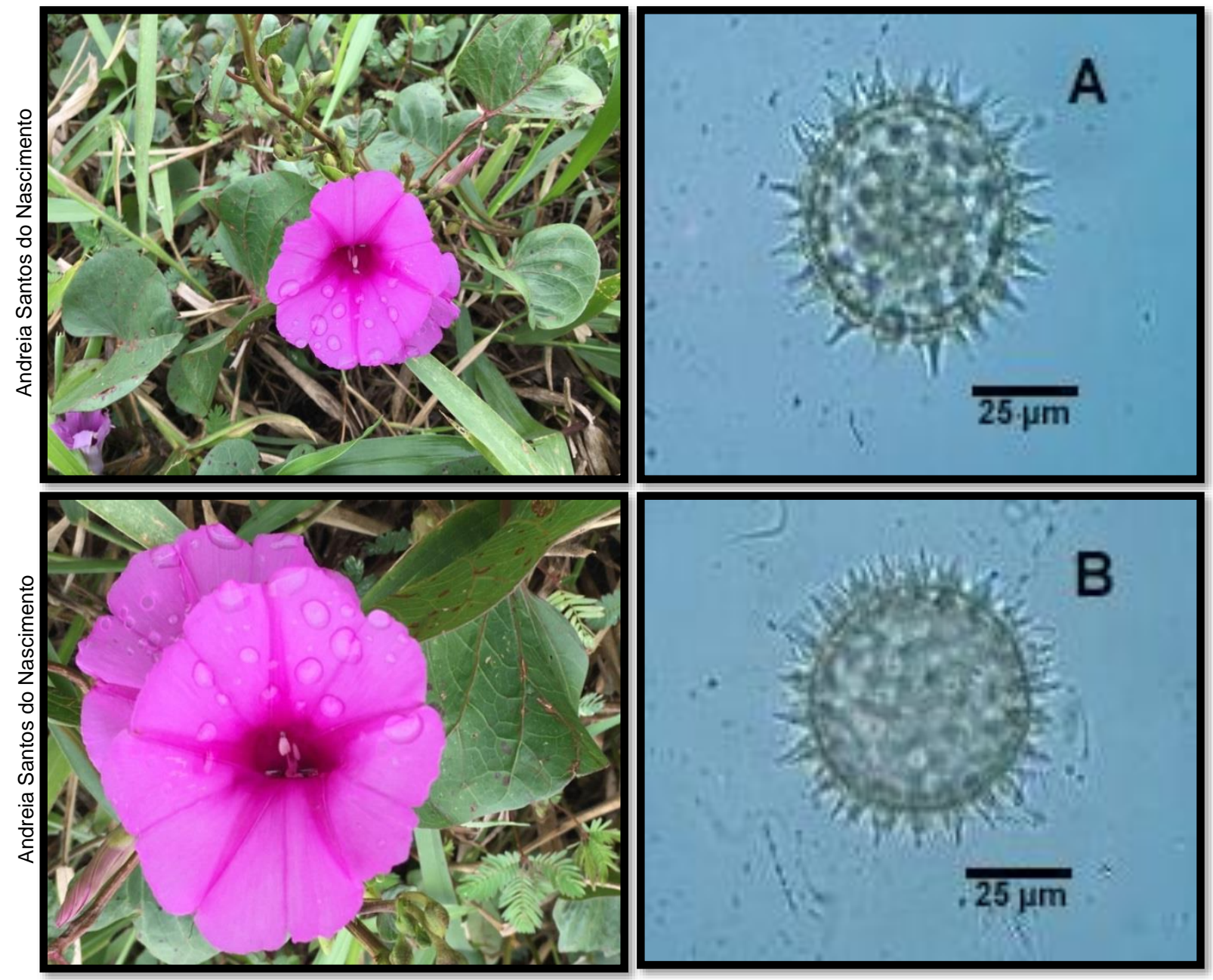

Descrição polínica: A-B = grão de pólen com simetria radial, apolar, nômade, âmbito circular, abertura polínica do tipo poro, exina equinada, tamanho grande, forma prolata esferoidal, diâmetro do eixo polar $=77,51 \mu \mathrm{m}$, diâmetro do eixo equatorial $=76,74 \mu \mathrm{m}$, $\mathrm{P} / \mathrm{E}=1,01 \mu \mathrm{m}$. 


\section{Convolvulaceae}

Espécie: Ipomoea batatas (L.) Lam.

Nome comum: Batata-doce

Hábito de crescimento: arbustivo

Fonte de recurso trófico: néctar/pólen

Período de Floração: junho a agosto

No Palinoteca: PA 32
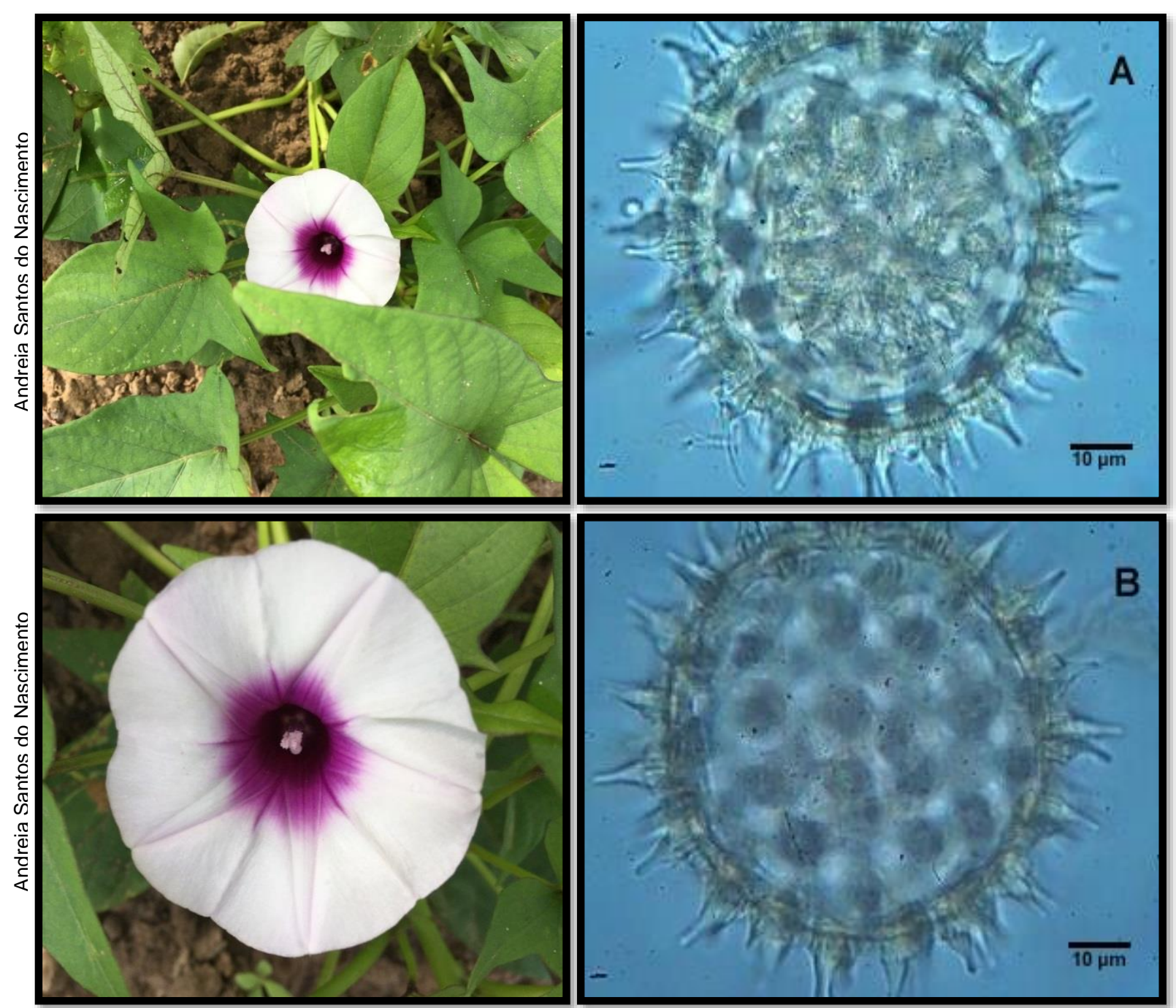

Descrição polínica: A-B = grão de pólen com simetria radial, apolar, nômade, âmbito circular, abertura polínica do tipo poro, exina equinada, tamanho grande, forma esferoidal, diâmetro do eixo polar $=66,06 \mu \mathrm{m}$, diâmetro do eixo equatorial $=65,75 \mu \mathrm{m}$, $\mathrm{P} / \mathrm{E}=1,00 \mu \mathrm{m}$. 


\section{Convolvulaceae}

Espécie: Ipomoea carnea Jacq.

Nome comum: Algodão-bravo; trombeta

Hábito de crescimento: arbustivo

Fonte de recurso trófico: néctar/pólen

Período de Floração: janeiro a dezembro No Palinoteca: PA 21

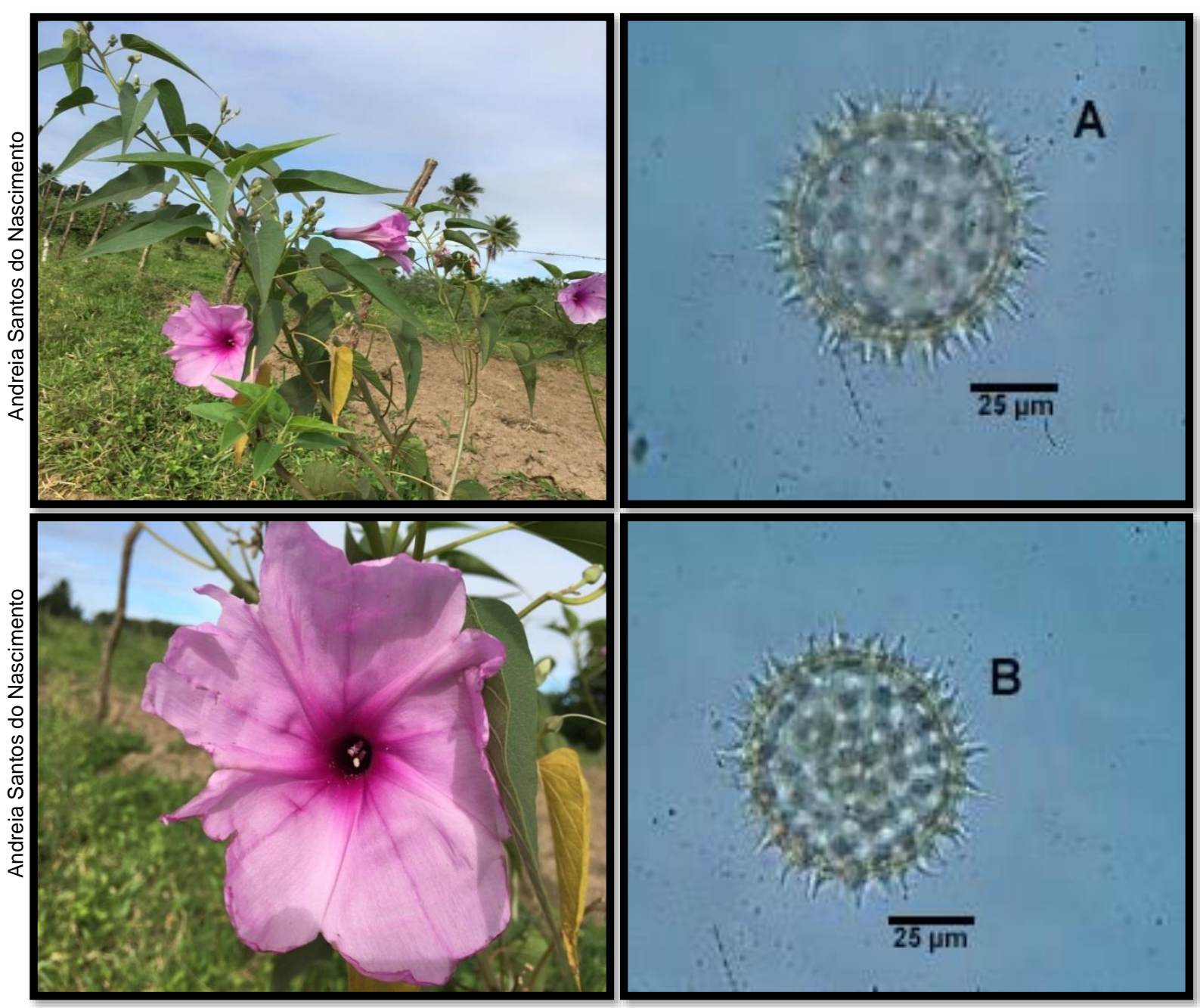

Descrição polínica: $A-B$ = grão de pólen com simetria radial, apolar, nômade, âmbito circular, abertura polínica do tipo poro, exina equinada, tamanho grande, forma esferoidal, diâmetro do eixo polar $=79,84 \mu \mathrm{m}$, diâmetro do eixo equatorial $=79,06$ $\mu \mathrm{m}, \mathrm{P} / \mathrm{E}=1,00 \mu \mathrm{m}$. 


\section{Cucurbitaceae}

Espécie: Cayaponia tayuya (Vell.) Cogn.

Nome comum: Abóbora-do-mato

Hábito de crescimento: liana

Fonte de recurso trófico: néctar

Período de Floração: agosto

No Palinoteca: PA 79
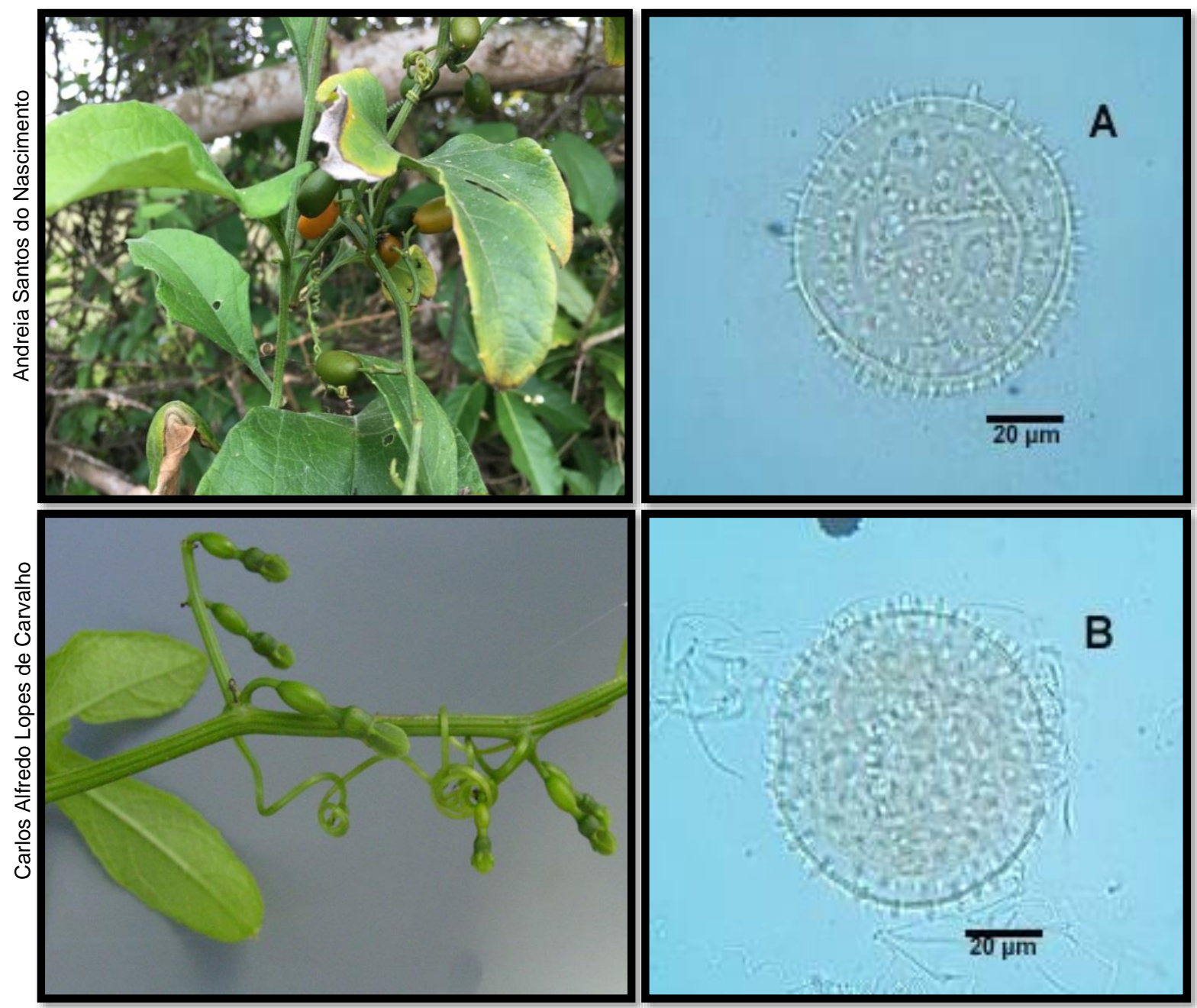

Descrição polínica: $A-B=$ grão de pólen com simetria radial, apolar, nômade, âmbito circular, abertura polínica do tipo poro, exina equinada, tamanho muito grande, forma esferoidal, diâmetro do eixo polar $=101,66 \mu \mathrm{m}$, diâmetro do eixo equatorial $=100,77 \mu \mathrm{m}, \mathrm{P} / \mathrm{E}=1,00 \mu \mathrm{m}$. 


\section{Cucurbitaceae}

Espécie: Cucurbita pepo L.

Nome comum: Abóbora

Hábito de crescimento: herbáceo

Fonte de recurso trófico: néctar

Período de Floração: maio a outubro

No Palinoteca: PA 88
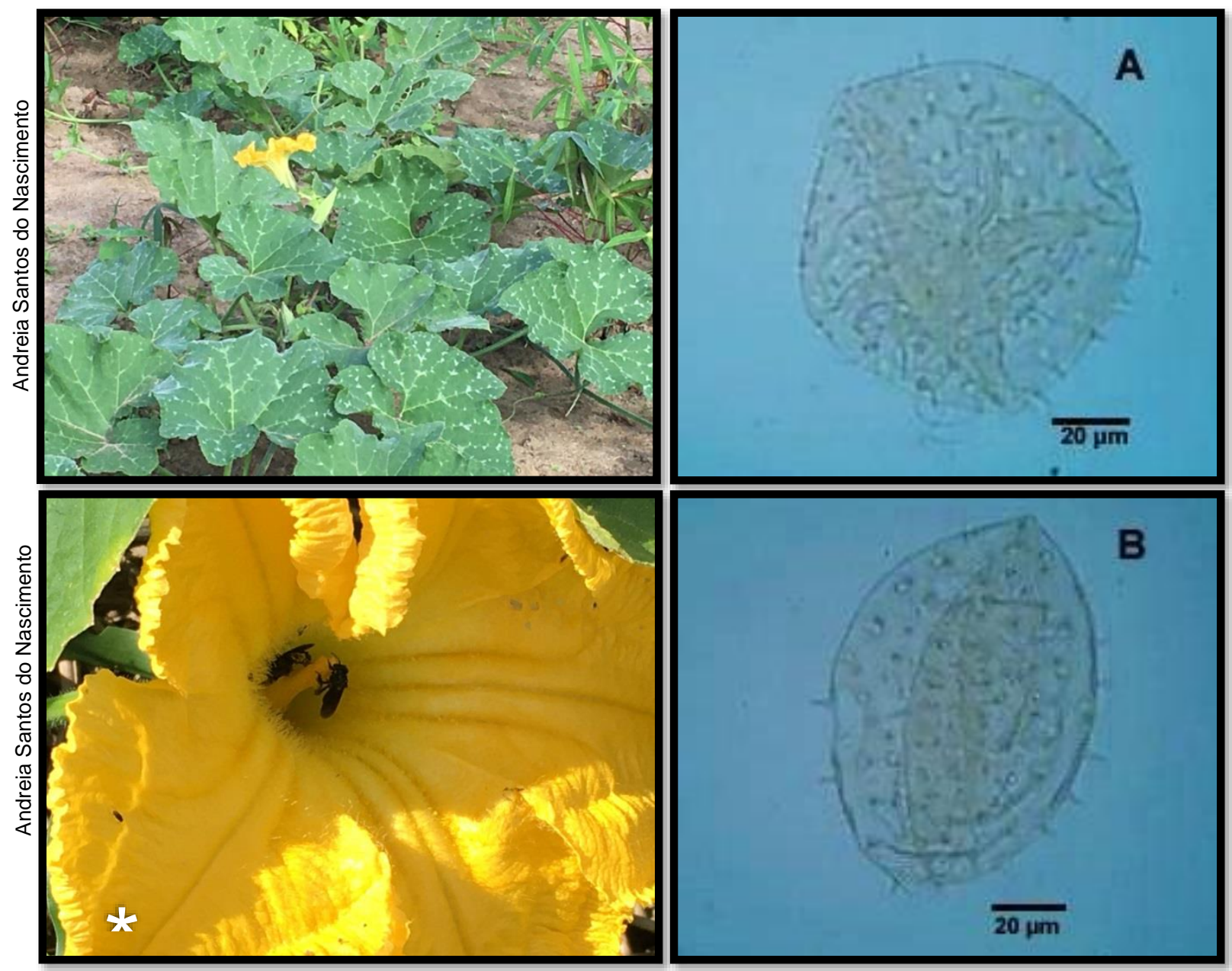

Descrição polínica: $A-B=$ grão de pólen com simetria radial, apolar, nômade, âmbito circular, abertura polínica do tipo poro, exina equinada, tamanho muito grande, forma esferoidal, diâmetro do eixo polar $=135,65 \mu \mathrm{m}$, diâmetro do eixo equatorial $=134,88 \mu \mathrm{m}, \mathrm{P} / \mathrm{E}=1,00 \mu \mathrm{m}$.

*Abelha visitante floral: Trigona spinipes Fabricius, 1793. 


\section{Cucurbitaceae}

Espécie: Momordica charantia L.

Nome comum: Melão-de-São-Caetano

Hábito de crescimento: liana

Fonte de recurso trófico: néctar

Período de Floração: julho a dezembro

No Palinoteca: PA 31
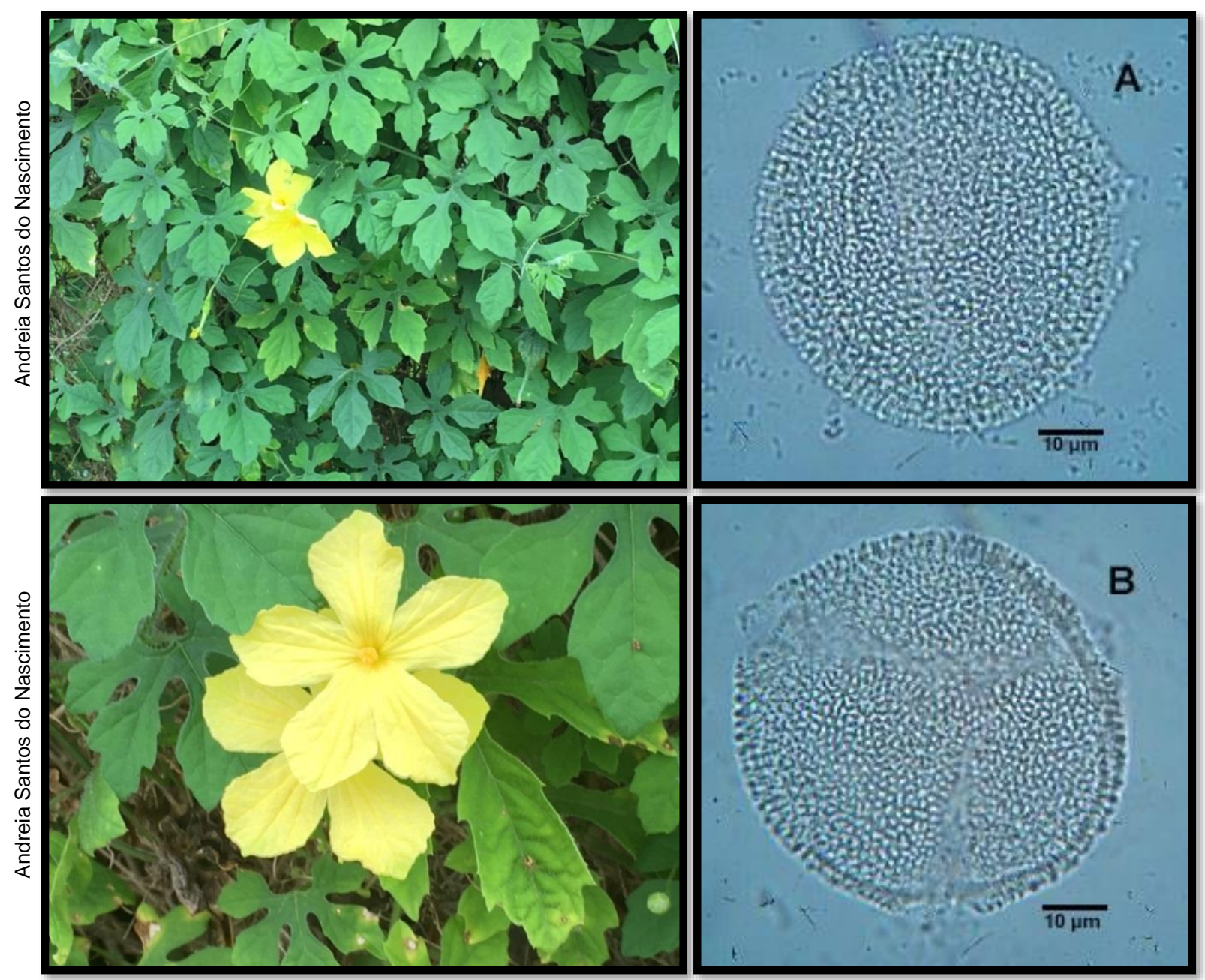

Descrição polínica: $A$ = vista equatorial e $B$ = vista polar, grão de pólen com simetria radial, isopolar, nômade, âmbito subcircular, abertura polínica do tipo colporo, exina heterobrocada/reticulada, tamanho grande, forma prolata esferoidal, eixo polar = $60,60 \mu \mathrm{m}$, eixo equatorial $=57,27 \mu \mathrm{m}, \mathrm{P} / \mathrm{E}=1,05 \mu \mathrm{m}$. 


\section{Euphorbiaceae}

Espécie: Cnidoscolus urens (L.) Arthur

Nome comum: Urtiga

Hábito de crescimento: herbáceo

Fonte de recurso trófico: néctar

Período de Floração: maio a setembro

No Palinoteca: NAS05

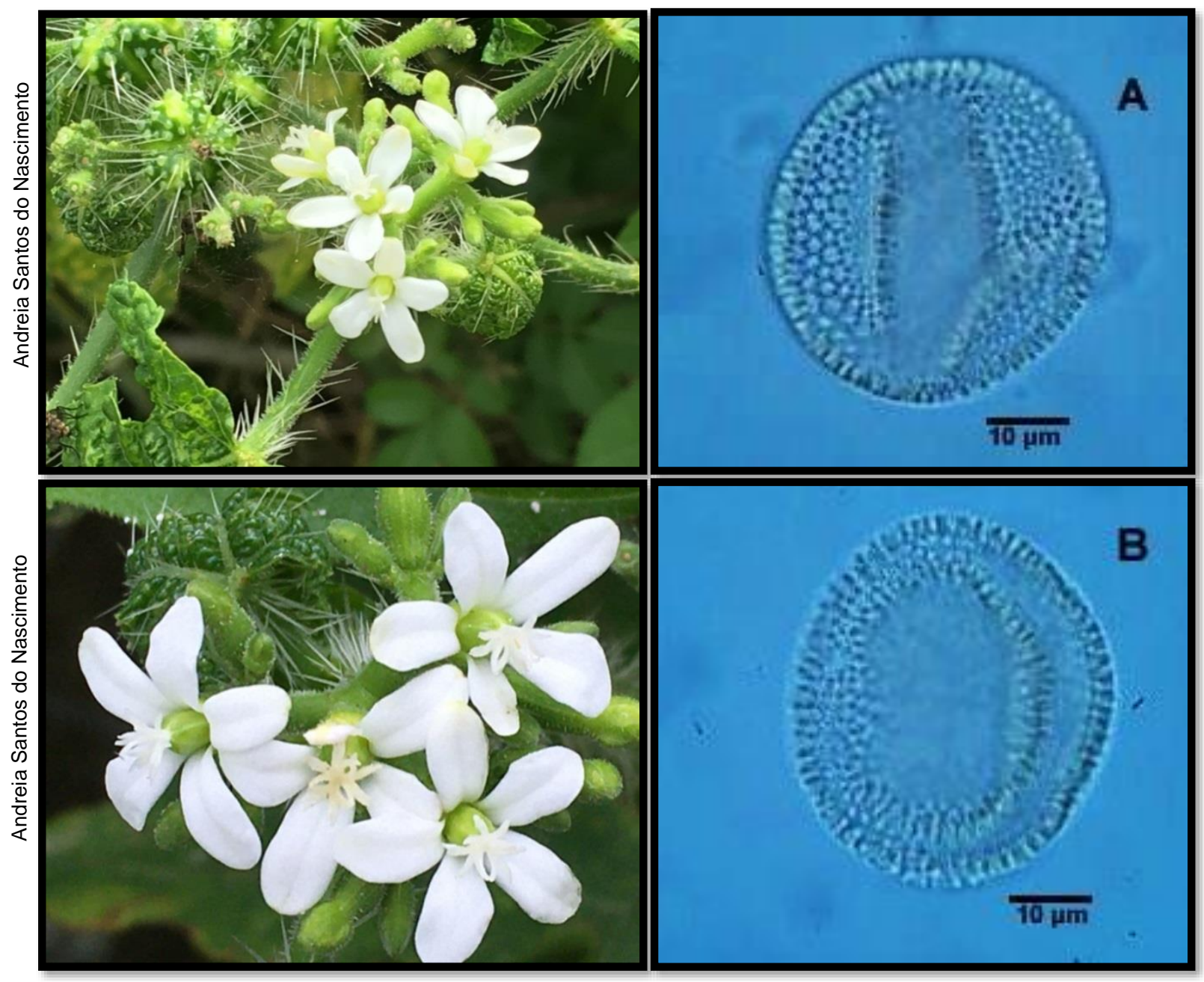

Descrição polínica: $A-B$ = grão de pólen com simetria radial, apolar, nômade, âmbito circular, abertura polínica do tipo inaperturado, exina padrão-croton, tamanho grande, forma prolata esferoidal, diâmetro do eixo polar $=55,15 \mu \mathrm{m}$, diâmetro do eixo equatorial $=54,54 \mu \mathrm{m}, \mathrm{P} / \mathrm{E}=1,01 \mu \mathrm{m}$. 


\section{Euphorbiaceae}

Espécie: Croton hirtus L'Hér.

Nome comum: Velame

Hábito de crescimento: herbáceo

Fonte de recurso trófico: néctar

Período de Floração: maio a setembro

No Palinoteca: PA 112

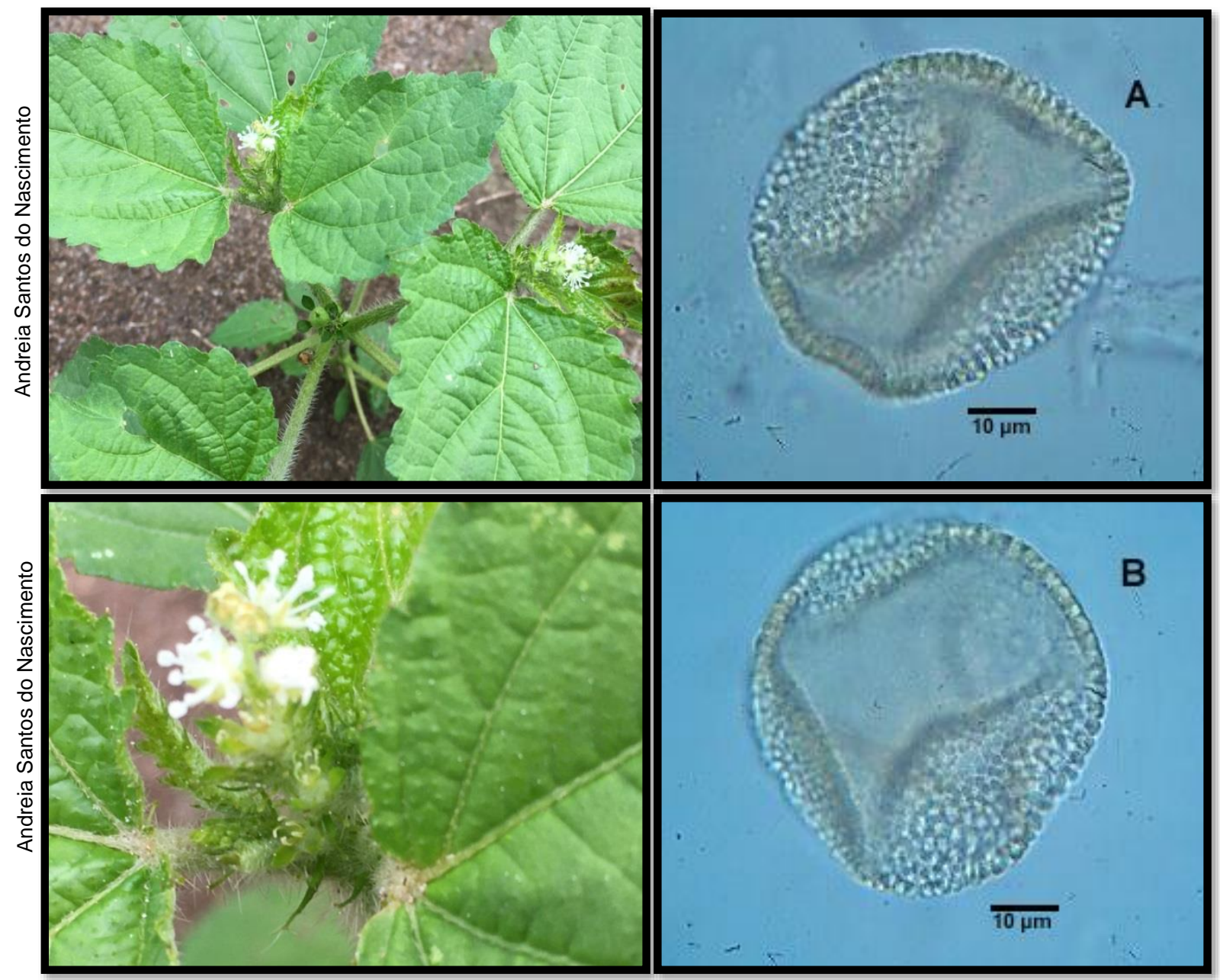

Descrição polínica: A-B = grão de pólen com simetria radial, apolar, nômade, âmbito circular, abertura polínica do tipo inaperturado, exina padrão-croton, tamanho grande, forma esferoidal, diâmetro do eixo polar $=55,75 \mu \mathrm{m}$, diâmetro do eixo equatorial $=$ $55,45 \mu \mathrm{m}, \mathrm{P} / \mathrm{E}=1,00 \mu \mathrm{m}$. 


\section{Euphorbiaceae}

Espécie: Croton lobatus L.

Nome comum: cabeça-de-formiga

Hábito de crescimento: herbáceo

Fonte de recurso trófico: néctar

Período de Floração: maio a setembro

No Palinoteca: PA 152

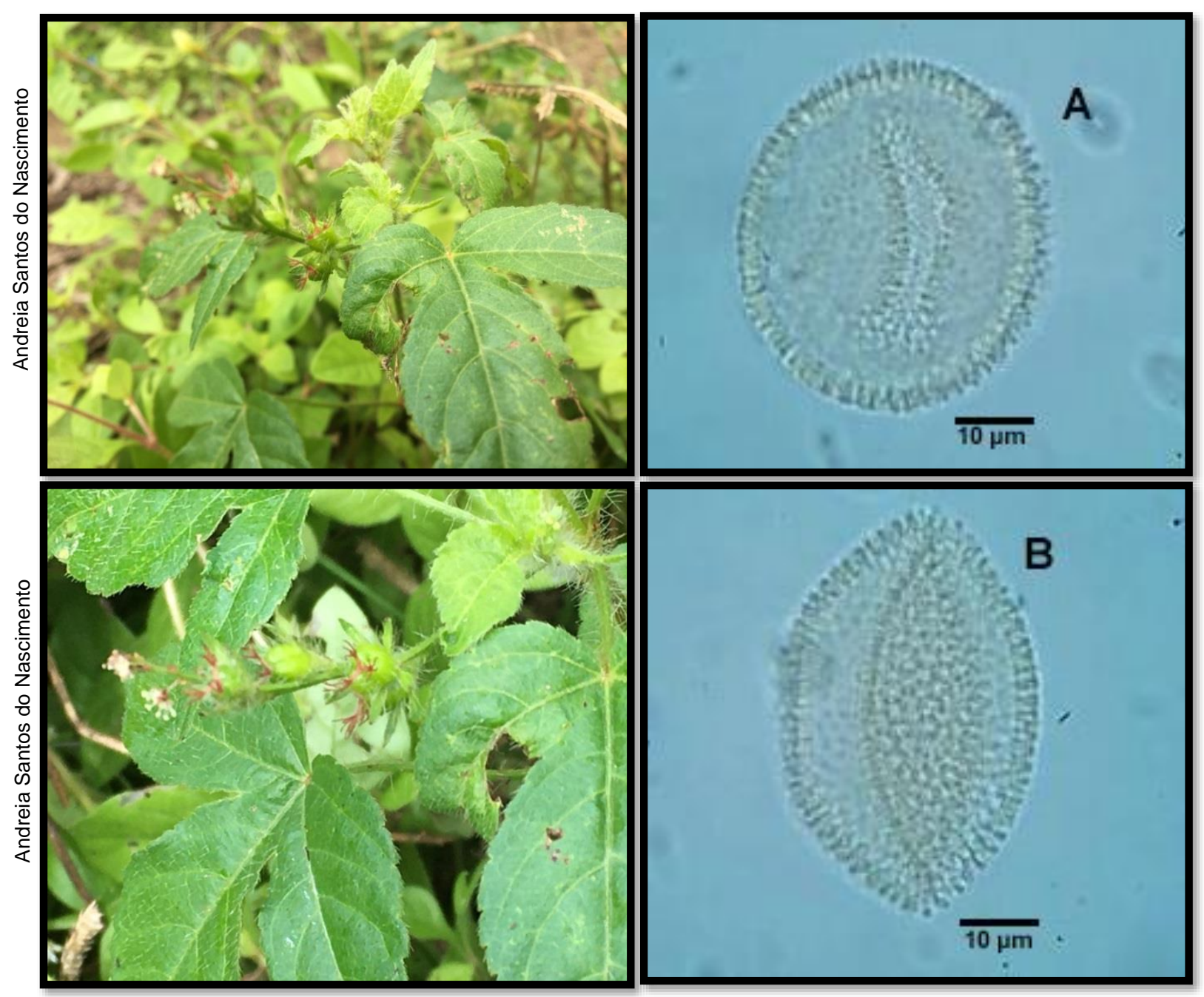

Descrição polínica: A-B = grão de pólen com simetria radial, apolar, nômade, âmbito circular, abertura polínica do tipo inaperturado, exina padrão-croton, tamanho grande, forma esferoidal, diâmetro do eixo polar $=51,51 \mu \mathrm{m}$, diâmetro do eixo equatorial $=$ $51,21 \mu \mathrm{m}, \mathrm{P} / \mathrm{E}=1,00 \mu \mathrm{m}$. 


\section{Euphorbiaceae}

Espécie: Croton moritibensis Baill.

Nome comum: Velame

Hábito de crescimento: arbustivo

Fonte de recurso trófico: néctar

Período de Floração: agosto a dezembro

No Palinoteca: PA 27

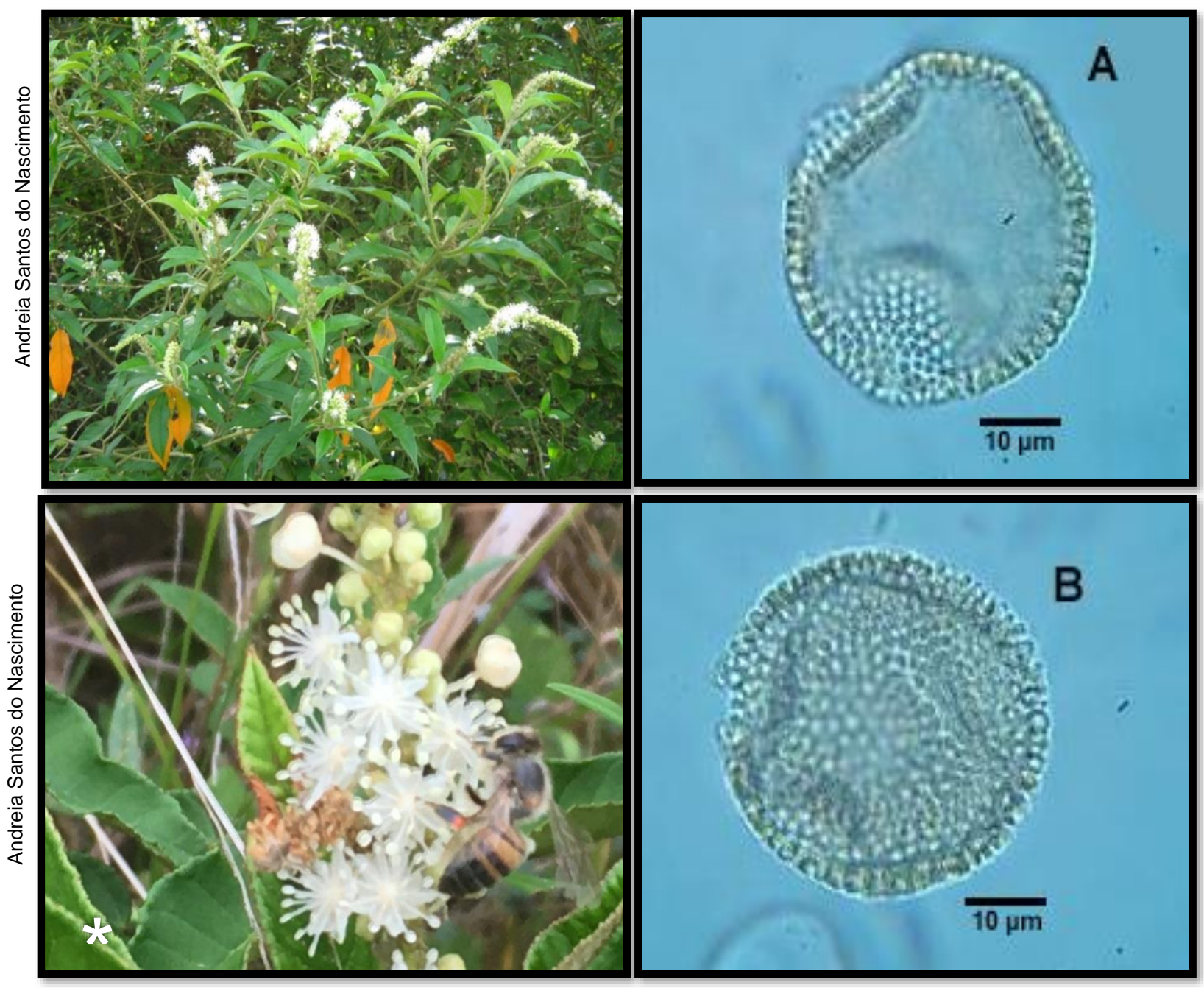

Descrição polínica: $A-B$ = grão de pólen com simetria radial, apolar, nômade, âmbito circular, abertura polínica do tipo inaperturado, exina padrão-croton, tamanho grande, forma esferoidal, diâmetro do eixo polar $=55,75 \mu \mathrm{m}$, diâmetro do eixo equatorial $=$ $55,15 \mu \mathrm{m}, \mathrm{P} / \mathrm{E}=1,01 \mu \mathrm{m}$.

*Abelha visitante floral: Apis mellifera Linnaeus, 1758. 


\section{Euphorbiaceae}

Espécie: Euphorbia hyssopifolia L.

Nome comum: Erva-de-Santa-Luzia

Hábito de crescimento: herbáceo

Fonte de recurso trófico: néctar

Período de Floração: abril a julho No Palinoteca: PA 36
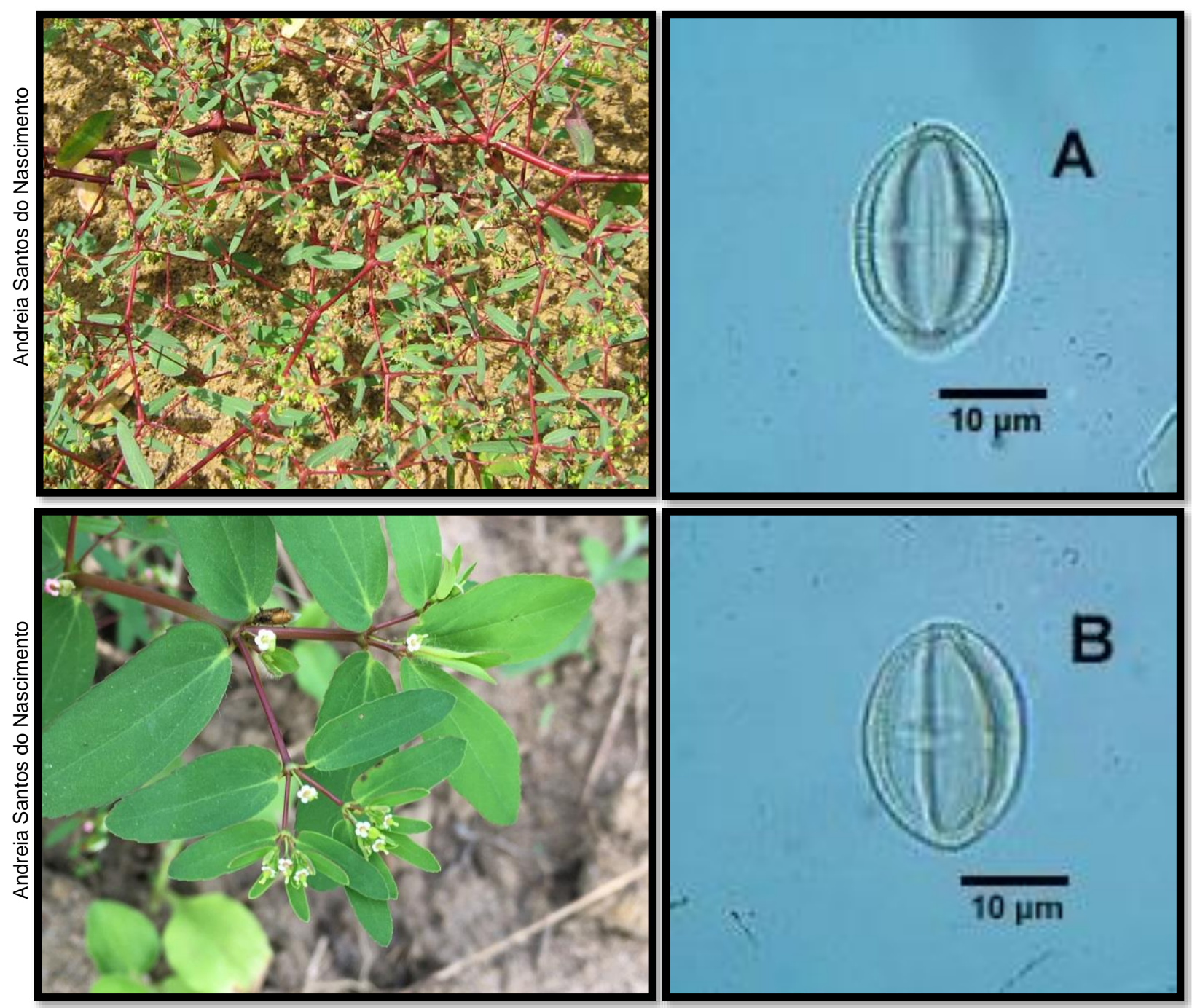

Descrição polínica: A-B = vista equatorial, grão de pólen com simetria radial, isopolar, nômade, âmbito subtriangular, abertura polínica do tipo colporo, exina microrreticulada, tamanho pequeno, forma prolata, eixo polar $=21,51 \mu \mathrm{m}$, eixo equatorial $=15,15 \mu \mathrm{m}, \mathrm{P} / \mathrm{E}=1,41 \mu \mathrm{m}$. 


\section{Euphorbiaceae}

Espécie: Euphorbia milii Des Moul.

Nome comum: Coroa-de-Cristo

Hábito de crescimento: herbáceo

Fonte de recurso trófico: resina

Período de Floração: maio a setembro

No Palinoteca: PA 44

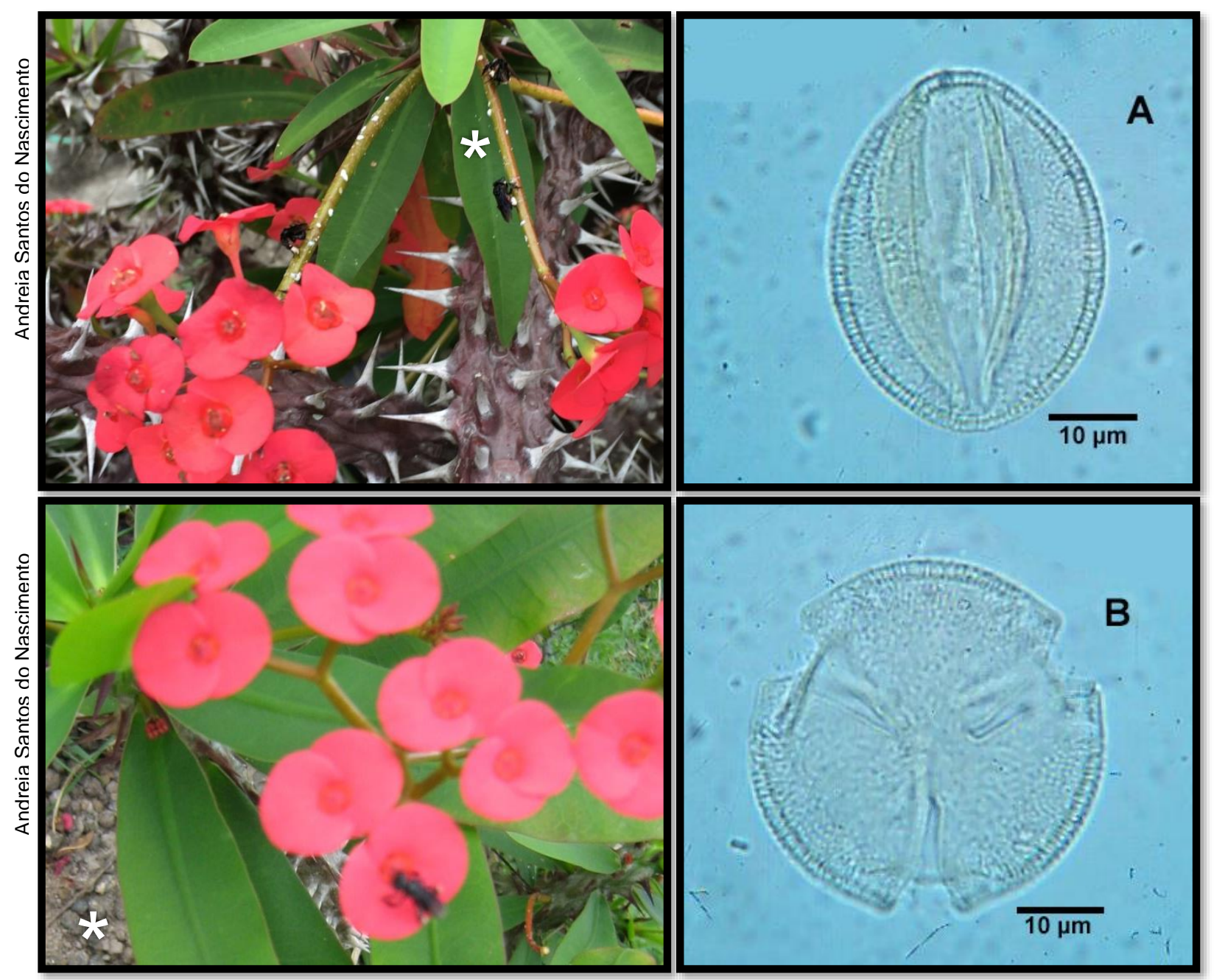

Descrição polínica: $A$ = vista equatorial e $B$ = vista polar, grão de pólen com simetria radial, isopolar, nômade, âmbito subtriangular, abertura polínica do tipo colporo, exina microrreticulada, tamanho médio, forma prolata, eixo polar $=40,60 \mu \mathrm{m}$, eixo equatorial $=30,30 \mu \mathrm{m}, \mathrm{P} / \mathrm{E}=1,33 \mu \mathrm{m}$.

*Abelha coletando resina: Trigona spinipes Fabricius, 1793. 


\section{Euphorbiaceae}

Espécie: Jatropha gossypiifolia L.

Nome comum: Pinhão-roxo

Hábito de crescimento: arbustivo

Fonte de recurso trófico: pólen

Período de Floração: junho a agosto

No Palinoteca: NAS06

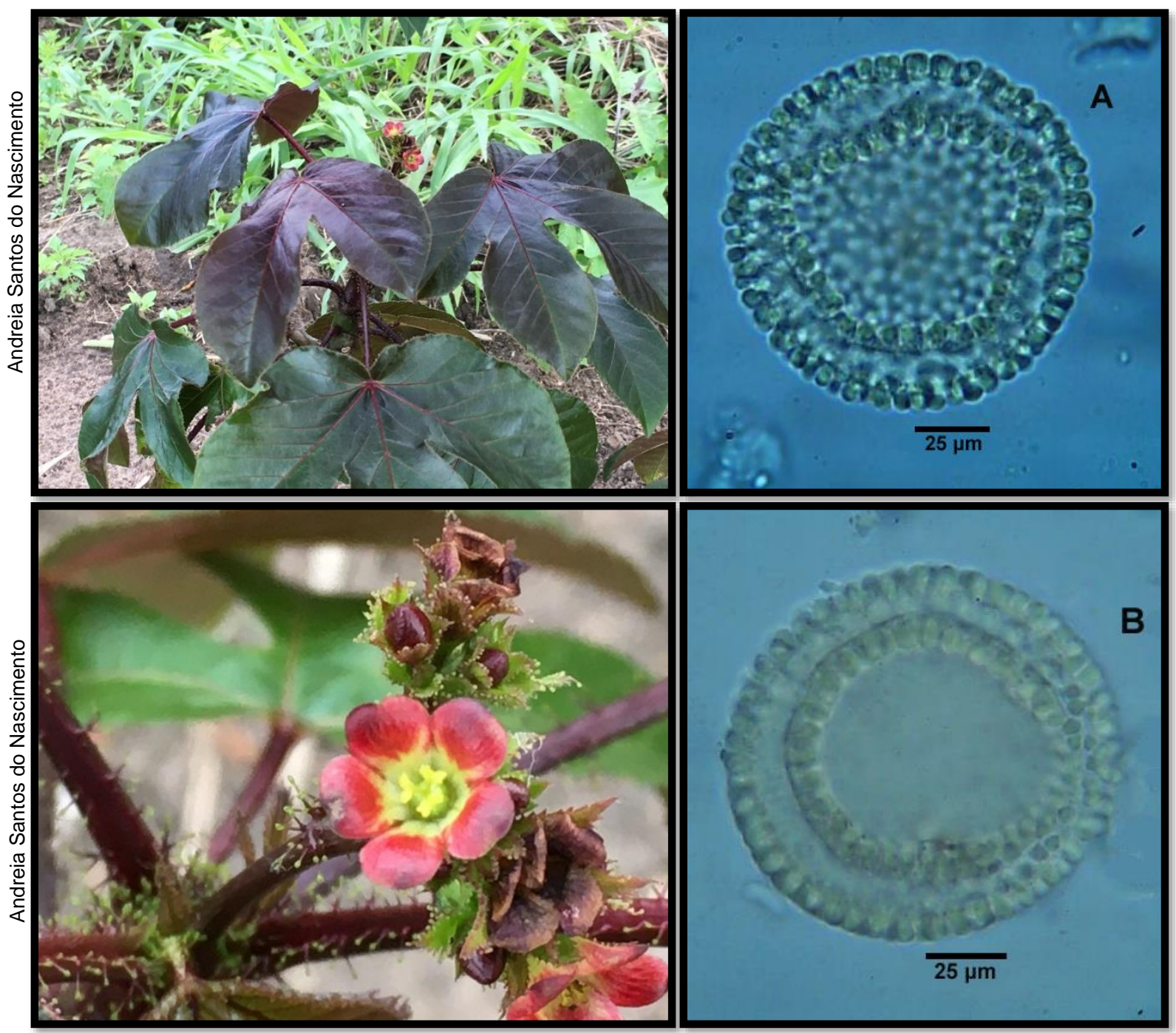

Descrição polínica: A-B = grão de pólen com simetria radial, apolar, nômade, âmbito circular, abertura polínica do tipo inaperturado, exina padrão-croton, tamanho muito grande, forma esferoidal, diâmetro do eixo polar $=108,52 \mu \mathrm{m}$, diâmetro do eixo equatorial $=107,75 \mu \mathrm{m}, \mathrm{P} / \mathrm{E}=1,00 \mu \mathrm{m}$. 


\section{Euphorbiaceae}

Espécie: Manihot esculenta Crantz

Nome comum: Mandioca

Hábito de crescimento: arbustivo

Fonte de recurso trófico: pólen

Período de Floração: agosto

No Palinoteca: PA 71

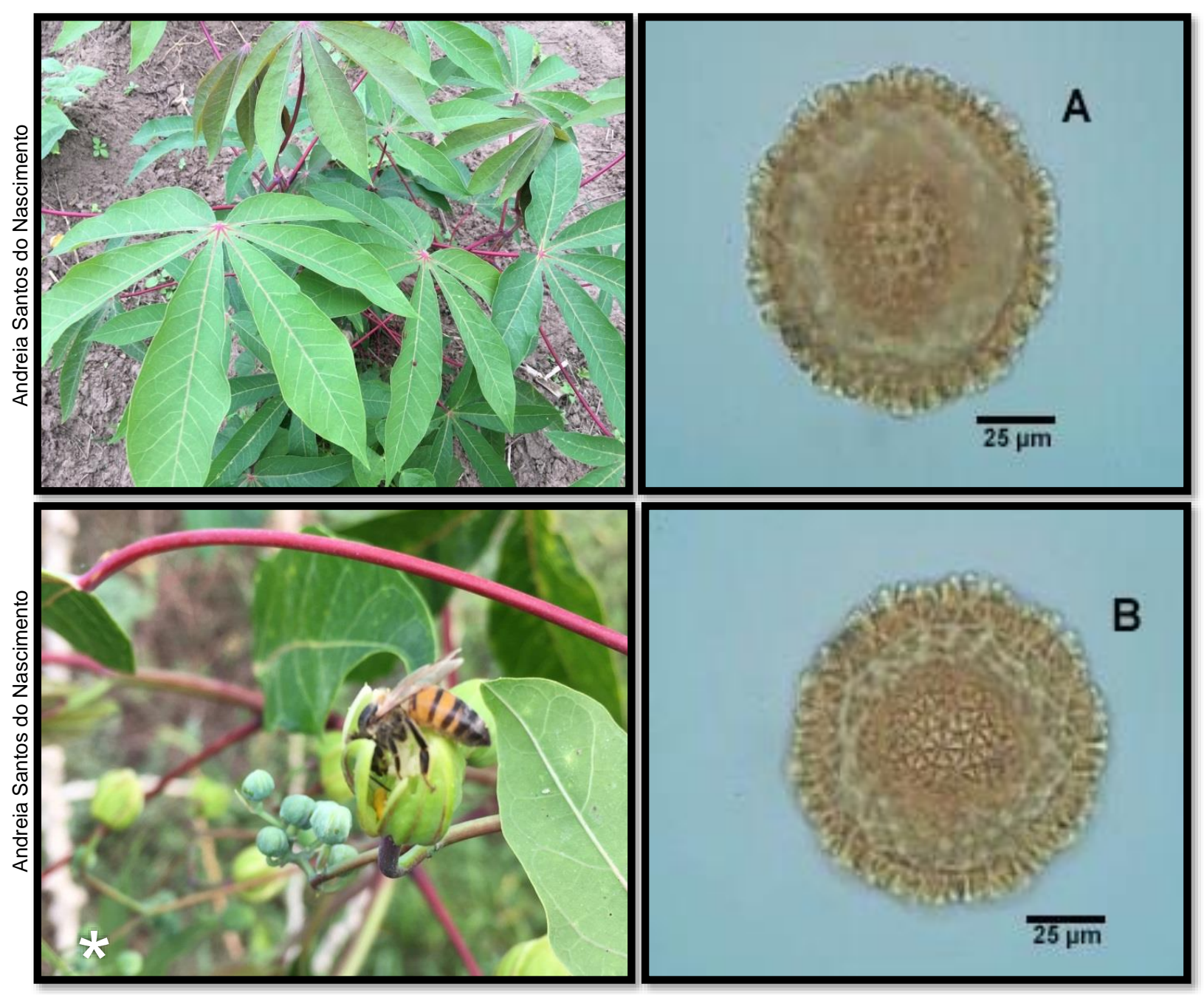

Descrição polínica: A-B = grão de pólen com simetria radial, apolar, nômade, âmbito circular, abertura polínica do tipo inaperturado, exina padrão-croton, tamanho muito grande, forma esferoidal, diâmetro do eixo polar $=106,20 \mu \mathrm{m}$, diâmetro do eixo equatorial $=105,42 \mu \mathrm{m}, \mathrm{P} / \mathrm{E}=1,00 \mu \mathrm{m}$.

*Abelha visitante floral: Apis mellifera Linnaeus, 1758. 


\section{Euphorbiaceae}

Espécie: Ricinus communis L.

Nome comum: Mamona

Hábito de crescimento: arbustivo

Fonte de recurso trófico: néctar/pólen

Período de Floração: janeiro a fevereiro e maio a abril

No Palinoteca: PA 77
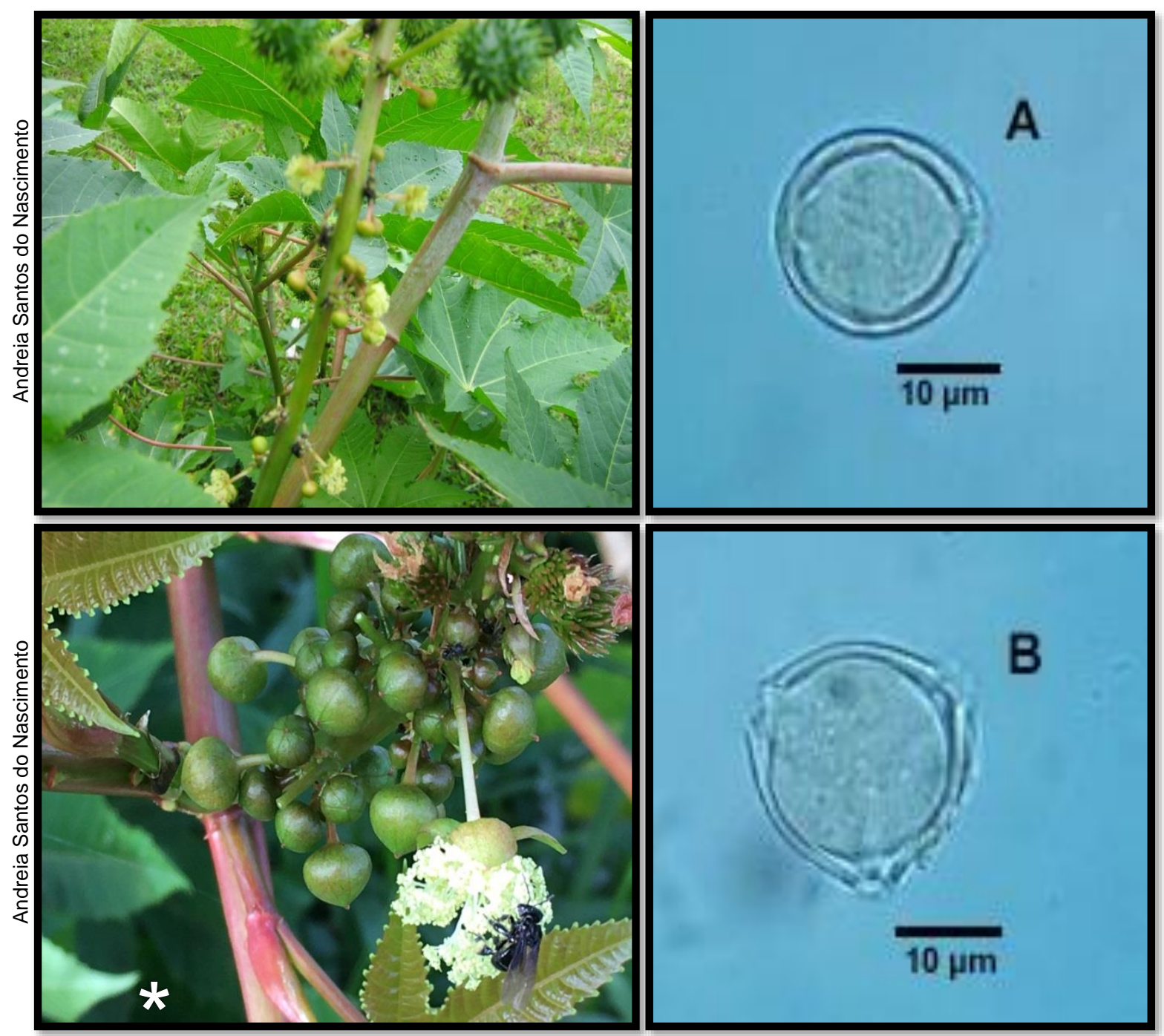

Descrição polínica: $A=$ vista equatorial e $B=$ vista polar, grão de pólen com simetria radial, isopolar, nômade, âmbito subtriangular, abertura polínica do tipo colporo, exina microrreticulada, tamanho pequeno, forma prolata esferoidal, eixo polar $=20,60 \mu \mathrm{m}$, eixo equatorial $=20,00 \mu \mathrm{m}, \mathrm{P} / \mathrm{E}=1,03 \mu \mathrm{m}$.

*Abelha visitante floral: Trigona spinipes Fabricius, 1793. 


\section{Fabaceae - Caesalpinioideae}

Espécie: Bauhinia variegata L.

Nome comum: Ingá-cipó

Hábito de crescimento: arbóreo

Fonte de recurso trófico: pólen

Período de Floração: outubro a janeiro No Palinoteca: PA 113
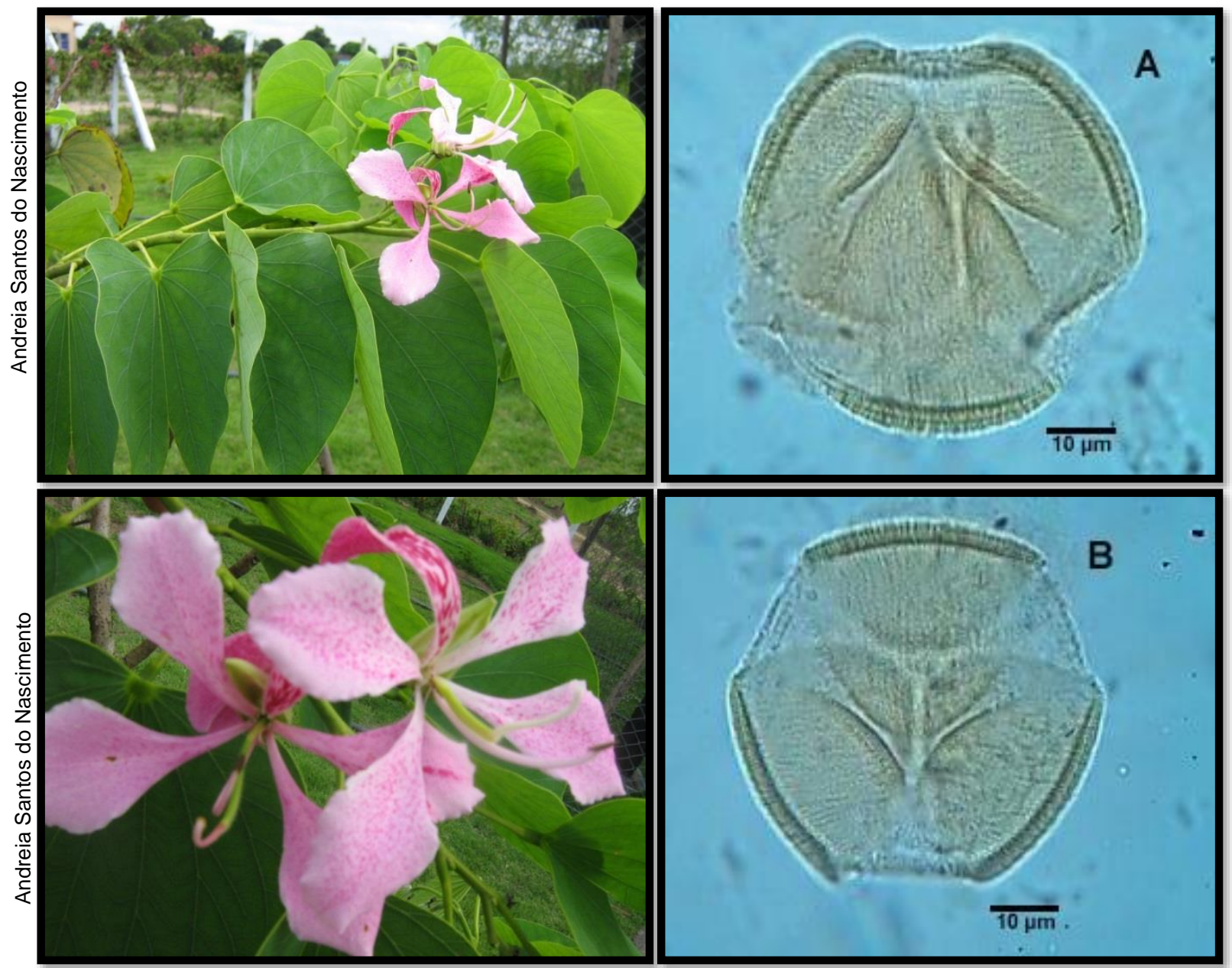

Descrição polínica: A-B = vista polar, grão de pólen com simetria radial, isopolar, nômade, âmbito subtriangular, abertura polínica do tipo colporo, exina microrreticulada, tamanho grande, forma prolata, eixo polar $=61,21 \mu \mathrm{m}$; eixo equatorial $=42,42 \mu \mathrm{m} ; \mathrm{P} / \mathrm{E}=1,44 \mu \mathrm{m}$. 


\section{Fabaceae - Caesalpinioideae}

Espécie: Caesalpinia pulcherrima (L.) Sw.

Nome comum: Flamboyanzinho

Hábito de crescimento: arbóreo

Fonte de recurso trófico: pólen

Período de Floração: janeiro a dezembro No Palinoteca: NAS07
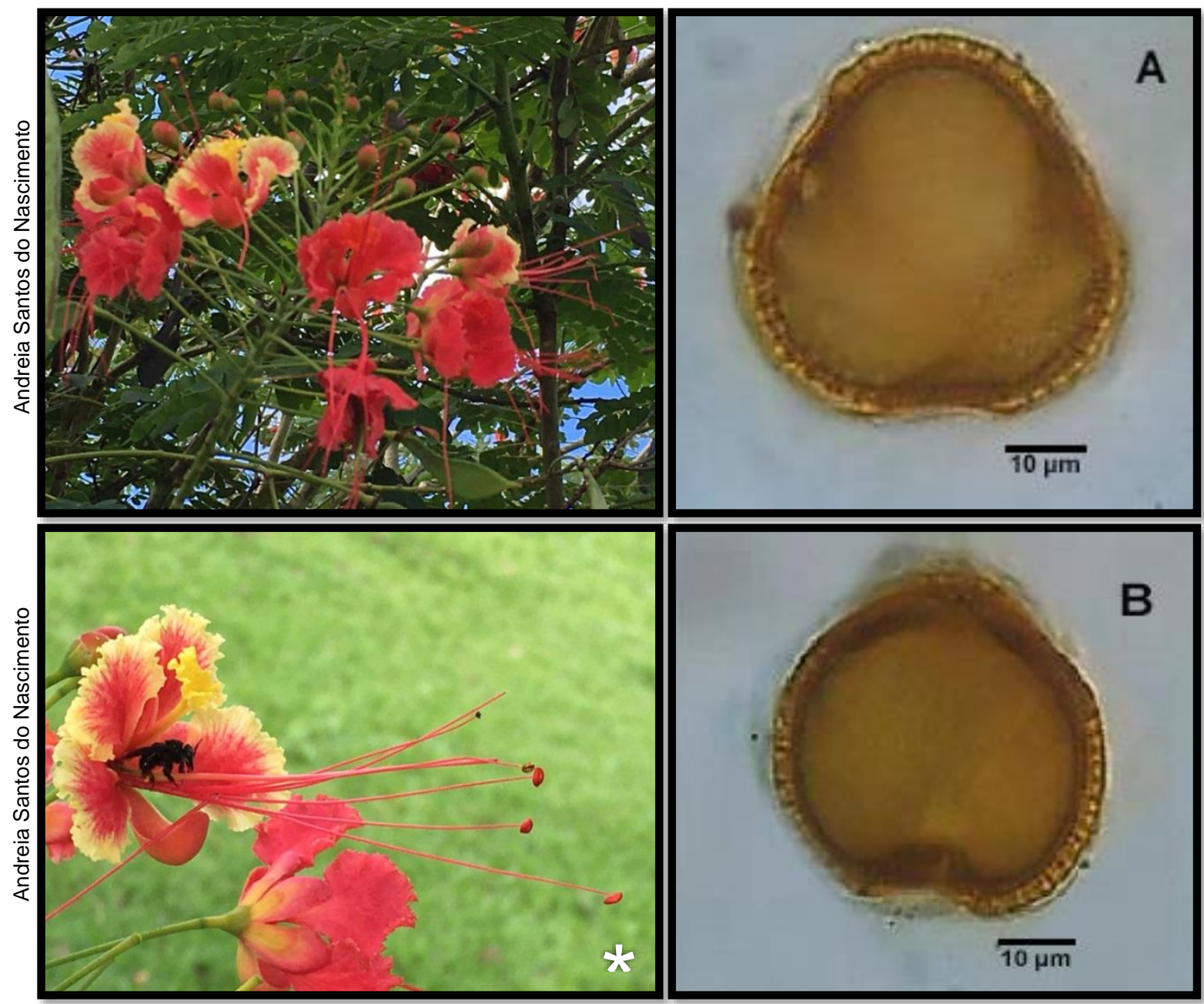

Descrição polínica: A-B = vista polar, grão de pólen com simetria radial, isopolar, nômade, âmbito subtriangular, abertura polínica do tipo colporo, exina microrreticulada, tamanho grande, forma esferoidal, eixo polar $=51,21 \mu \mathrm{m}$; eixo equatorial $=50,90 \mu \mathrm{m} ; \mathrm{P} / \mathrm{E}=1,00 \mu \mathrm{m}$.

*Abelha visitante floral: Trigona spinipes Fabricius, 1793. 


\section{Fabaceae - Caesalpinioideae}

Espécie: Cassia fistula L.

Nome comum: Cássia-imperial; chuva-de- ouro

Hábito de crescimento: arbóreo

Fonte de recurso trófico: pólen

Período de Floração: abril a maio

No Palinoteca: NAS08

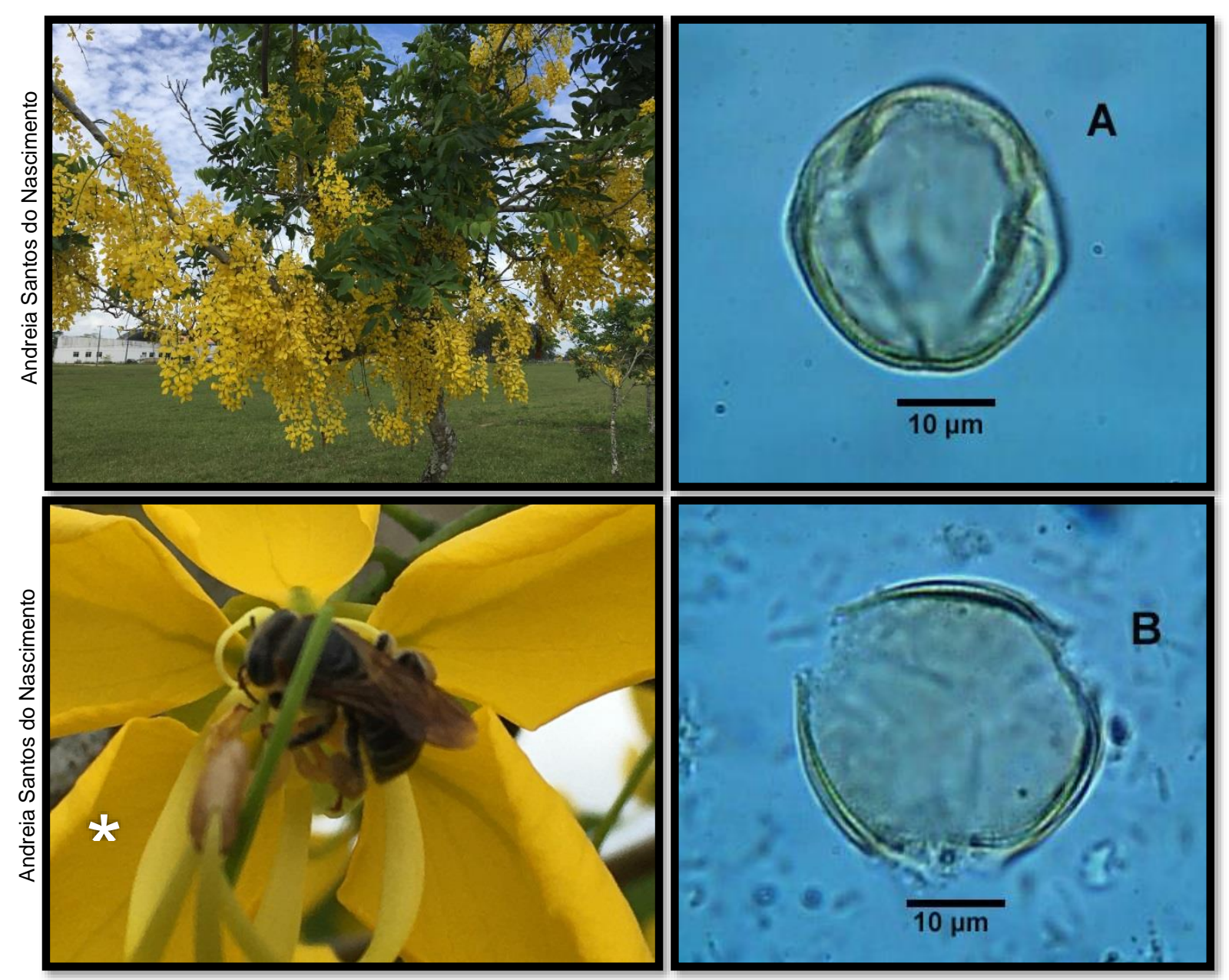

Descrição polínica: $A$ = vista equatorial e $B=$ vista polar, grão de pólen com simetria radial, isopolar, nômade, âmbito subtriangular, abertura polínica do tipo colporo, exina microrreticulada, tamanho grande, forma prolata esferoidal, eixo polar $=51,51 \mu \mathrm{m}$; eixo equatorial $=50,60 \mu \mathrm{m} ; \mathrm{P} / \mathrm{E}=1,01 \mu \mathrm{m}$.

${ }^{*}$ Abelha visitante floral: Melipona sp. 


\section{Fabaceae - Caesalpinioideae}

Espécie: Cenostigma pluviosum var. peltophoroides (Benth.) Gagnon \& G.P.Lewis.

Nome comum: Sibipiruna

Hábito de crescimento: arbóreo

Fonte de recurso trófico: pólen

Período de Floração: janeiro a março

No Palinoteca: PA 08
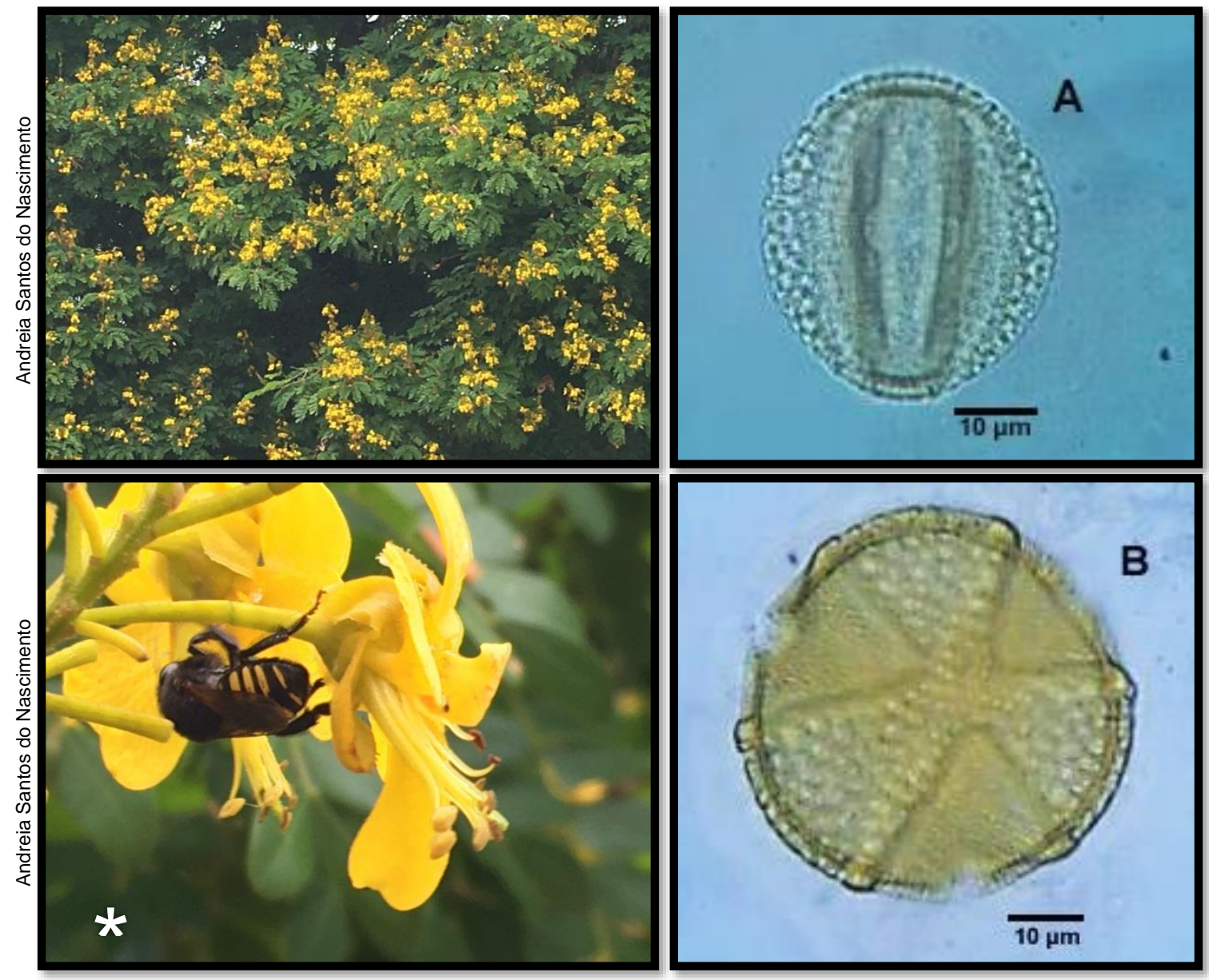

Descrição polínica: $A$ = vista equatorial e $B$ = vista polar, grão de pólen com simetria radial, isopolar, nômade, âmbito subtriangular, abertura polínica do tipo colporo, exina microrreticulada, tamanho grande, forma prolata esferoidal, eixo polar $=52,12 \mu \mathrm{m}$; eixo equatorial $=51,51 \mu \mathrm{m} ; \mathrm{P} / \mathrm{E}=1,01 \mu \mathrm{m}$.

*Abelha visitante floral: Melipona quadrifasciata anthidioides Lepeletier, 1836. 


\section{Fabaceae - Caesalpinioideae}

Espécie: Delonix regia (Bojer ex Hook.) Raf.

Nome comum: Flamboaiã

Hábito de crescimento: arbóreo

Fonte de recurso trófico: pólen

Período de Floração: janeiro e novembro

No Palinoteca: PA 114

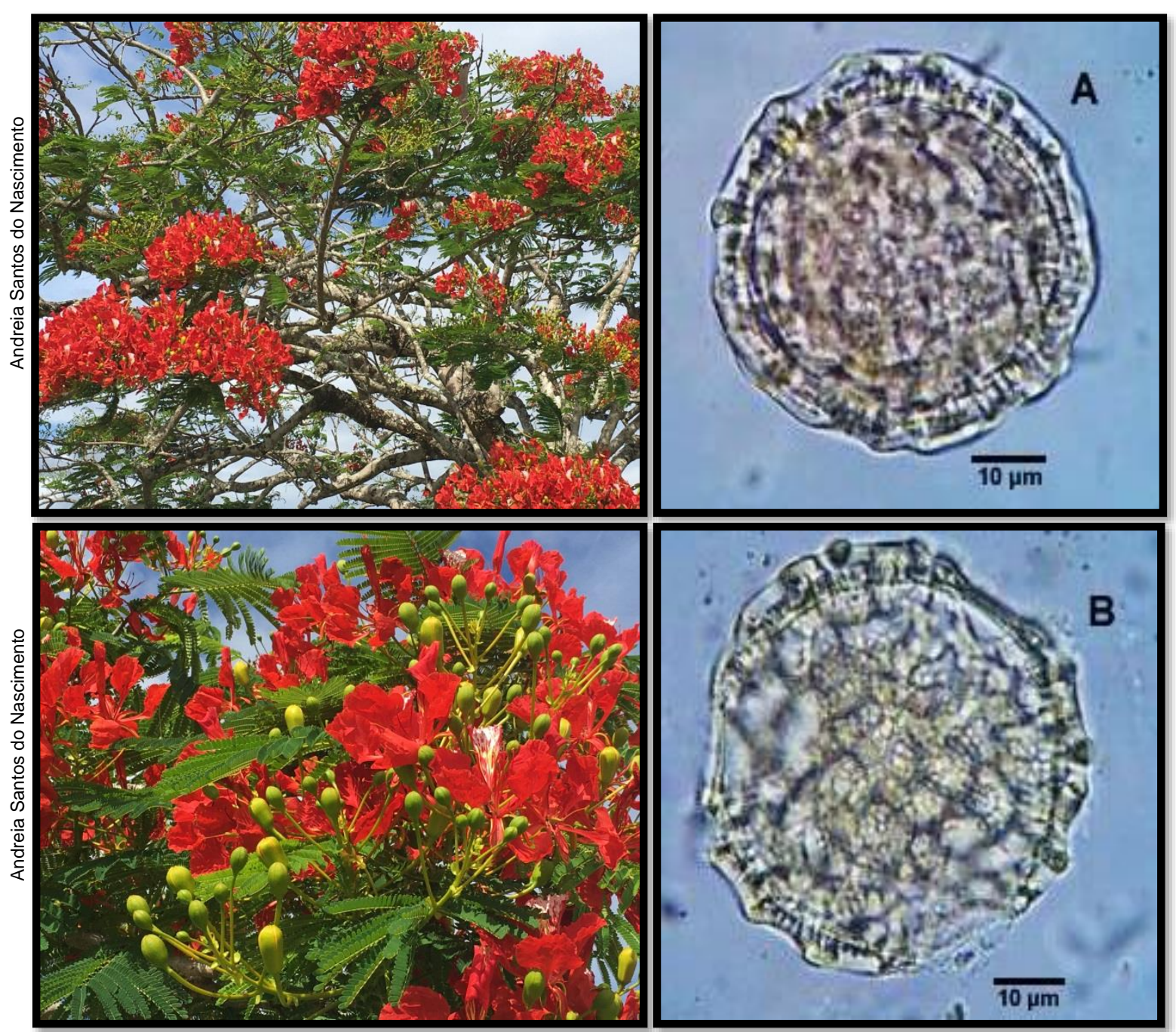

Descrição polínica: $\mathrm{A}$ = vista equatorial e $\mathrm{B}$ = vista polar, grão de pólen com simetria radial, isopolar, nômade, âmbito circular, abertura polínica do tipo colporo, exina reticulada, tamanho grande, forma esferoidal, eixo polar $=52,42 \mu \mathrm{m}$; eixo equatorial $=$ $52,12 \mu \mathrm{m} ; \mathrm{P} / \mathrm{E}=1,00 \mu \mathrm{m}$. 


\section{Fabaceae - Caesalpinioideae}

Espécie: Paubrasilia echinata (Lam.) Gagnon, H.C.Lima \& G.P.Lewis.

Nome comum: Pau-brasil

Hábito de crescimento: arbóreo

Fonte de recurso trófico: pólen

Período de Floração: outubro a novembro

No Palinoteca: NAS29
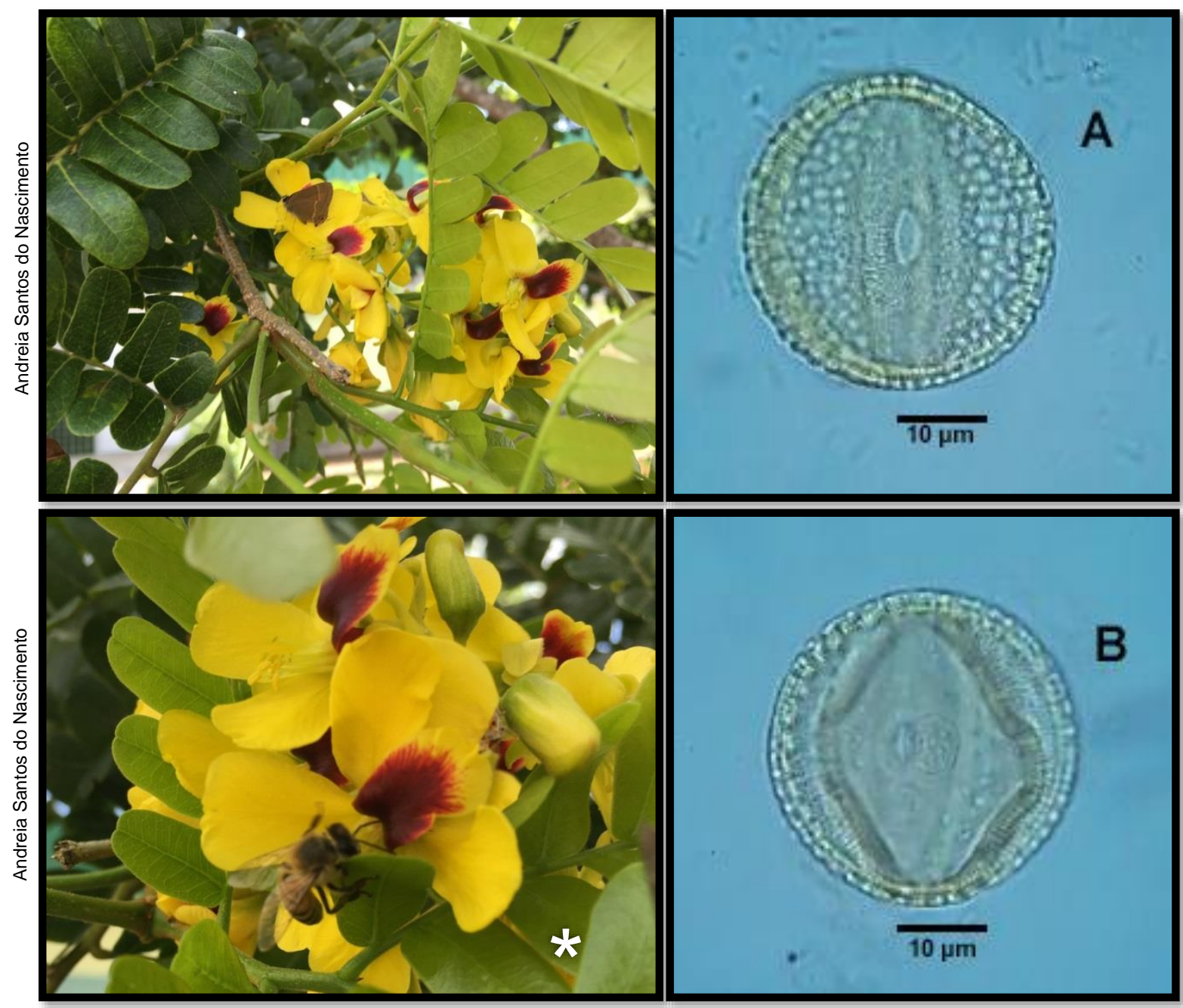

Descrição polínica: $A-B$ = vista equatorial, grão de pólen com simetria radial, isopolar, nômade, âmbito circular, abertura polínica do tipo colporo, exina microrreticulada, tamanho grande, forma oblata esferoidal, eixo polar $=47,54 \mu \mathrm{m}$; eixo equatorial $=50,60 \mu \mathrm{m} ; \mathrm{P} / \mathrm{E}=0,93 \mu \mathrm{m}$.

*Abelha visitante floral: Apis mellifera Linnaeus, 1758. 


\section{Fabaceae - Caesalpinioideae}

Espécie: Peltophorum dubium (Spreng.) Taub.

Nome comum: Canafístula

Hábito de crescimento: arbóreo

Fonte de recurso trófico: pólen

Período de Floração: outubro a novembro

No Palinoteca: PA 124
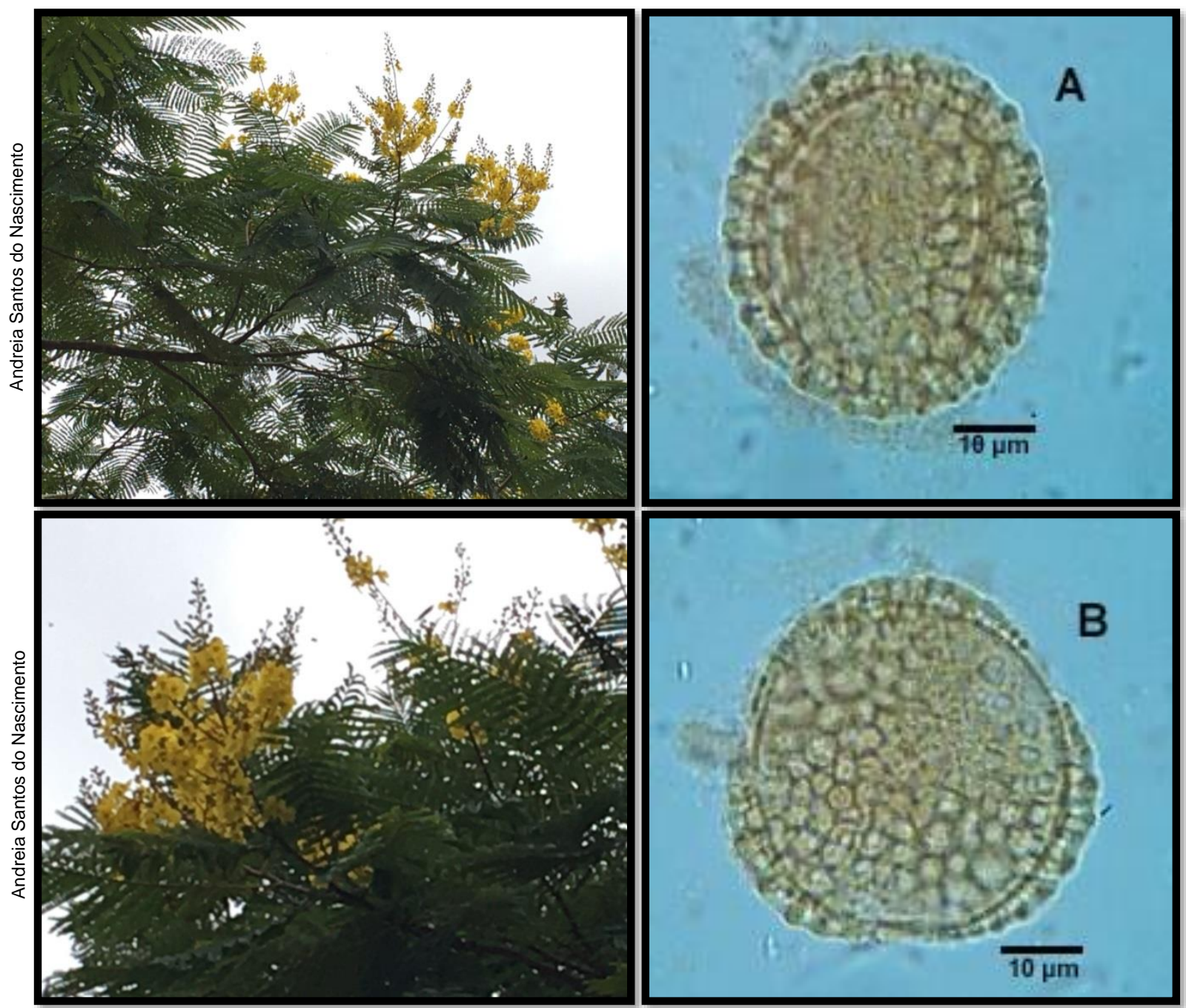

Descrição polínica: $A$ = vista equatorial e $B$ = vista polar, grão de pólen com simetria radial, isopolar, nômade, âmbito subtriangular, abertura polínica do tipo colporo, exina heterobrocada/reticulada, tamanho grande, forma prolata esferoidal, eixo polar = $53,93 \mu \mathrm{m}$; eixo equatorial $=51,51 \mu \mathrm{m} ; \mathrm{P} / \mathrm{E}=1,04 \mu \mathrm{m}$. 


\section{Fabaceae - Caesalpinioideae}

Espécie: Senna obtusifolia (L.) H.S.Irwin \& Barneby

Nome comum: Mata-pasto

Hábito de crescimento: arbustivo

Fonte de recurso trófico: pólen

Período de Floração: agosto a dezembro

No Palinoteca: PA 133

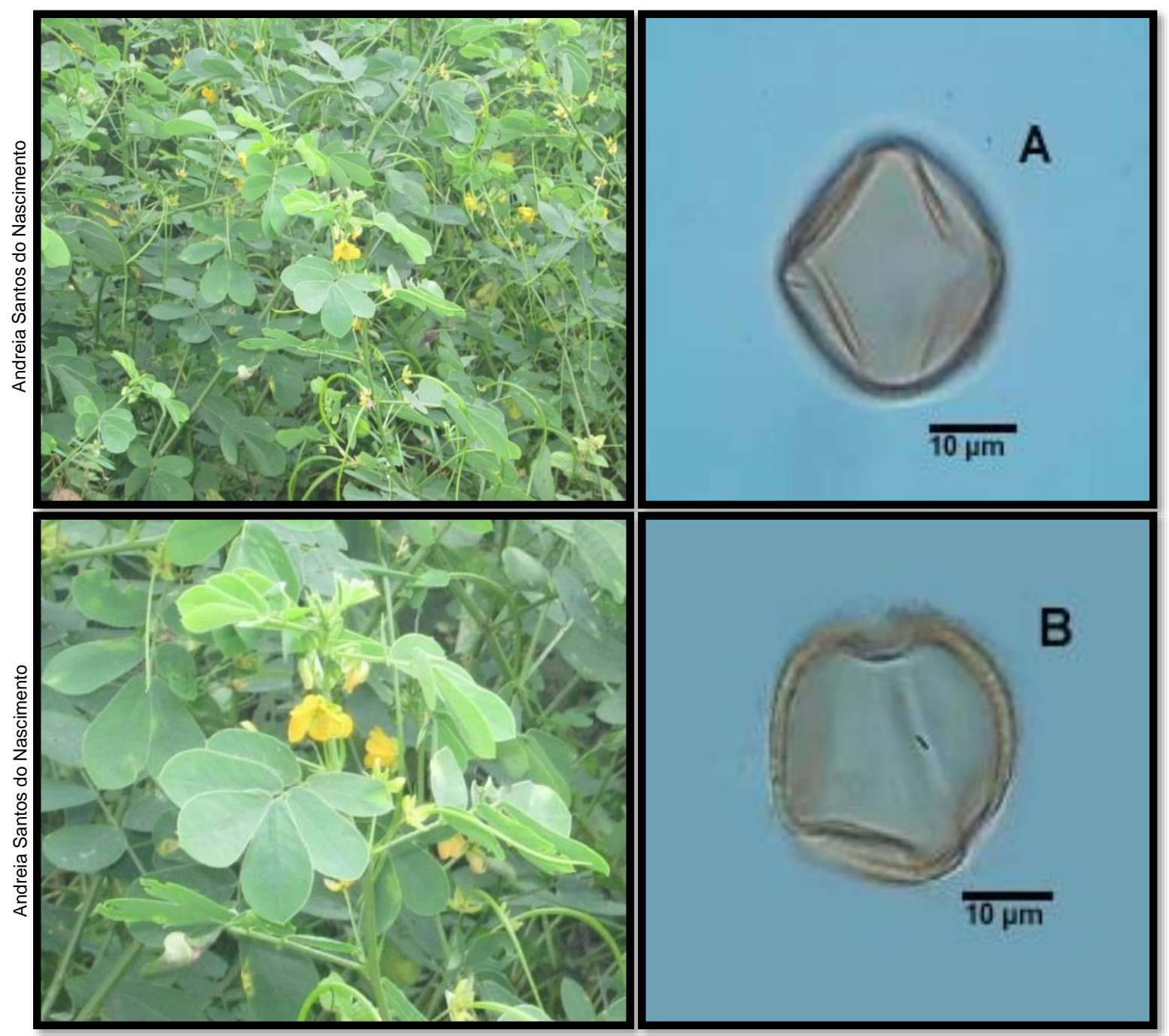

Descrição polínica: $A$ = vista equatorial e $B=$ vista polar, grão de pólen com simetria radial, isopolar, nômade, âmbito circular, abertura polínica do tipo colporo, exina microrreticulada, tamanho médio, forma subprolata, eixo polar $=32,72 \mu \mathrm{m}$; eixo equatorial $=26,36 \mu \mathrm{m} ; \mathrm{P} / \mathrm{E}=1,24 \mu \mathrm{m}$. 


\section{Fabaceae - Caesalpinioideae}

Espécie: Senna occidentalis (L.) Link

Nome comum: Fedegoso

Hábito de crescimento: arbustivo

Fonte de recurso trófico: pólen

Período de Floração: março a junho

No Palinoteca: PA 03
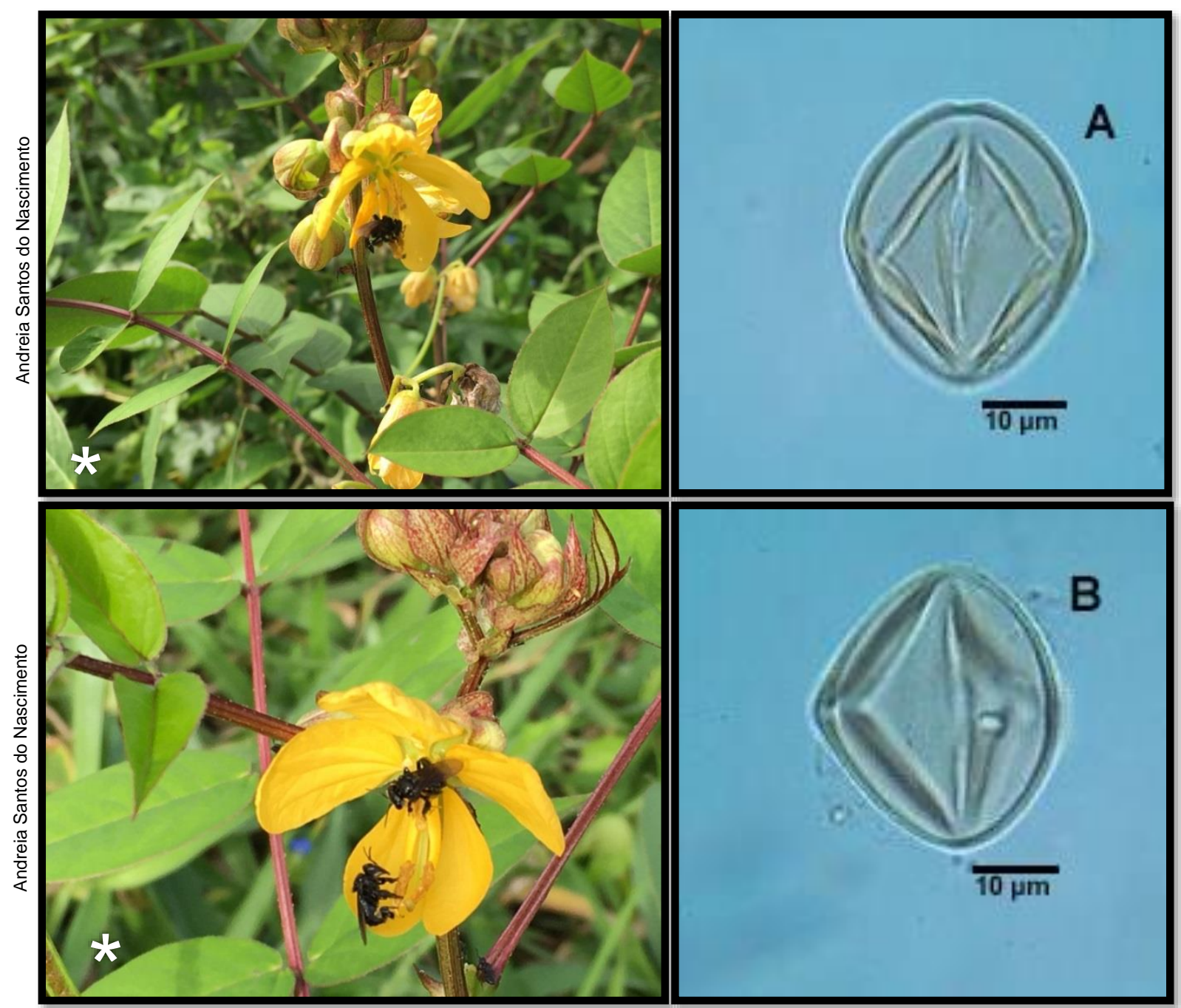

Descrição polínica: $A-B=$ vista equatorial, grão de pólen com simetria radial, isopolar, nômade, âmbito circular, abertura polínica do tipo colporo, exina microrreticulada, tamanho médio, forma prolata esferoidal, eixo polar $=31,51 \mu \mathrm{m}$; eixo equatorial $=27,57 \mu \mathrm{m} ; \mathrm{P} / \mathrm{E}=1,14 \mu \mathrm{m}$.

${ }^{*}$ Abelha visitante floral: Trigona spinipes Fabricius, 1793. 


\section{Fabaceae - Caesalpinioideae}

Espécie: Senna rugosa (G.Don) H.S.Irwin \& Barneby

Nome comum: Flor-de-são-joão, cássia-amarela

Hábito de crescimento: arbustivo

Fonte de recurso trófico: pólen

Período de Floração: março a junho

No Palinoteca: PA 138

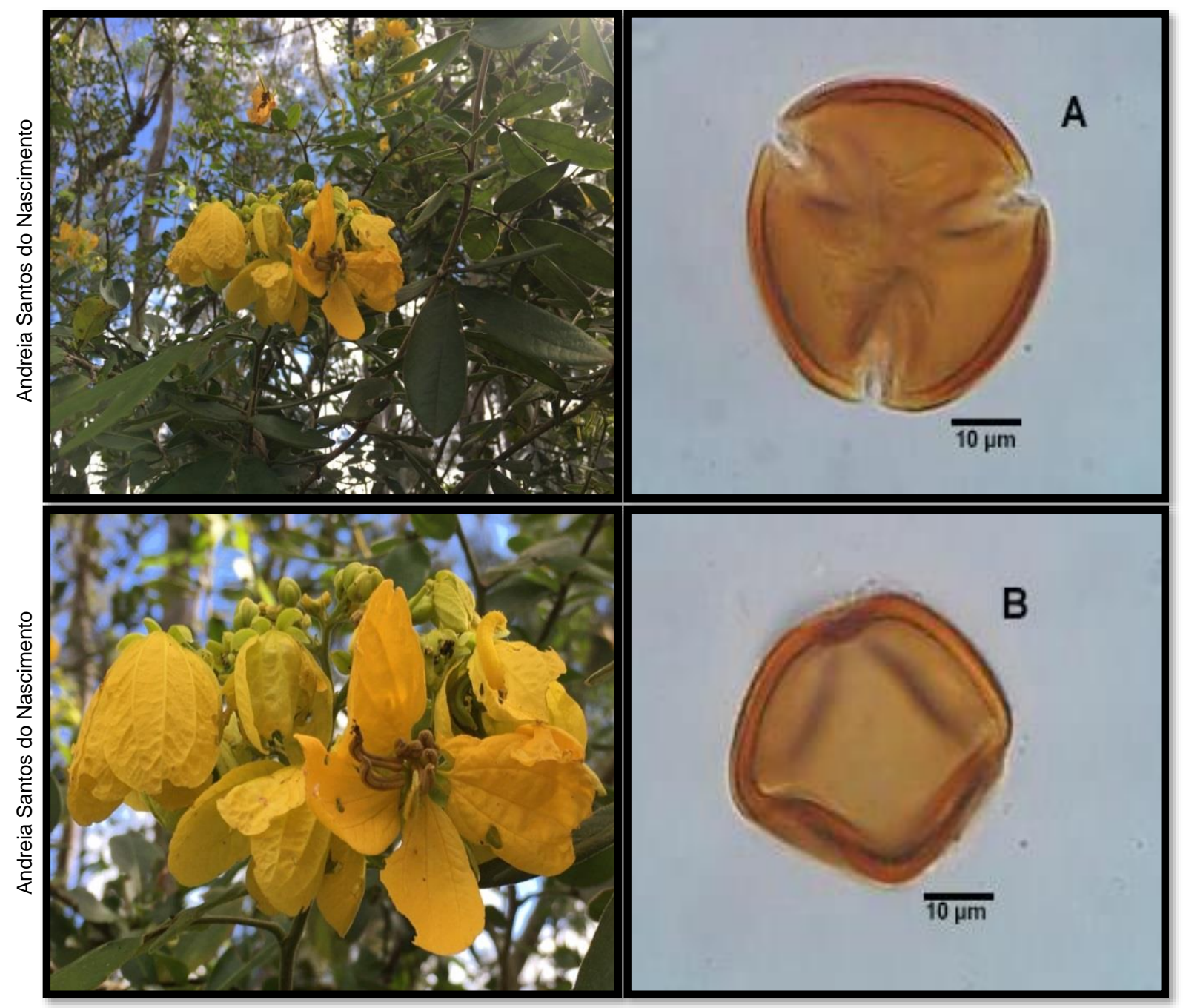

Descrição polínica: $A$ = vista polar e $B$ = vista equatorial, grão de pólen com simetria radial, isopolar, nômade, âmbito circular, abertura polínica do tipo colporo, exina perfurada, tamanho grande, forma prolata esferoidal, eixo polar $=52,42 \mu \mathrm{m}$; eixo equatorial $=46,06 \mu \mathrm{m} ; \mathrm{P} / \mathrm{E}=1,13 \mu \mathrm{m}$. 


\section{Fabaceae - Caesalpinioideae}

Espécie: Senna siamea (Lam) H.S.Irwin \& Barneby

Nome comum: Cássia-de-sião; cássia-amarela

Hábito de crescimento: arbóreo

Fonte de recurso trófico: pólen

Período de Floração: março a junho

No Palinoteca: PA 123
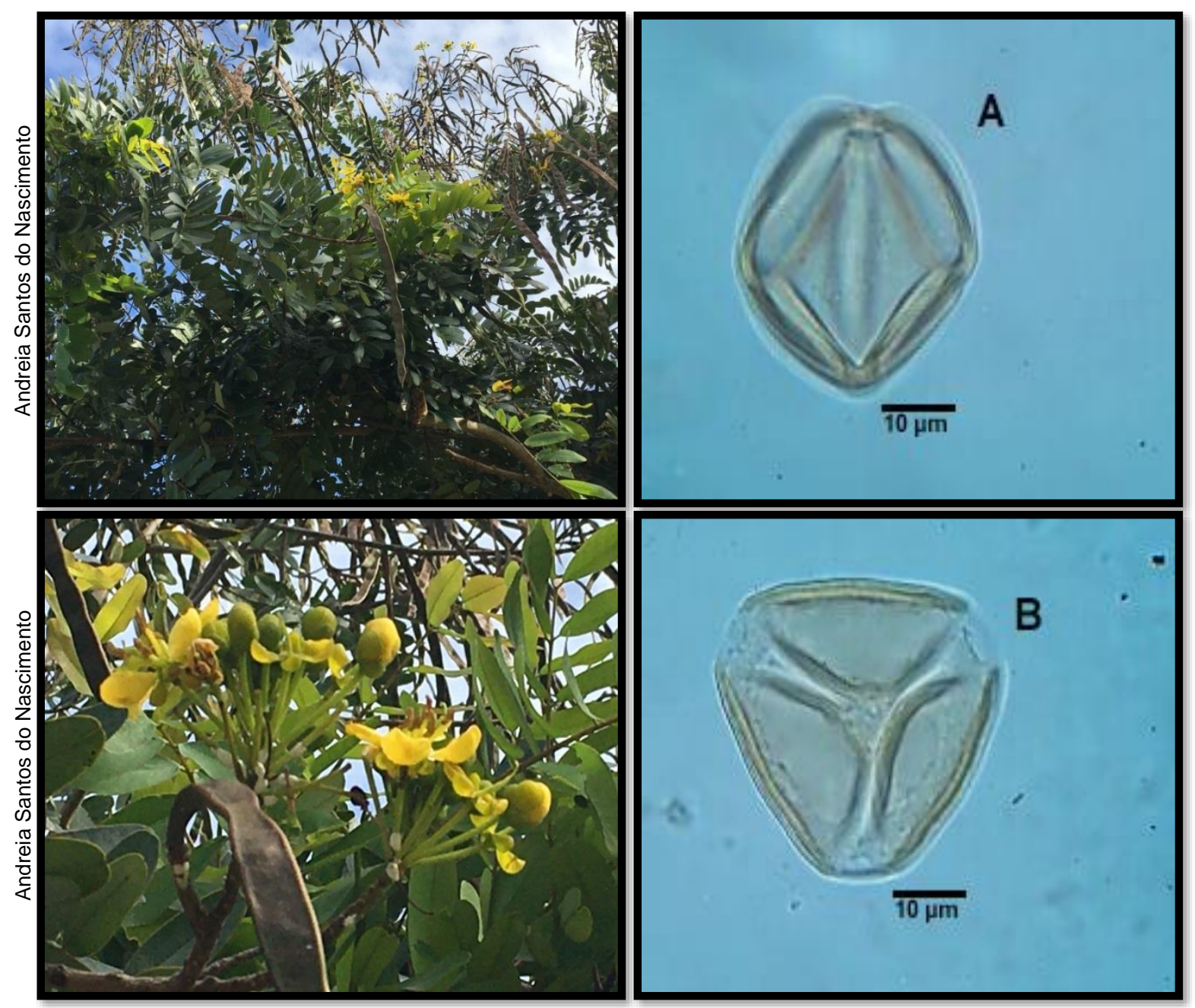

Descrição polínica: $A=$ vista equatorial e $B=$ vista polar, grão de pólen com simetria radial, isopolar, nômade, âmbito subtriangular, abertura polínica do tipo colporo, exina microrreticulada, tamanho médio, forma subprolata, eixo polar $=47,57 \mu \mathrm{m}$; eixo equatorial $=40,30 \mu \mathrm{m} ; \mathrm{P} / \mathrm{E}=1,18 \mu \mathrm{m}$. 


\section{Fabaceae - Caesalpinioideae}

Espécie: Tamarindus indica L.

Nome comum: Tamarindo

Hábito de crescimento: arbóreo

Fonte de recurso trófico: pólen

Período de Floração: novembro a janeiro

No Palinoteca: PA 02

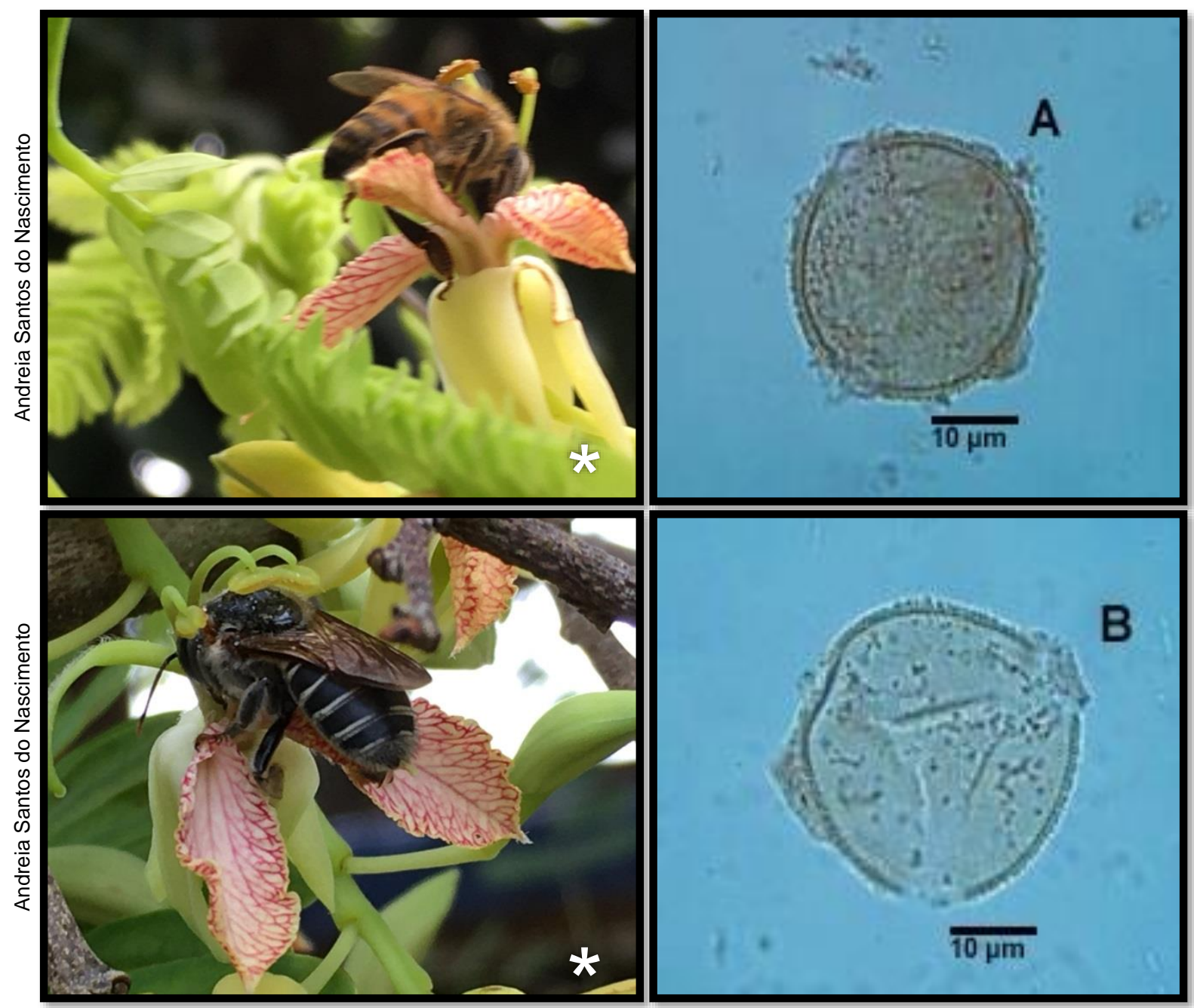

Descrição polínica: A-B = vista polar, grão de pólen com simetria radial, isopolar, nômade, âmbito subtriangular, abertura polínica do tipo colporo, exina reticulada, tamanho médio, forma prolata esferoidal, eixo maior $=31,81 \mu \mathrm{m}$; eixo menor $=30,30$ $\mu \mathrm{m} ; \mathrm{P} / \mathrm{E}=1,04 \mu \mathrm{m}$.

*Abelha visitante floral: Apis mellifera Linnaeus, 1758 e Melipona sp. 


\section{Fabaceae - Faboideae}

Espécie: Cajanus cajans (L.) Millsp.

Nome comum: Feijão guandu

Hábito de crescimento: arbustivo

Fonte de recurso trófico: pólen

Período de Floração: maio a junho

No Palinoteca: PA 14
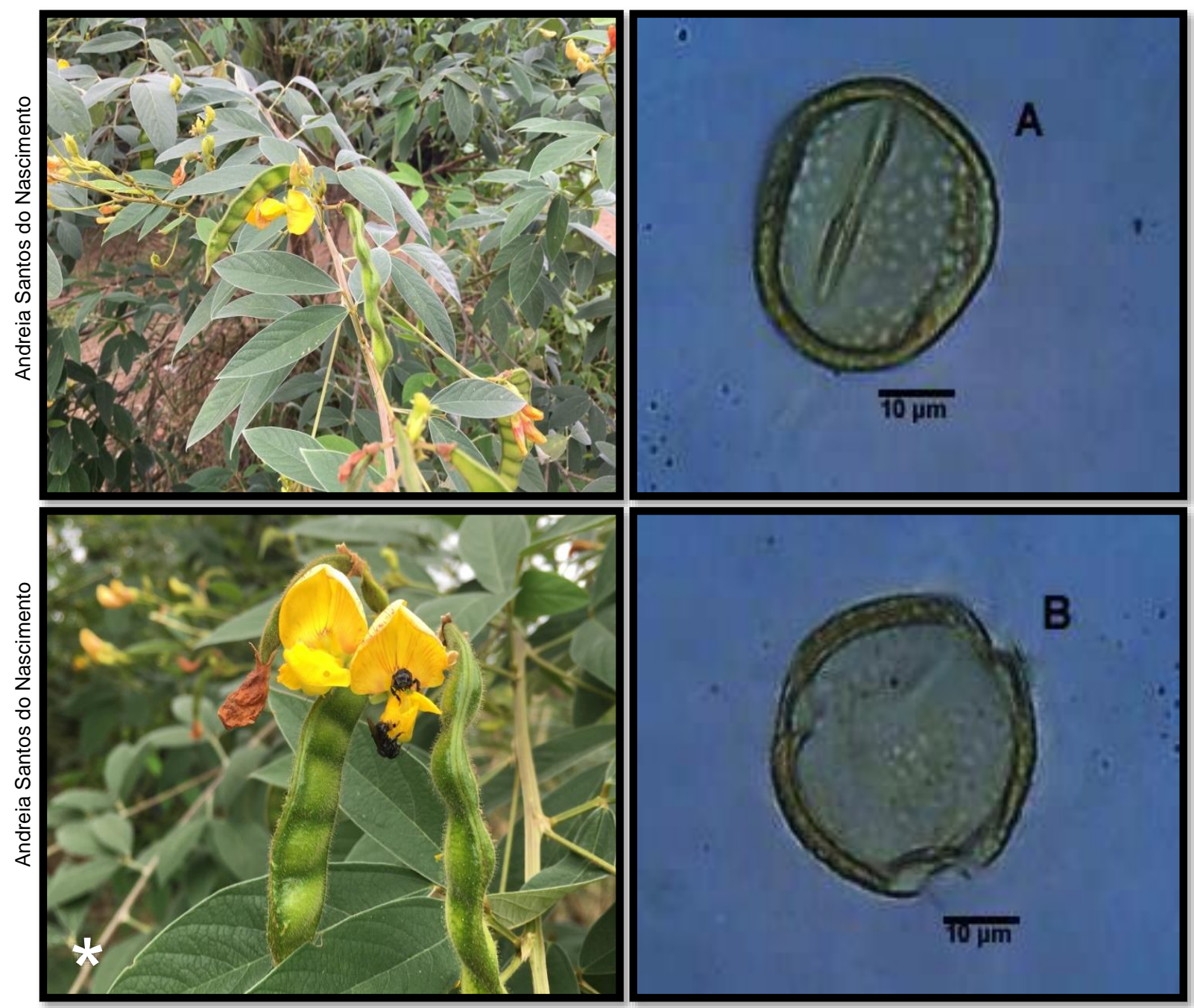

Descrição polínica: $A$ = vista equatorial e $B$ = vista polar, grão de pólen com simetria radial, isopolar, nômade, âmbito subtriangular, abertura polínica do tipo colporo, exina reticulada, tamanho médio, forma subprolata, eixo polar $=31,51 \mu \mathrm{m}$; eixo equatorial $=27,27 \mu \mathrm{m} ; \mathrm{P} / \mathrm{E}=1,15 \mu \mathrm{m}$.

*Abelha visitante floral: Trigona spinipes Fabricius, 1793. 


\section{Fabaceae - Faboideae}

Espécie: Canavalia brasiliensis Mart. ex Benth.

Nome comum: Feijão-bravo

Hábito de crescimento: liana

Fonte de recurso trófico: pólen

Período de Floração: setembro a novembro

No Palinoteca: PA 129
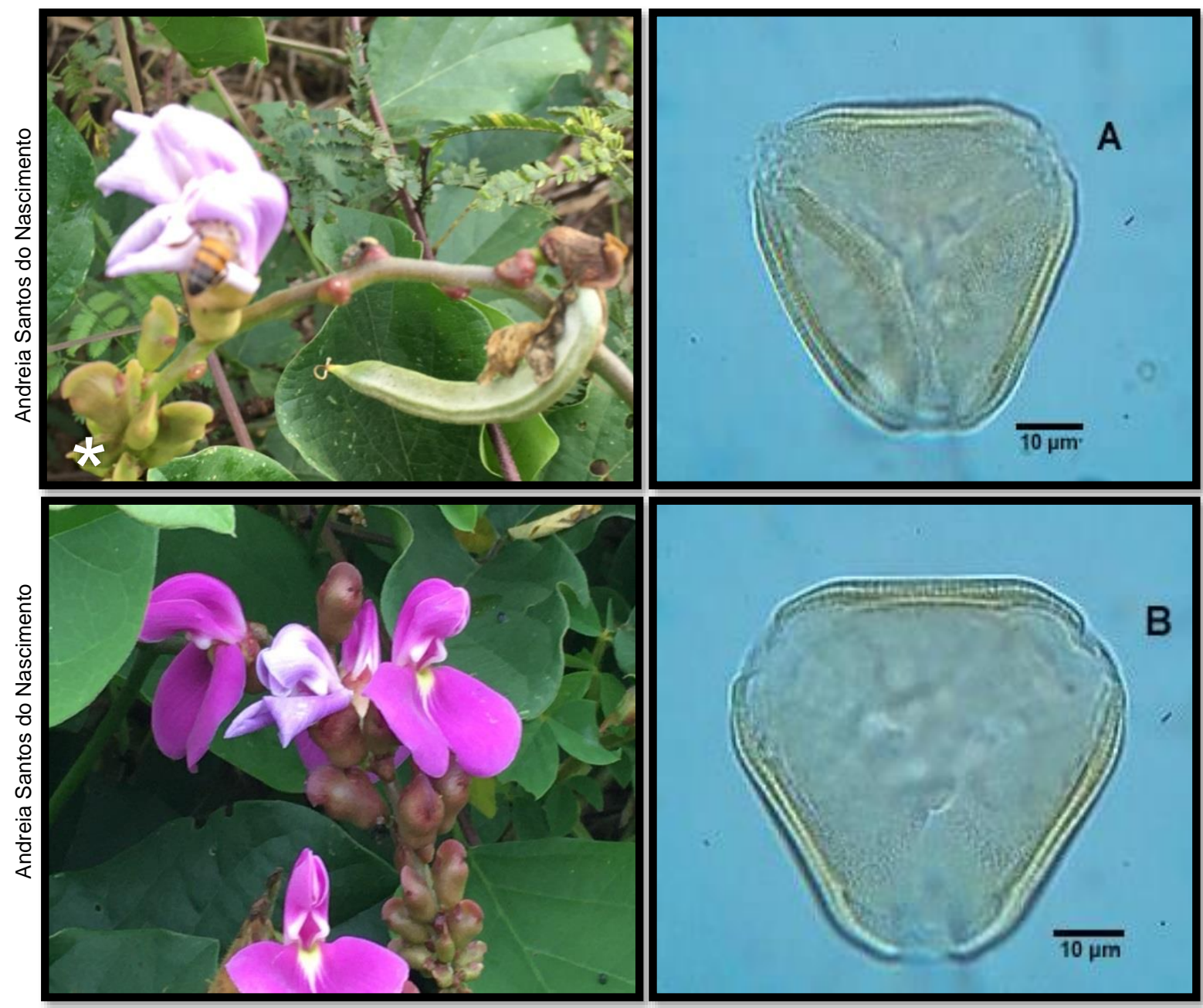

Descrição polínica: A-B = vista polar, grão de pólen com simetria radial, isopolar, nômade, âmbito subtriangular, abertura polínica do tipo colporo, exina reticulada, tamanho médio, forma prolata esferoidal, eixo polar $=50,60 \mu \mathrm{m}$; eixo equatorial $=47,57$ $\mu \mathrm{m} ; \mathrm{P} / \mathrm{E}=1,06 \mu \mathrm{m}$.

*Abelha visitante floral: Apis mellifera Linnaeus, 1758. 


\section{Fabaceae - Faboideae}

Espécie: Centrosema pubescens Benth.

Nome comum: Ervilha-borboleta

Hábito de crescimento: herbáceo

Fonte de recurso trófico: pólen

Período de Floração: maio a junho

NN Palinoteca: PA 162
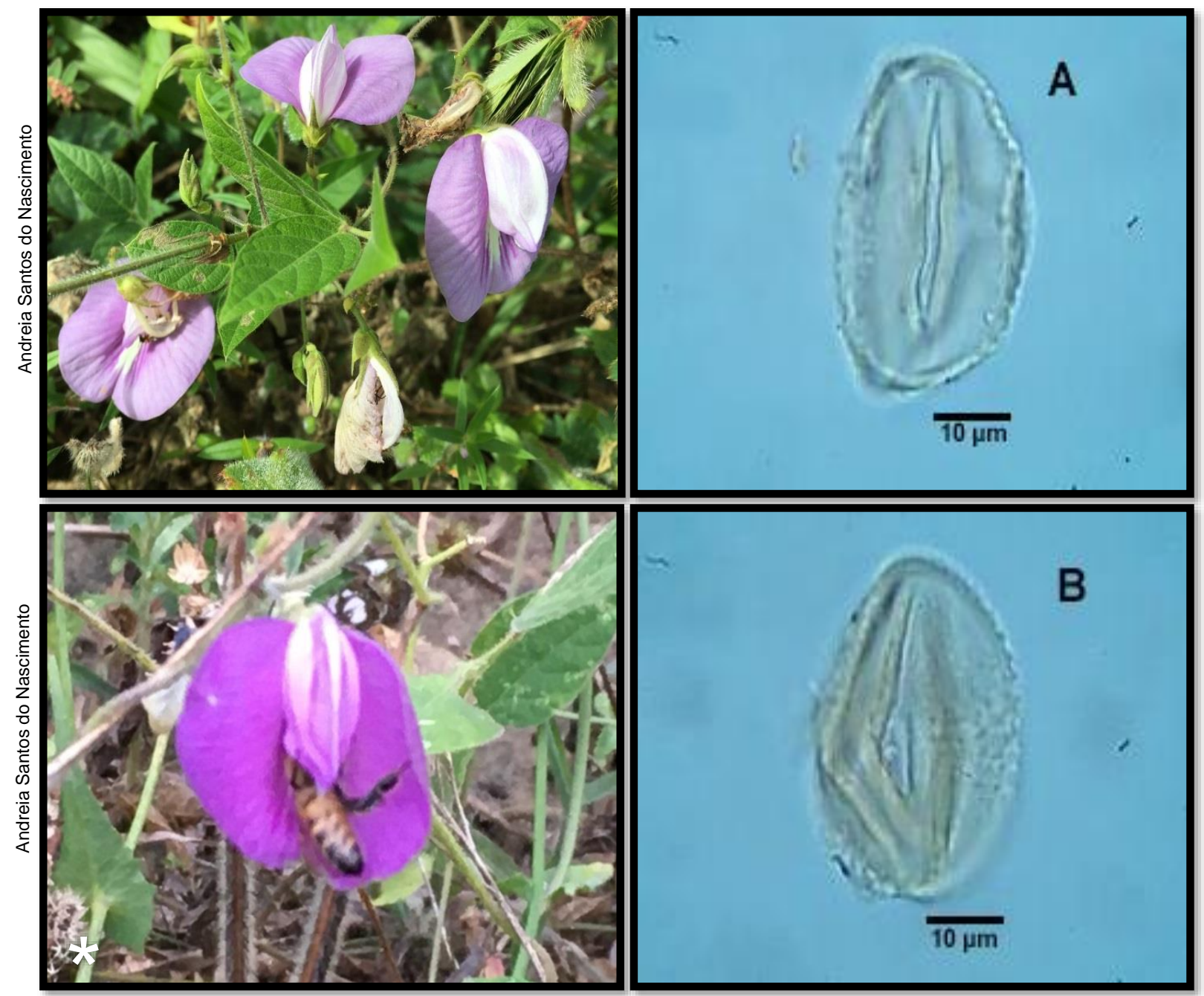

Descrição polínica: A-B = vista equatorial, grão de pólen com simetria radial, isopolar, nômade, âmbito subtriangular, abertura polínica do tipo colporo, exina reticulada, tamanho médio, forma prolata, eixo polar $=42,12 \mu \mathrm{m}$; eixo equatorial $=$ $26,36 \mu \mathrm{m} ; \mathrm{P} / \mathrm{E}=1,59 \mu \mathrm{m}$.

*Abelha visitante floral: Apis mellifera Linnaeus, 1758. 


\section{Fabaceae - Faboideae}

Espécie: Chamaecrista flexuosa (L.) Greene

Nome comum: Canela-de-ema

Hábito de crescimento: herbáceo

Fonte de recurso trófico: pólen

Período de Floração: maio a junho

No Palinoteca: PA 46

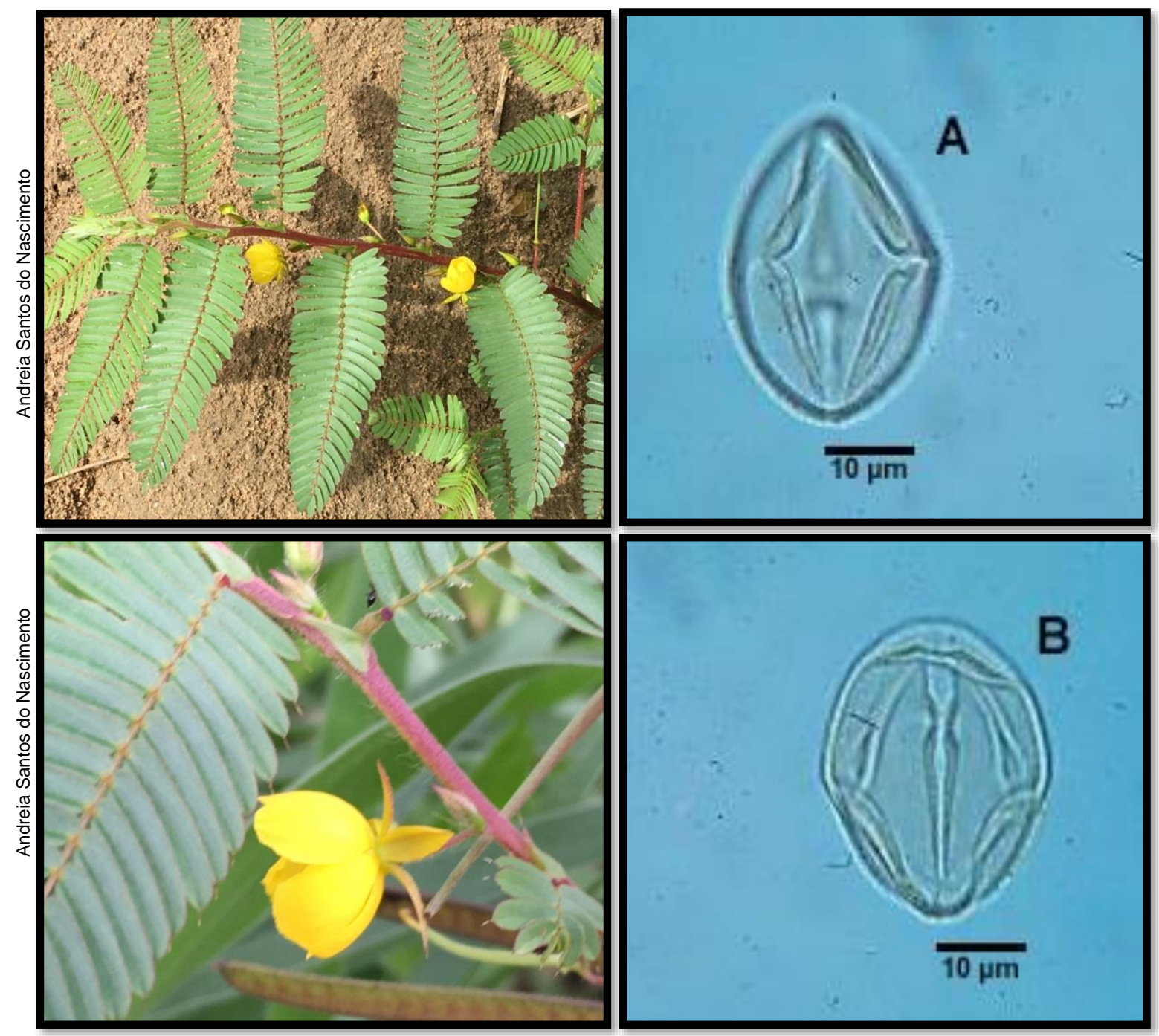

Descrição polínica: A-B = vista equatorial, grão de pólen com simetria radial, isopolar, nômade, âmbito subtriangular, abertura polínica do tipo colporo, exina microrreticulada, tamanho médio, forma subprolata, eixo polar $=32,12 \mu \mathrm{m}$; eixo equatorial $=23,03 \mu \mathrm{m} ; \mathrm{P} / \mathrm{E}=1,39 \mu \mathrm{m}$. 


\section{Fabaceae - Faboideae}

Espécie: Chamaecrista rotundifolia (Pers.) Greene

Nome comum: Pasto-rasteiro

Hábito de crescimento: herbáceo

Fonte de recurso trófico: pólen

Período de Floração: maio a junho

No Palinoteca: PA 45
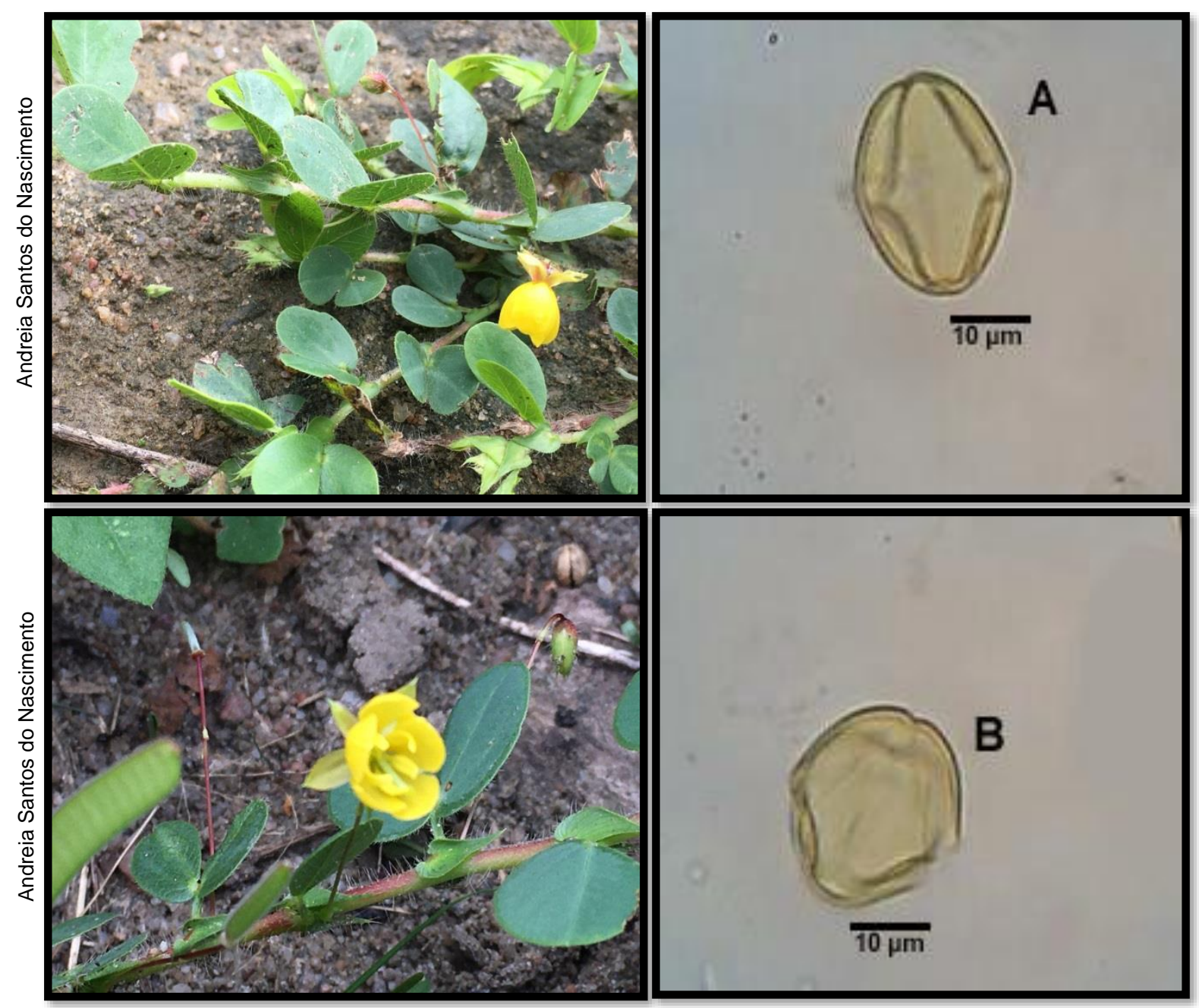

Descrição polínica: A-B = vista equatorial, grão de pólen com simetria radial, isopolar, nômade, âmbito subtriangular, abertura polínica do tipo colporo, exina microrreticulada, tamanho pequeno, forma subprolata, eixo polar $=24,84 \mu \mathrm{m}$; eixo equatorial $=18,18 \mu \mathrm{m} ; \mathrm{P} / \mathrm{E}=1,36 \mu \mathrm{m}$. 


\section{Fabaceae - Faboideae}

Espécie: Clitoria fairchildiana R.A.Howard

Nome comum: Sombreiro

Hábito de crescimento: arbóreo

Fonte de recurso trófico: pólen

Período de Floração: maio a junho

No Palinoteca: PA 117
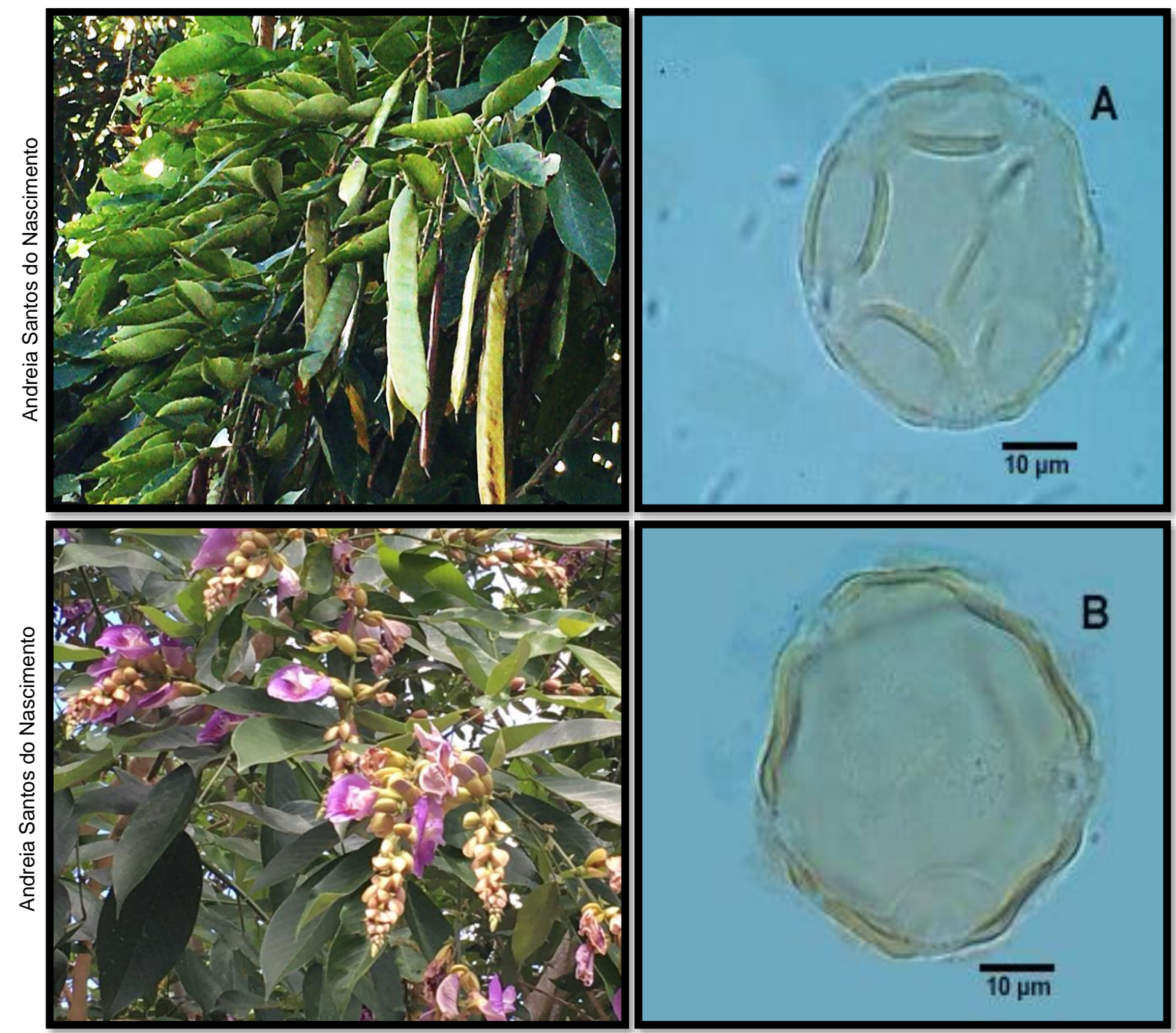

Descrição polínica: A-B = vista polar, grão de pólen com simetria radial, isopolar, nômade, âmbito circular, abertura polínica do tipo poro, exina microrreticulada, tamanho grande, forma esferoidal, eixo maior $=53,93 \mu \mathrm{m}$; eixo menor $=53,63 \mu \mathrm{m}$; $\mathrm{P} / \mathrm{E}=1,00 \mu \mathrm{m}$. 


\section{Fabaceae - Faboideae}

Espécie: Crotalaria incana L.

Nome comum: Crotalária

Hábito de crescimento: herbáceo

Fonte de recurso trófico: pólen

Período de Floração: maio a junho

No Palinoteca: PA 28

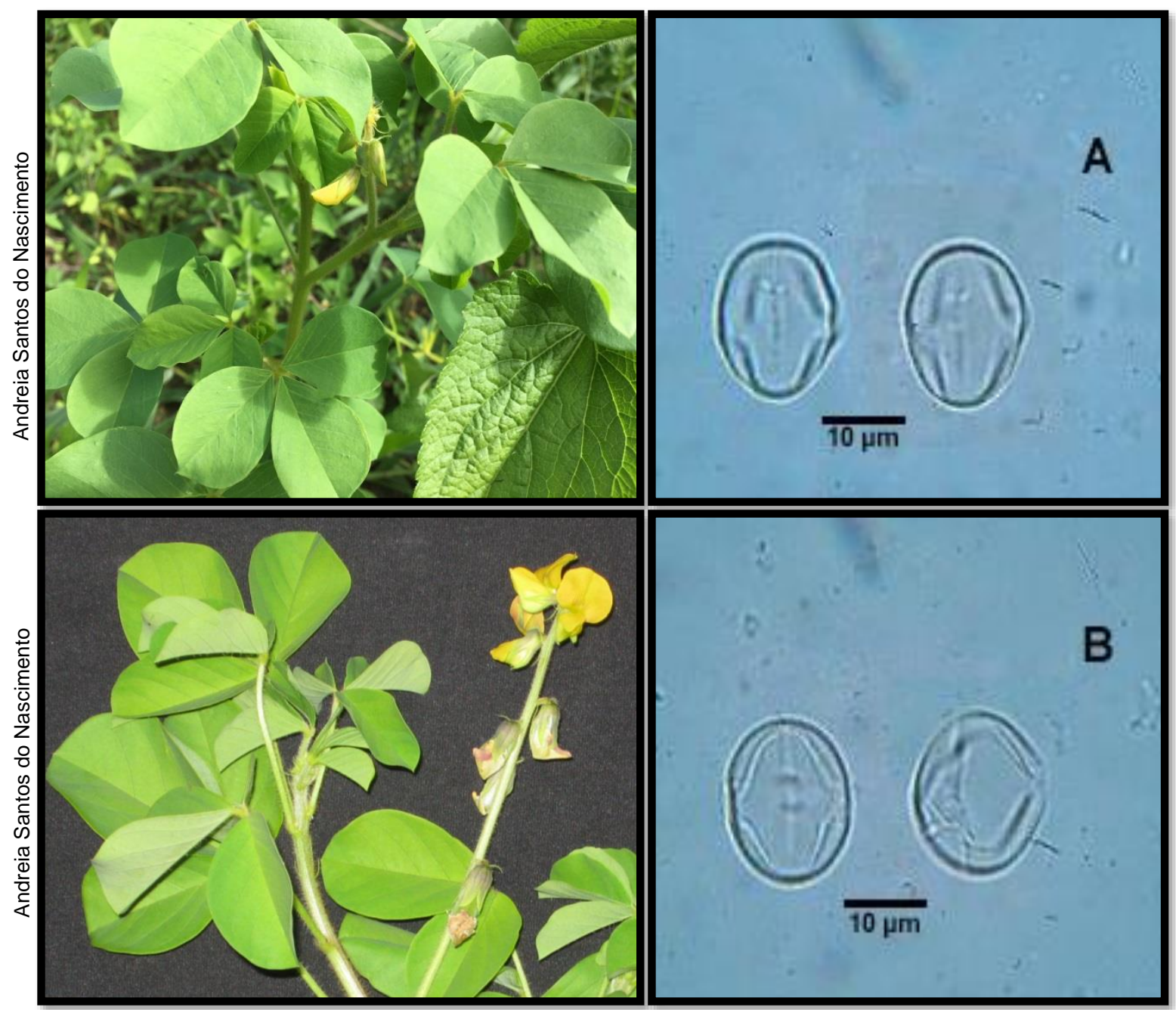

Descrição polínica: $A-B=$ vista equatorial, grão de pólen com simetria radial, isopolar, nômade, âmbito subtriangular, abertura polínica do tipo colporo, exina microrreticulada, tamanho pequeno, forma subprolata, eixo polar $=19,09 \mu \mathrm{m}$; eixo equatorial $=15,15 \mu \mathrm{m} ; \mathrm{P} / \mathrm{E}=1,26 \mu \mathrm{m}$. 


\section{Fabaceae - Faboideae}

Espécie: Dalbergia ecastaphyllum (L.) Taub.

Nome comum: Rabo-de-bugio

Hábito de crescimento: arbustivo

Fonte de recurso trófico: pólen/resina

Período de Floração: maio a junho

No Palinoteca: NASO9
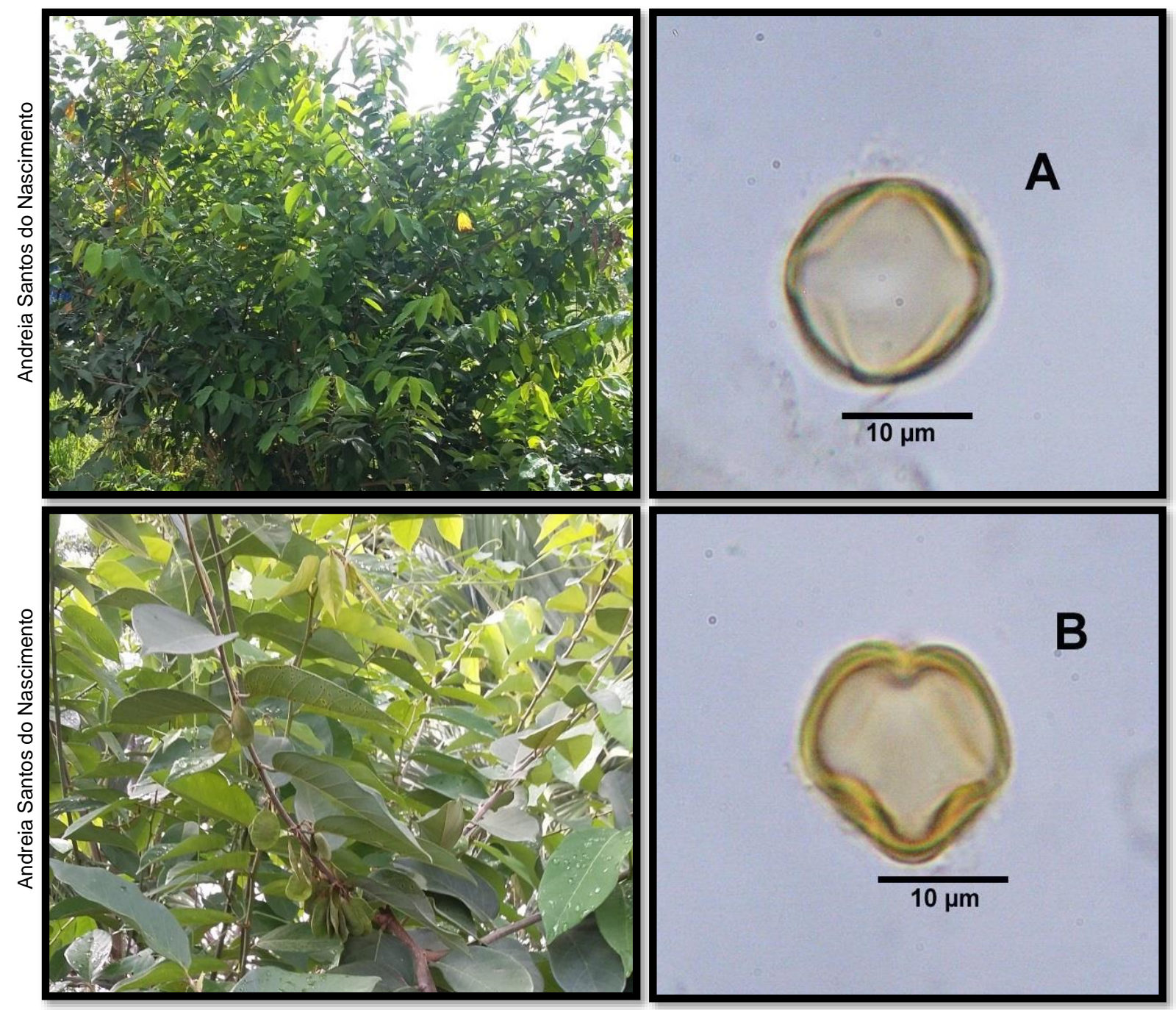

Descrição polínica: $A-B$ = vista equatorial, grão de pólen com simetria radial, isopolar, nômade, âmbito subtriangular, abertura polínica do tipo colporo, exina microrreticulada, tamanho pequeno, forma prolata esferoidal, eixo polar $=20,90 \mu \mathrm{m}$; eixo equatorial $=19,69 \mu \mathrm{m} ; \mathrm{P} / \mathrm{E}=1,06 \mu \mathrm{m}$. 


\section{Fabaceae - Faboideae}

Espécie: Desmodium incanum (Sw.) DC.

Nome comum: Carrapicho

Hábito de crescimento: herbáceo

Fonte de recurso trófico: pólen

Período de Floração: maio a junho

No Palinoteca: PA 148
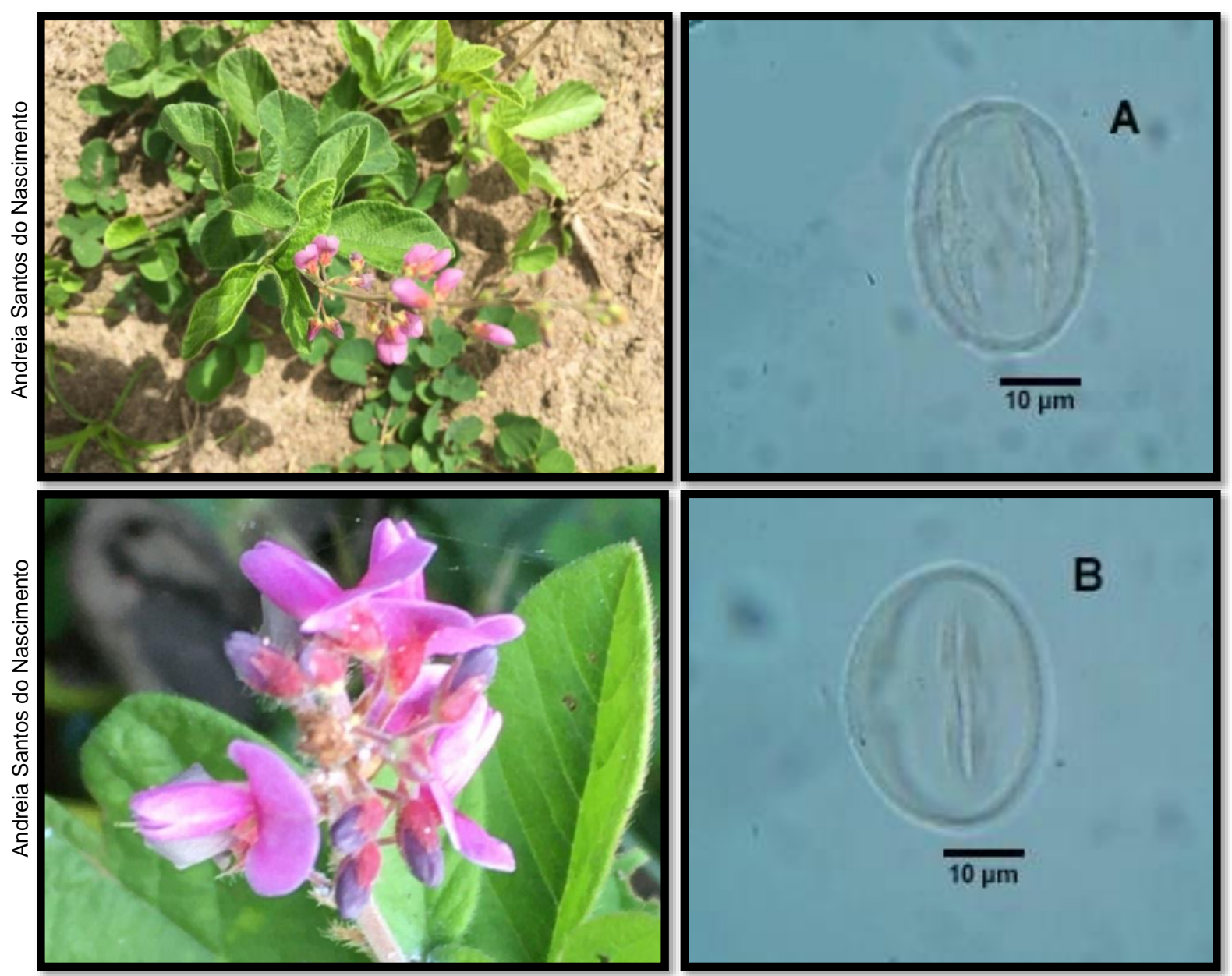

Descrição polínica: $A-B=$ vista equatorial, grão de pólen com simetria radial, isopolar, nômade, âmbito subtriangular, abertura polínica do tipo colporo, exina microrreticulada, tamanho médio, forma subprolata, eixo polar $=30,00 \mu \mathrm{m}$; eixo equatorial $=23,03 \mu \mathrm{m} ; \mathrm{P} / \mathrm{E}=1,30 \mu \mathrm{m}$. 


\section{Fabaceae - Faboideae}

Espécie: Desmodium tortuosum (Sw.) DC.

Nome comum: Carrapicho; pega-pega

Hábito de crescimento: herbáceo

Fonte de recurso trófico: pólen

Período de Floração: maio a junho

No Palinoteca: NAS10
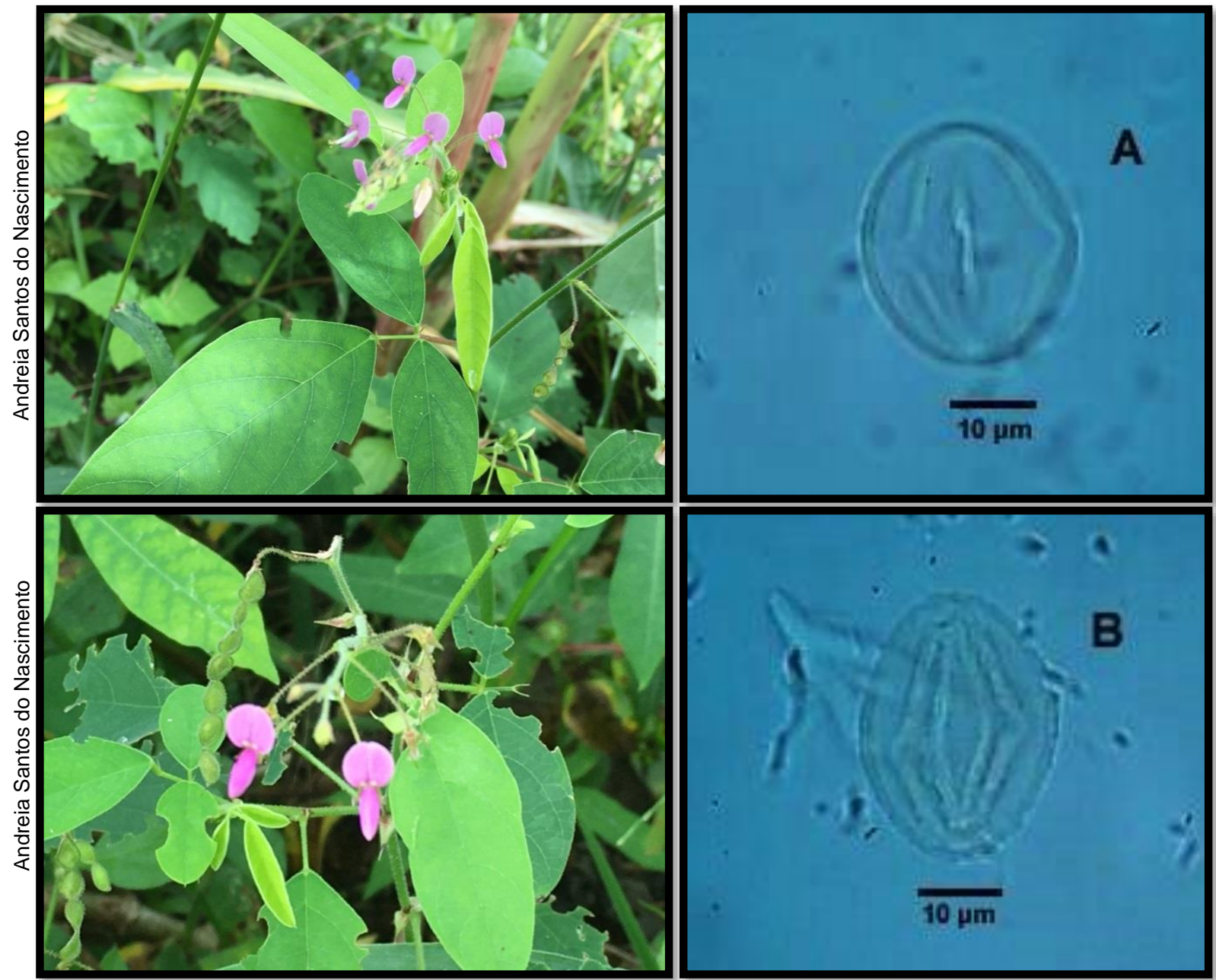

Descrição polínica: $A-B$ = vista equatorial, grão de pólen com simetria radial, isopolar, nômade, âmbito subtriangular, abertura polínica do tipo colporo, exina microrreticulada, tamanho médio, forma subprolata, eixo polar $=30,30 \mu \mathrm{m}$; eixo equatorial $=23,63 \mu \mathrm{m} ; \mathrm{P} / \mathrm{E}=1,28 \mu \mathrm{m}$. 


\section{Fabaceae - Faboideae}

Espécie: Gliricidia sepium (Jacq.) Kunth ex Walp.

Nome comum: Glircídia

Hábito de crescimento: arbóreo

Fonte de recurso trófico: pólen

Período de Floração: agosto a setembro

No Palinoteca: PA 83

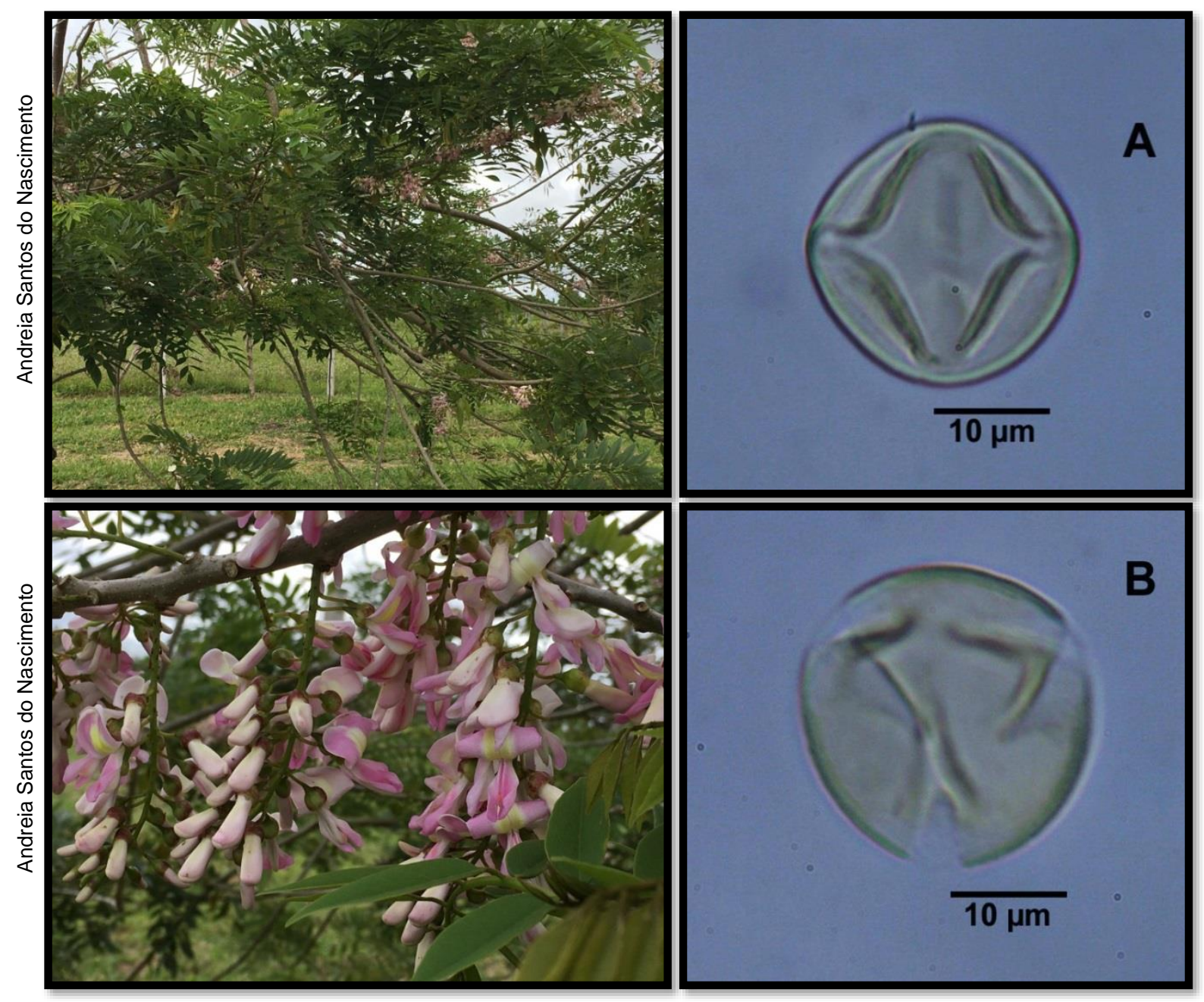

Descrição polínica: $\mathrm{A}$ = vista equatorial e $\mathrm{B}=$ vista polar, grão de pólen com simetria radial, isopolar, nômade, âmbito subtriangular, abertura polínica do tipo colporo, exina microrreticulada, tamanho médio, forma oblata esferoidal, eixo polar $=25,75$ $\mu \mathrm{m}$; eixo equatorial $=26,06 \mu \mathrm{m} ; \mathrm{P} / \mathrm{E}=0,98 \mu \mathrm{m}$. 


\section{Fabaceae - Faboideae}

Espécie: Indigofera hirsuta L.

Nome comum: Anileira

Hábito de crescimento: herbáceo

Fonte de recurso trófico: pólen

Período de Floração: maio a julho

No Palinoteca: PA 42
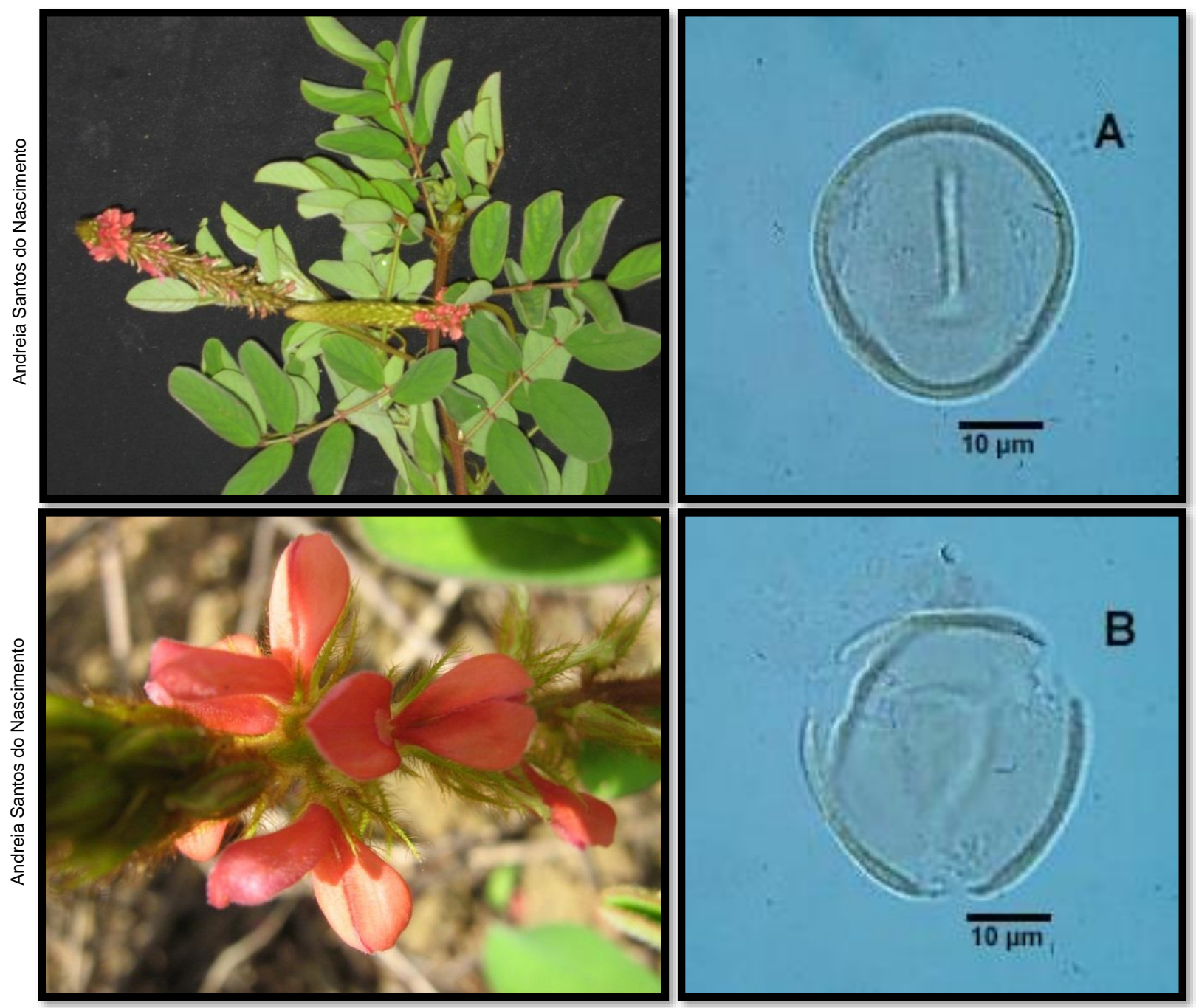

Descrição polínica: $A$ = vista equatorial e $B$ = vista polar, grão de pólen com simetria radial, isopolar, nômade, âmbito subtriangular, abertura polínica do tipo colporo, exina microrreticulada, tamanho médio, forma prolata esferoidal, eixo polar $=34,24 \mu \mathrm{m}$; eixo equatorial $=32,72 \mu \mathrm{m} ; \mathrm{P} / \mathrm{E}=1,04 \mu \mathrm{m}$. 


\section{Fabaceae - Faboideae}

Espécie: Lablab purpureus (L.) Sweet

Nome comum: Mangalô

Hábito de crescimento: herbáceo

Fonte de recurso trófico: pólen

Período de Floração: agosto a setembro

No Palinoteca: PA 75

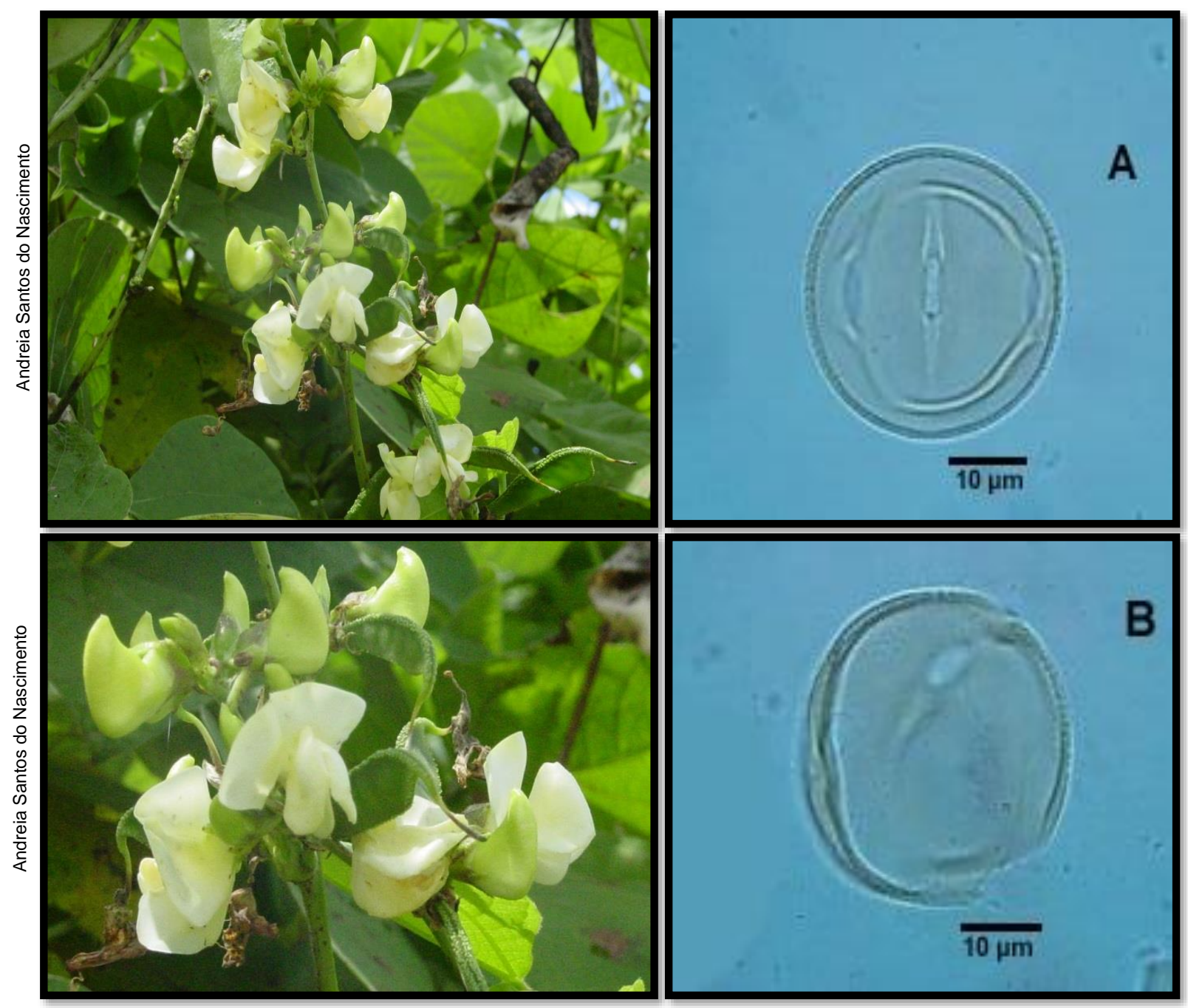

Descrição polínica: A-B = vista equatorial, grão de pólen com simetria radial, isopolar, nômade, âmbito subtriangular, abertura polínica do tipo colporo, exina microrreticulada, tamanho médio, forma oblata esferoidal, eixo polar $=42,72 \mu \mathrm{m}$; eixo equatorial $=43,03 \mu \mathrm{m} ; \mathrm{P} / \mathrm{E}=0,99 \mu \mathrm{m}$. 


\section{Fabaceae - Faboideae}

Espécie: Macroptilium lathyroides (L.) Urb.

Nome comum: Feijão-de-rola

Hábito de crescimento: herbáceo

Fonte de recurso trófico: pólen

Período de Floração: maio a julho

No Palinoteca: PA 40

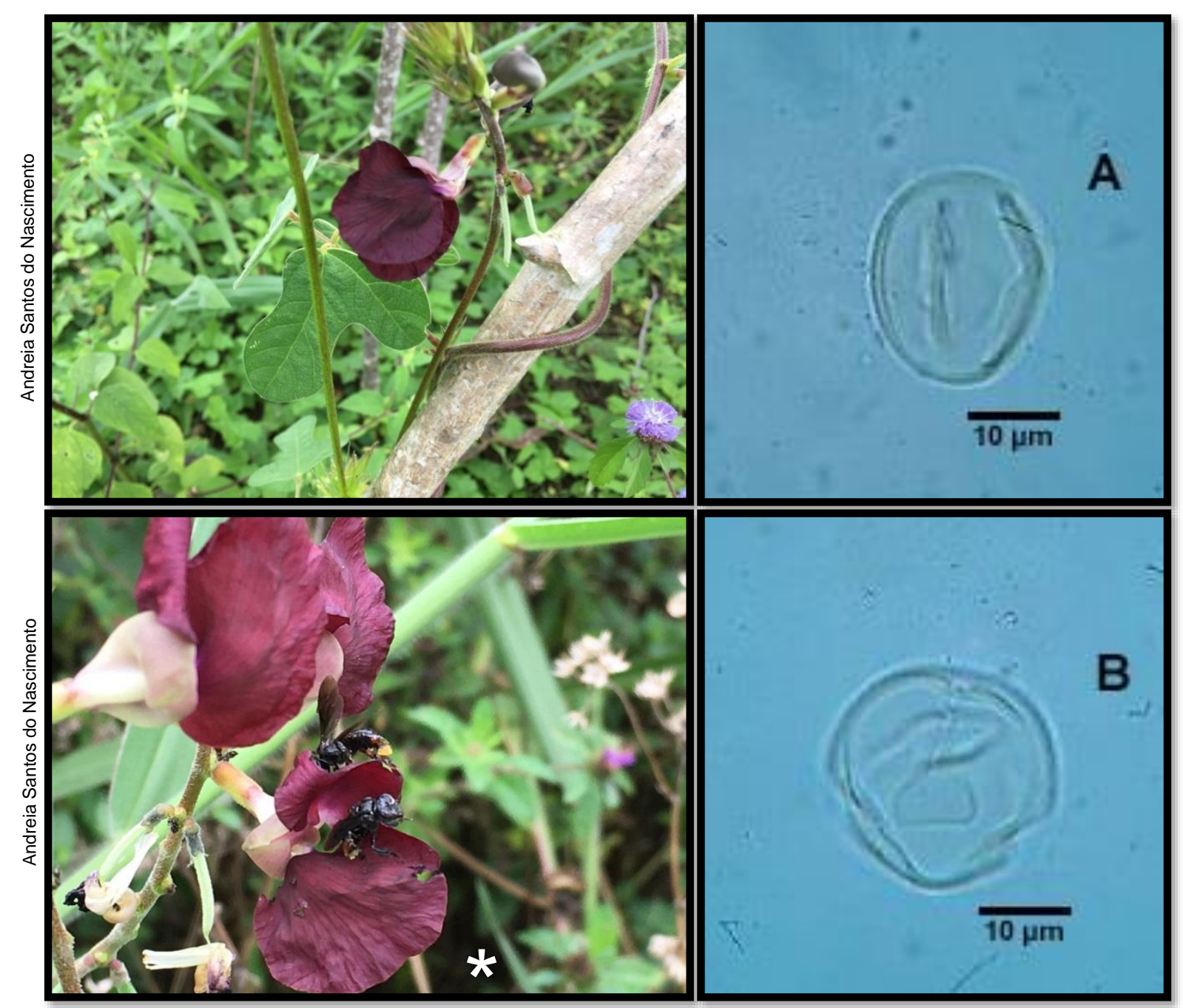

Descrição polínica: $A$ = vista equatorial e $B$ = vista polar, grão de pólen com simetria radial, isopolar, nômade, âmbito subtriangular, abertura polínica do tipo colporo, exina microrreticulada, tamanho médio, forma prolata esferoidal, eixo polar $=25,45$ $\mu \mathrm{m}$; eixo equatorial $=23,03 \mu \mathrm{m} ; \mathrm{P} / \mathrm{E}=1,10 \mu \mathrm{m}$.

*Abelha visitante floral: Trigona spinipes Fabricius, 1793. 


\section{Fabaceae - Faboideae}

Espécie: Stylosanthes viscosa (L.) Sw.

Nome comum: Alfafa-do-campo

Hábito de crescimento: herbáceo

Fonte de recurso trófico: pólen

Período de Floração: maio a agosto

No Palinoteca: PA 81

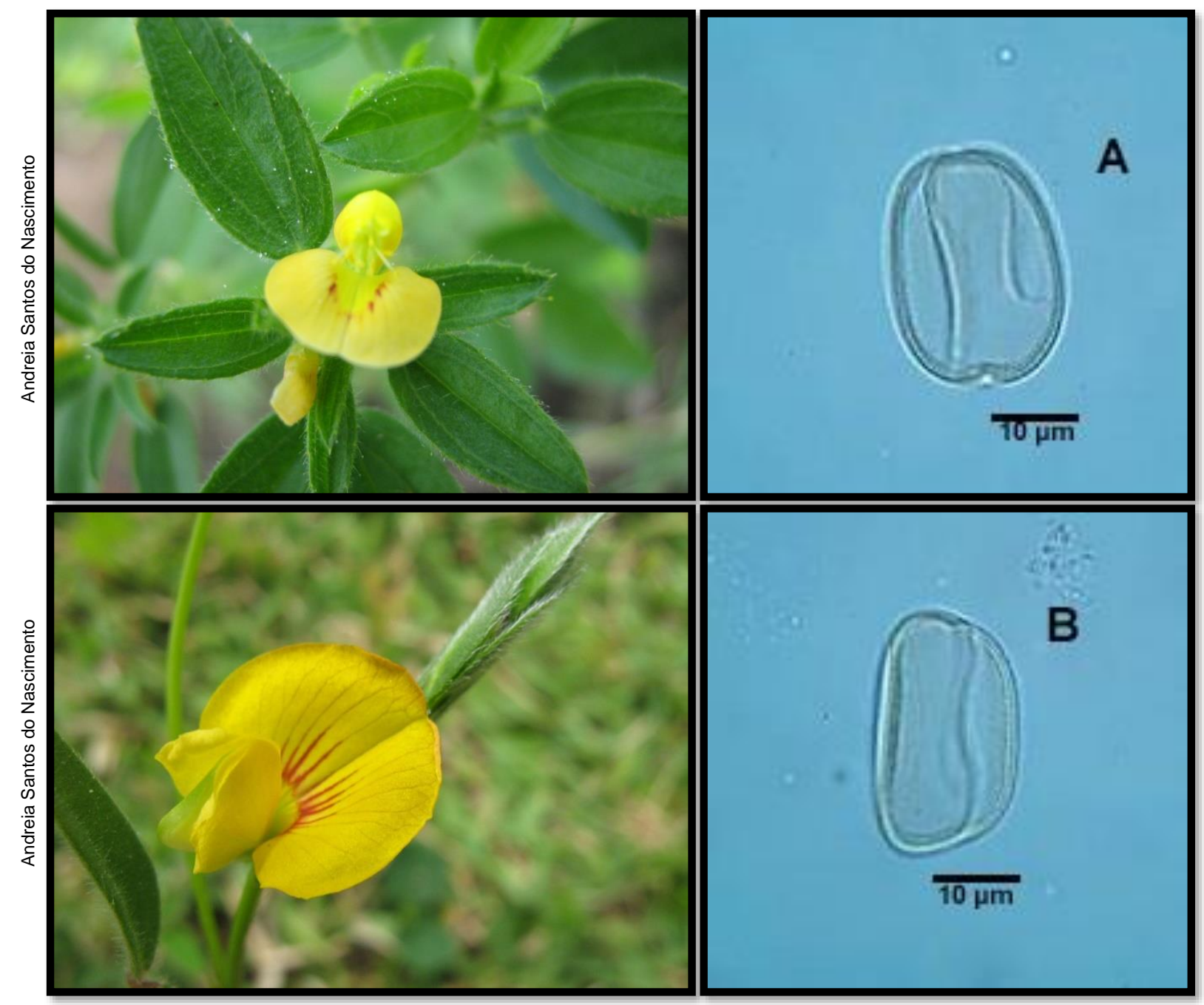

Descrição polínica: $A-B$ = vista equatorial, grão de pólen com simetria radial, isopolar, nômade, âmbito subtriangular, abertura polínica do tipo colpo, exina microrreticulada, tamanho médio, forma prolata, eixo polar $=28,48 \mu \mathrm{m}$; eixo equatorial $=18,78 \mu \mathrm{m} ; \mathrm{P} / \mathrm{E}=1,51 \mu \mathrm{m}$. 


\section{Fabaceae - Faboideae}

Espécie: Vigna unguiculata (L.) Walp.

Nome comum: Feijão-de-corda

Hábito de crescimento: herbáceo

Fonte de recurso trófico: pólen

Período de Floração: agosto a setembro

No Palinoteca: PA 63

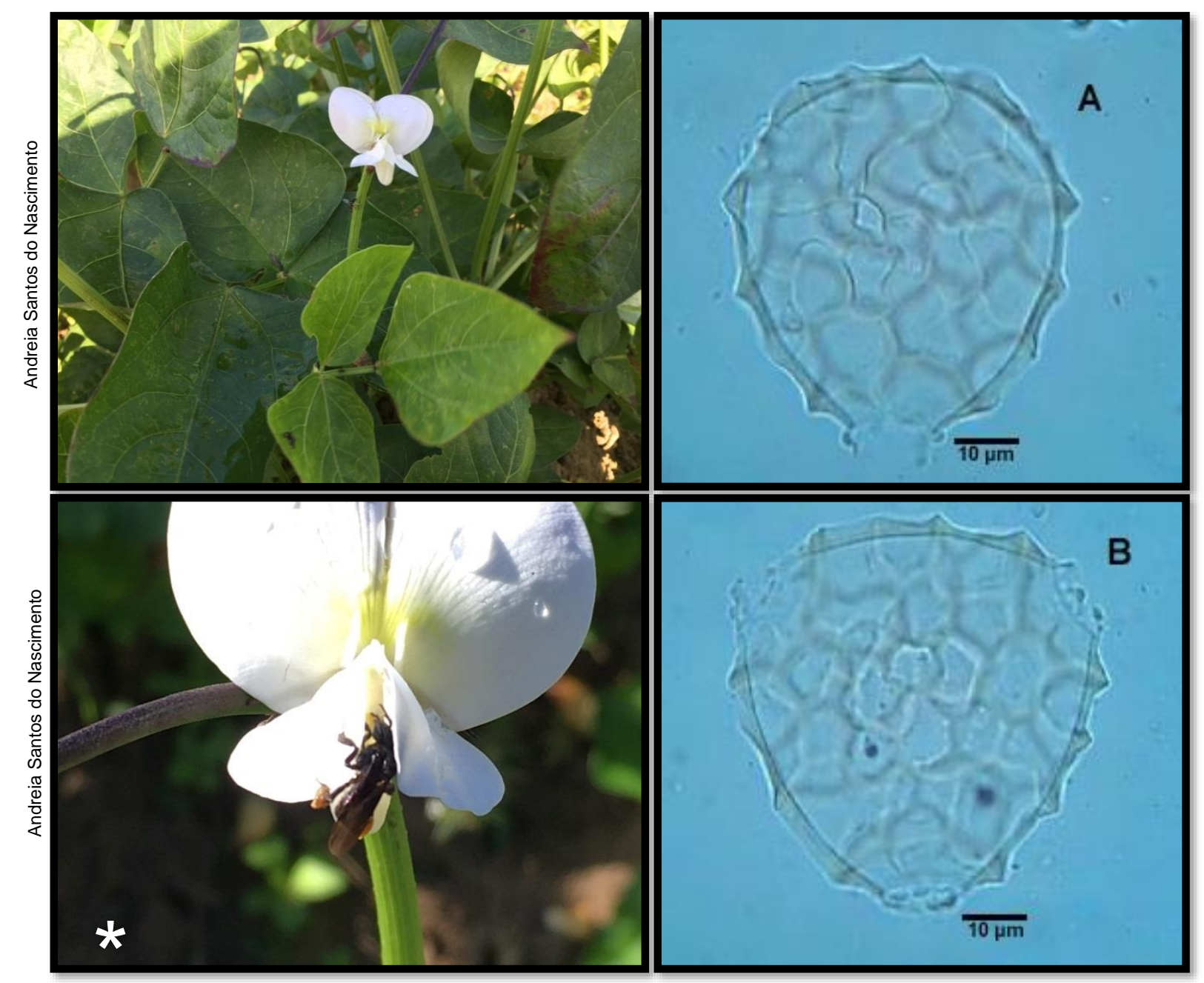

Descrição polínica: A-B = vista polar, grão de pólen com simetria radial, isopolar, nômade, âmbito subcircular, abertura polínica do tipo poro, exina reticulada/heterobrocada, tamanho grande, forma prolata esferoidal, eixo maior $=$ $55,45 \mu \mathrm{m}$; eixo menor $=52,12 \mu \mathrm{m} ; \mathrm{P} / \mathrm{E}=1,06 \mu \mathrm{m}$.

*Abelha visitante floral: Trigona spinipes Fabricius, 1793. 


\section{Fabaceae - Mimosoideae}

Espécie: Acacia sp.

Nome comum: Calumbi

Hábito de crescimento: arbóreo

Fonte de recurso trófico: néctar/pólen

Período de Floração: fevereiro a abril

No Palinoteca: PA 127
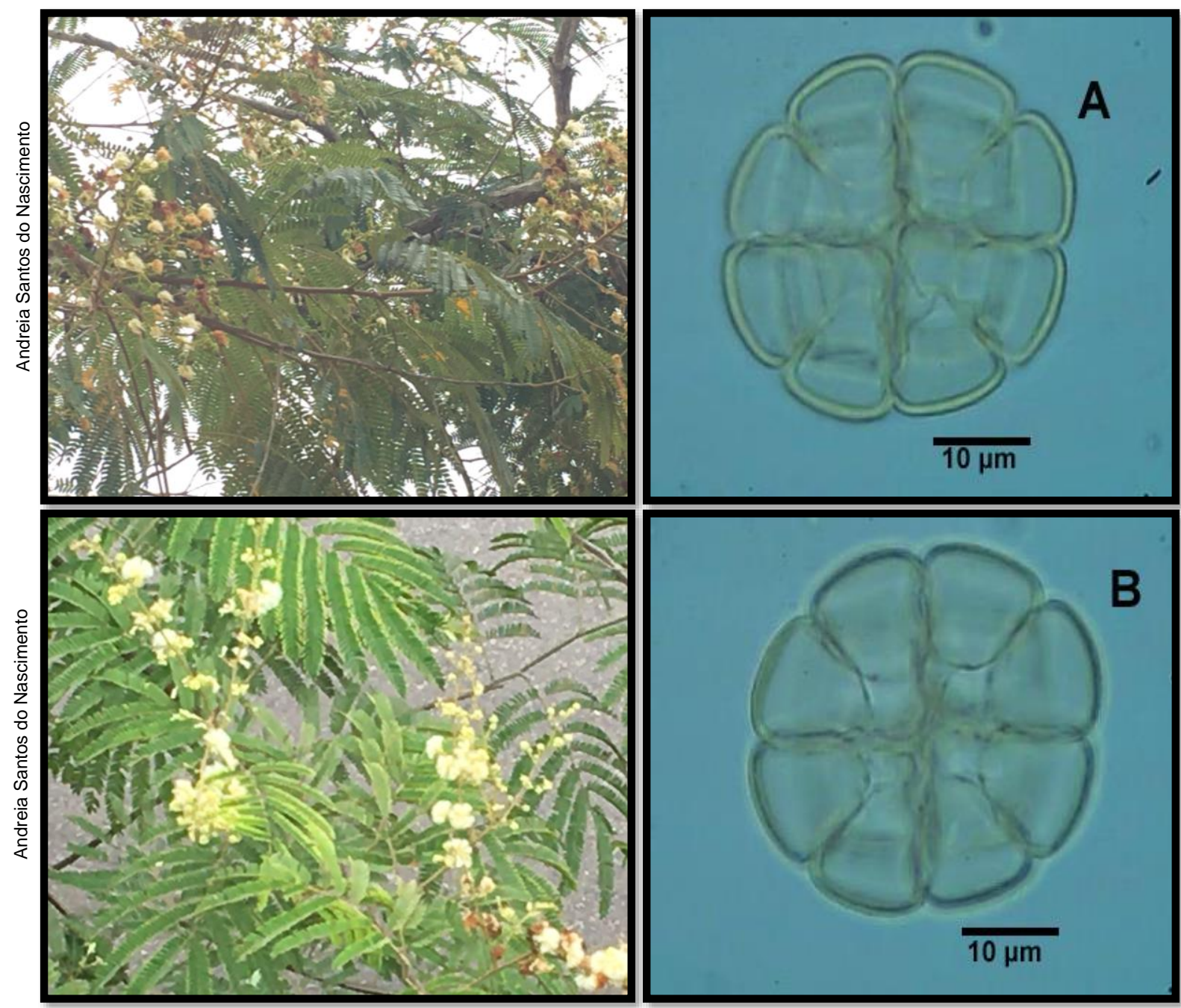

Descrição polínica: A-B = vista polar, grão de pólen com simetria radial, isopolar, políade, âmbito circular em vista frontal, exina psilada, tamanho grande, forma esferoidal, diâmetro do eixo polar $=59,39 \mu \mathrm{m}$; diâmetro do eixo equatorial $=59,09$ $\mu \mathrm{m} ; \mathrm{P} / \mathrm{E}=1,00 \mu \mathrm{m}$. 


\section{Fabaceae - Mimosoideae}

Espécie: Adenanthera pavonina L.

Nome comum: Carolina

Hábito de crescimento: arbóreo

Fonte de recurso trófico: néctar/pólen

Período de Floração: abril a outubro

No Palinoteca: PA 179
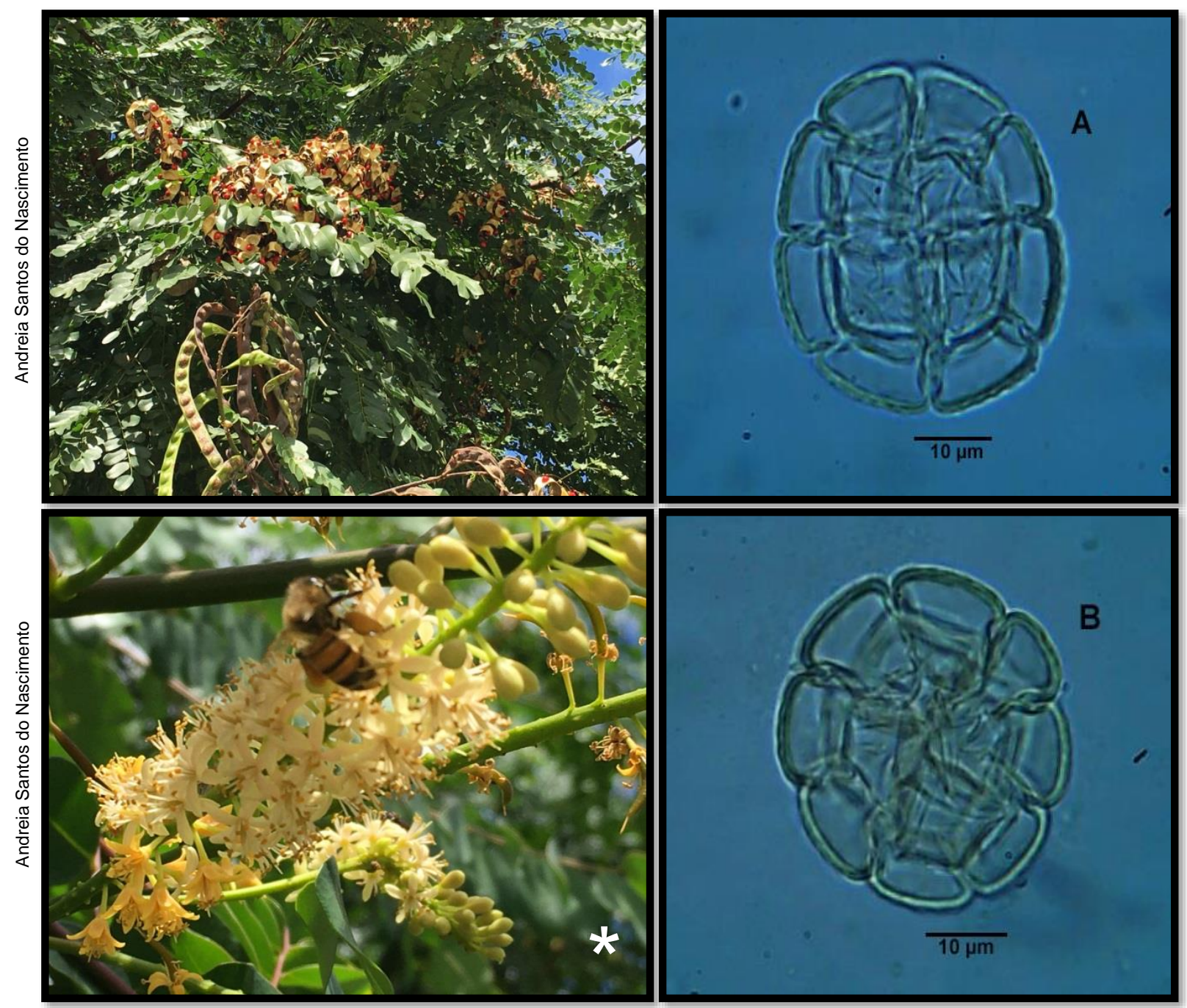

Descrição polínica: A-B = vista polar, grão de pólen com simetria radial, isopolar, políade, âmbito circular em vista frontal, exina microrreticulada, tamanho grande, forma subprolata, diâmetro do eixo polar $=52,42 \mu \mathrm{m}$; diâmetro do eixo equatorial $=$ 45,45 $\mu \mathrm{m} ; \mathrm{P} / \mathrm{E}=1,15 \mu \mathrm{m}$.

*Abelha visitante floral: Apis mellifera Linnaeus, 1758. 


\section{Fabaceae - Mimosoideae}

Espécie: Desmanthus virgatus (L.) Willd.

Nome comum: Jureminha

Hábito de crescimento: arbóreo

Fonte de recurso trófico: néctar/pólen

Período de Floração: abril a junho

No Palinoteca: NAS11
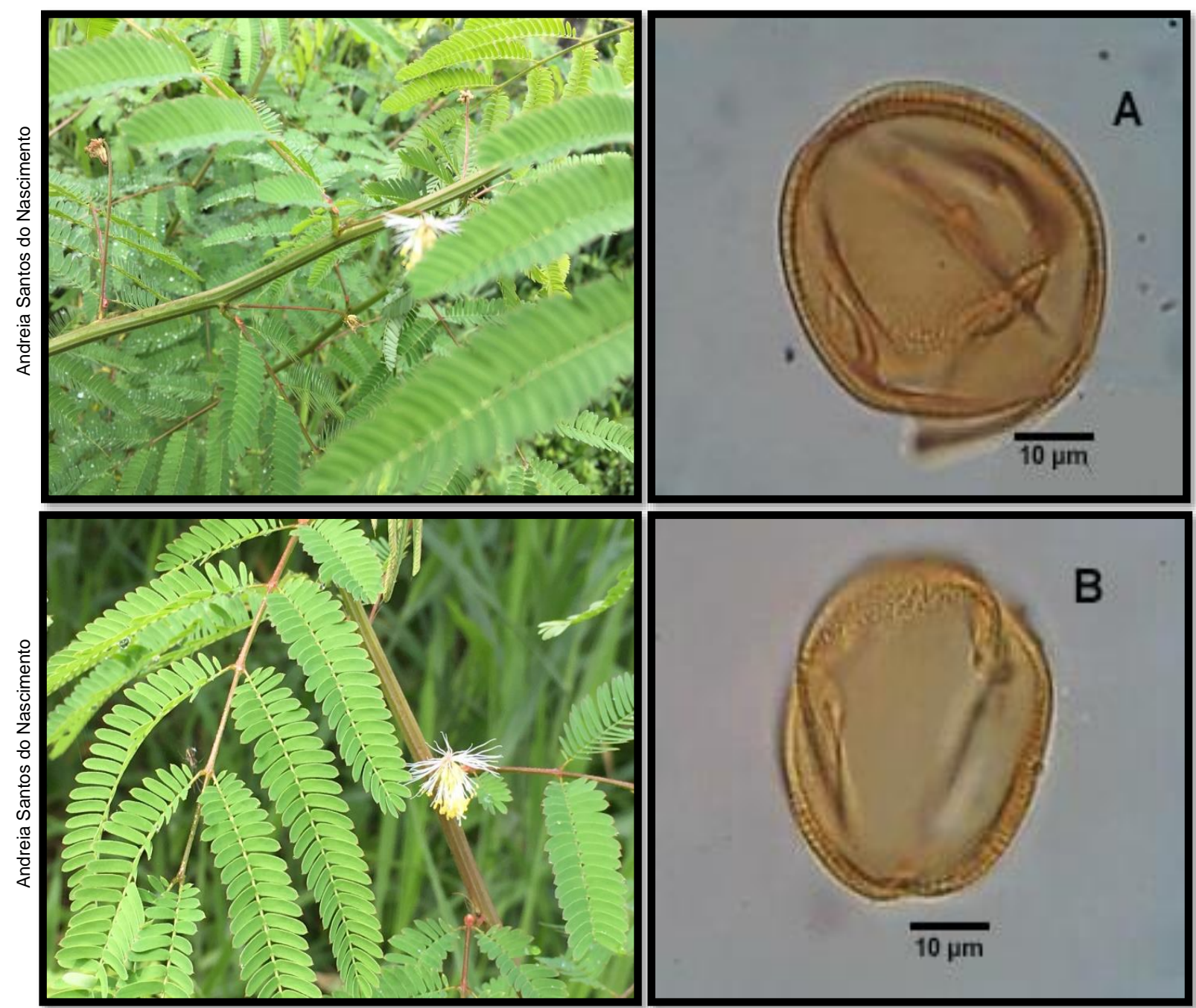

Descrição polínica: A-B = vista equatorial, grão de pólen com simetria radial, isopolar, nômade, âmbito subtriangular, abertura polínica do tipo colporo, exina reticulada, tamanho médio, forma prolata esferoidal, eixo polar $=42,72 \mu \mathrm{m}$; eixo equatorial $=$ $40,60 \mu \mathrm{m} ; \mathrm{P} / \mathrm{E}=1,06 \mu \mathrm{m}$. 


\section{Fabaceae - Mimosoideae}

Espécie: Inga edulis Mart.

Nome comum: Ingá-cipó

Hábito de crescimento: arbóreo

Fonte de recurso trófico: néctar/pólen

Período de Floração: agosto a dezembro No Palinoteca: PA 73
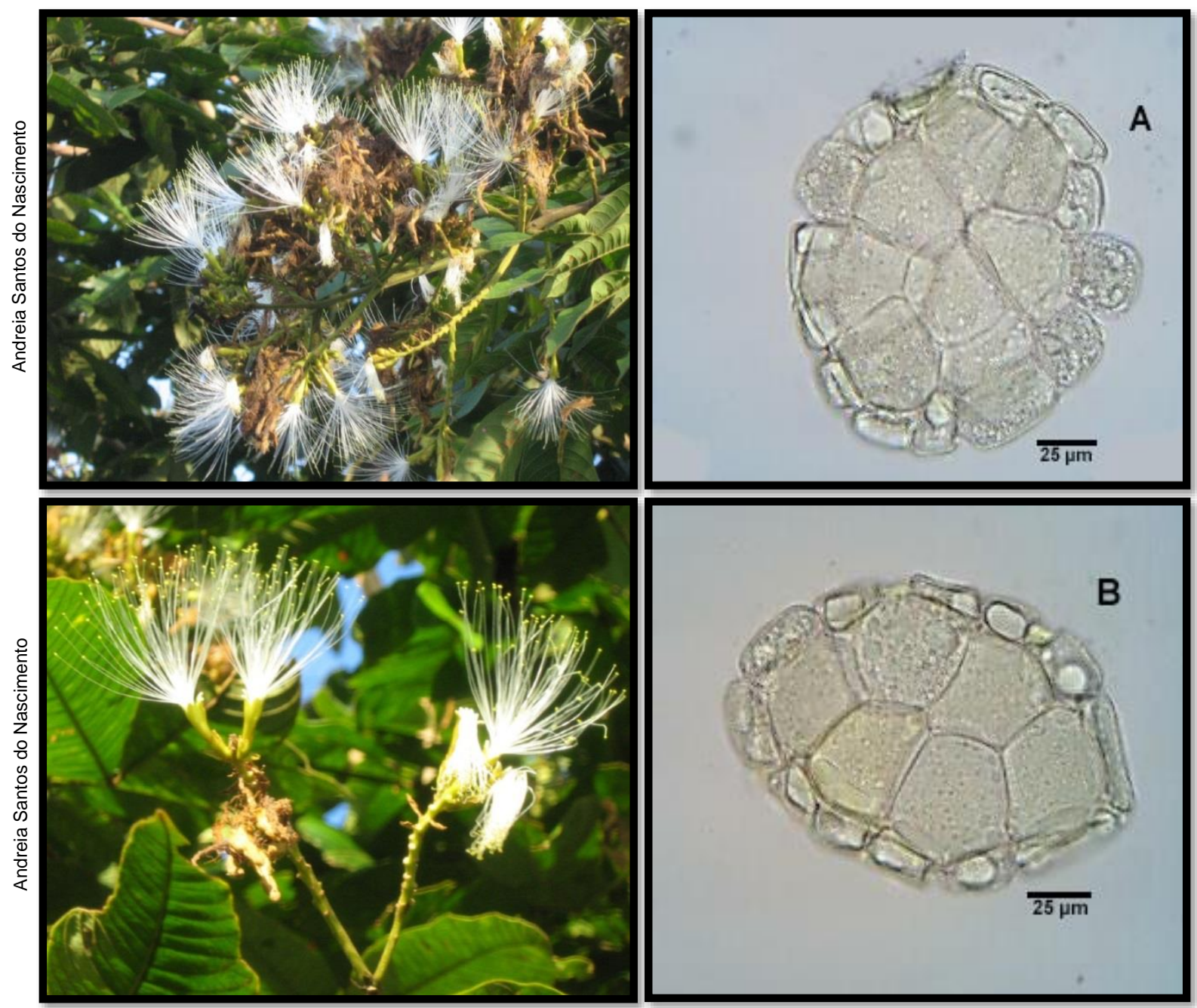

Descrição polínica: A-B = vista polar, grão de pólen com simetria radial, isopolar, políade, âmbito circular em vista frontal, exina regulada, tamanho muito grande, forma esferoidal, diâmetro do eixo polar $=144,96 \mu \mathrm{m}$; diâmetro do eixo equatorial $=$ $144,18 \mu \mathrm{m} ; \mathrm{P} / \mathrm{E}=1,00 \mu \mathrm{m}$. 


\section{Fabaceae - Mimosoideae}

Espécie: Leucaena leucocephala (Lam.) de Wit

Nome comum: Leucena

Hábito de crescimento: arbóreo

Fonte de recurso trófico: néctar/pólen

Período de Floração: setembro a dezembro No Palinoteca: PA 86
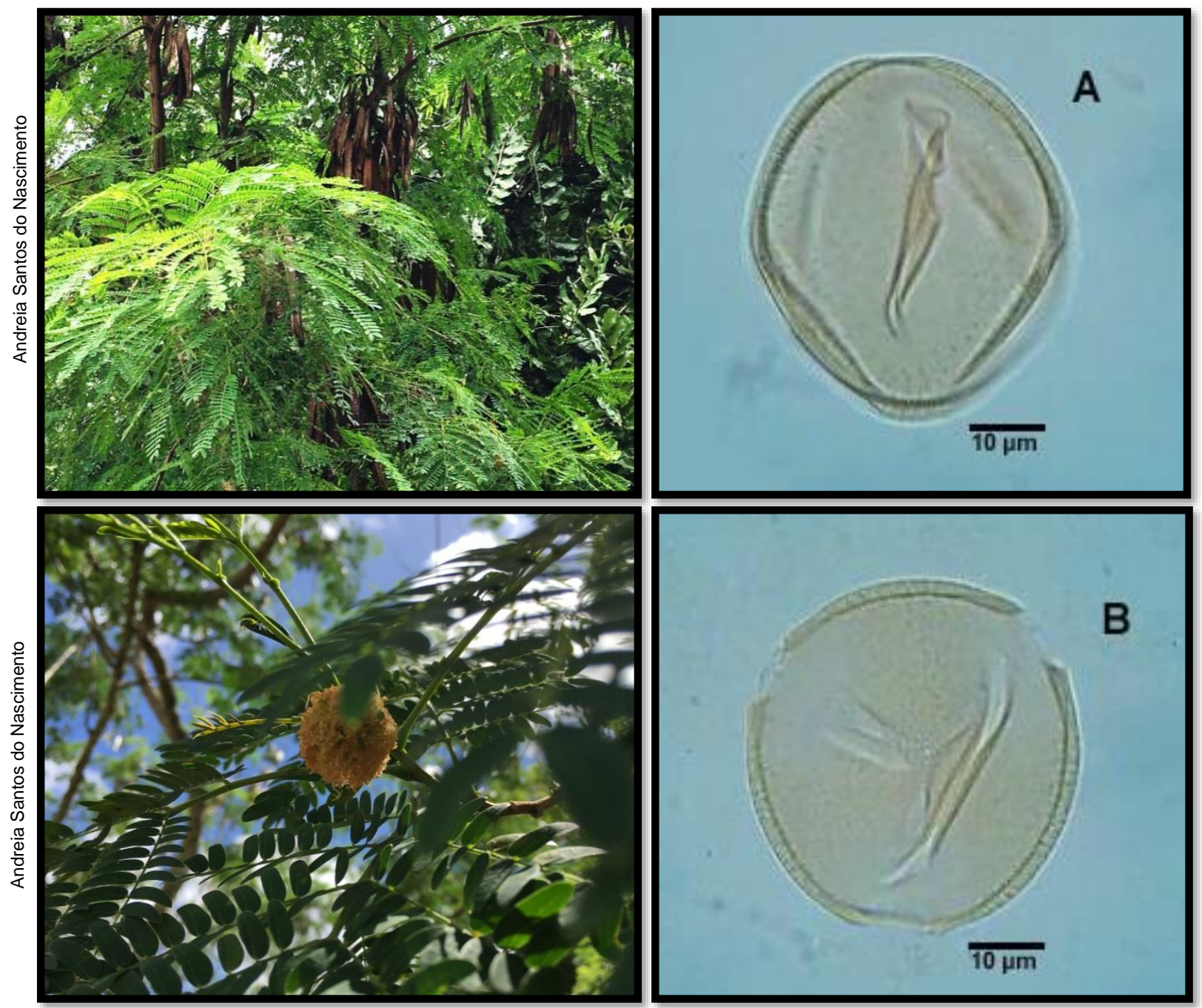

Descrição polínica: $A$ = vista equatorial e $B=$ vista polar, grão de pólen com simetria radial, isopolar, nômade, âmbito subtriangular, abertura polínica do tipo colporo, exina reticulada, tamanho médio, forma prolata esferoidal, eixo polar $=44,54 \mu \mathrm{m}$; eixo equatorial $=40,03 \mu \mathrm{m} ; \mathrm{P} / \mathrm{E}=1,16 \mu \mathrm{m}$. 


\section{Fabaceae - Mimosoideae}

Espécie: Mimosa arenosa (Willd.) Poir.

Nome comum: Jurema

Hábito de crescimento: arbustivo

Fonte de recurso trófico: néctar/pólen

Período de Floração: abril a julho; agosto a novembro No Palinoteca: PA 85

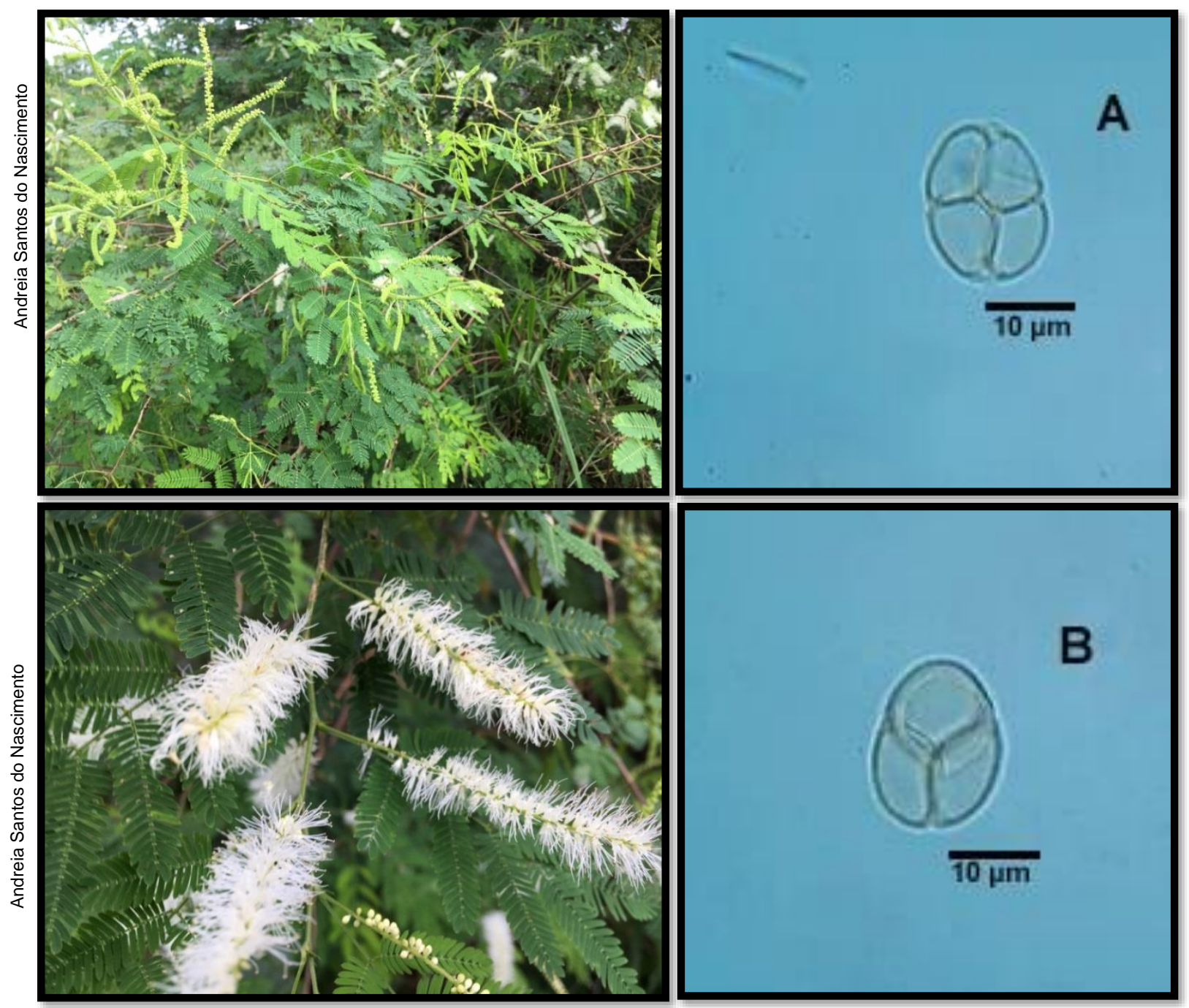

Descrição polínica: A-B = vista polar, grão de pólen com simetria radial, isopolar, tétrade, âmbito circular em vista frontal, exina areolada/verrucada, tamanho pequeno, forma esferoidal, eixo maior $=17,57 \mu \mathrm{m}$; eixo menor $=17,27 \mu \mathrm{m} ; \mathrm{P} / \mathrm{E}=$ $1,00 \mu \mathrm{m}$. 


\section{Fabaceae - Mimosoideae}

Espécie: Mimosa caesalpiniaefolia Benth.

Nome comum: Sabiá

Hábito de crescimento: arbustivo

Fonte de recurso trófico: néctar

Período de Floração: junho a setembro

No Palinoteca: PA 174

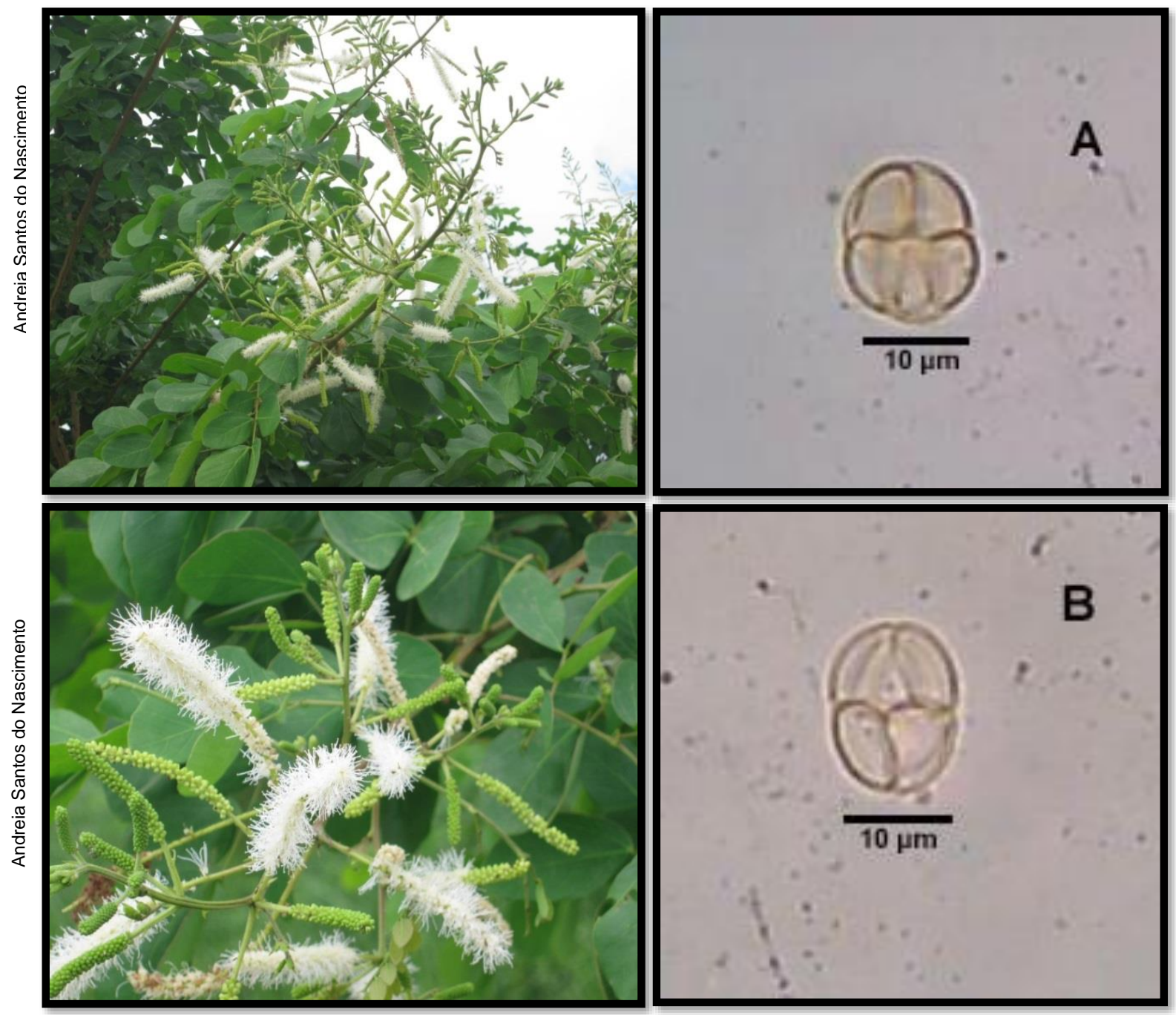

Descrição polínica: A-B = vista polar, grão de pólen com simetria radial, isopolar, políade, âmbito circular em vista frontal, exina areolada/verrucada, tamanho pequeno, forma esferoidal, eixo maior $=10,60 \mu \mathrm{m}$; eixo menor $=10,30 \mu \mathrm{m} ; \mathrm{P} / \mathrm{E}=1,00 \mu \mathrm{m}$. 


\section{Fabaceae - Mimosoideae}

Espécie: Mimosa candollei R.Grether.

Nome comum: Arranhadeira

Hábito de crescimento: herbáceo

Fonte de recurso trófico: néctar

Período de Floração: março a julho

No Palinoteca: NAS12
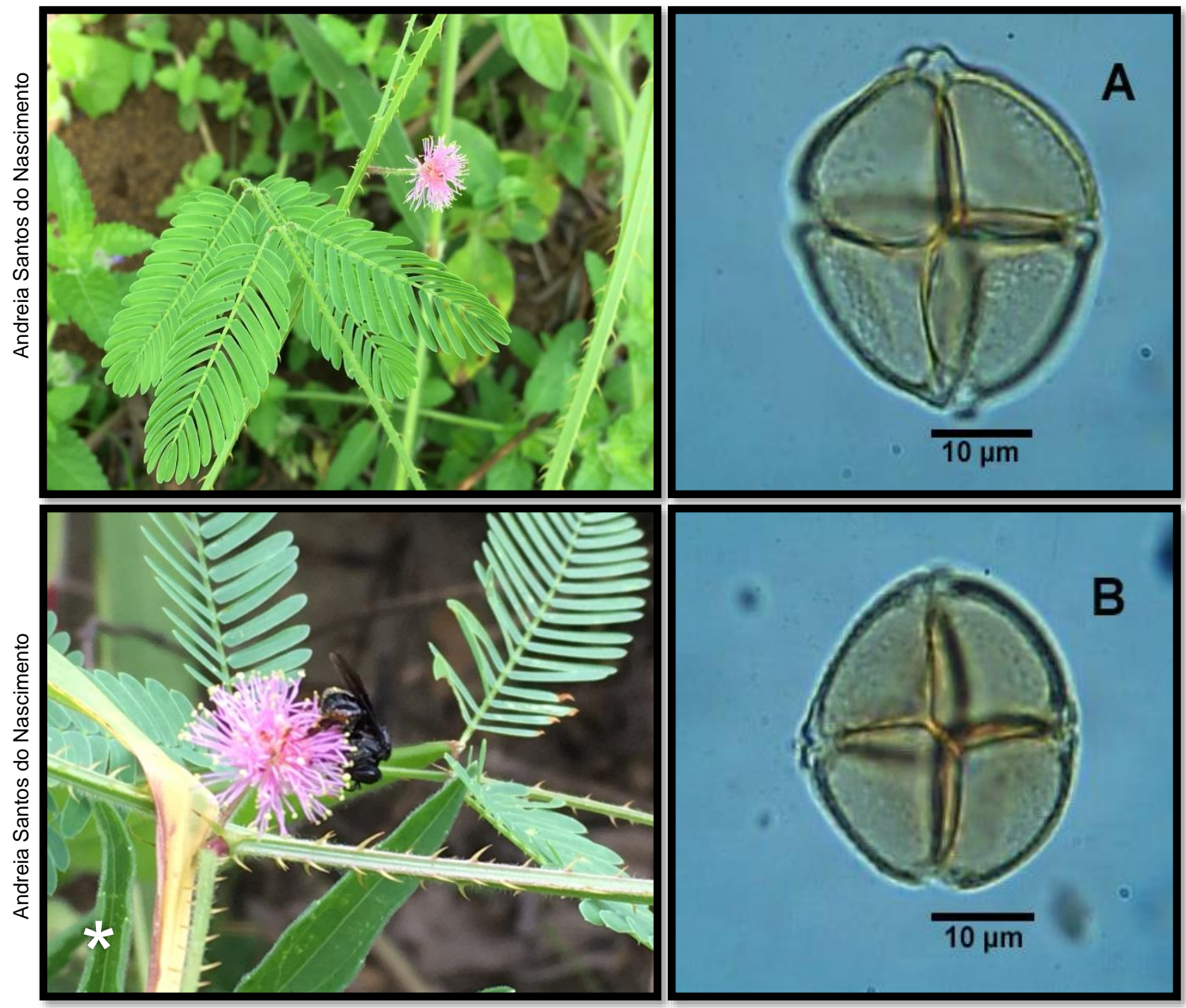

Descrição polínica: A-B = vista polar, grão de pólen com simetria radial, isopolar, tétrade, âmbito circular em vista frontal, exina areolada/verrucada, tamanho médio, forma esferoidal, eixo maior $=43,63 \mu \mathrm{m}$; eixo menor $=43,33 \mu \mathrm{m} ; \mathrm{P} / \mathrm{E}=1,00 \mu \mathrm{m}$. ${ }^{*}$ Abelha visitante floral: Trigona spinipes Fabricius, 1793. 


\section{Fabaceae - Mimosoideae}

Espécie: Mimosa modesta Mart.

Nome comum: Maliça

Hábito de crescimento: herbáceo

Fonte de recurso trófico: néctar/pólen

Período de Floração: março a julho

No Palinoteca: NAS13
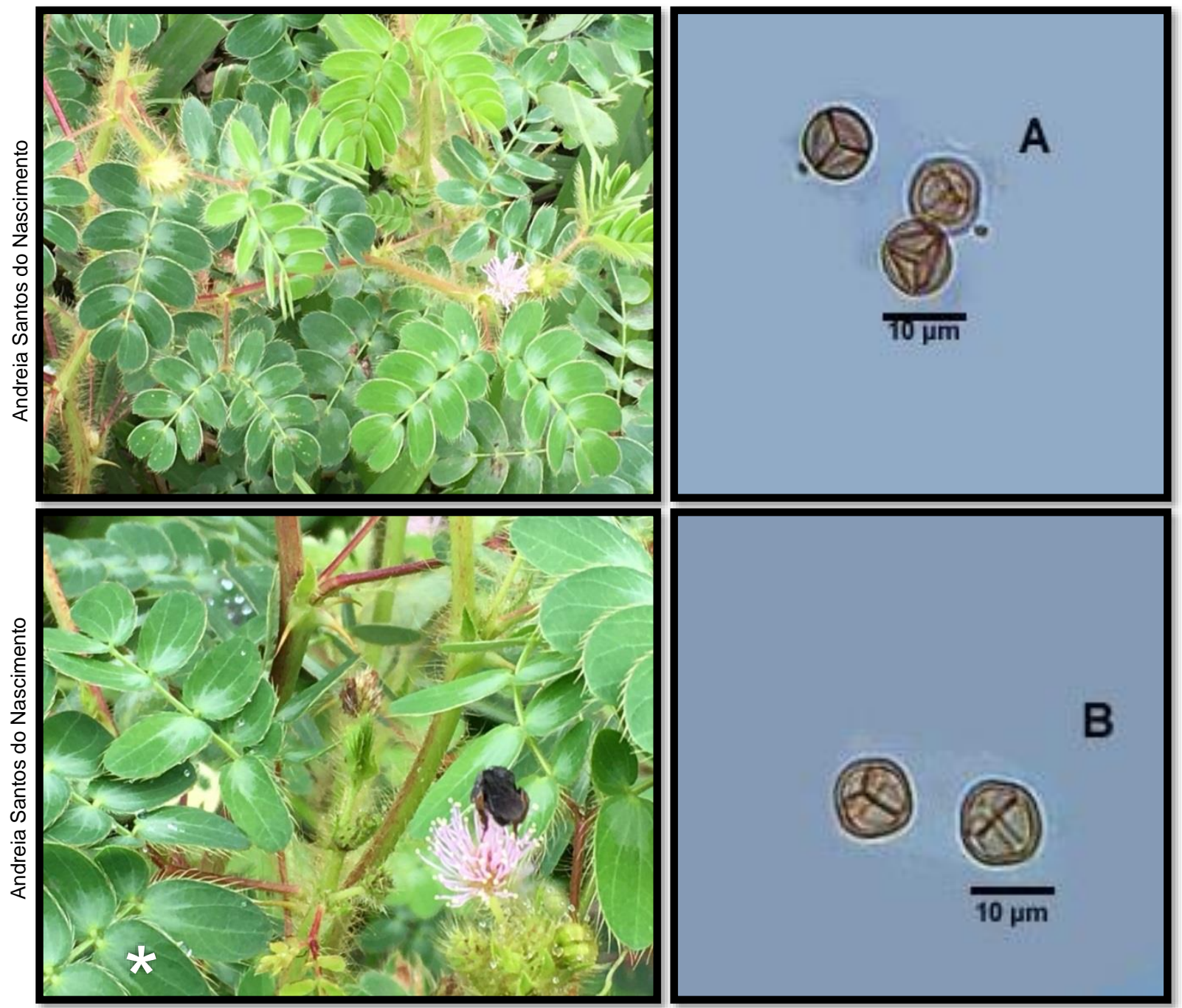

Descrição polínica: $A-B$ = vista polar, grão de pólen com simetria radial, isopolar, tétrade, âmbito circular em vista frontal, exina areolada, tamanho muito pequeno, forma esferoidal, eixo maior $=7,87 \mu \mathrm{m}$; eixo menor $=7,87 \mu \mathrm{m} ; \mathrm{P} / \mathrm{E}=1,00 \mu \mathrm{m}$.

*Abelha visitante floral: Trigona spinipes Fabricius, 1793. 


\section{Fabaceae - Mimosoideae}

Espécie: Mimosa pudica L.

Nome comum: Dormideira

Hábito de crescimento: herbáceo

Fonte de recurso trófico: néctar/pólen

Período de Floração: março a julho

No Palinoteca: PA 23

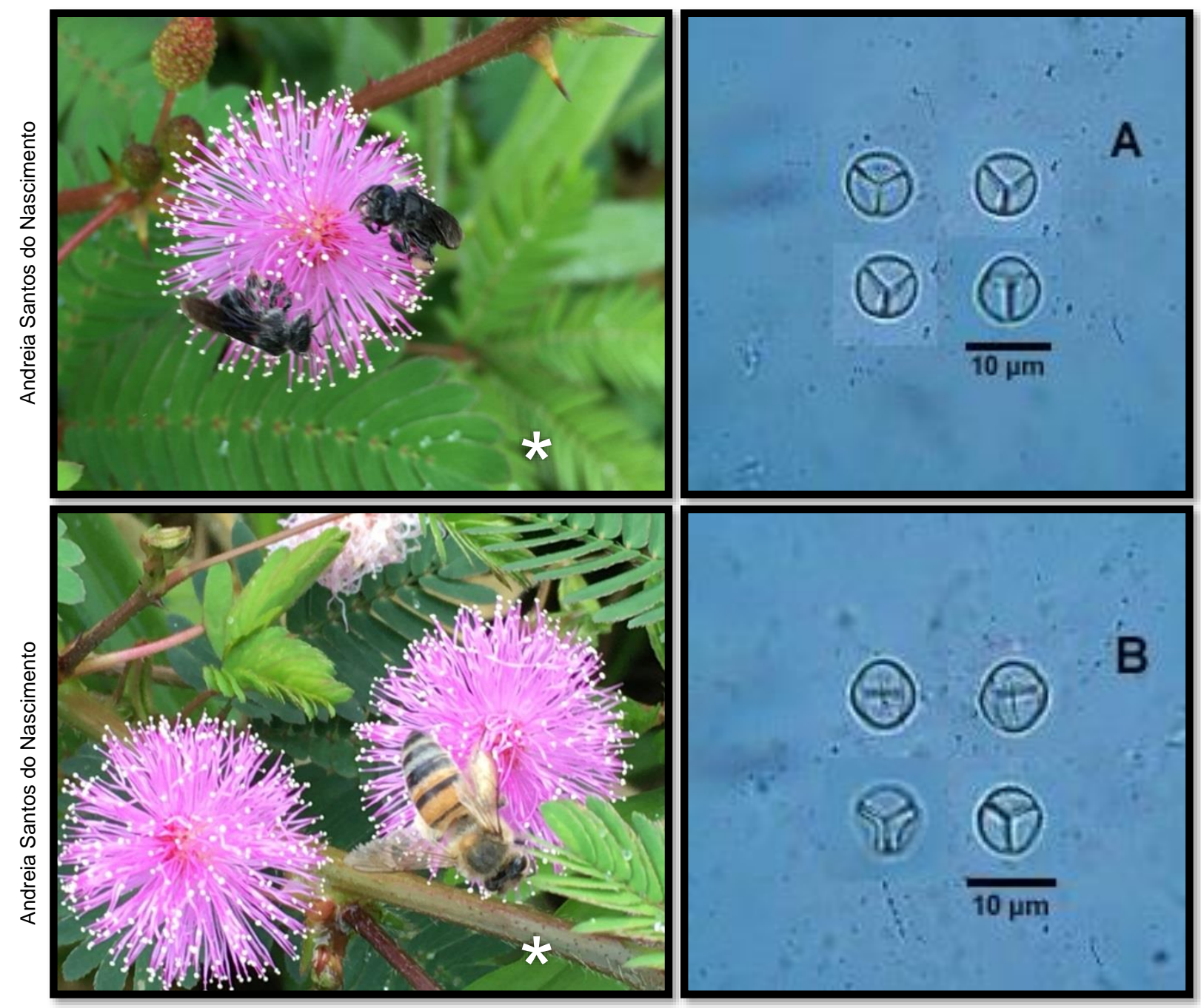

Descrição polínica: A-B = vista polar, grão de pólen com simetria radial, isopolar, tétrade, âmbito circular em vista frontal, exina areolada, tamanho muito pequeno, forma esferoidal, eixo maior = 7,57 $\mu \mathrm{m}$; eixo menor = 7,57 $\mu \mathrm{m}$; P/E =1,00 $\mu \mathrm{m}$.

*Abelha visitante floral: Trigona spinipes Fabricius, 1793 e Apis mellifera Linnaeus, 1758. 


\section{Fabaceae - Mimosoideae}

Espécie: Mimosa sensitiva L.

Nome comum: Unha-de-gato

Hábito de crescimento: herbáceo

Fonte de recurso trófico: néctar/pólen

Período de Floração: março a julho

No Palinoteca: NAS14
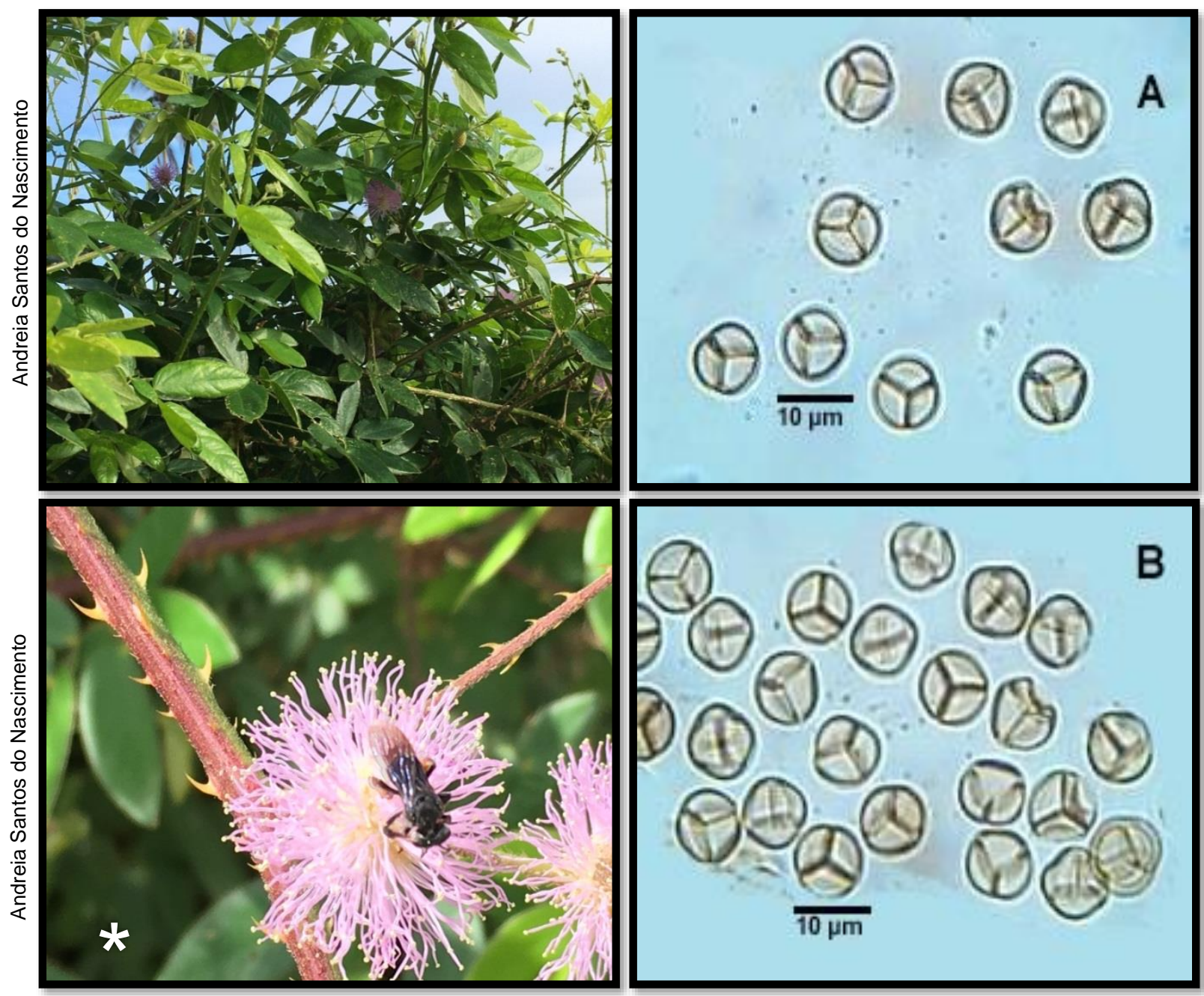

Descrição polínica: A-B = vista polar, grão de pólen com simetria radial, isopolar, tétrade, âmbito circular em vista frontal, exina areolada, tamanho muito pequeno, forma esferoidal, eixo maior $=8,18 \mu \mathrm{m}$; eixo menor $=8,18 \mu \mathrm{m} ; \mathrm{P} / \mathrm{E}=1,00 \mu \mathrm{m}$.

*Abelha visitante floral: Trigona spinipes Fabricius, 1793. 


\section{Fabaceae - Mimosoideae}

Espécie: Mimosa tenuiflora (Willd.) Poir.

Nome comum: Jurema-preta

Hábito de crescimento: arbóreo

Fonte de recurso trófico: néctar/pólen

Período de Floração: abril a julho; agosto a novembro

$\mathbf{N}^{\circ}$ Palinoteca: NAS15
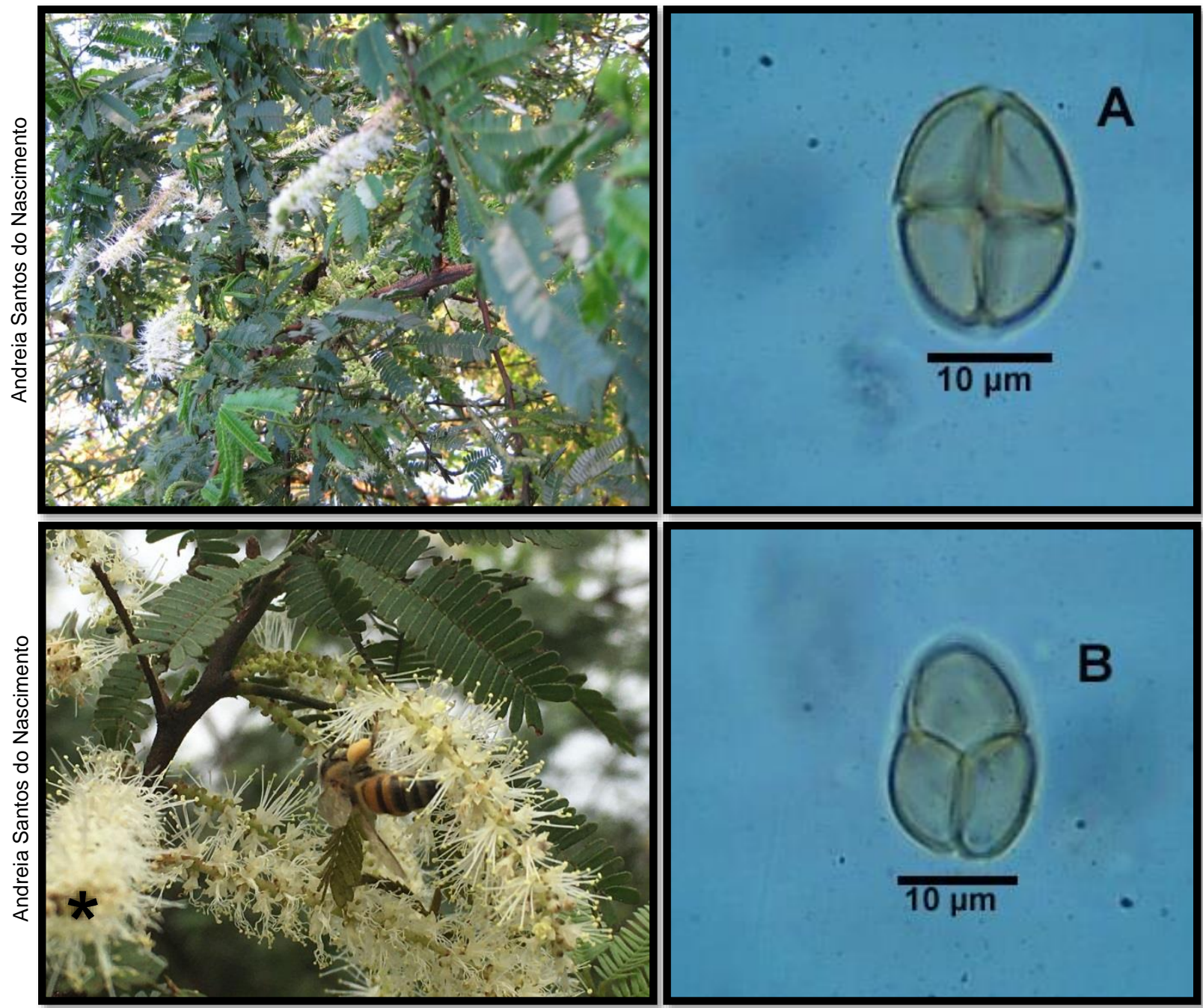

Descrição polínica: A-B = vista polar, grão de pólen com simetria radial, isopolar, tétrade, âmbito circular em vista frontal, exina areolada/verrucada, tamanho pequeno, forma esferoidal, eixo maior $=18,18 \mu \mathrm{m}$; eixo menor $=17,87 \mu \mathrm{m} ; \mathrm{P} / \mathrm{E}=$ $1,01 \mu \mathrm{m}$.

*Abelha visitante floral: Apis mellifera Linnaeus, 1758. 


\section{Fabaceae - Papilionoideae}

Espécie: Arachis hypogaea L.

Nome comum: Amendoim

Hábito de crescimento: herbáceo

Fonte de recurso trófico: pólen

Período de Floração: março a julho

No Palinoteca: PA 184
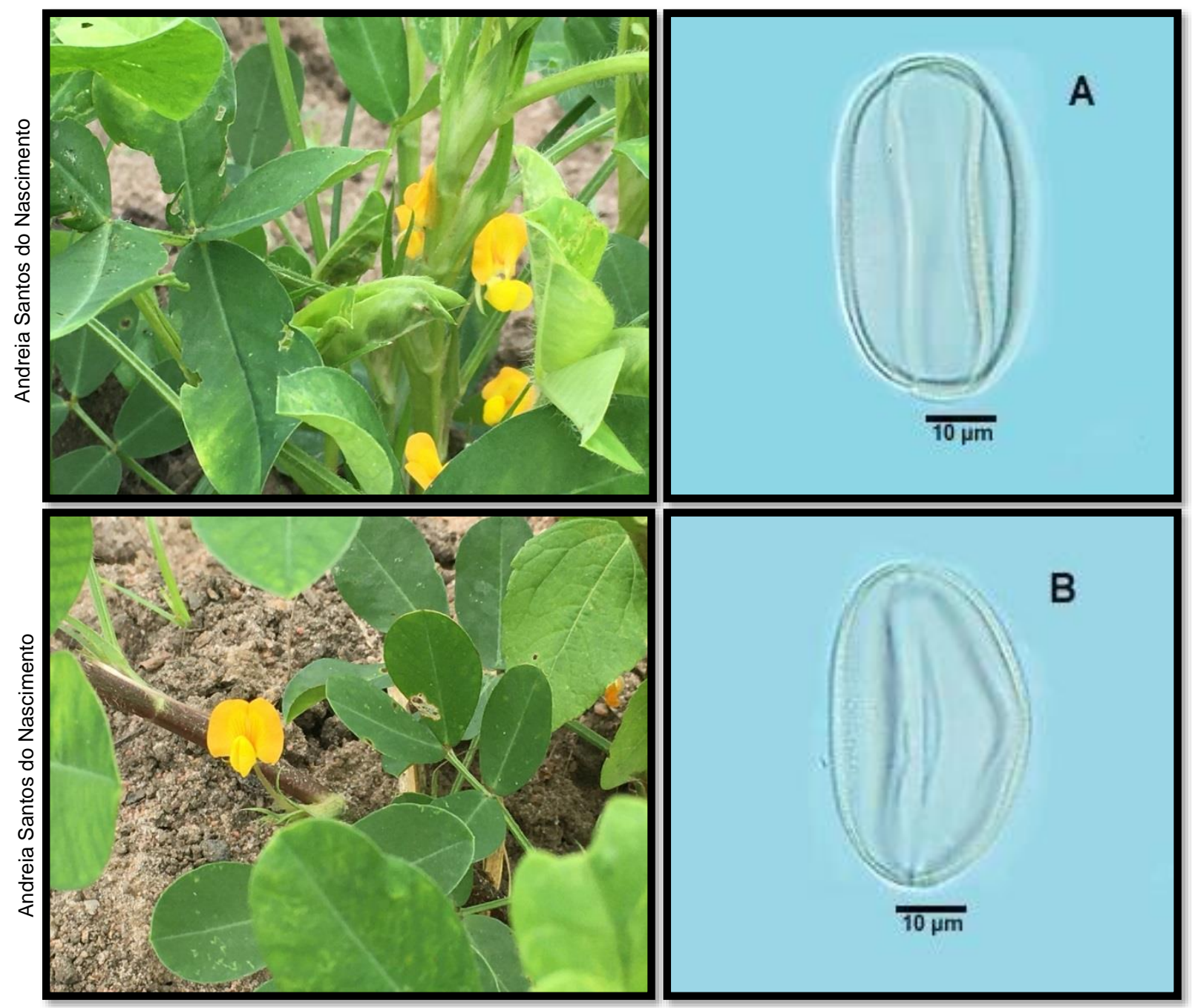

Descrição polínica: $A-B$ = vista equatorial, grão de pólen com simetria radial, isopolar, nômade, âmbito subtriangular, abertura polínica do tipo colpo, exina microrreticulada, tamanho médio, forma prolata, eixo maior $=44,54 \mu \mathrm{m}$; eixo menor $=26,96 \mu \mathrm{m} ; \mathrm{P} / \mathrm{E}=1,65 \mu \mathrm{m}$. 


\section{Fabaceae - Papilionoideae}

Espécie: Zornia diphylla (L.) Pers.

Nome comum: Arrozinho-do-campo

Hábito de crescimento: herbáceo

Fonte de recurso trófico: pólen

Período de Floração: março a julho

No Palinoteca: PA 37
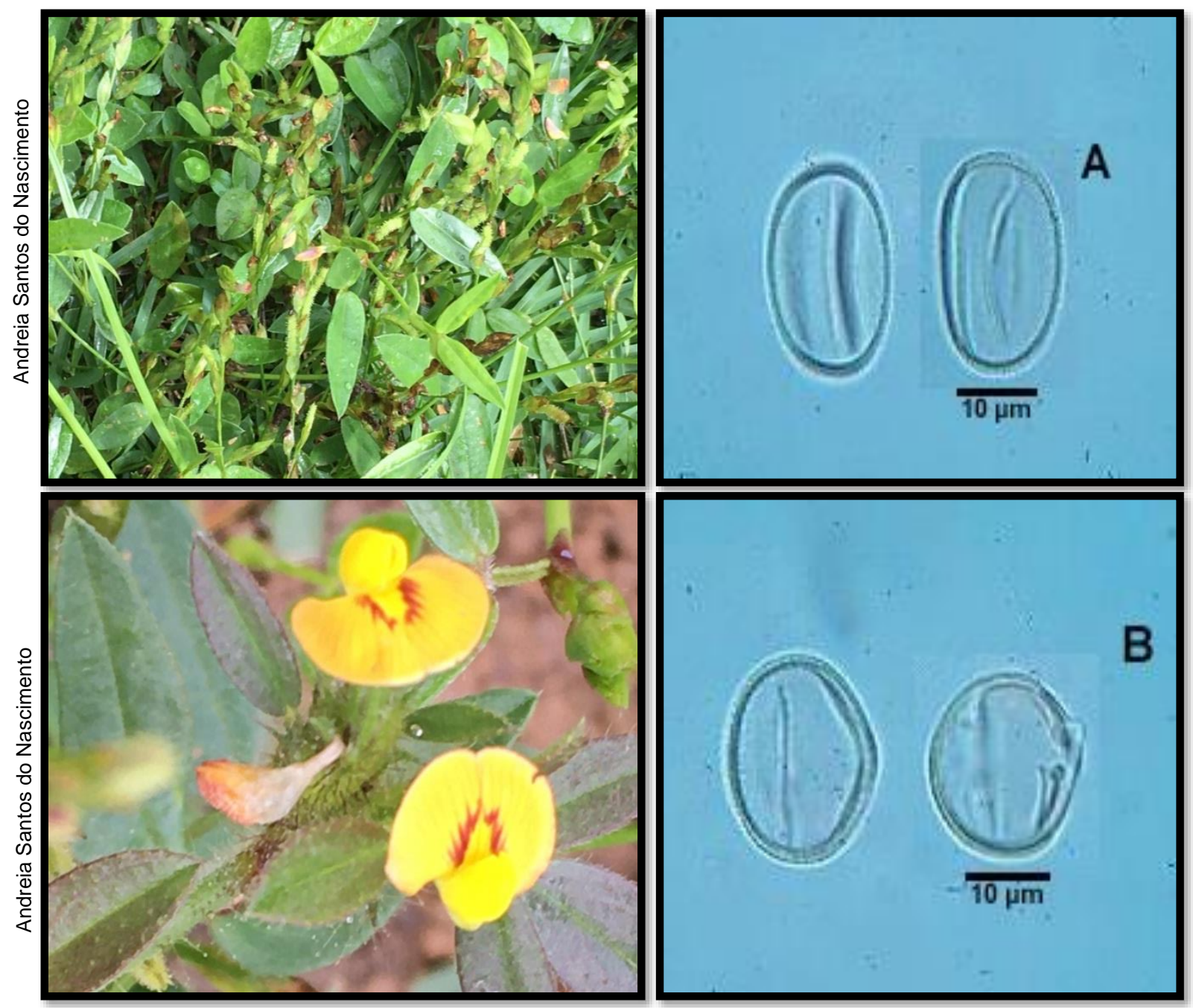

Descrição polínica: $A-B=$ vista equatorial, grão de pólen com simetria radial, isopolar, nômade, âmbito subtriangular, abertura polínica do tipo colpo, exina microrreticulada, tamanho médio, forma prolata, eixo maior $=25,45 \mu \mathrm{m}$; eixo menor $=$ $16,96 \mu \mathrm{m} ; \mathrm{P} / \mathrm{E}=1,50 \mu \mathrm{m}$. 


\section{Lamiaceae}

Espécie: Hyptis suaveolens Poit.

Nome comum: Bamburral; betônica-brava

Hábito de crescimento: herbáceo

Fonte de recurso trófico: néctar

Período de Floração: abril a agosto

No Palinoteca: NAS16

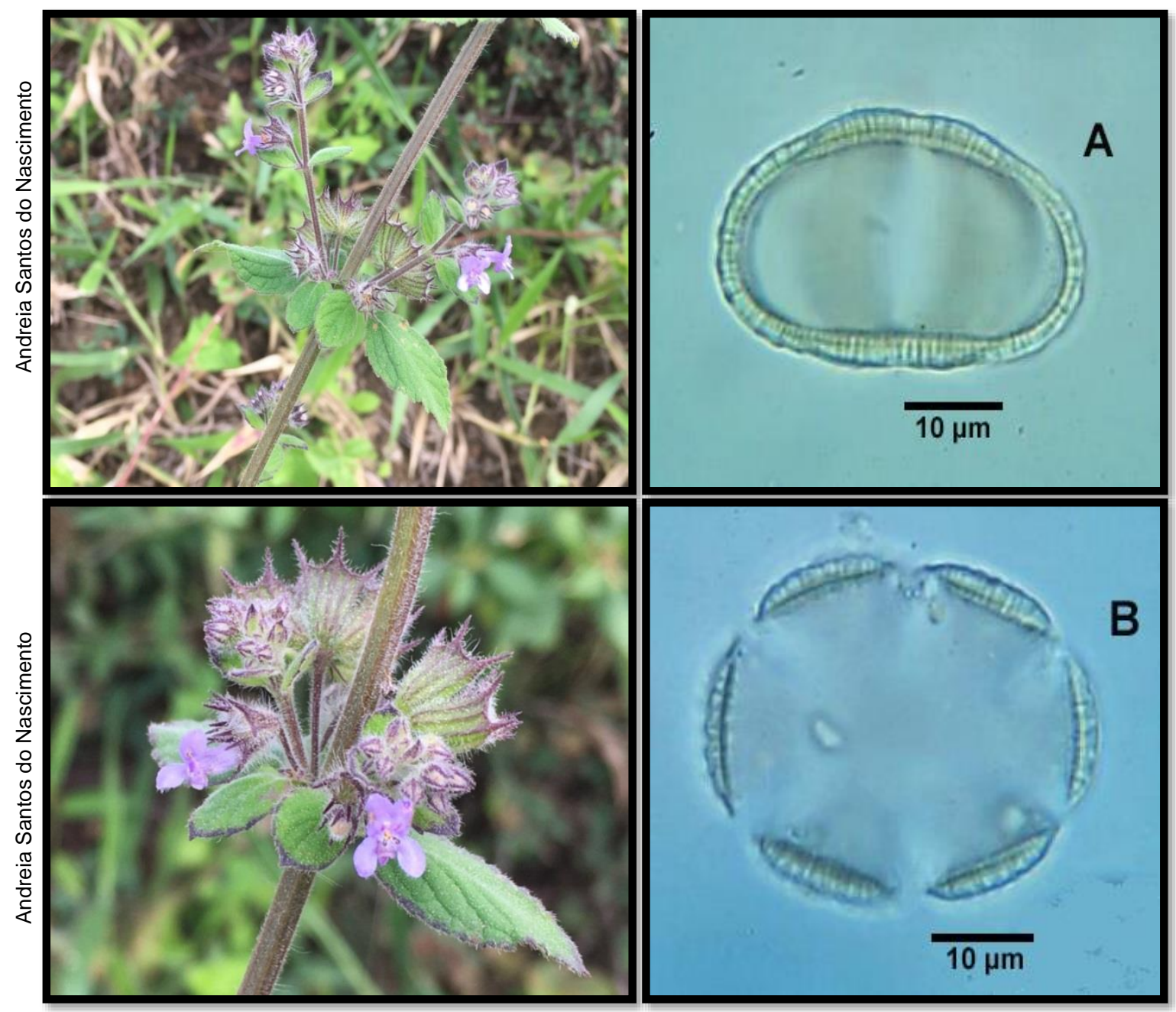

Descrição polínica: $A$ = vista equatorial e $B$ = vista polar, grão de pólen com simetria radial, isopolar, nômade, âmbito circular, abertura polínica do tipo colpo, exina microrreticulada, tamanho grande, forma prolato esferoidal, eixo maior $=52,12 \mu \mathrm{m}$; eixo menor $=51,21 \mu \mathrm{m} ; \mathrm{P} / \mathrm{E}=1,00 \mu \mathrm{m}$. 


\section{Lamiaceae}

Espécie: Marsypianthes chamaedrys (Vahl) Kuntze

Nome comum: Hortelã-do-campo

Hábito de crescimento: herbáceo

Fonte de recurso trófico: néctar

Período de Floração: abril a agosto

No Palinoteca: PA 64
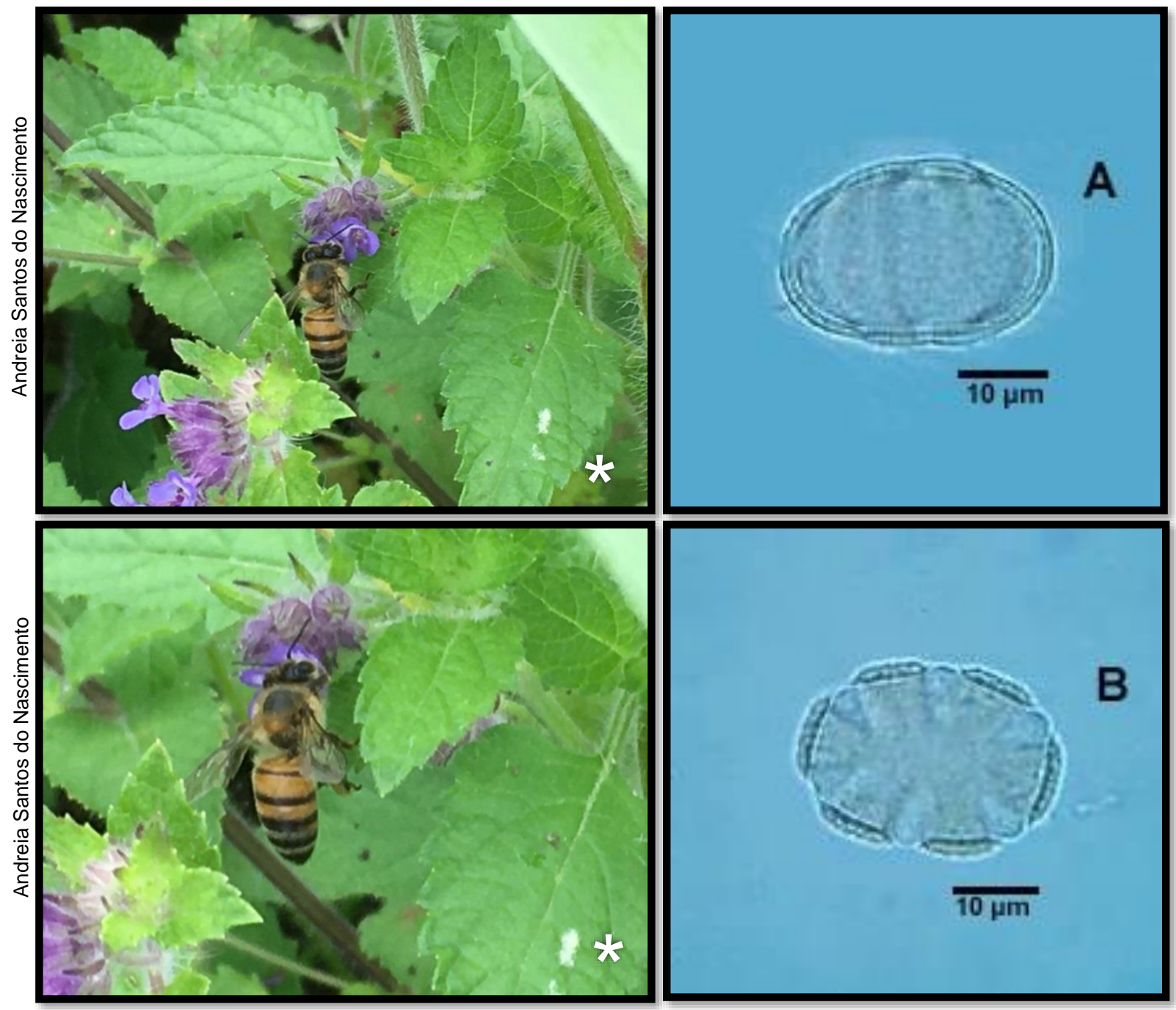

Descrição polínica: $A$ = vista equatorial e $B=$ vista polar, grão de pólen com simetria radial, isopolar, nômade, âmbito subcircular, abertura polínica do tipo colpo, exina reticulada/heterobrocada, tamanho médio, forma subprolata, eixo maior $=44,84 \mu \mathrm{m}$; eixo menor $=34,84 \mu \mathrm{m} ; \mathrm{P} / \mathrm{E}=1,28 \mu \mathrm{m}$.

*Abelha visitante floral: Apis mellifera Linnaeus, 1758. 


\section{Lamiaceae}

Espécie: Ocimum basilicum L.

Nome comum: Manjericão

Hábito de crescimento: herbáceo

Fonte de recurso trófico: néctar

Período de Floração: agosto a dezembro

No Palinoteca: PA 22
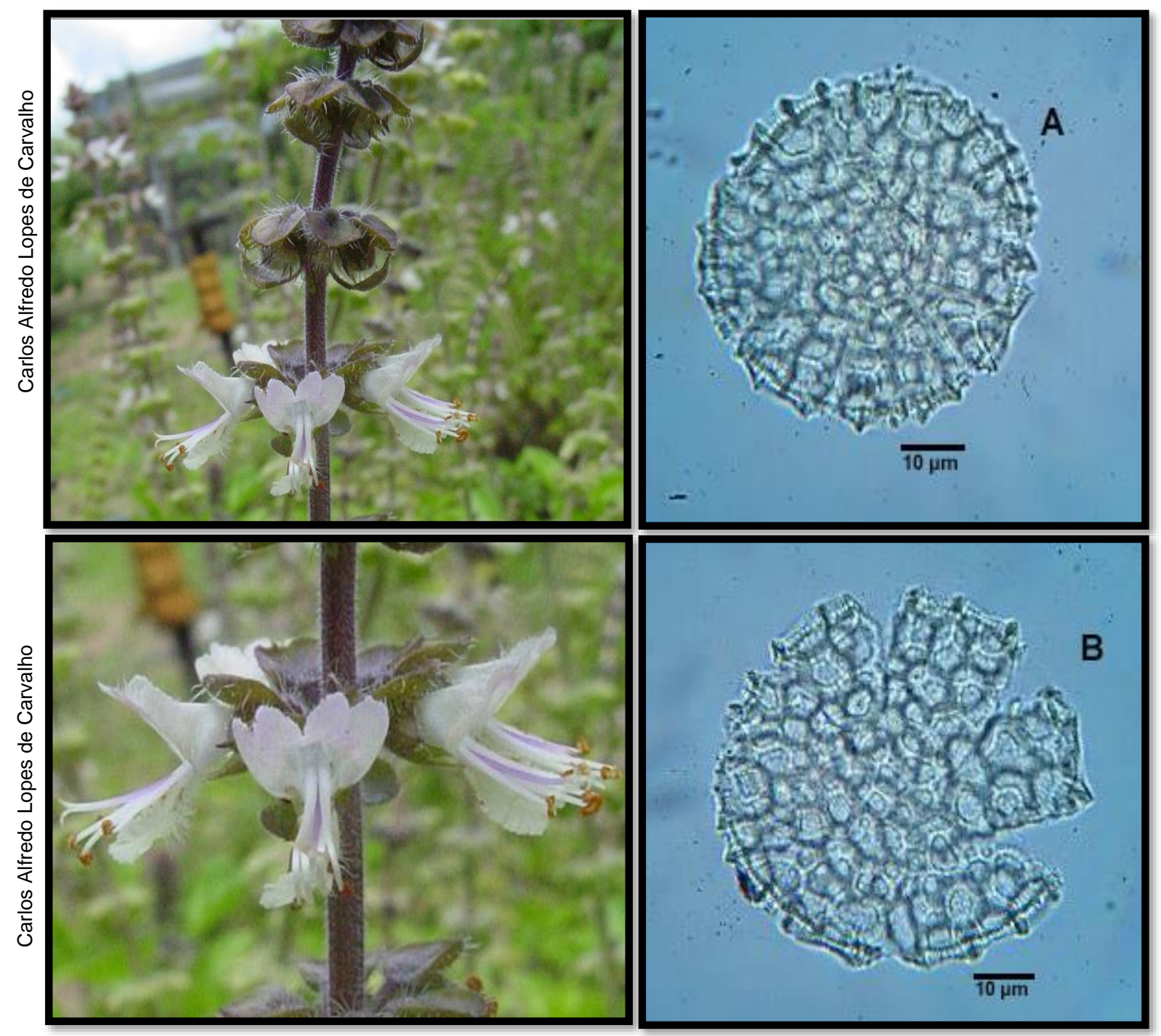

Descrição polínica: $A-B$ = vista polar, grão de pólen com simetria radial, isopolar, nômade, âmbito circular, abertura polínica do tipo colpo, exina reticulada/heterobrocada, tamanho grande, forma esferoidal, diâmetro do eixo polar $=51,51 \mu \mathrm{m}$; diâmetro do eixo equatorial $=51,51 \mu \mathrm{m} ; \mathrm{P} / \mathrm{E}=1,00 \mu \mathrm{m}$. 


\section{Lamiaceae}

Espécie: Ocimum gratissimum L.

Nome comum: Alfavaca

Hábito de crescimento: herbáceo

Fonte de recurso trófico: néctar/pólen

Período de Floração: fevereiro a maio No Palinoteca: PA 109
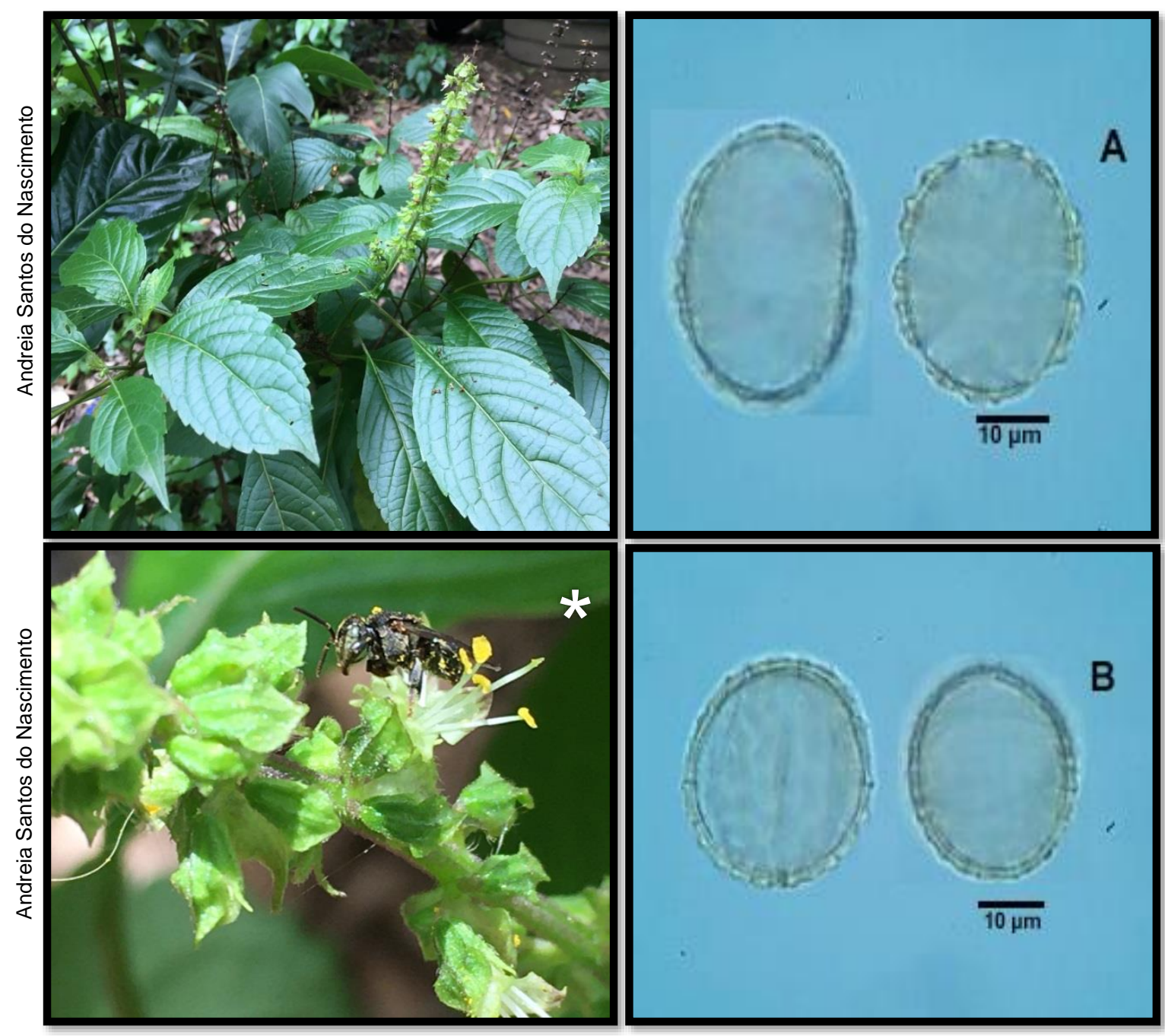

Descrição polínica: $A$ = vista polar e $B$ = vista equatorial, grão de pólen com simetria radial, isopolar, nômade, âmbito subcircular, abertura polínica do tipo colpo, exina reticulada, tamanho médio, forma subprolata, eixo maior $=31,81 \mu \mathrm{m}$; eixo menor $=$ 26,66 $\mu \mathrm{m} ; \mathrm{P} / \mathrm{E}=1,19 \mu \mathrm{m}$.

${ }^{*}$ Abelha visitante floral: Nannotrigona testaceicornis Lepeletier, 1836. 


\section{Lamiaceae}

Espécie: Rhaphiodon echinus (Nees \& Mart.) Schauer

Nome comum: Beton; falsa-menta

Hábito de crescimento: herbáceo

Fonte de recurso trófico: néctar

Período de Floração: abril a julho

No Palinoteca: PA 39

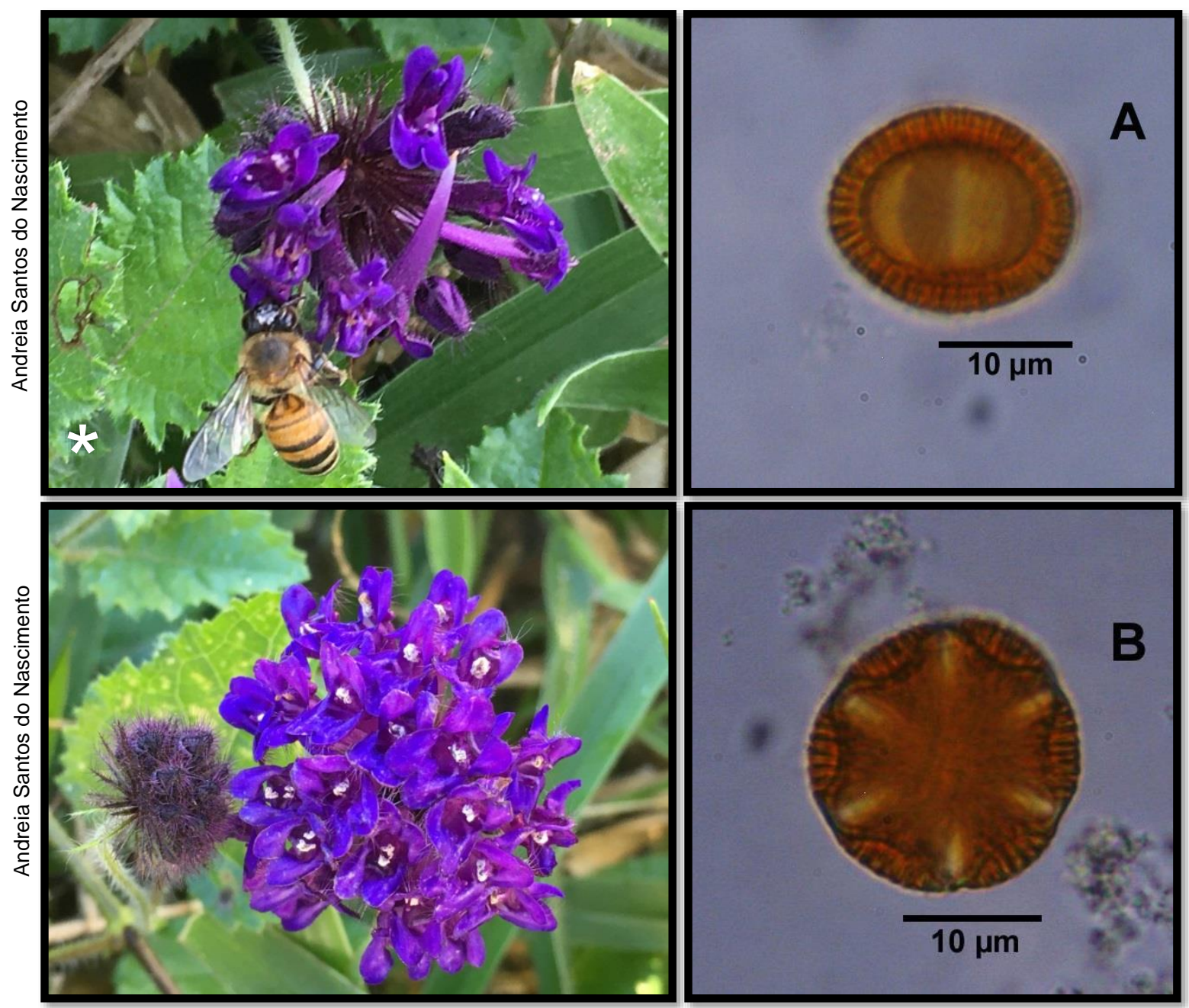

Descrição polínica: $A$ = vista polar e $B=$ vista equatorial, grão de pólen com simetria radial, isopolar, nômade, âmbito subcircular, abertura polínica do tipo colpo, exina reticulada, tamanho médio, forma oblata, diâmetro do eixo polar $=20,00 \mu \mathrm{m}$; diâmetro do eixo equatorial $=28,78 \mu \mathrm{m} ; \mathrm{P} / \mathrm{E}=0,69 \mu \mathrm{m}$.

${ }^{*}$ Abelha visitante floral: Apis mellifera Linnaeus, 1758. 


\section{Lamiaceae}

Espécie: Struthanthus flexicaulis (Mart.) Mart.

Nome comum: Erva-de-passarinho

Hábito de crescimento: herbáceo

Fonte de recurso trófico: néctar

Período de Floração: abril a junho

No Palinoteca: PA 84
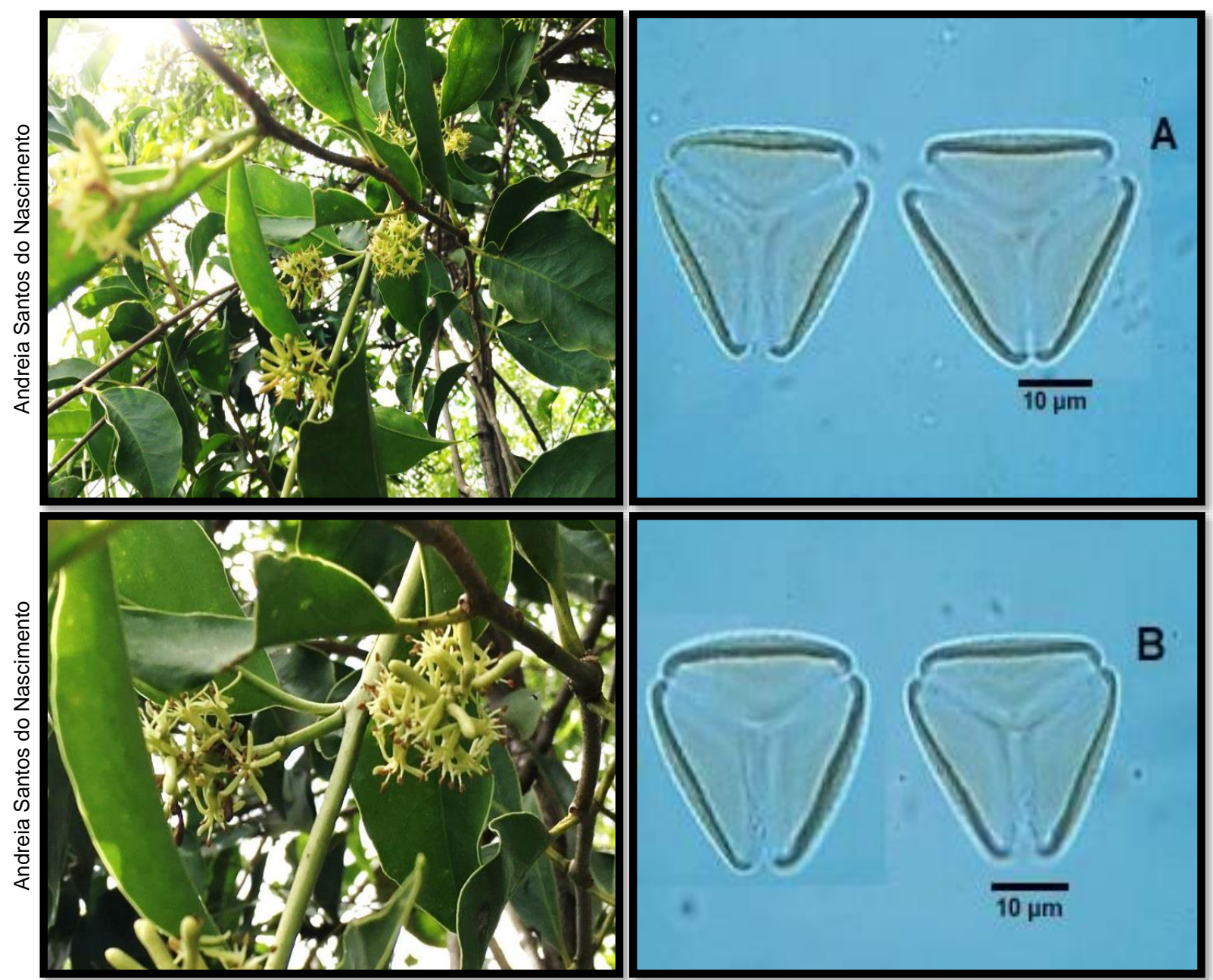

Descrição polínica: A-B = vista polar, grão de pólen com simetria radial, isopolar, nômade, âmbito triangular, abertura polínica do tipo colpo, exina microrreticulada, tamanho médio, forma oblata esferoidal, diâmetro da área polar $=26,06 \mu \mathrm{m}$; diâmetro do eixo equatorial em vista polar $=28,18 \mu \mathrm{m} ; \mathrm{P} / \mathrm{E}=0,92 \mu \mathrm{m}$. 


\section{Lythraceae}

Espécie: Cuphea racemosa (L.f.) Spreng.

Nome comum: Sete-sangrias

Hábito de crescimento: herbáceo

Fonte de recurso trófico: néctar/pólen

Período de Floração: abril a junho

No Palinoteca: NAS17

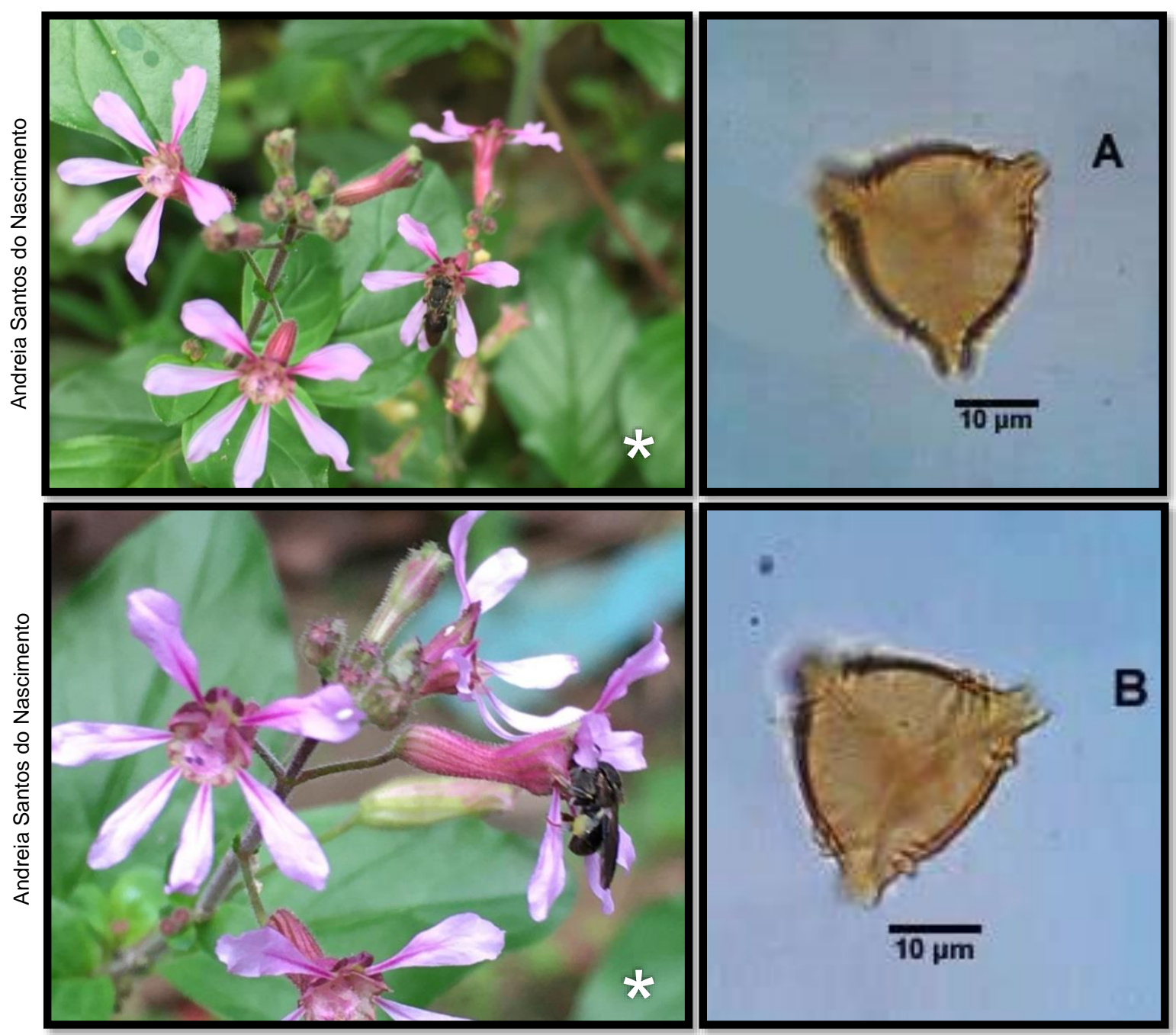

Descrição polínica: A-B = vista polar, grão de pólen com simetria radial, isopolar, nômade, âmbito triangular, abertura polínica do tipo colporo, exina estriada, tamanho médio, forma oblata esferoidal, diâmetro da área polar $=24,54 \mu \mathrm{m}$; diâmetro do eixo equatorial em vista polar $=27,27 \mu \mathrm{m} ; \mathrm{P} / \mathrm{E}=0,89 \mu \mathrm{m}$.

*Abelha visitante floral: Nannotrigona testaceicornis Lepeletier, 1836. 


\section{Malpighiaceae}

Espécie: Byrsonima verbascifolia (L.) DC.

Nome comum: Murici

Hábito de crescimento: arbustivo

Fonte de recurso trófico: óleo/pólen

Período de Floração: abril a junho

No Palinoteca: PA 118
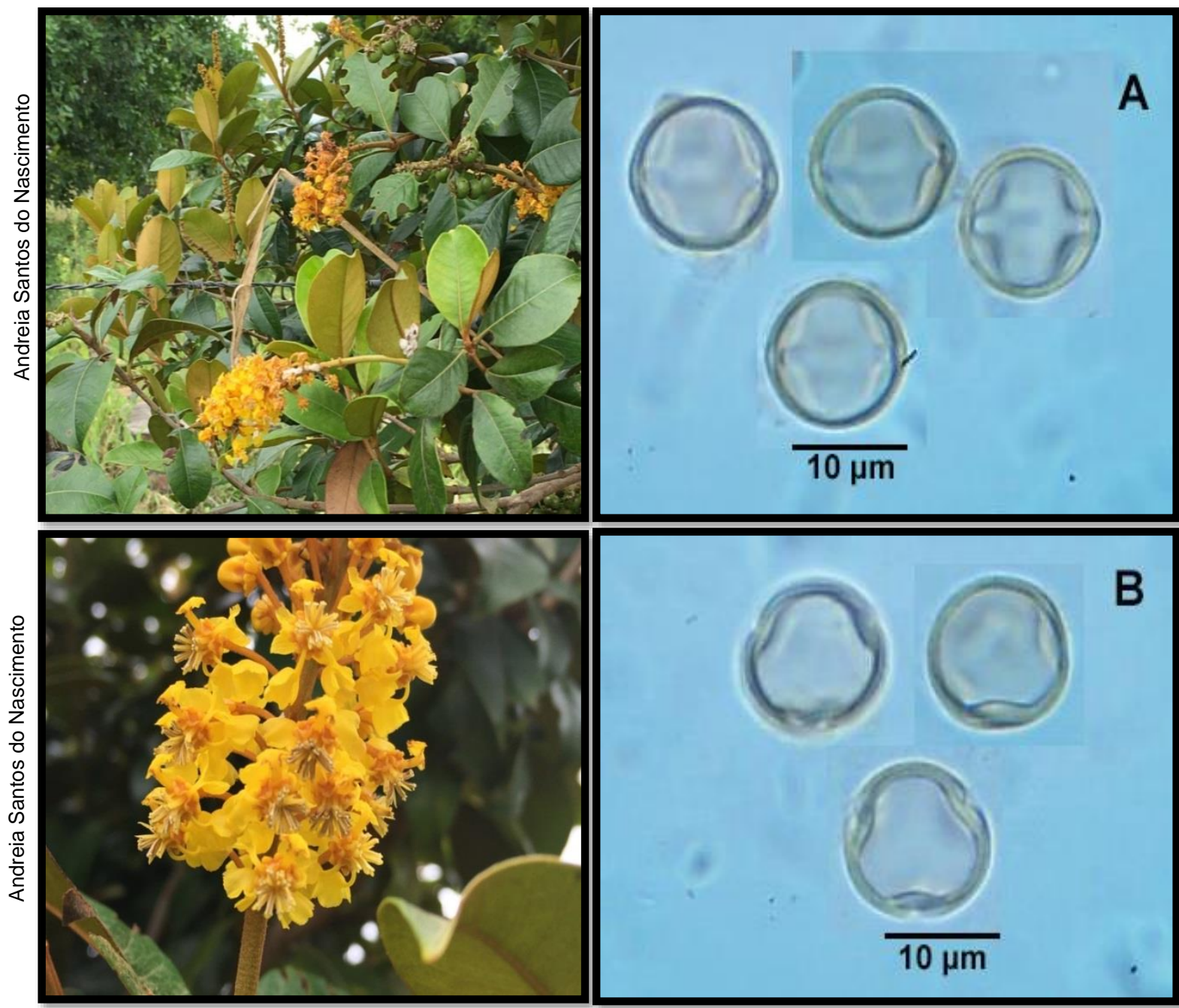

Descrição polínica: $A=$ vista equatorial e $B=$ vista polar, grão de pólen com simetria radial, isopolar, nômade, âmbito subcircular, abertura polínica do tipo colporo, exina perfurada, tamanho pequeno, forma prolata esferoidal, eixo polar = $12,42 \mu \mathrm{m}$; eixo equatorial $=12,12 \mu \mathrm{m} ; \mathrm{P} / \mathrm{E}=1,02 \mu \mathrm{m}$. 


\section{Malpighiaceae}

Espécie: Malpighia emarginata DC.

Nome comum: Acerola

Hábito de crescimento: arbustivo

Fonte de recurso trófico: óleo/pólen

Período de Floração: abril a junho

No Palinoteca: PA 108

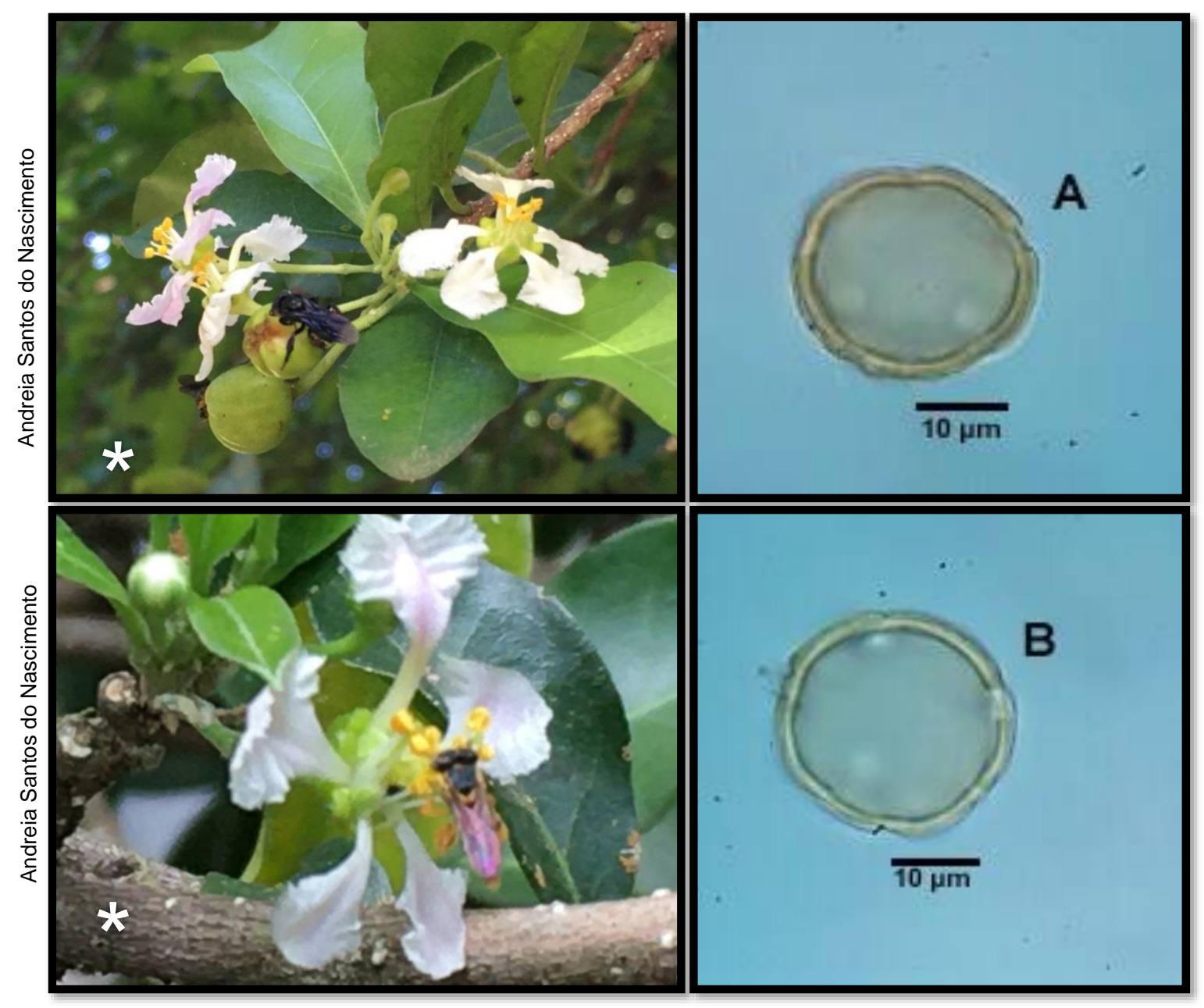

Descrição polínica: A-B = vista polar, grão de pólen com simetria radial, isopolar, nômade, âmbito circular, abertura polínica do tipo colporo, exina areolada, tamanho médio, forma prolata esferoidal, diâmetro do eixo polar $=26,36 \mu \mathrm{m}$; diâmetro do eixo equatorial $=23,93 \mu \mathrm{m} ; \mathrm{P} / \mathrm{E}=1,10 \mu \mathrm{m}$.

*Abelha coletando resina no fruto: Trigona spinipes Fabricius, 1793 e Abelha visitante floral: Tetragonisca angustula Latreille, 1811. 


\section{Malvaceae}

Espécie: Abelmoschus esculentus (L.) Moench.

Nome comum: Quiabeiro

Hábito de crescimento: herbáceo

Fonte de recurso trófico: pólen

Período de Floração: abril a junho

No Palinoteca: PA 175
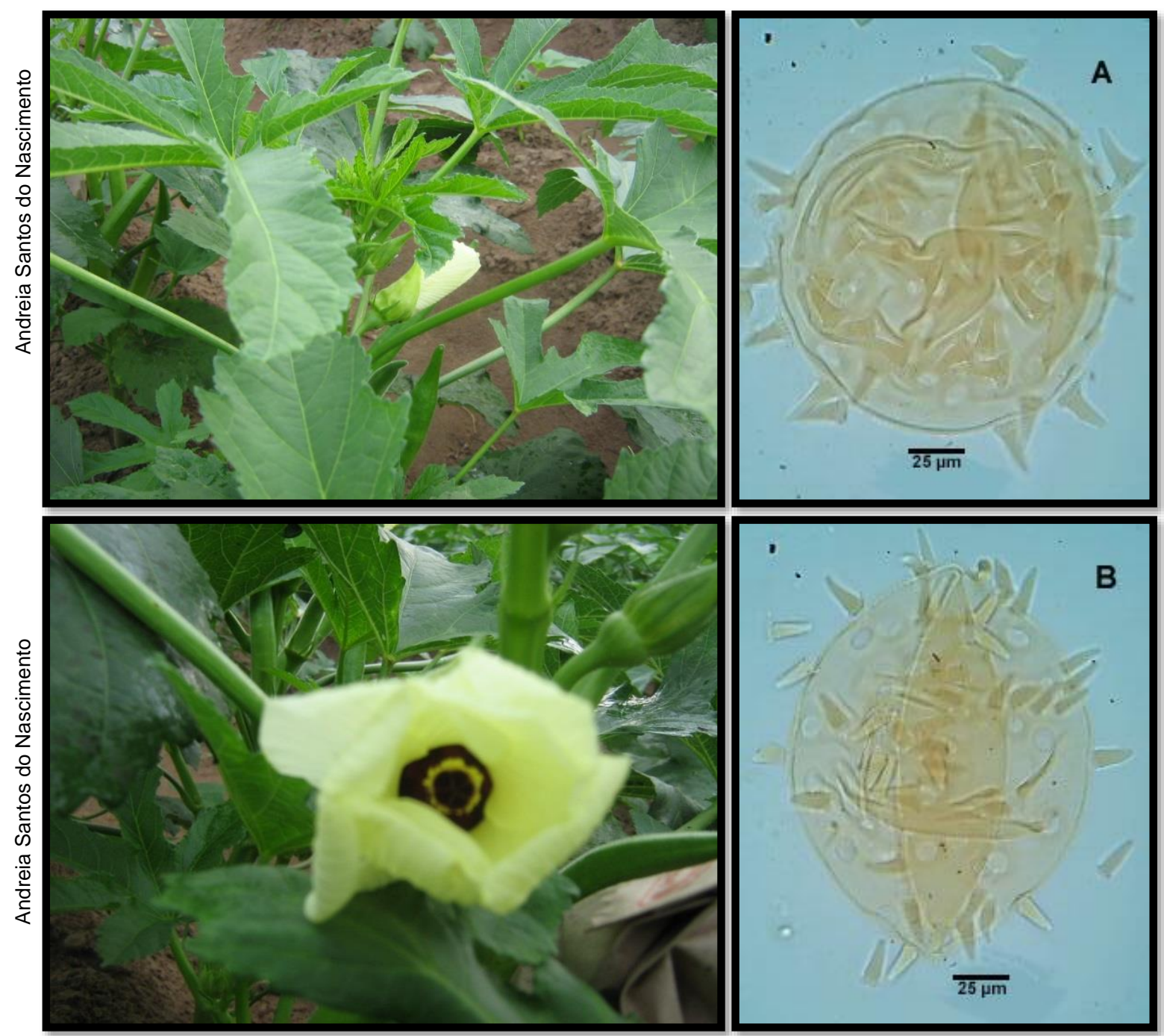

Descrição polínica: $A$ = vista polar e $B=$ vista equatorial, grão de pólen com simetria radial, apolar, nômade, âmbito circular, abertura polínica do tipo poro, exina equinada, tamanho muito grande, forma esferoidal, diâmetro do eixo polar $=191,47 \mu \mathrm{m}$; diâmetro do eixo equatorial $=190,69 \mu \mathrm{m} ; \mathrm{P} / \mathrm{E}=1,00 \mu \mathrm{m}$. 


\section{Malvaceae}

Espécie: Corchorus hirtus L.

Nome comum: Malva

Hábito de crescimento: herbáceo

Fonte de recurso trófico: pólen

Período de Floração: abril a junho

No Palinoteca: NAS18

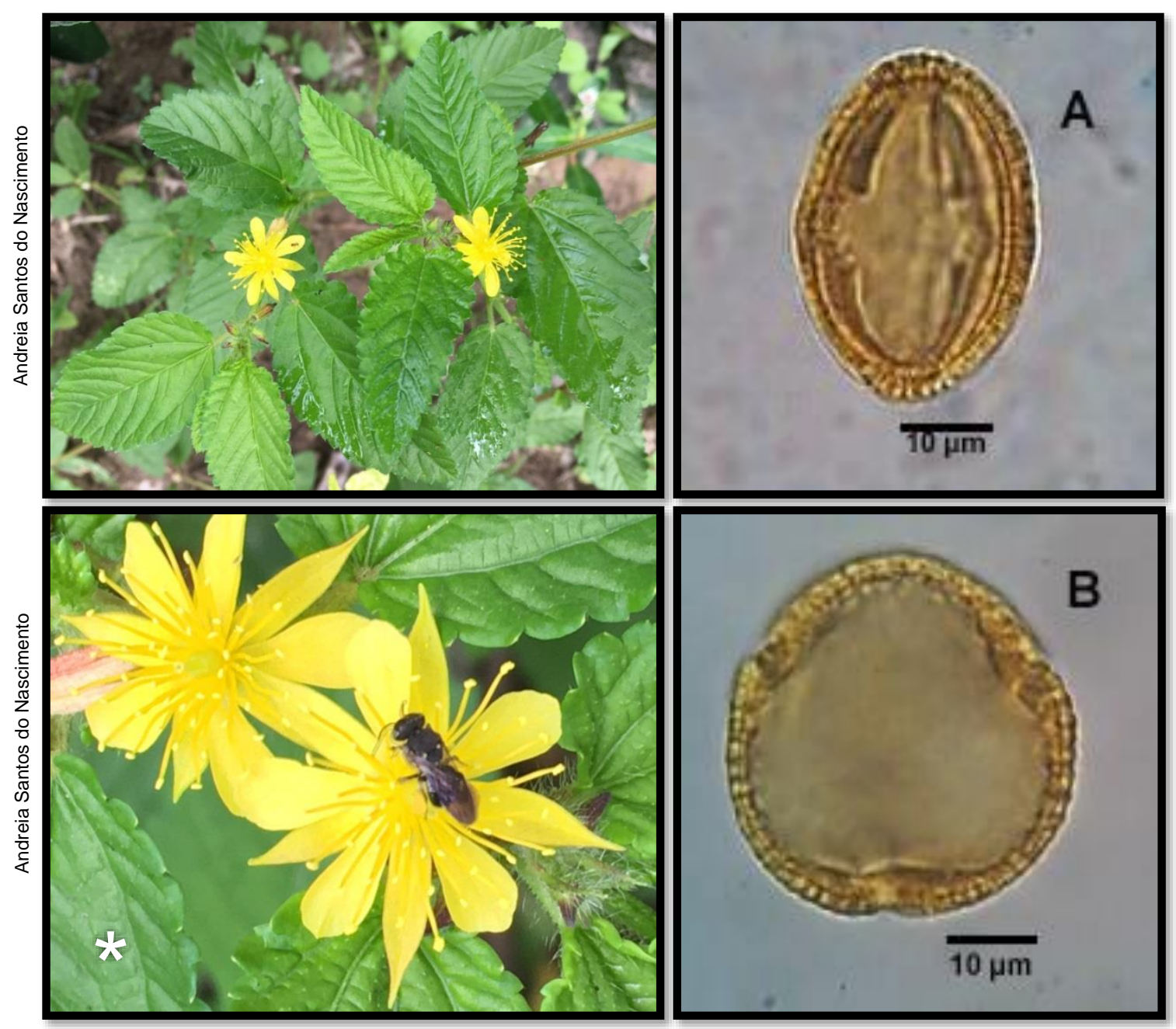

Descrição polínica: $A=$ vista equatorial e $B=$ vista polar, grão de pólen com simetria radial, isopolar, nômade, âmbito subtriangular, abertura polínica do tipo colporo, exina reticulada/heterobrocada, tamanho médio, forma subprolata, eixo polar $=37,27 \mu \mathrm{m}$; eixo equatorial $=30,60 \mu \mathrm{m} ; \mathrm{P} / \mathrm{E}=1,21 \mu \mathrm{m}$.

*Abelha visitante floral: Nannotrigona testaceicornis Lepeletier, 1836. 


\section{Malvaceae}

Espécie: Gossypium hirsutum L.

Nome comum: Algodão

Hábito de crescimento: arbustivo

Fonte de recurso trófico: pólen

Período de Floração: abril a junho No Palinoteca: PA 100
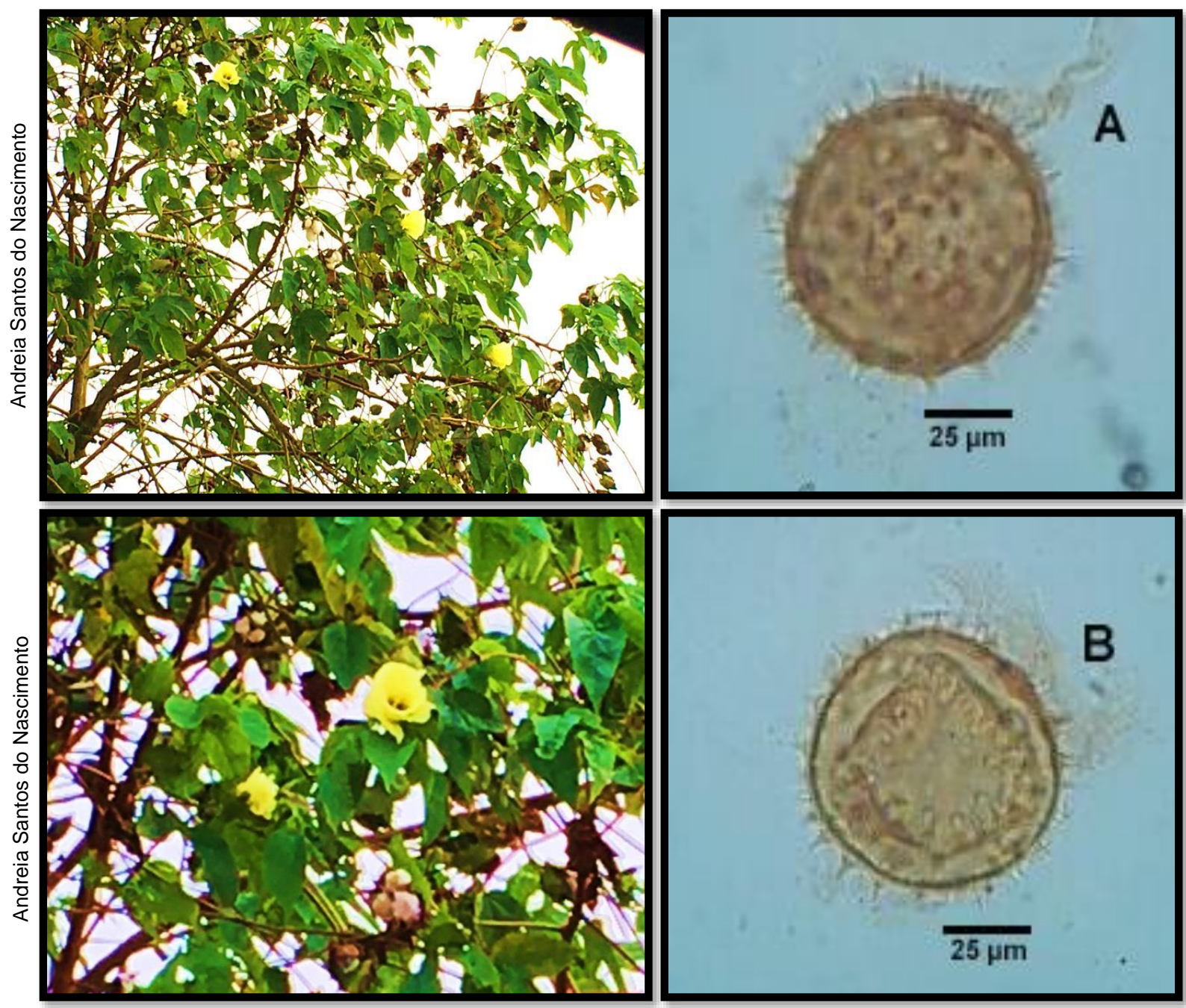

Descrição polínica: $A-B=$ vista polar, grão de pólen com simetria radial, apolar, nômade, âmbito circular, abertura polínica do tipo poro, exina equinada, tamanho grande, forma esferoidal, diâmetro do eixo polar $=86,04 \mu \mathrm{m}$; diâmetro do eixo equatorial $=85,27 \mu \mathrm{m} ; \mathrm{P} / \mathrm{E}=1,00 \mu \mathrm{m}$. 


\section{Malvaceae}

Espécie: Herissantia crispa (L.) Brizicky

Nome comum: Malva

Hábito de crescimento: herbáceo

Fonte de recurso trófico: néctar/pólen

Período de Floração: janeiro a junho

No Palinoteca: PA 159
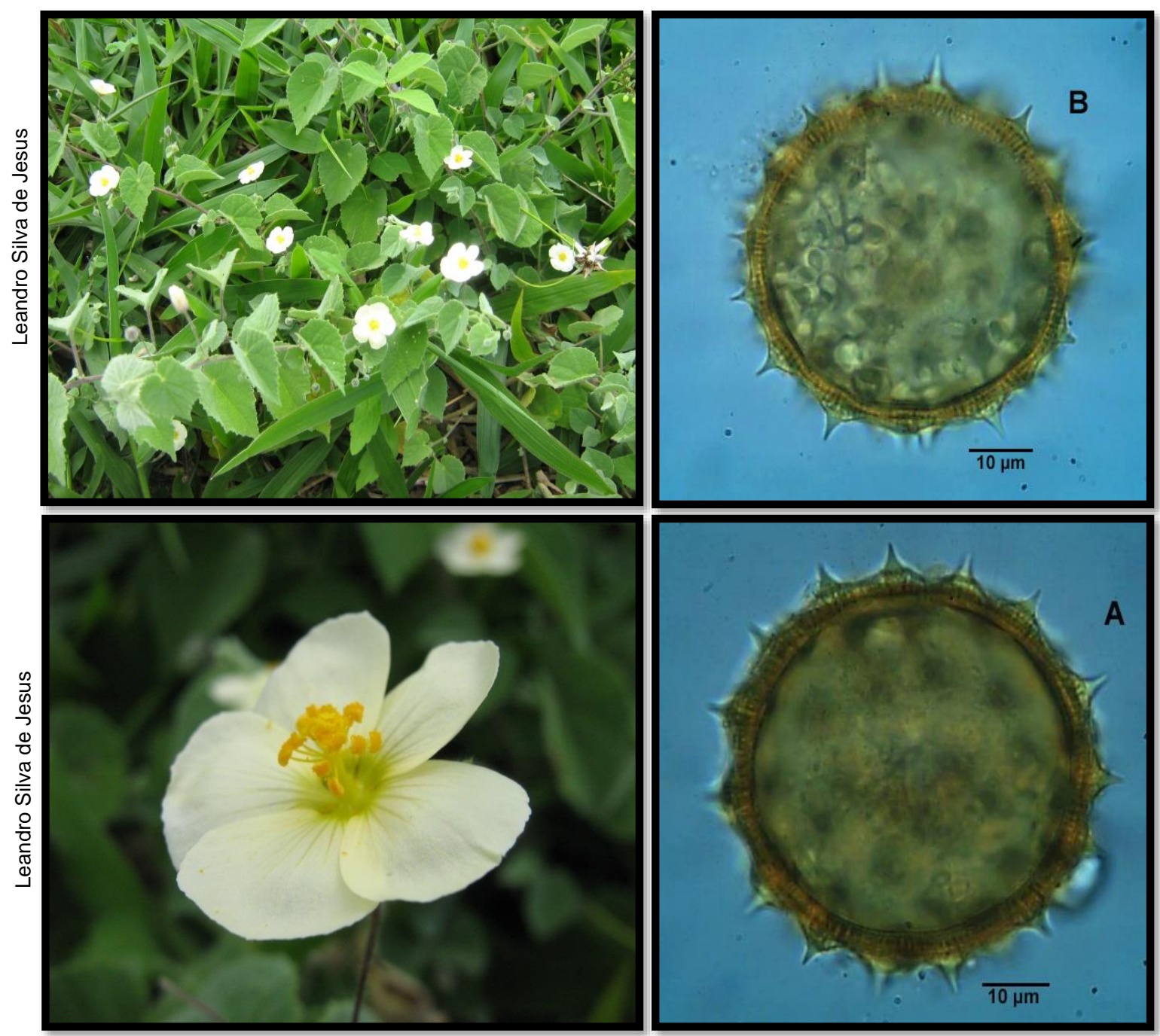

Descrição polínica: A-B = vista polar, grão de pólen com simetria radial, apolar, nômade, âmbito circular, abertura polínica do tipo poro, exina equinada, tamanho grande, forma esferoidal, diâmetro do eixo polar $=63,33 \mu \mathrm{m}$; diâmetro do eixo equatorial $=63,03 \mu \mathrm{m} ; \mathrm{P} / \mathrm{E}=1,00 \mu \mathrm{m}$. 


\section{Malvaceae}

Espécie: Hibiscus rosa-sinensis L.

Nome comum: Mimo-de-vênus

Hábito de crescimento: arbustivo

Fonte de recurso trófico: pólen

Período de Floração: abril a agosto

No Palinoteca: PA 130
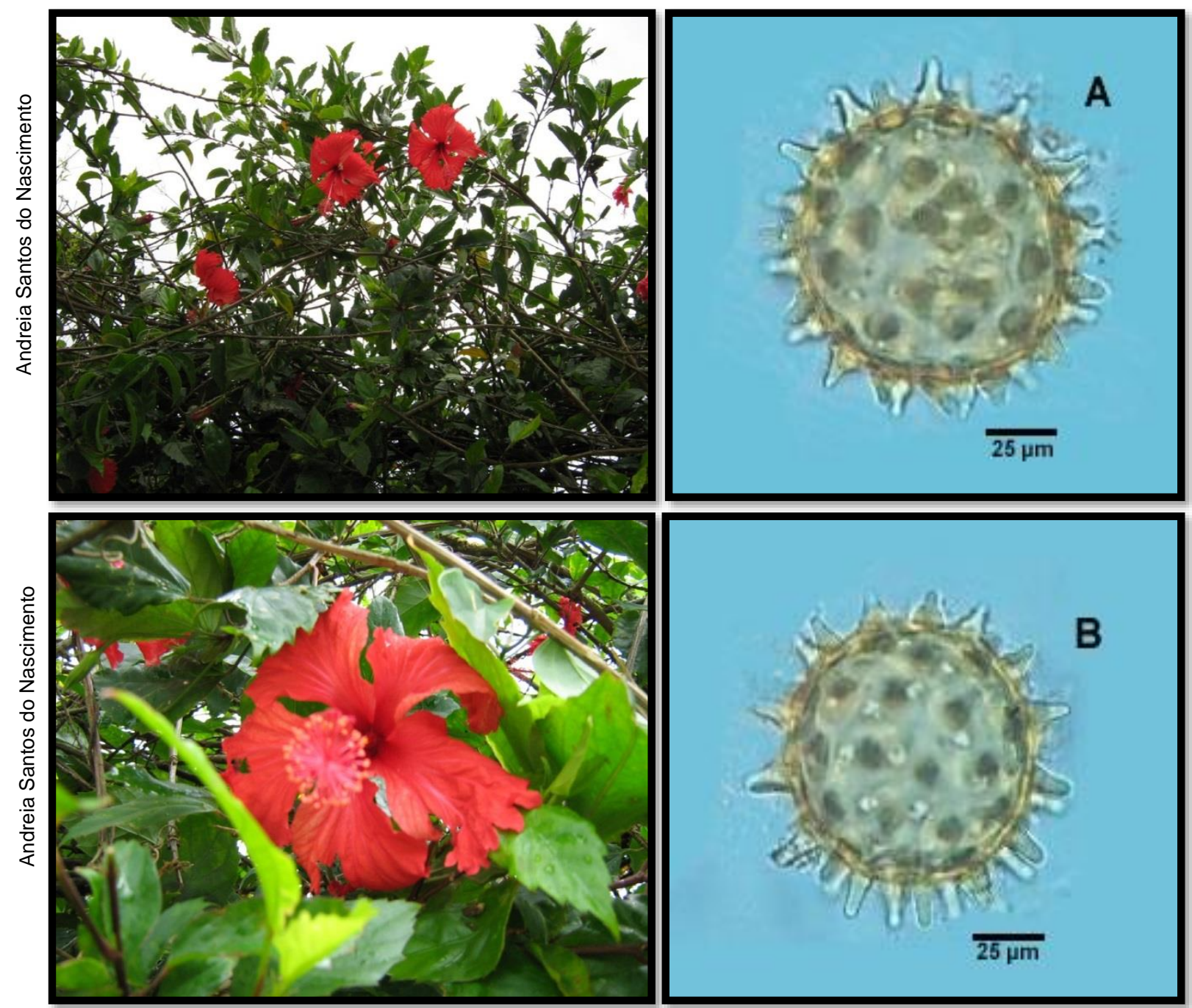

Descrição polínica: $A-B=$ vista polar, grão de pólen com simetria radial, apolar, nômade, âmbito circular, abertura polínica do tipo poro, exina equinada, tamanho muito grande, forma esferoidal, diâmetro do eixo polar $=127,90 \mu \mathrm{m}$; diâmetro do eixo equatorial $=127,13 \mu \mathrm{m} ; \mathrm{P} / \mathrm{E}=1,00 \mu \mathrm{m}$. 


\section{Malvaceae}

Espécie: Pachira aquatica Aubl.

Nome comum: Munguba

Hábito de crescimento: arbóreo

Fonte de recurso trófico: pólen

Período de Floração: dezembro No Palinoteca: PA 111
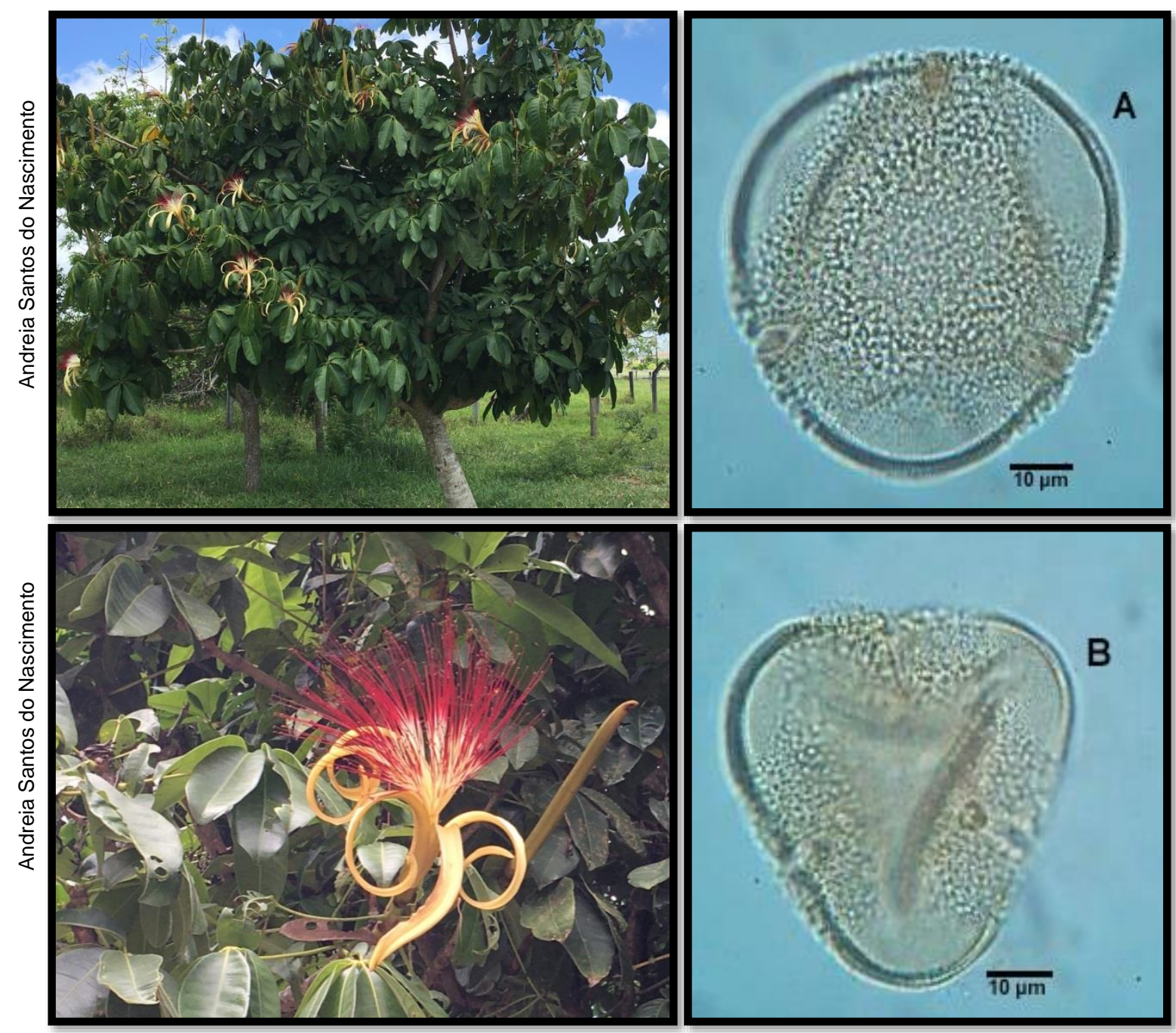

Descrição polínica: A-B = vista polar, grão de pólen com simetria radial, isopolar, nômade, âmbito subtriangular, abertura polínica do tipo colporo, exina reticulada, tamanho grande, forma prolata esferoidal, eixo maior $=59,09 \mu \mathrm{m}$; eixo menor $=$ $56,06 \mu \mathrm{m} ; \mathrm{P} / \mathrm{E}=1,05 \mu \mathrm{m}$. 


\section{Malvaceae}

Espécie: Pavonia cancellata (L.) Cav.

Nome comum: Malva-rasteira

Hábito de crescimento: herbáceo

Fonte de recurso trófico: pólen

Período de Floração: janeiro a dezembro

No Palinoteca: PA 06
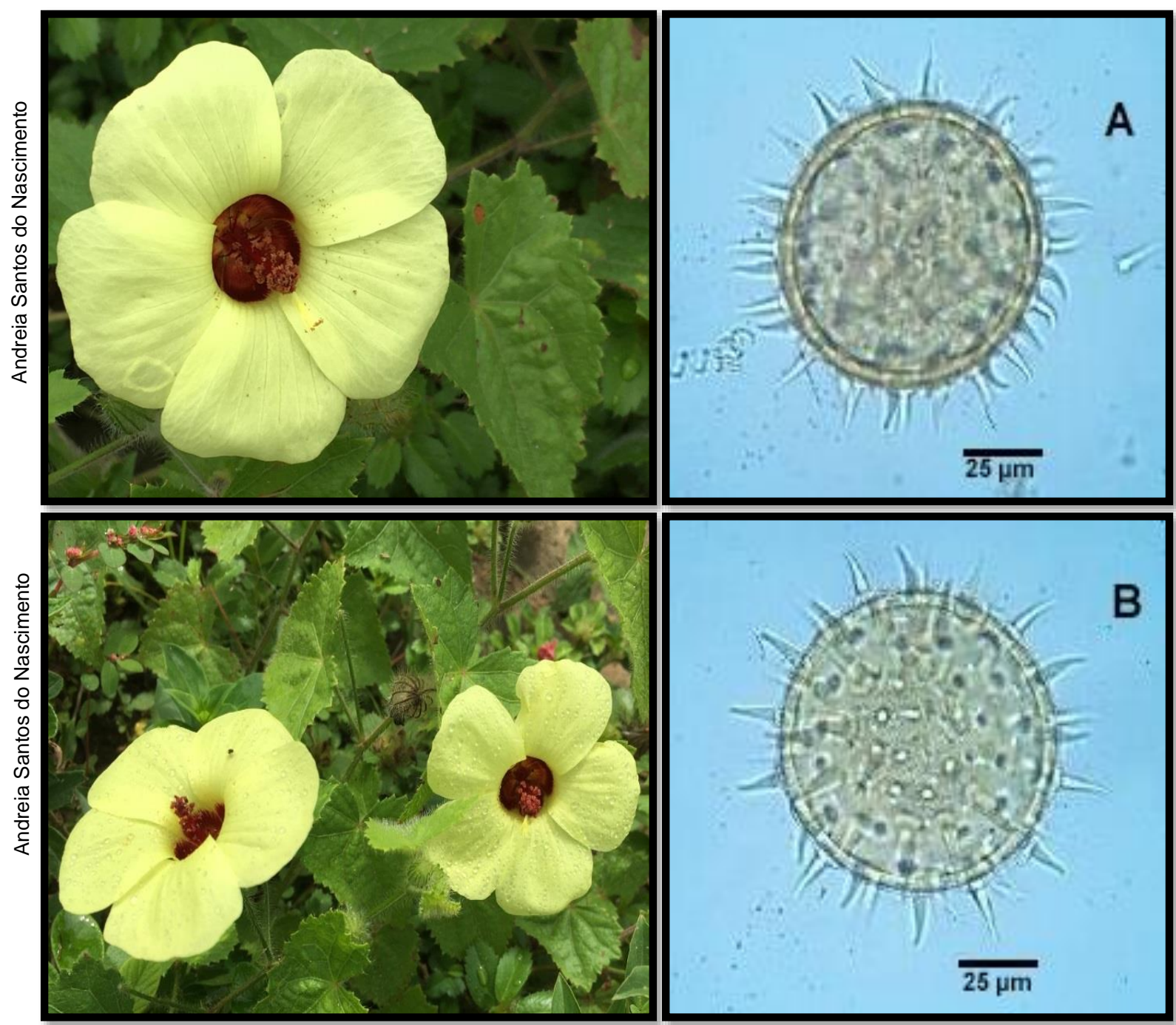

Descrição polínica: A-B = vista polar, grão de pólen com simetria radial, apolar, nômade, âmbito circular, abertura polínica do tipo poro, exina equinada, tamanho grande, forma esferoidal, diâmetro do eixo polar $=117,82 \mu \mathrm{m}$; diâmetro do eixo equatorial $=117,05 \mu \mathrm{m} ; \mathrm{P} / \mathrm{E}=1,00 \mu \mathrm{m}$. 


\section{Malvaceae}

Espécie: Sida acuta (Burm.f.) Kurz.

Nome comum: guanxuma

Hábito de crescimento: herbáceo

Fonte de recurso trófico: néctar/pólen

Período de Floração: janeiro a junho

No Palinoteca: PA 10
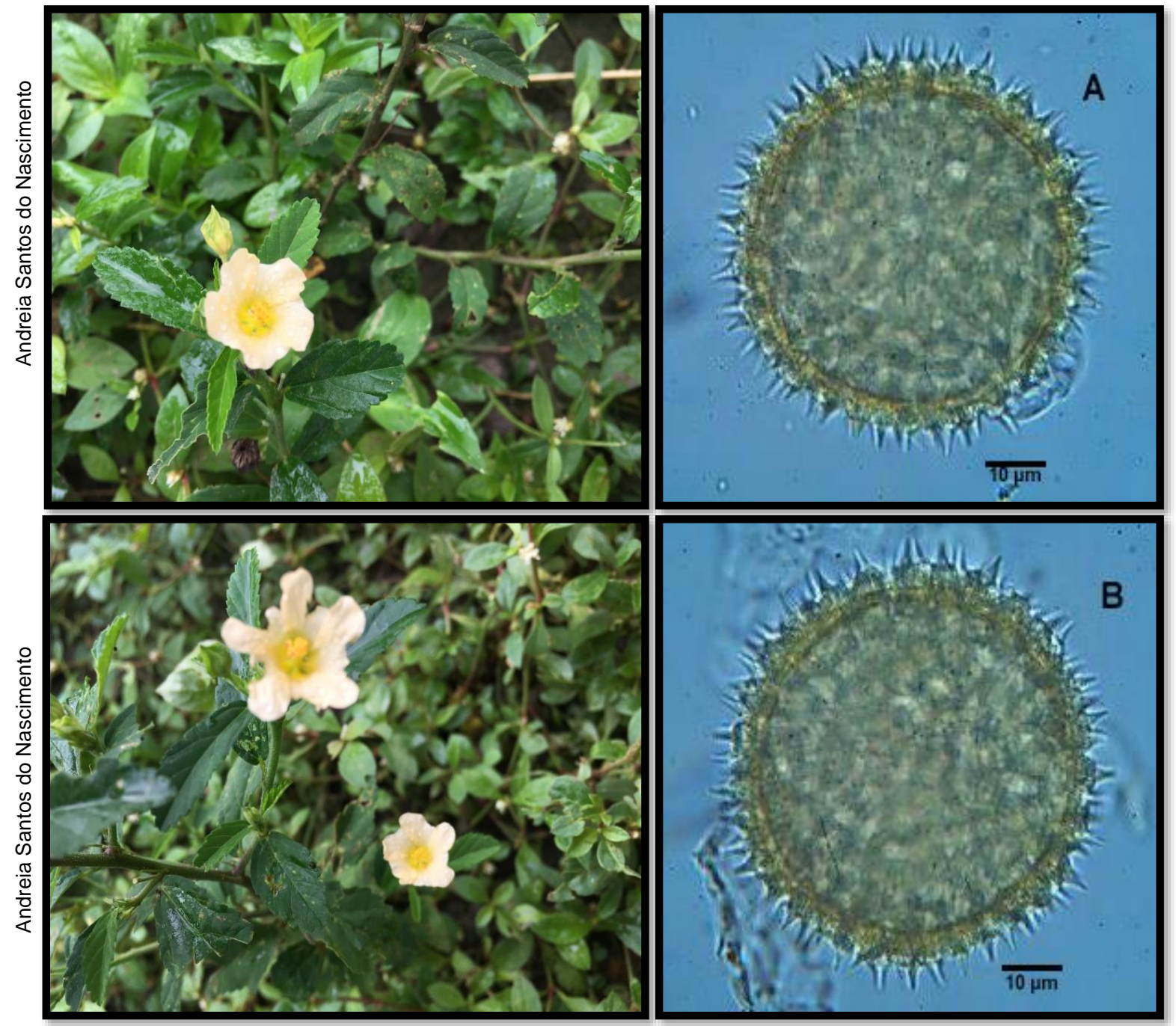

Descrição polínica: A-B = vista polar, grão de pólen com simetria radial, apolar, nômade, âmbito circular, abertura polínica do tipo poro, exina equinada, tamanho grande, forma esferoidal, diâmetro do eixo polar $=72,86 \mu \mathrm{m}$; diâmetro do eixo equatorial $=72,09 \mu \mathrm{m} ; \mathrm{P} / \mathrm{E}=1,00 \mu \mathrm{m}$. 


\section{Malvaceae}

Espécie: Sida ciliaris L.

Nome comum: Malva-rasteira

Hábito de crescimento: herbáceo

Fonte de recurso trófico: néctar/pólen

Período de Floração: janeiro a junho

No Palinoteca: PA 173
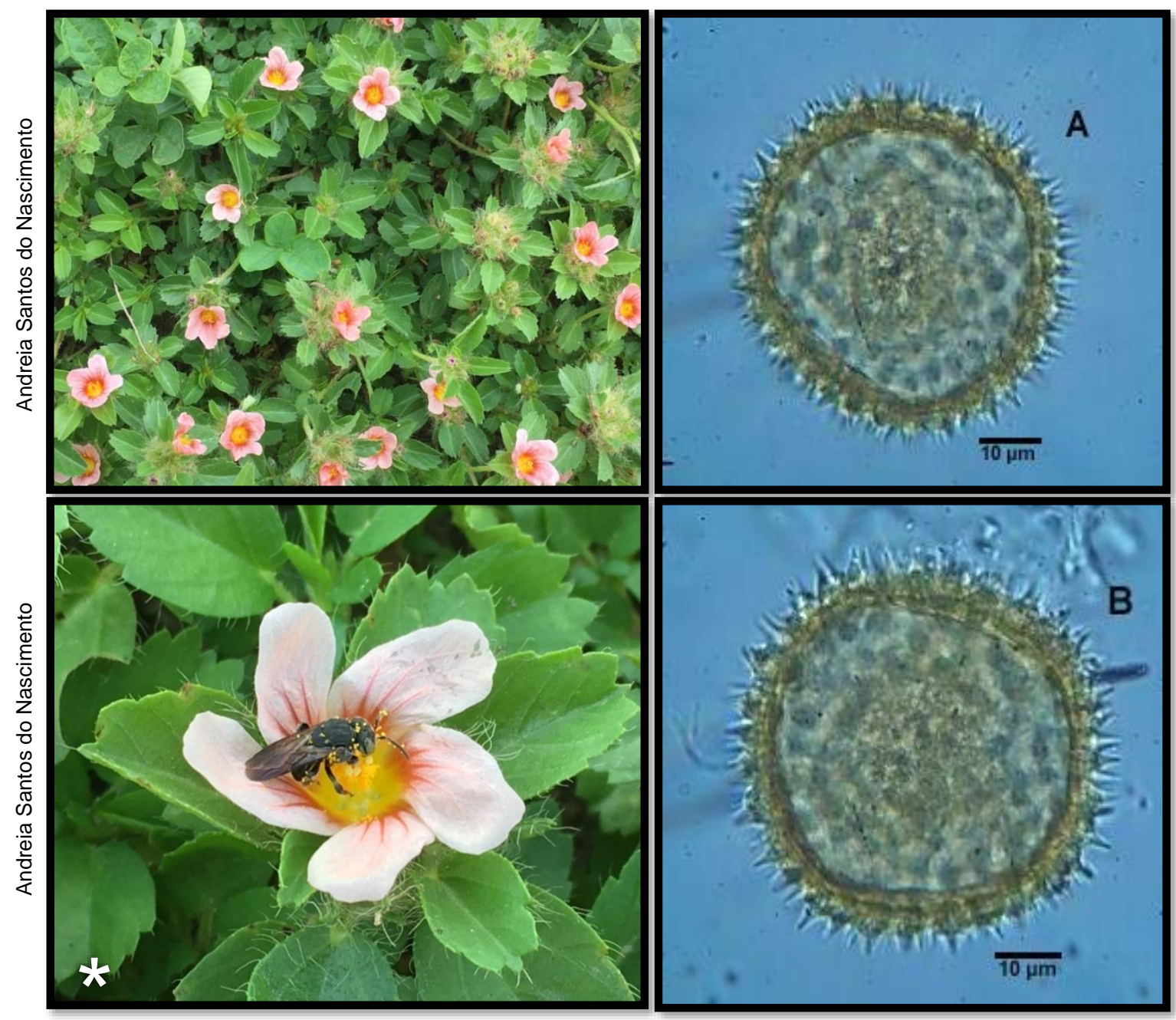

Descrição polínica: $A-B$ = vista polar, grão de pólen com simetria radial, apolar, nômade, âmbito circular, abertura polínica do tipo poro, exina equinada, tamanho grande, forma esferoidal, diâmetro do eixo polar $=63,63 \mu \mathrm{m}$; diâmetro do eixo equatorial $=63,33 \mu \mathrm{m} ; \mathrm{P} / \mathrm{E}=1,00 \mu \mathrm{m}$.

${ }^{*}$ Abelha visitante floral: Nannotrigona testaceicornis Lepeletier, 1836. 


\section{Malvaceae}

Espécie: Sida cordifolia L.

Nome comum: Malva-veludo

Hábito de crescimento: herbáceo

Fonte de recurso trófico: néctar/pólen

Período de Floração: janeiro a junho

No Palinoteca: PA 26
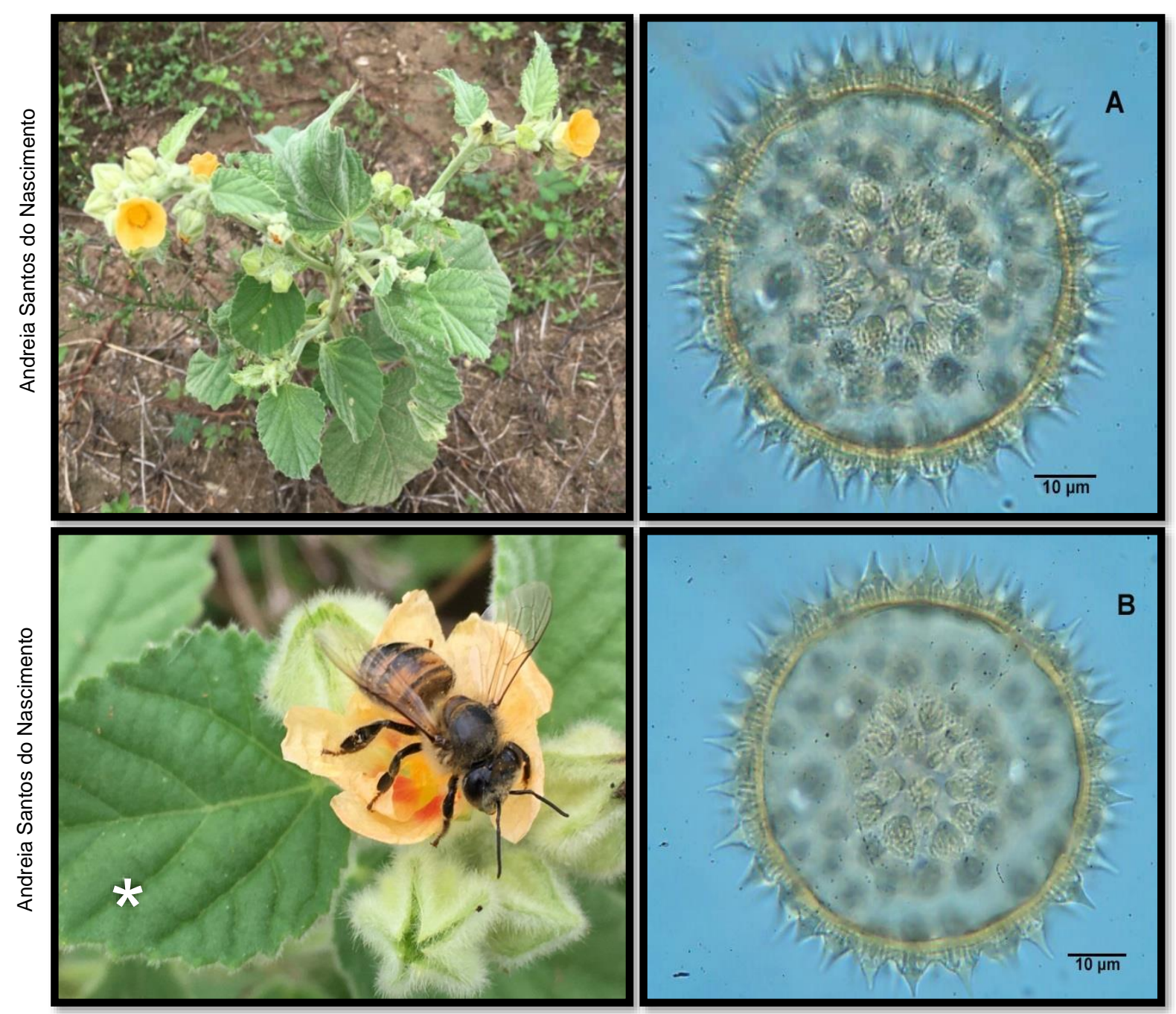

Descrição polínica: $A-B=$ vista polar, grão de pólen com simetria radial, apolar, nômade, âmbito circular, abertura polínica do tipo poro, exina equinada, tamanho grande, forma esferoidal, diâmetro do eixo polar $=71,31 \mu \mathrm{m}$; diâmetro do eixo equatorial $=71,31 \mu \mathrm{m} ; \mathrm{P} / \mathrm{E}=1,00 \mu \mathrm{m}$.

*Abelha visitante floral: Apis mellifera Linnaeus, 1758. 


\section{Malvaceae}

Espécie: Sida linifolia Juss. ex Cav.

Nome comum: Malva-relógio

Hábito de crescimento: herbáceo

Fonte de recurso trófico: néctar/pólen

Período de Floração: janeiro a junho

No Palinoteca: PA 143

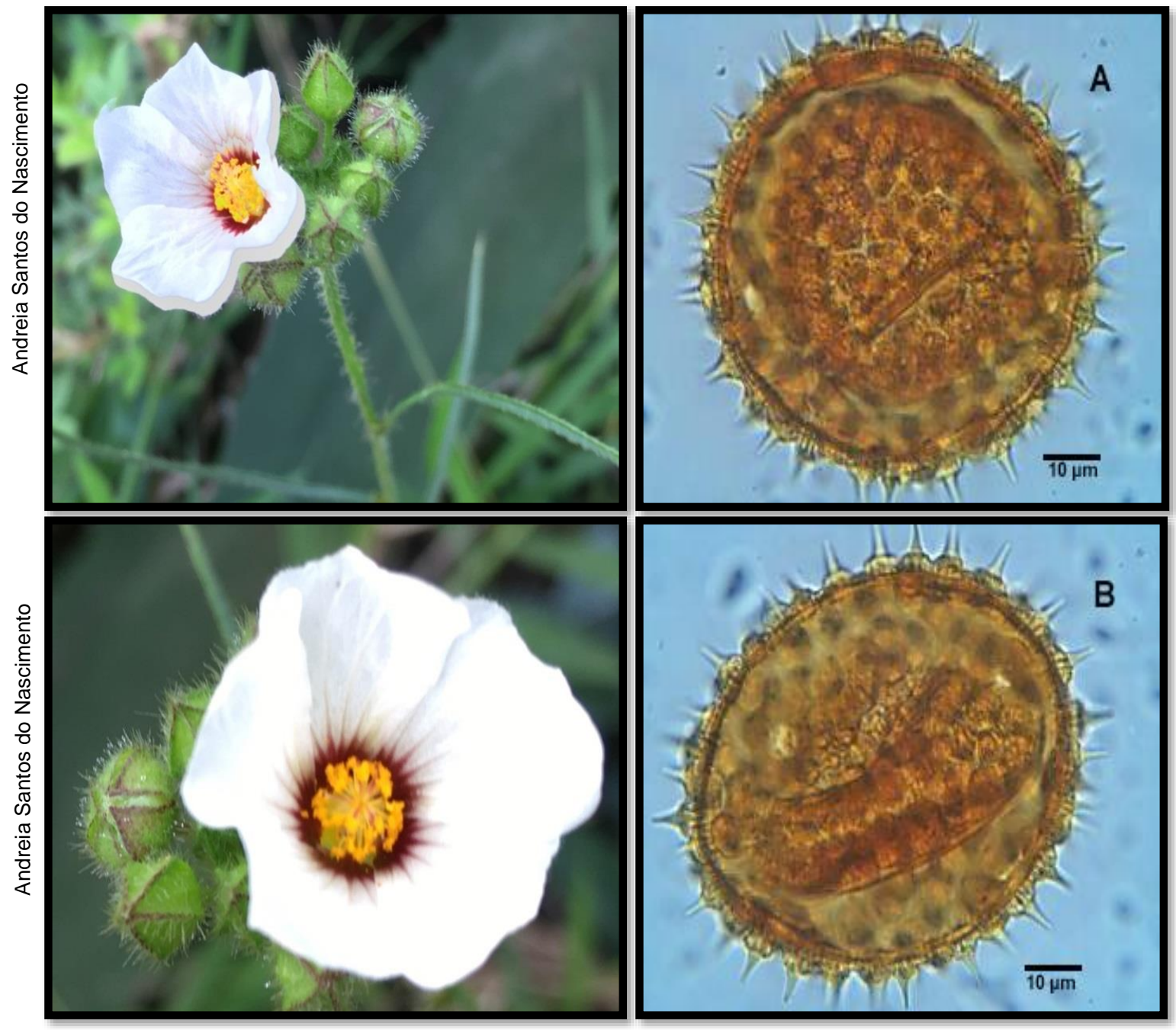

Descrição polínica: A-B = vista polar, grão de pólen com simetria radial, apolar, nômade, âmbito circular, abertura polínica do tipo poro, exina equinada, tamanho grande, forma esferoidal, diâmetro do eixo polar $=86,04 \mu \mathrm{m}$; diâmetro do eixo equatorial $=86,04 \mu \mathrm{m} ; \mathrm{P} / \mathrm{E}=1,00 \mu \mathrm{m}$. 


\section{Malvaceae}

Espécie: Sida rhombifolia L.

Nome comum: Guanxuma; vassourinha

Hábito de crescimento: herbáceo

Fonte de recurso trófico: néctar/pólen

Período de Floração: janeiro a junho

No Palinoteca: PA 147
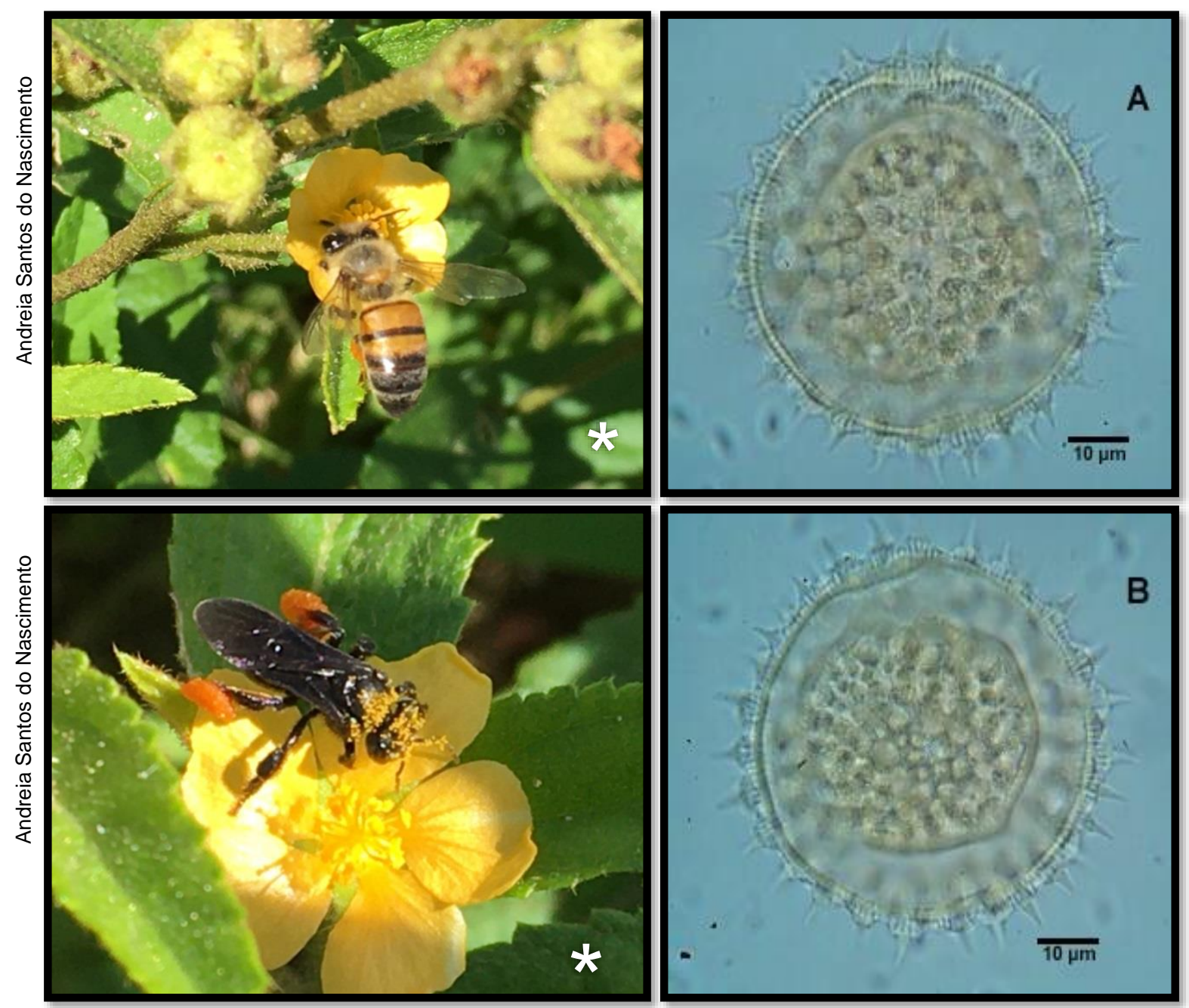

Descrição polínica: A-B = vista polar, grão de pólen com simetria radial, apolar, nômade, âmbito circular, abertura polínica do tipo poro, exina equinada, tamanho grande, forma esferoidal, diâmetro do eixo polar $=67,87 \mu \mathrm{m}$; diâmetro do eixo equatorial $=67,87 \mu \mathrm{m} ; \mathrm{P} / \mathrm{E}=1,00 \mu \mathrm{m}$.

*Abelha visitante floral: Apis mellifera Linnaeus, 1758; Trigona spinipes Fabricius, 1793. 


\section{Malvaceae}

Espécie: Sida spinosa L.

Nome comum: Malva-amarela

Hábito de crescimento: herbáceo

Fonte de recurso trófico: néctar/pólen

Período de Floração: janeiro a junho

No Palinoteca: PA 145
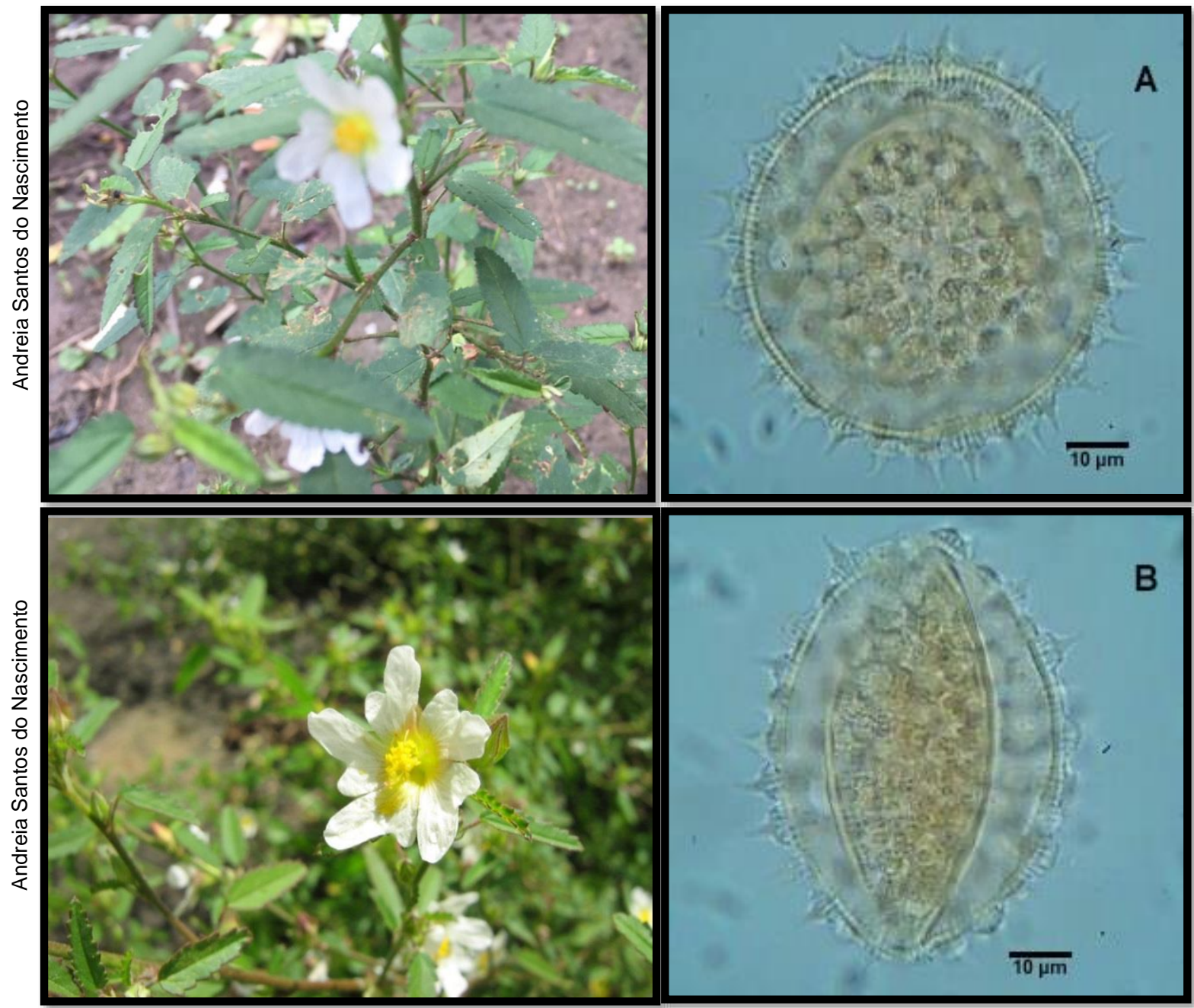

Descrição polínica: $A$ = vista polar e $B$ = vista equatorial, grão de pólen com simetria radial, apolar, nômade, âmbito circular, abertura polínica do tipo poro, exina equinada, tamanho grande, forma esferoidal, diâmetro do eixo polar $=72,42 \mu \mathrm{m}$; diâmetro do eixo equatorial $=72,42 \mu \mathrm{m} ; \mathrm{P} / \mathrm{E}=1,00 \mu \mathrm{m}$. 


\section{Malvaceae}

Espécie: Sidastrum micranthum (A.St.-Hil.) Fryxell.

Nome comum: Malva-preta

Hábito de crescimento: herbáceo

Fonte de recurso trófico: néctar/pólen

Período de Floração: janeiro a junho

No Palinoteca: PA 156

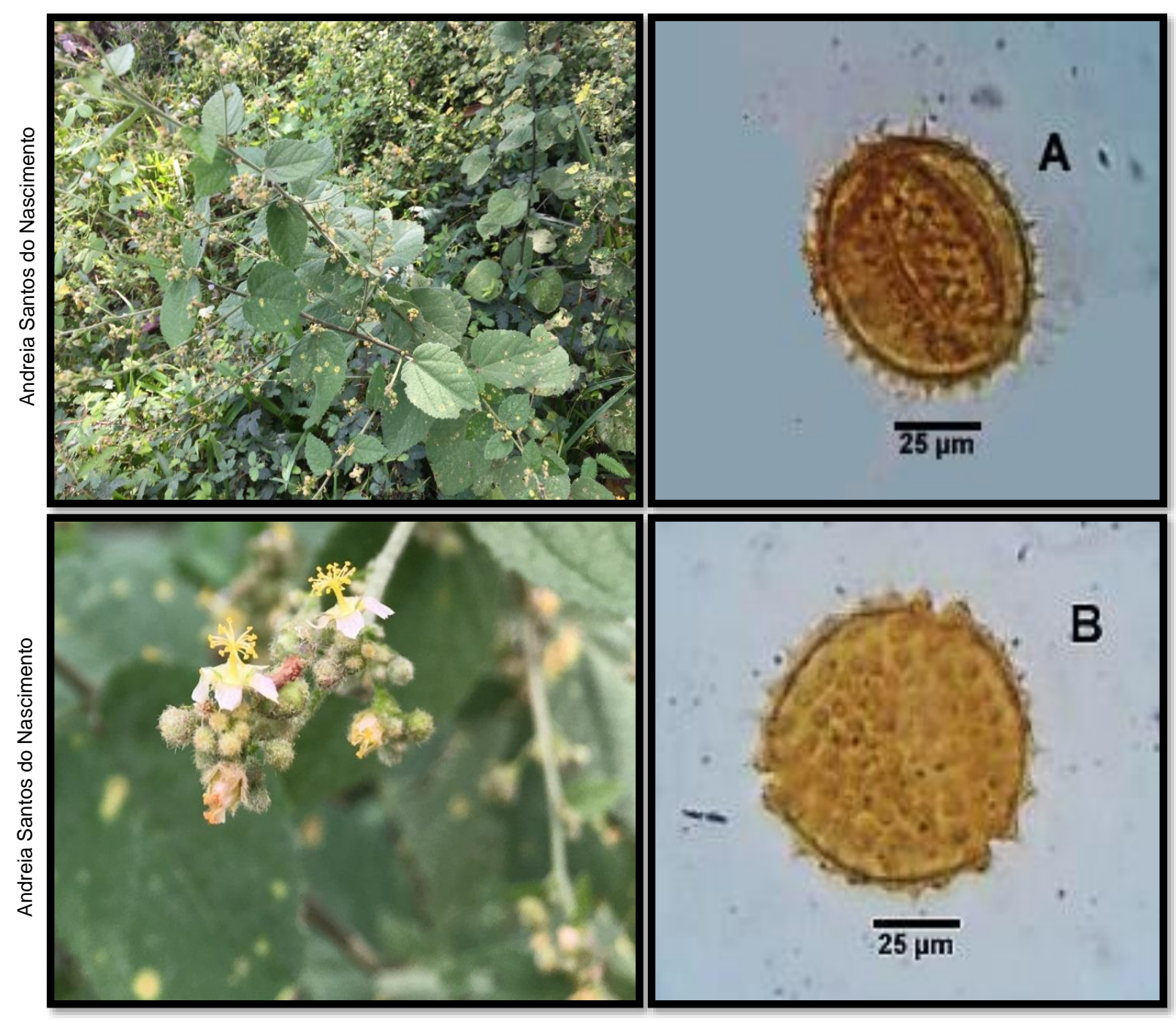

Descrição polínica: $A=$ vista polar e $B=$ vista equatorial, grão de pólen com simetria radial, apolar, nômade, âmbito subcircular, abertura polínica do tipo poro, exina equinada, tamanho grande, forma prolata esferoidal, diâmetro do eixo polar = $71,31 \mu \mathrm{m}$; diâmetro do eixo equatorial $=70,54 \mu \mathrm{m} ; \mathrm{P} / \mathrm{E}=1,01 \mu \mathrm{m}$. 


\section{Malvaceae}

Espécie: Waltheria indica L.

Nome comum: Malva-branca

Hábito de crescimento: herbáceo

Fonte de recurso trófico: néctar

Período de Floração: abril a agosto

No Palinoteca: PA 35

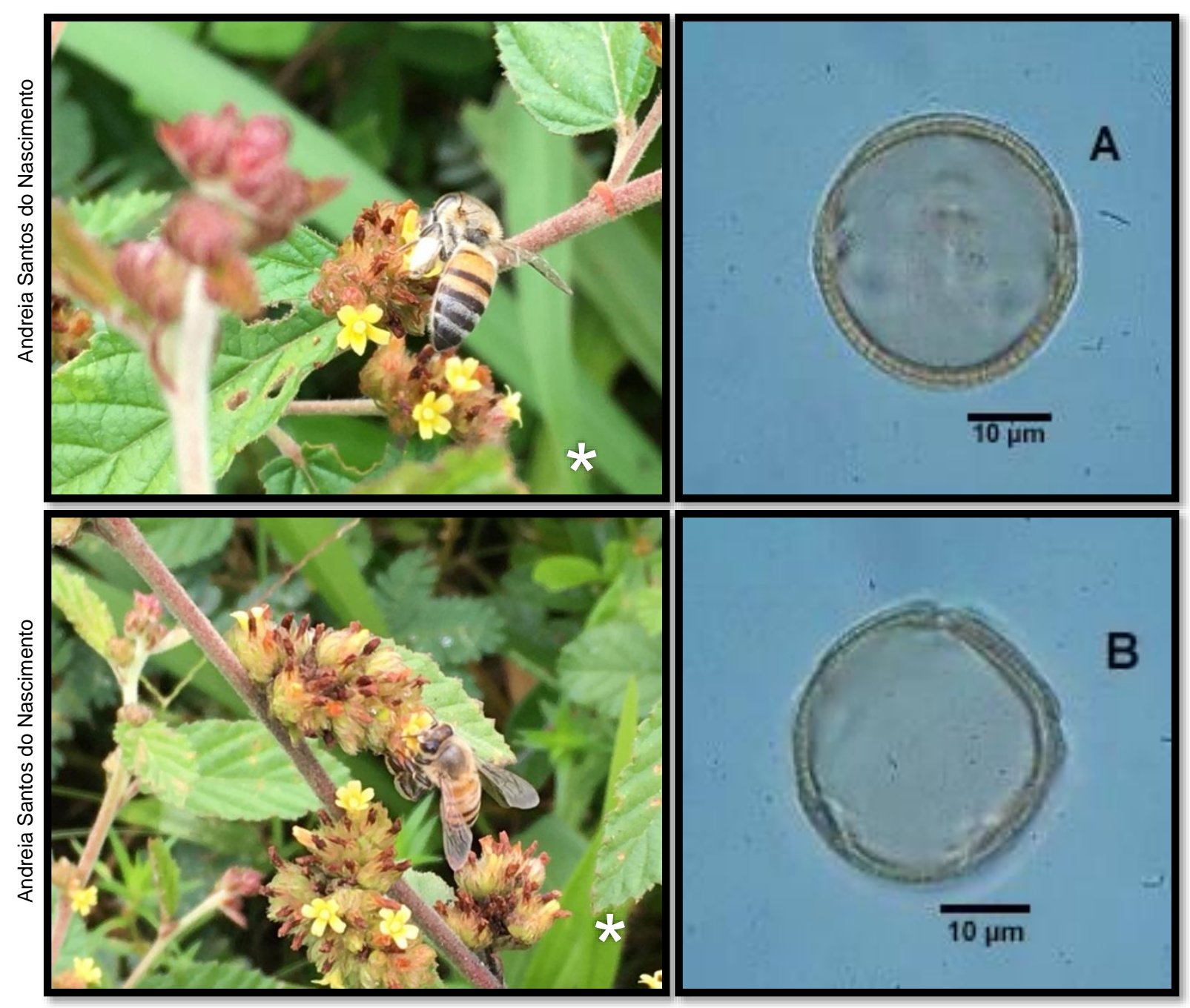

Descrição polínica: $A$ = vista equatorial e $B$ = vista polar, grão de pólen com simetria radial, isopolar, nômade, âmbito circular, abertura polínica do tipo colporo, exina reticulada, tamanho médio, forma prolata esferoidal, eixo polar $=30,30 \mu \mathrm{m}$; eixo equatorial $=29,69 \mu \mathrm{m} ; \mathrm{P} / \mathrm{E}=1,02 \mu \mathrm{m}$.

*Abelha visitante floral: Apis mellifera Linnaeus, 1758. 


\section{Melastomataceae}

Espécie: Clidemia hirta (L.) D.Don.

Nome comum: Erva-sabão; maldição de Koster

Hábito de crescimento: arbustivo

Fonte de recurso trófico: pólen

Período de Floração: abril a maio

No Palinoteca: NAS19
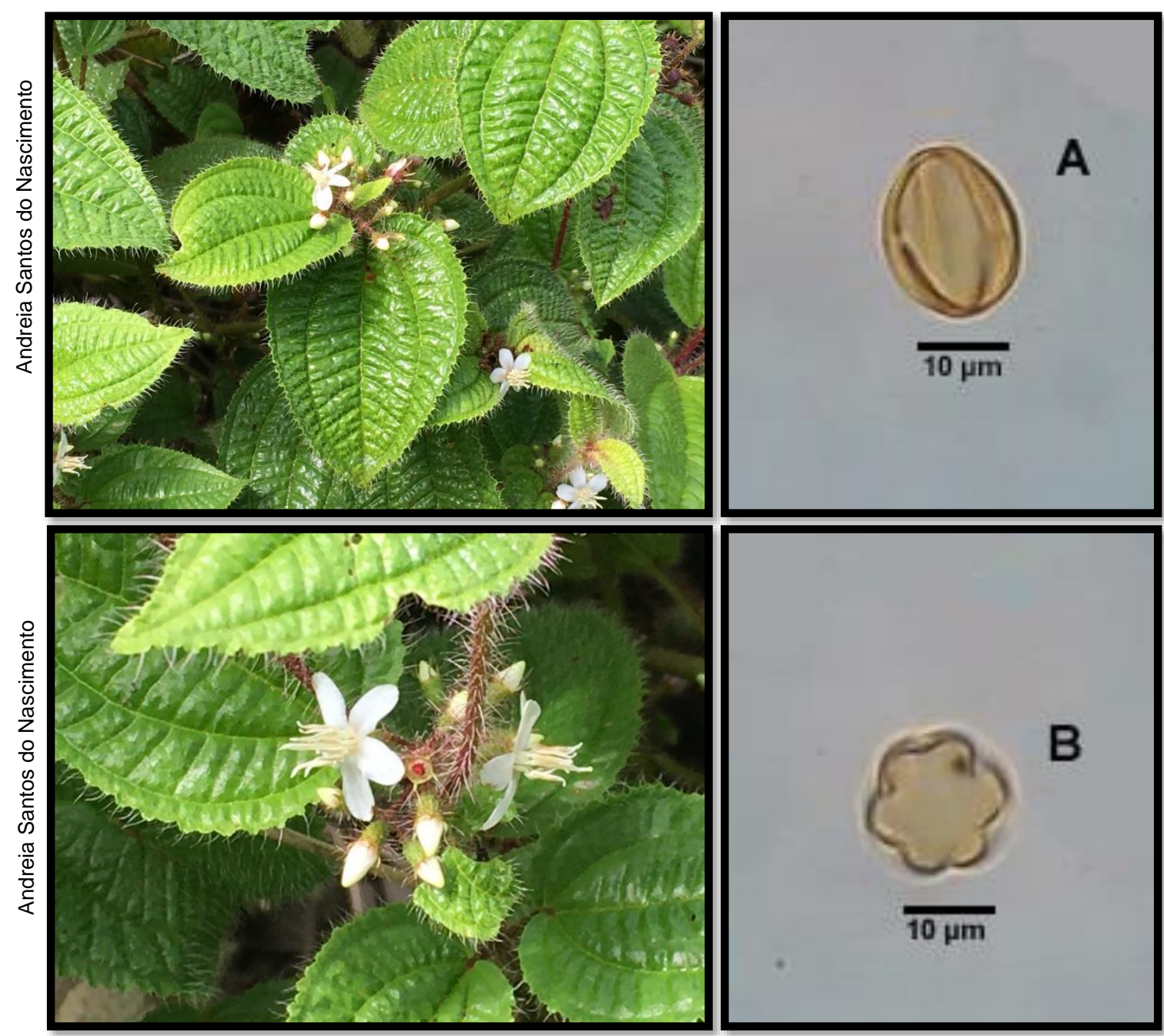

Descrição polínica: $A$ = vista equatorial e $B$ = vista polar, grão de pólen com simetria radial, isopolar, nômade, âmbito circular, abertura polínica do tipo colporo, exina microrreticulada, tamanho pequeno, forma prolata esferoidal, eixo polar $=13,03 \mu \mathrm{m}$; eixo equatorial $=12,72 \mu \mathrm{m} ; \mathrm{P} / \mathrm{E}=1,02 \mu \mathrm{m}$. 


\title{
Melastomataceae
}

\author{
Espécie: Tibouchina granulosa (Desr.) Cogn. \\ Nome comum: Quaresmeira \\ Hábito de crescimento: arbóreo \\ Fonte de recurso trófico: pólen \\ Período de Floração: maio a julho \\ No Palinoteca: NAS20
}

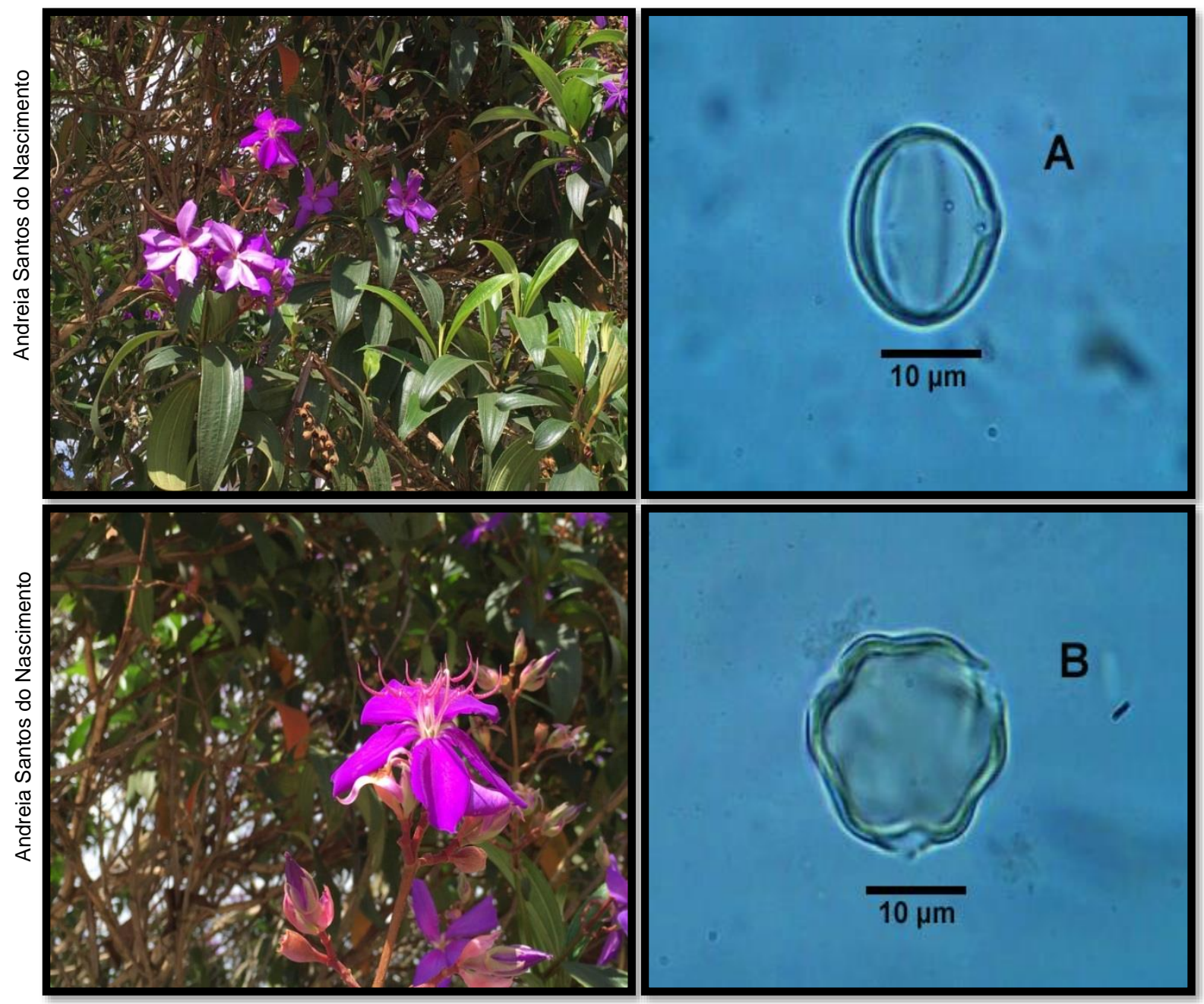

Descrição polínica: $A=$ vista equatorial e $B=$ vista polar, grão de pólen com simetria radial, isopolar, nômade, âmbito circular, abertura polínica do tipo colporo, exina microrreticulada, tamanho pequeno, forma prolata esferoidal, eixo polar $=$ $21,81 \mu \mathrm{m}$; eixo equatorial $=20,90 \mu \mathrm{m} ; \mathrm{P} / \mathrm{E}=1,04 \mu \mathrm{m}$. 


\section{Molluginaceae}

Espécie: Mollugo verticillata $\mathrm{L}$.

Nome comum: Cabelo-de-guia, capim tapete

Hábito de crescimento: herbáceo

Fonte de recurso trófico: pólen

Período de Floração: abril a maio No Palinoteca: PA 34
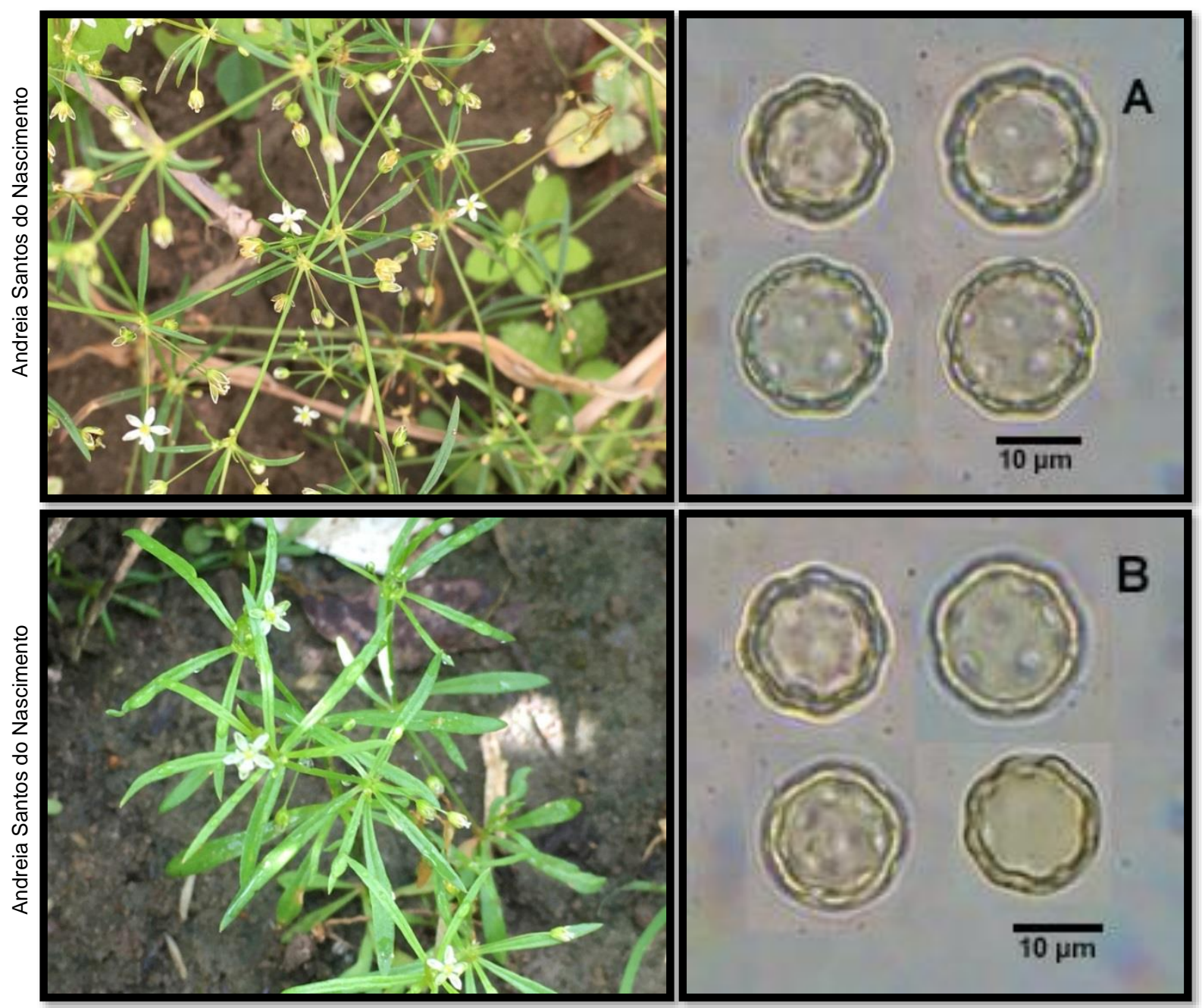

Descrição polínica: $A$ = vista polar, grão de pólen com simetria radial, apolar, nômade, âmbito circular, abertura polínica do tipo colpo, exina microequinada, tamanho pequeno, forma esferoidal, diâmetro do eixo polar $=13,10 \mu \mathrm{m}$; diâmetro do eixo equatorial $=13,10 \mu \mathrm{m} ; \mathrm{P} / \mathrm{E}=1,00 \mu \mathrm{m}$. 


\section{Moringaceae}

Espécie: Moringa oleifera Lam.

Nome comum: Moringa

Hábito de crescimento: arbóreo

Fonte de recurso trófico: néctar/pólen

Período de Floração: janeiro a dezembro

No Palinoteca: PA 07
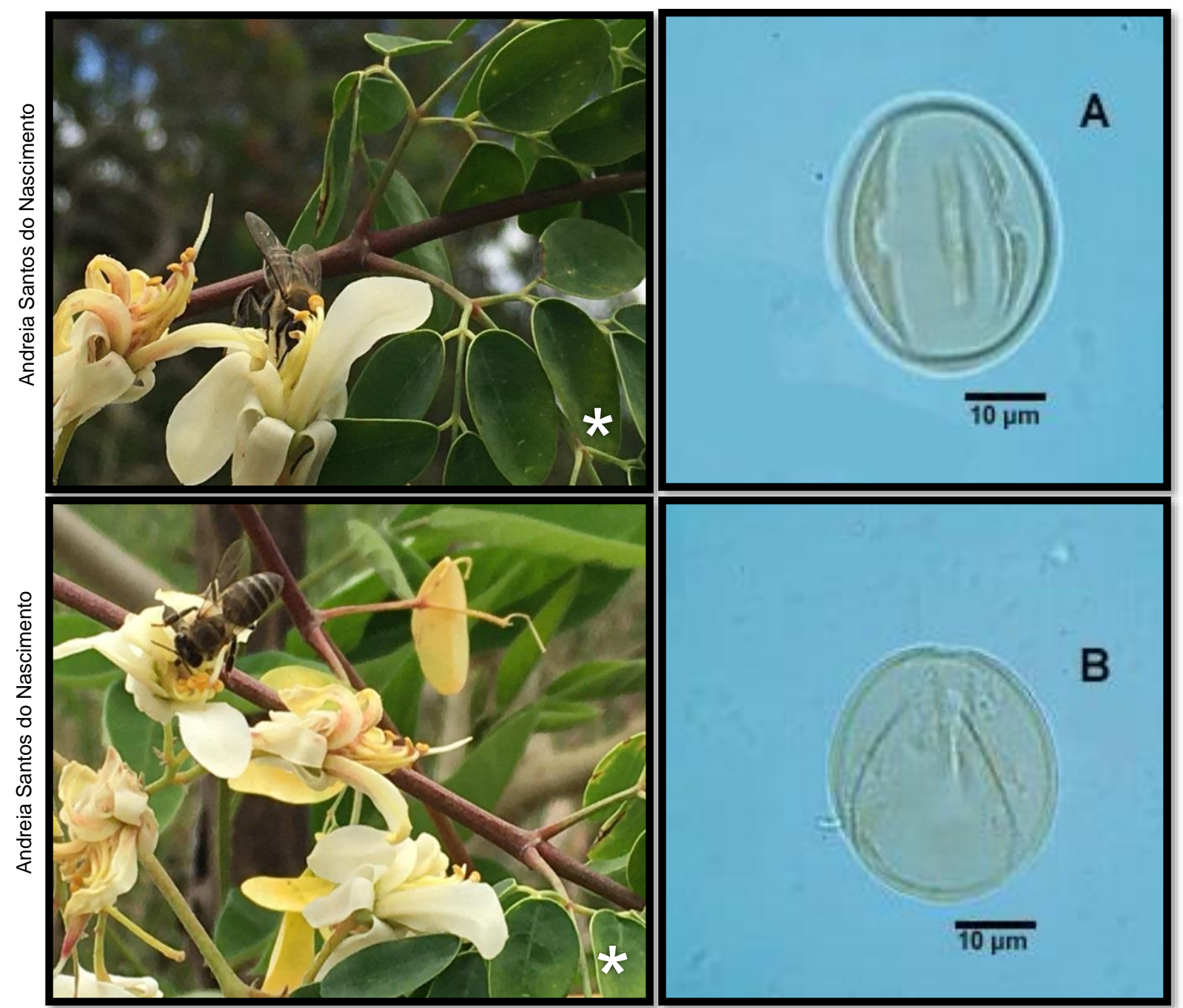

Descrição polínica: A = vista equatorial, grão de pólen com simetria radial, isopolar, nômade, âmbito subtriangular, abertura polínica do tipo colpo, exina microrreticulada, tamanho médio, forma subprolata, eixo polar $=32,42 \mu \mathrm{m}$; eixo equatorial $=28,18 \mu \mathrm{m} ; \mathrm{P} / \mathrm{E}=1,15 \mu \mathrm{m}$.

*Abelha visitante floral: Apis mellifera Linnaeus, 1758. 


\section{Myrtaceae}

Espécie: Eucalyptus alba Reinw. ex Blume

Nome comum: Eucalipto-branco

Hábito de crescimento: arbóreo

Fonte de recurso trófico: néctar/pólen

Período de Floração: janeiro a março

N Palinoteca: PA 106
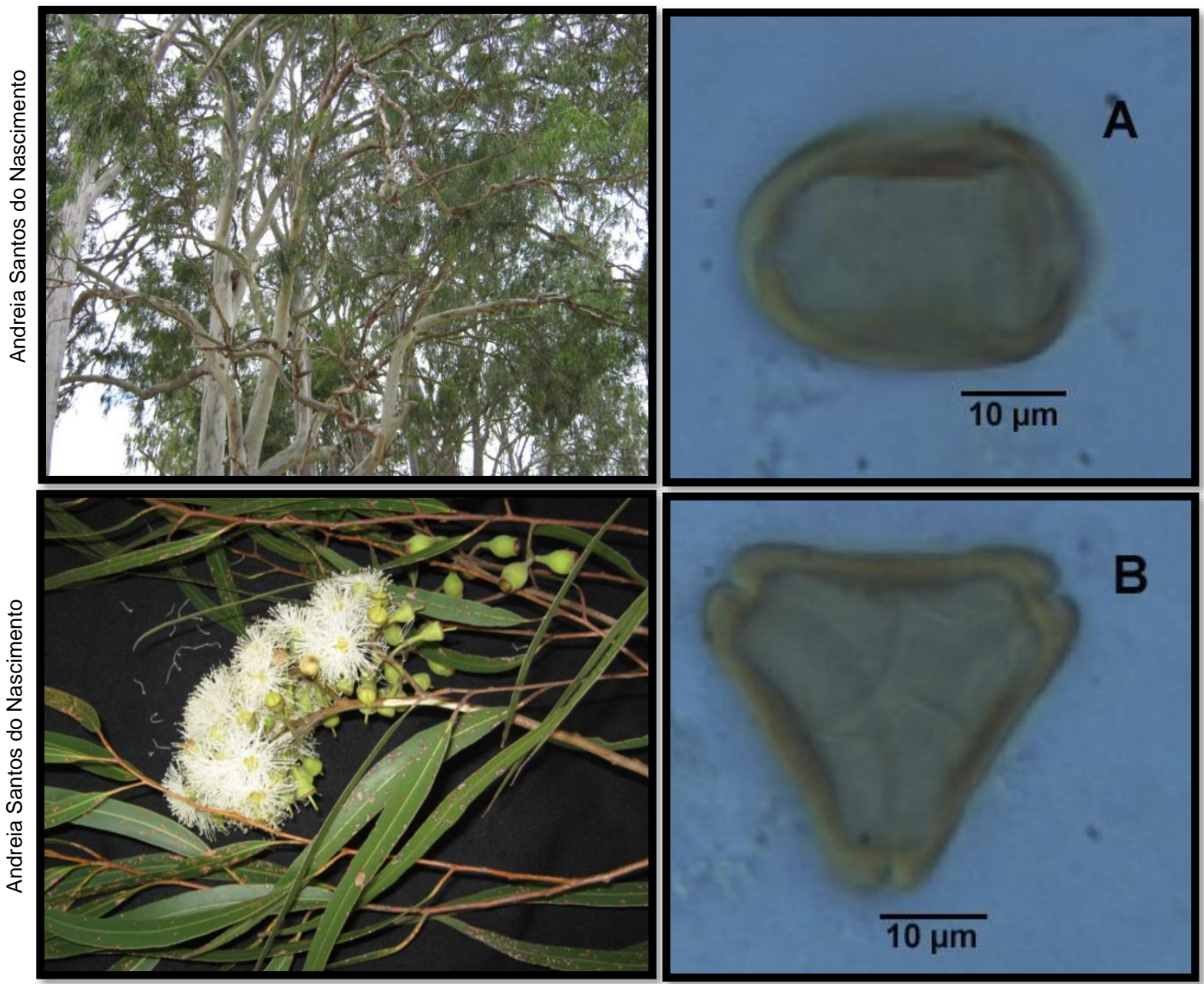

Descrição polínica: $A=$ vista equatorial e $B=$ vista polar, grão de pólen com simetria radial, isopolar, nômade, âmbito triangular, abertura polínica do tipo colporo, parassincolpado, exina psilada, tamanho médio, forma oblata, eixo polar = $17,72 \mu \mathrm{m}$; eixo equatorial $=26,35 \mu \mathrm{m} ; \mathrm{P} / \mathrm{E}=0,67 \mu \mathrm{m}$. 


\section{Myrtaceae}

Espécie: Eucalyptus torelliana F. Muell.

Nome comum: Eucalipto

Hábito de crescimento: arbóreo

Fonte de recurso trófico: néctar/pólen

Período de Floração: janeiro a março

$N^{\circ}$ Palinoteca: PA 188
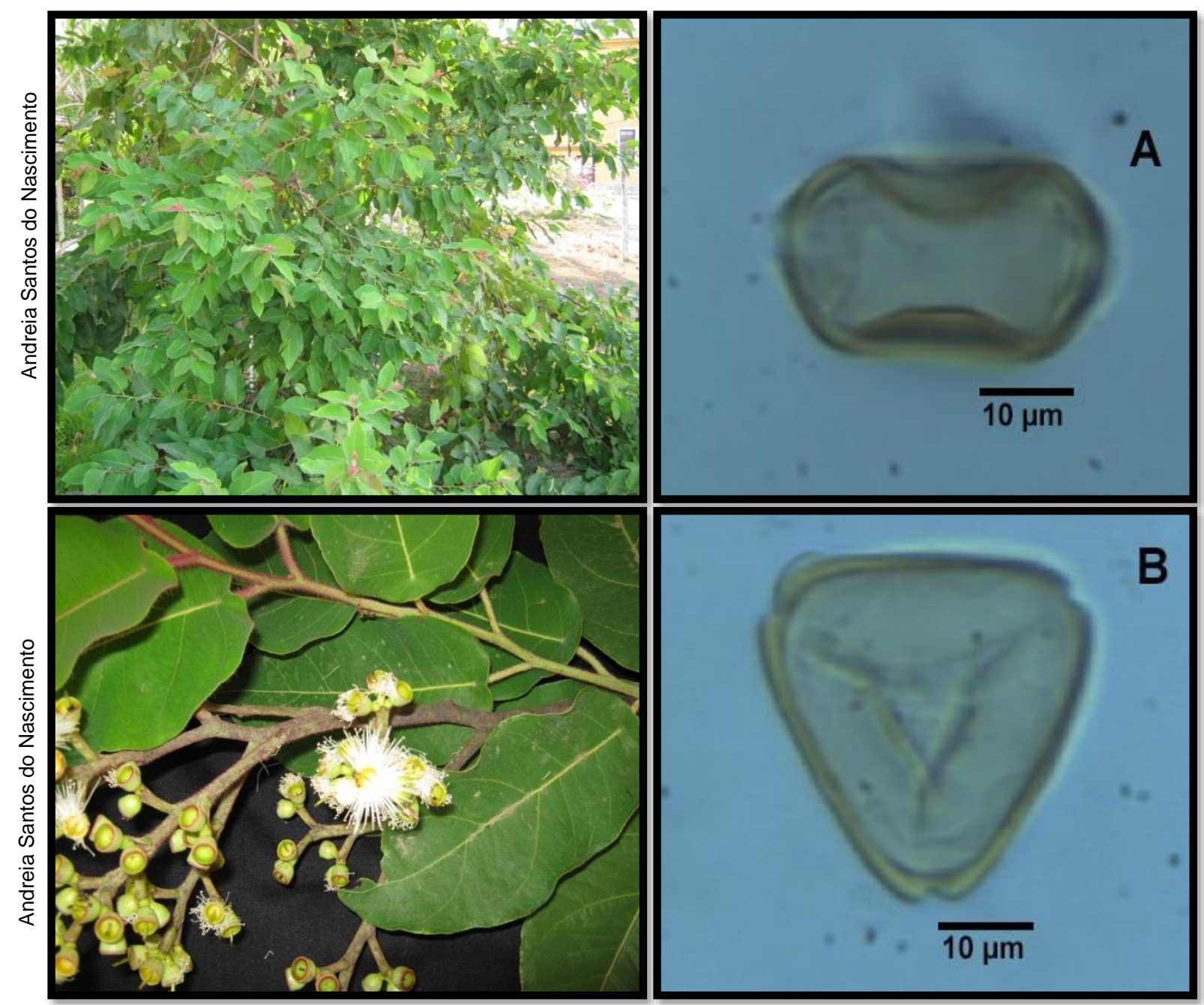

Descrição polínica: $A$ = vista equatorial e $B$ = vista polar, grão de pólen com simetria radial, isopolar, nômade, âmbito triangular, abertura polínica do tipo colporo, parassincolpado, exina psilada, tamanho médio, forma oblata, eixo polar $=15,38 \mu \mathrm{m}$; eixo equatorial $=26,24 \mu \mathrm{m} ; \mathrm{P} / \mathrm{E}=0,60 \mu \mathrm{m}$. 


\section{Myrtaceae}

Espécie: Eugenia uniflora L.

Nome comum: Pitanga

Hábito de crescimento: arbustivo

Fonte de recurso trófico: néctar/pólen

Período de Floração: janeiro a março

No Palinoteca: PA 18

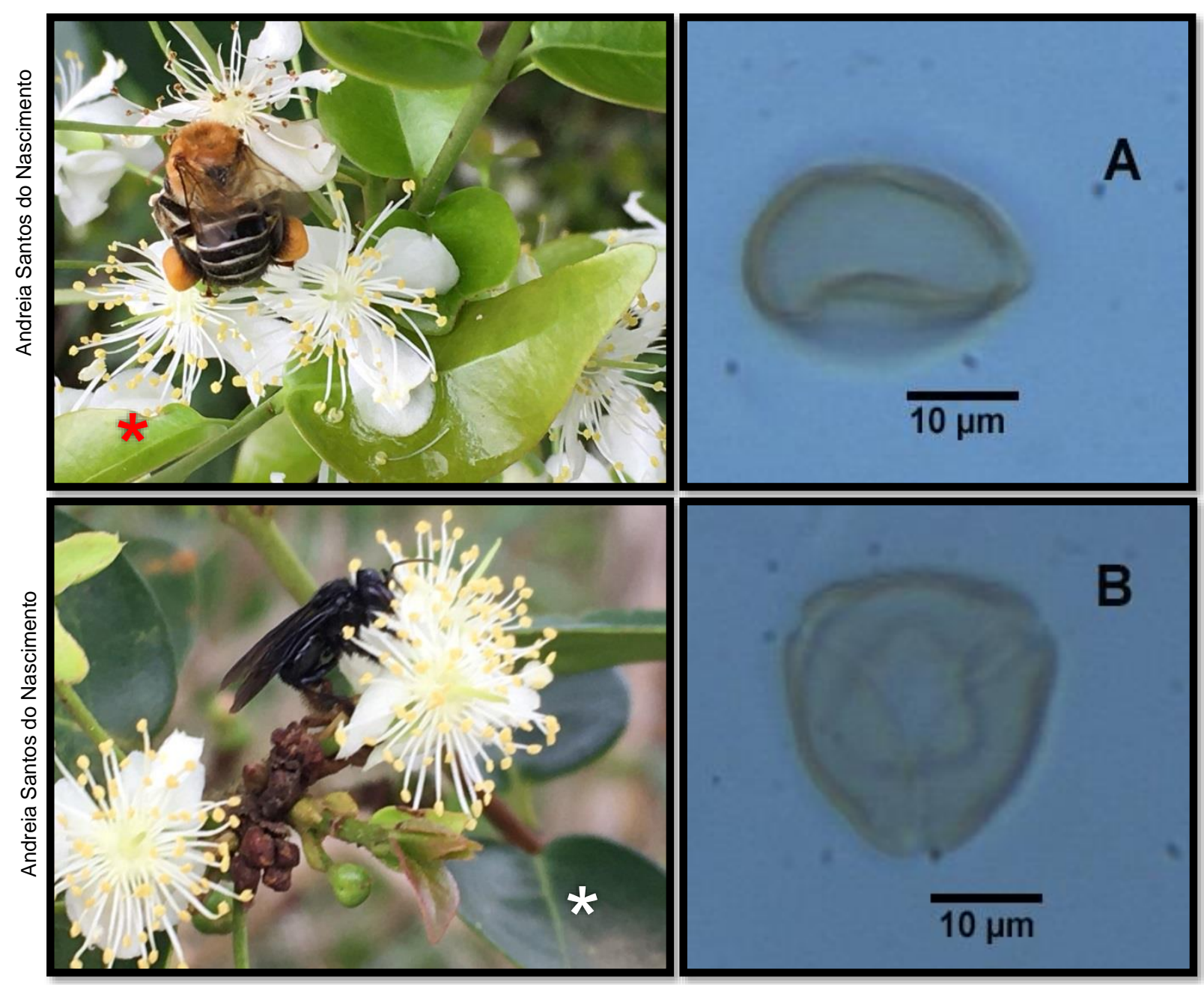

Descrição polínica: $A=$ vista equatorial e $B=$ vista polar, grão de pólen com simetria radial, isopolar, nômade, âmbito triangular, abertura polínica do tipo colporo, parassincolpado, exina psilada, tamanho pequeno, forma oblata, eixo polar $=10,98 \mu \mathrm{m}$; eixo equatorial $=17,08 \mu \mathrm{m} ; \mathrm{P} / \mathrm{E}=0,64 \mu \mathrm{m}$.

*Abelha visitante floral: Melipona scutellaris Latreille, 1811 e Trigona spinipes Fabricius, 1793. 


\section{Myrtaceae}

Espécie: Psidium araca Raddi

Nome comum: Arraça-mirim

Hábito de crescimento: arbustivo

Fonte de recurso trófico: néctar/pólen

Período de Floração: janeiro a março

No Palinoteca: PA 190
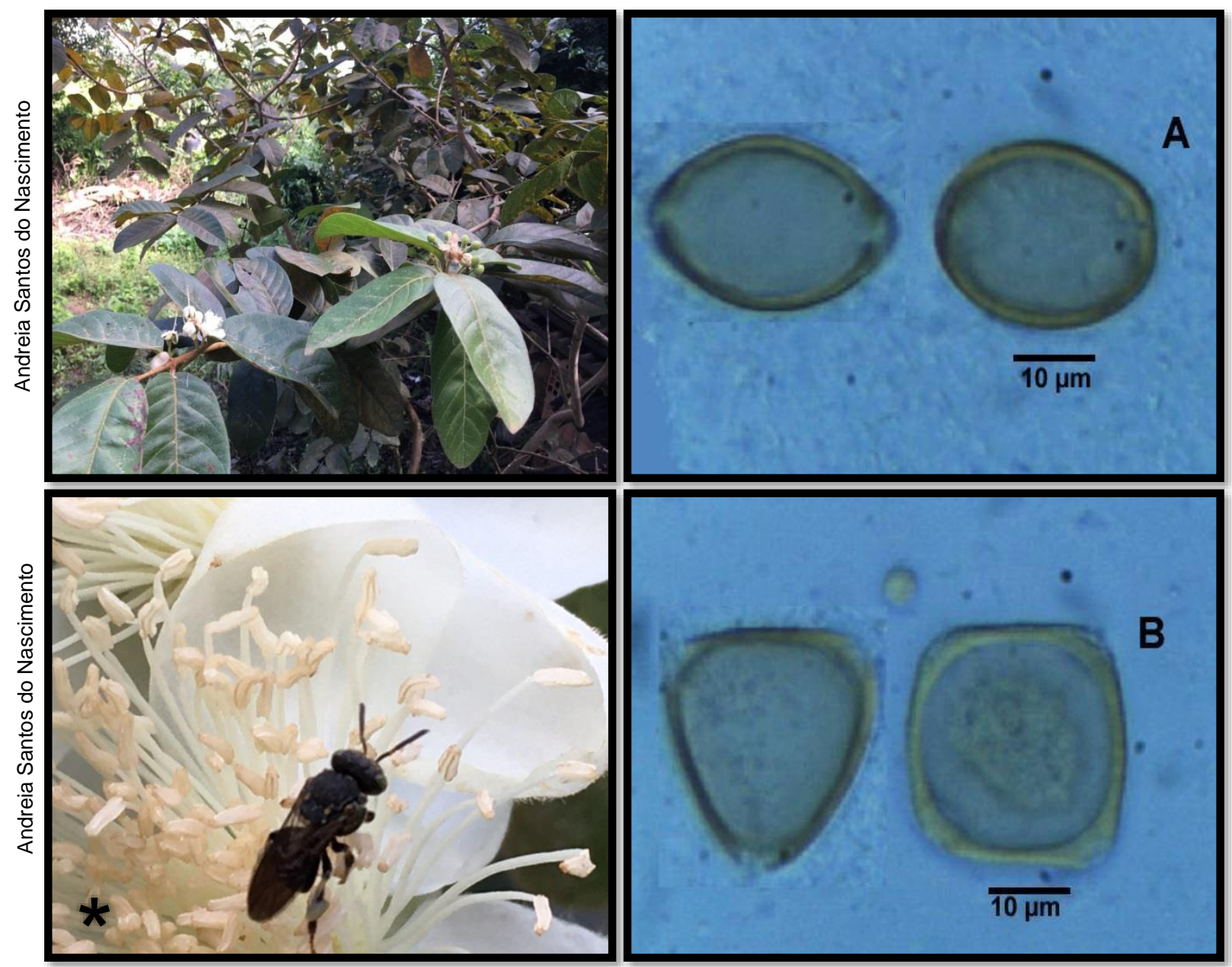

Descrição polínica: $A$ = vista equatorial e $B=$ vista polar, grão de pólen com simetria radial, isopolar, nômade, âmbito triangular/quadrangular, abertura polínica do tipo colporo, parassincolpado, exina psilada, tamanho pequeno, forma oblata, eixo polar = $16,73 \mu \mathrm{m}$; eixo equatorial $=23,33 \mu \mathrm{m} ; \mathrm{P} / \mathrm{E}=0,72 \mu \mathrm{m}$.

*Abelha visitante floral: Nannotrigona testaceicornis Lepeletier, 1836. 


\section{Myrtaceae}

Espécie: Psidium guajava L.

Nome comum: Goiaba

Hábito de crescimento: arbustivo

Fonte de recurso trófico: néctar/pólen

Período de Floração: janeiro a março

No Palinoteca: PA 94
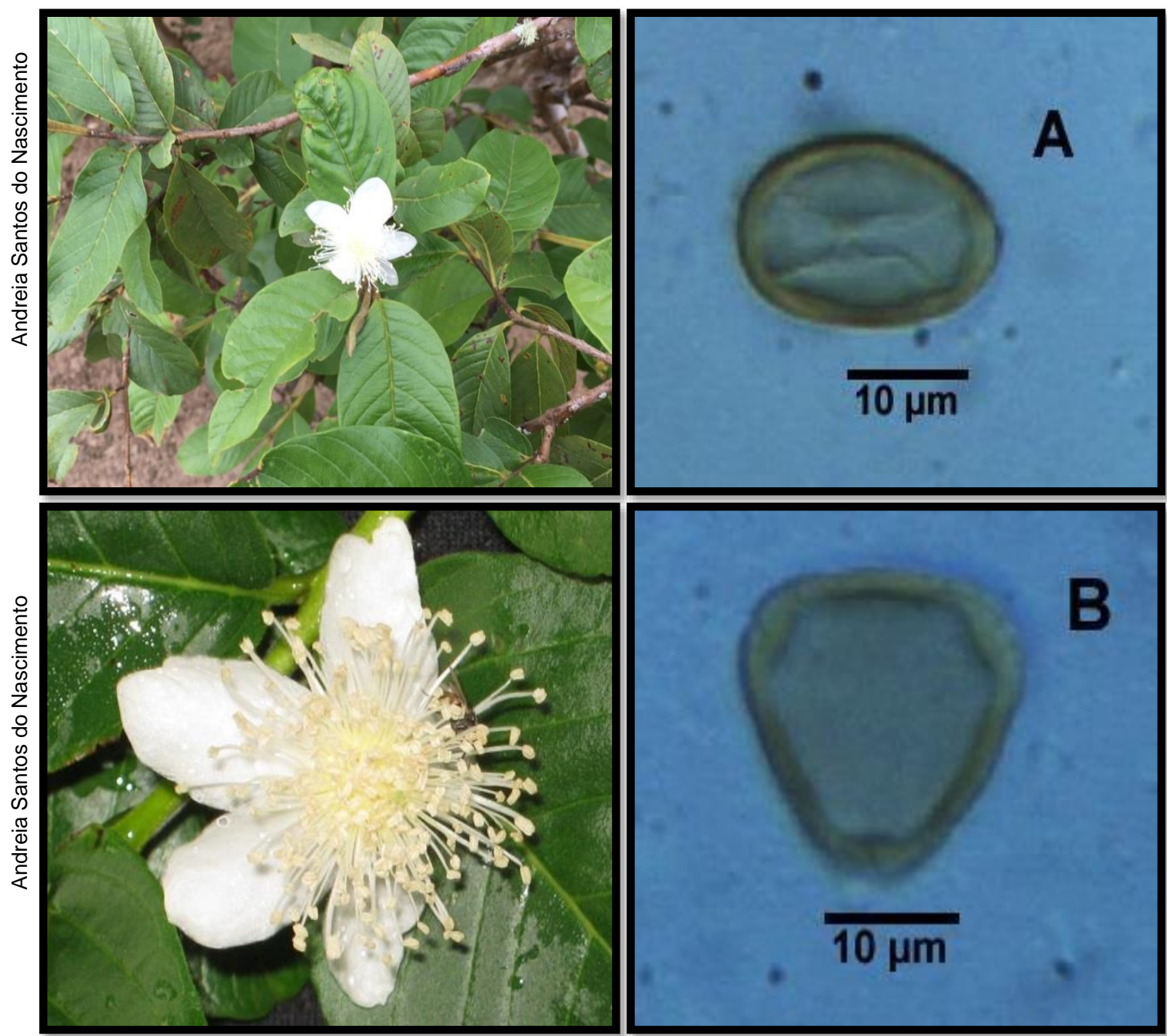

Descrição polínica: $A=$ vista equatorial e $B=$ vista polar, grão de pólen com simetria radial, isopolar, nômade, âmbito triangular, abertura polínica do tipo colporo, parassincolpado, exina psilada, tamanho pequeno, forma oblata, eixo polar = 10,39 $\mu \mathrm{m}$; eixo equatorial $=16,69 \mu \mathrm{m} ; \mathrm{P} / \mathrm{E}=0,62 \mu \mathrm{m}$. 


\section{Myrtaceae}

Espécie: Syzygium cumini (L.) Skeels

Nome comum: Jamelão

Hábito de crescimento: arbóreo

Fonte de recurso trófico: néctar/pólen

Período de Floração: janeiro a março

No Palinoteca: PA 115

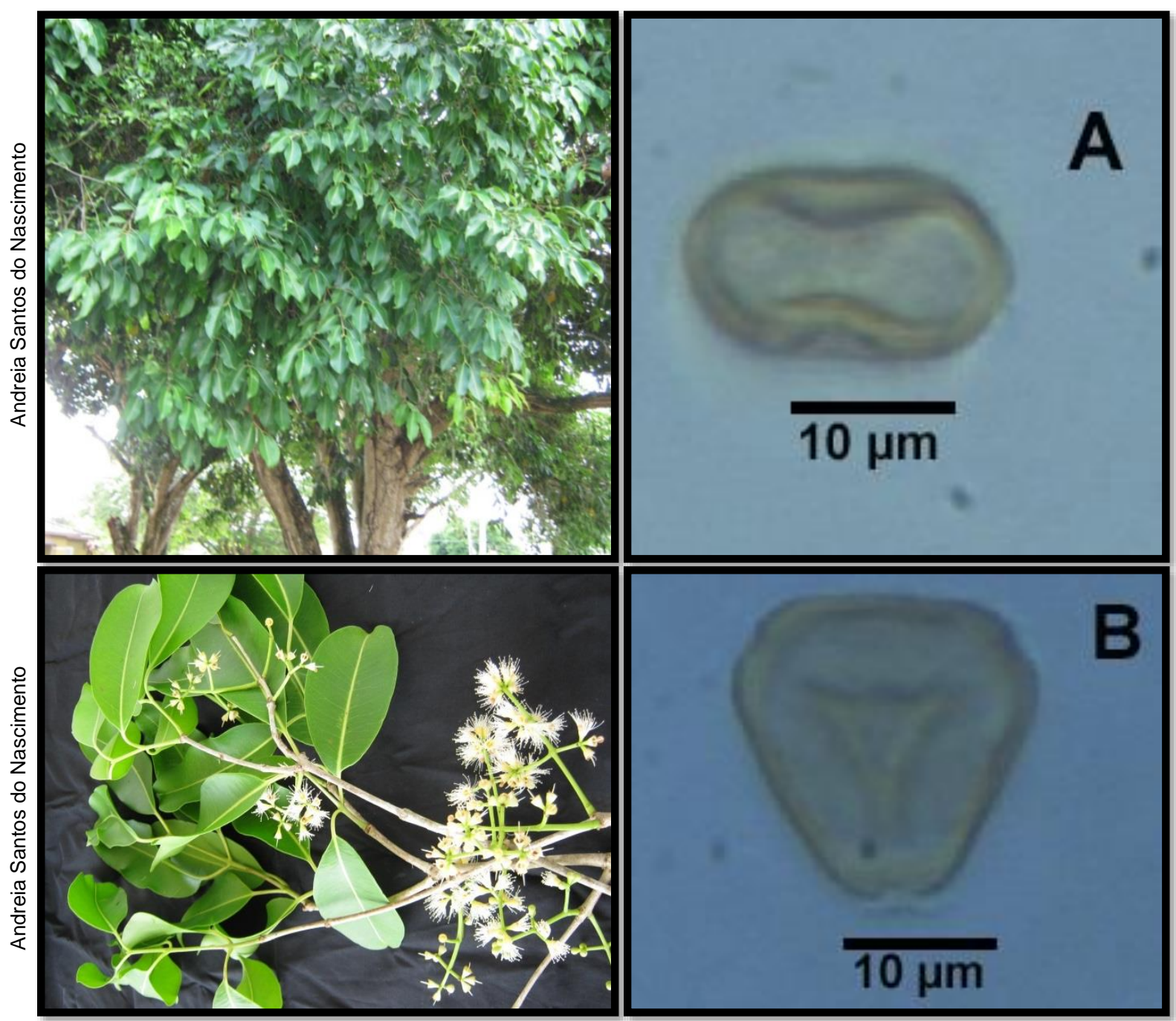

Descrição polínica: $A=$ vista equatorial e $B=$ vista polar, grão de pólen com simetria radial, isopolar, nômade, âmbito triangular, abertura polínica do tipo colporo, parassincolpado, exina psilada, tamanho pequeno, forma oblata, eixo polar = 9,68 $\mu \mathrm{m}$; eixo equatorial $=16,21 \mu \mathrm{m} ; \mathrm{P} / \mathrm{E}=0,60 \mu \mathrm{m}$. 


\section{Myrtaceae}

Espécie: Syzygium malaccensis (L.) Merr. \& L.M.Perry

Nome comum: Jambo

Hábito de crescimento: arbóreo

Fonte de recurso trófico: néctar/pólen

Período de Floração: novembro a dezembro

No Palinoteca: PA 110

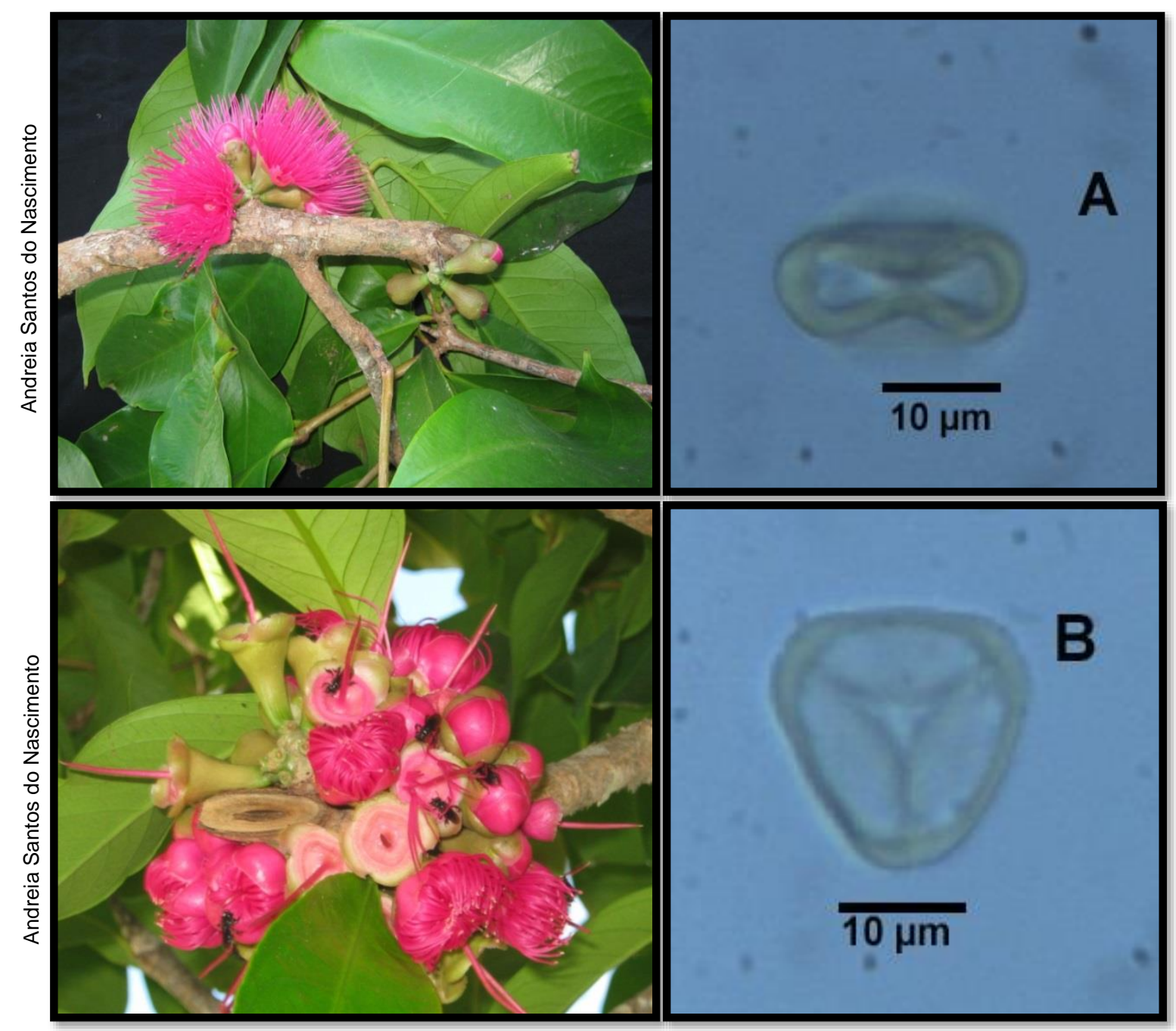

Descrição polínica: $A$ = vista equatorial e $B=$ vista polar, grão de pólen com simetria radial, isopolar, nômade, âmbito triangular, abertura polínica do tipo colporo, parassincolpado, exina psilada, tamanho pequeno, forma oblata, eixo polar $=8,76 \mu \mathrm{m}$; eixo equatorial $=17,00 \mu \mathrm{m} ; \mathrm{P} / \mathrm{E}=0,52 \mu \mathrm{m}$.

*Abelha visitante floral: Trigona spinipes Fabricius, 1793. 


\section{Papaveraceae}

Espécie: Argemone mexicana L.

Nome comum: Papoula

Hábito de crescimento: herbáceo

Fonte de recurso trófico: pólen

Período de Floração: julho a agosto

No Palinoteca: PA 80
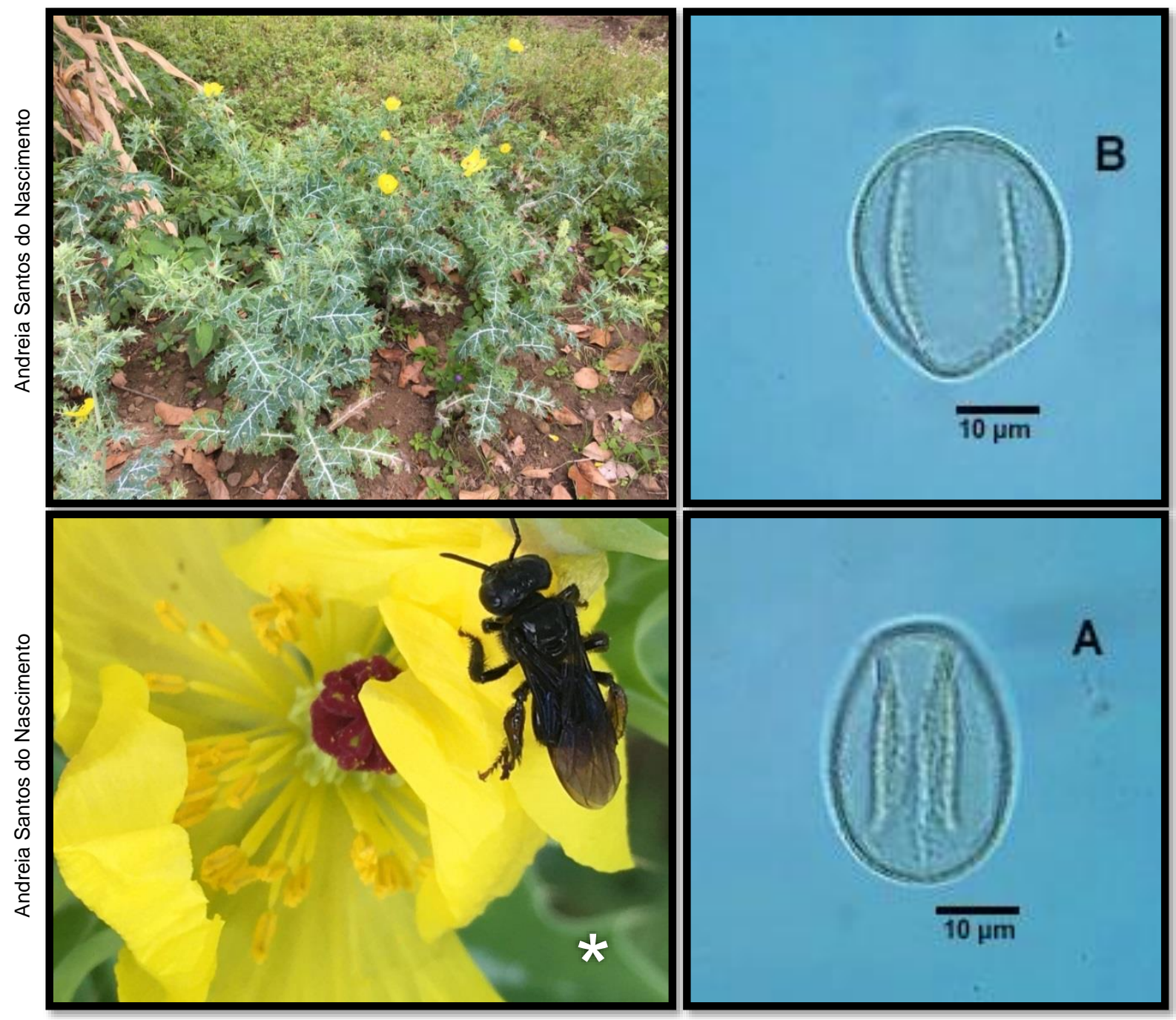

Descrição polínica: A-B = vista equatorial, grão de pólen com simetria radial, isopolar, nômade, âmbito subtriangular, abertura polínica do tipo colporo, exina escabrada, tamanho médio, forma oblata, eixo polar $=29,69 \mu \mathrm{m}$; eixo equatorial $=$ 22,72 $\mu \mathrm{m} ; \mathrm{P} / \mathrm{E}=1,30 \mu \mathrm{m}$.

${ }^{*}$ Abelha visitante floral: Trigona spinipes Fabricius, 1793. 


\section{Passifloraceae}

Espécie: Passiflora foetida L.

Nome comum: Maracujá silvestre

Hábito de crescimento: liana

Fonte de recurso trófico: pólen

Período de Floração: março a junho

No Palinoteca: PA 105
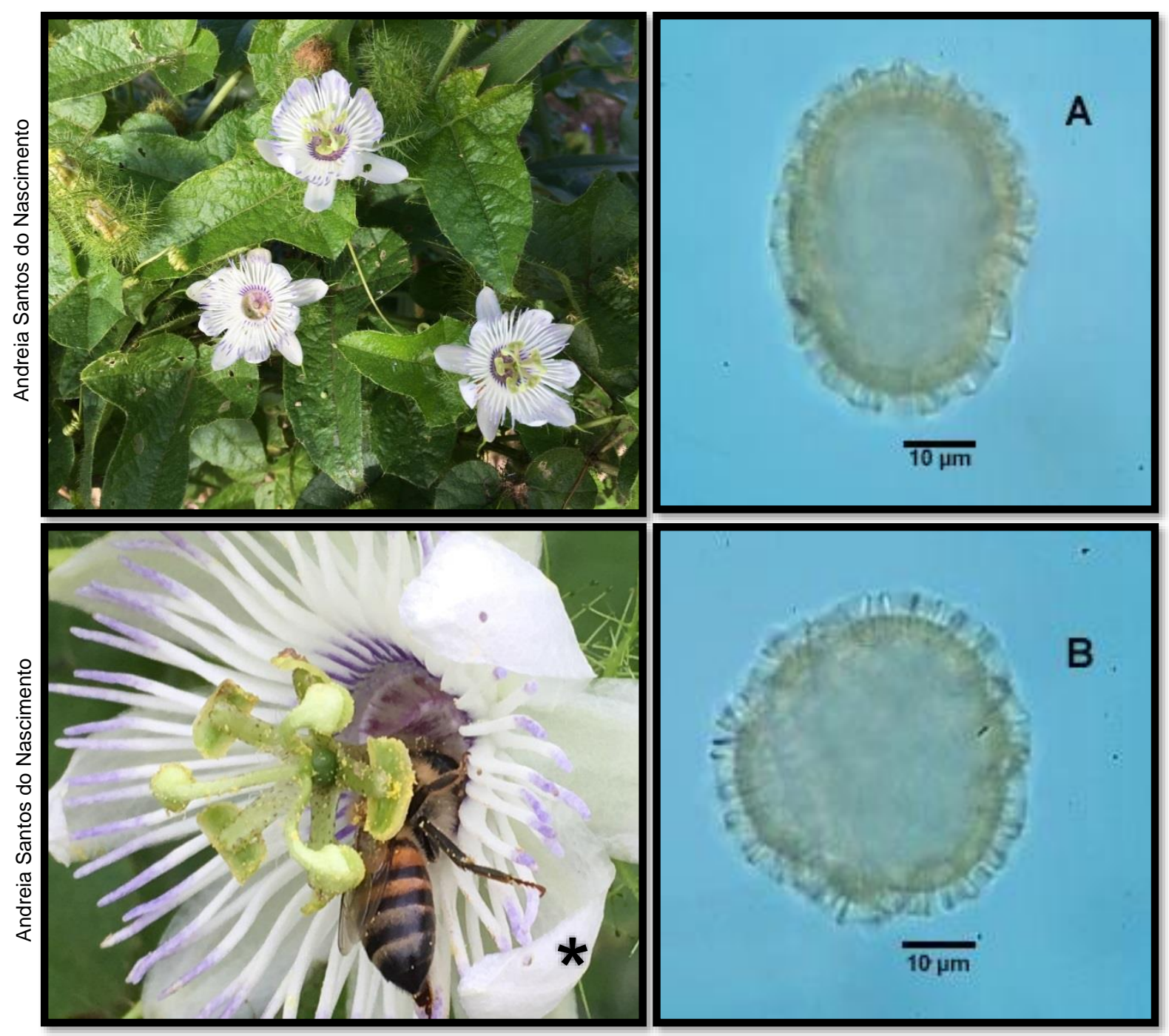

Descrição polínica: $A$ = vista equatorial e $B=$ vista polar, grão de pólen com simetria radial, isopolar, nômade, âmbito circular, abertura polínica do tipo colpo, sincolpado exina heterobrocada/reticulada, tamanho grande, forma prolata esferoidal, eixo maior $=54,54 \mu \mathrm{m}$; eixo menor $=51,51 \mu \mathrm{m} ; \mathrm{P} / \mathrm{E}=1,05 \mu \mathrm{m}$.

${ }^{*}$ Abelha visitante floral: Apis mellifera Linnaeus, 1758. 


\section{Plantaginaceae}

Espécie: Scoparia dulcis L.

Nome comum: Vassourinha-doce

Hábito de crescimento: herbáceo

Fonte de recurso trófico: néctar

Período de Floração: março a agosto

No Palinoteca: PA 25
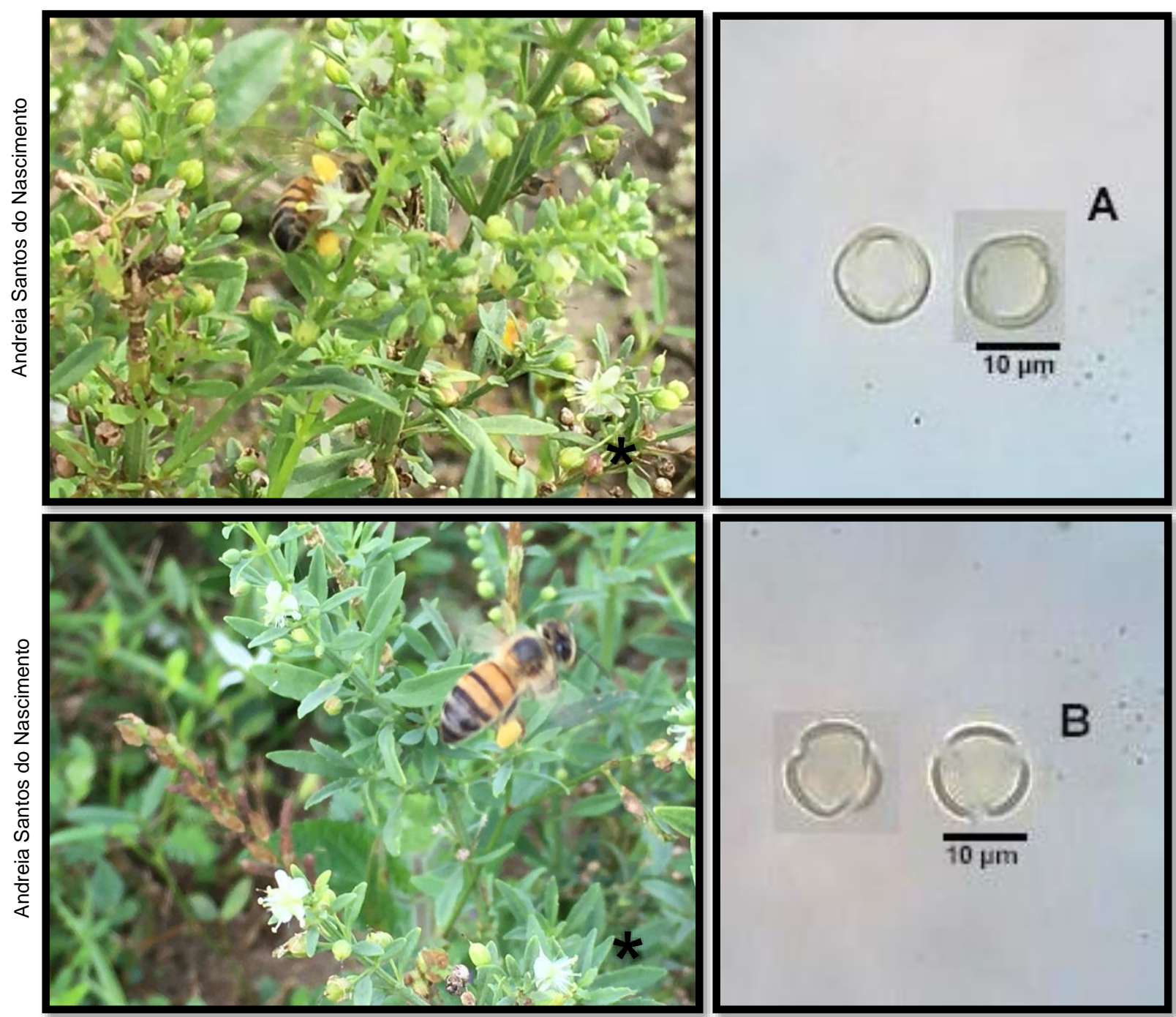

Descrição polínica: $A=$ vista equatorial e $B=$ vista polar, grão de pólen com simetria radial, isopolar, nômade, âmbito subtriangular, abertura polínica do tipo colporo, exina microrreticulada, tamanho muito pequeno, forma prolata esferoidal, eixo polar $=9,09 \mu \mathrm{m}$; eixo equatorial $=8,48 \mu \mathrm{m} ; \mathrm{P} / \mathrm{E}=1,07 \mu \mathrm{m}$.

*Abelha visitante floral: Apis mellifera Linnaeus, 1758. 


\section{Plantaginaceae}

Espécie: Stemodia sp.

Nome comum: meladinha

Hábito de crescimento: arbustivo

Fonte de recurso trófico: pólen

Período de Floração: maio a junho

No Palinoteca: NAS21

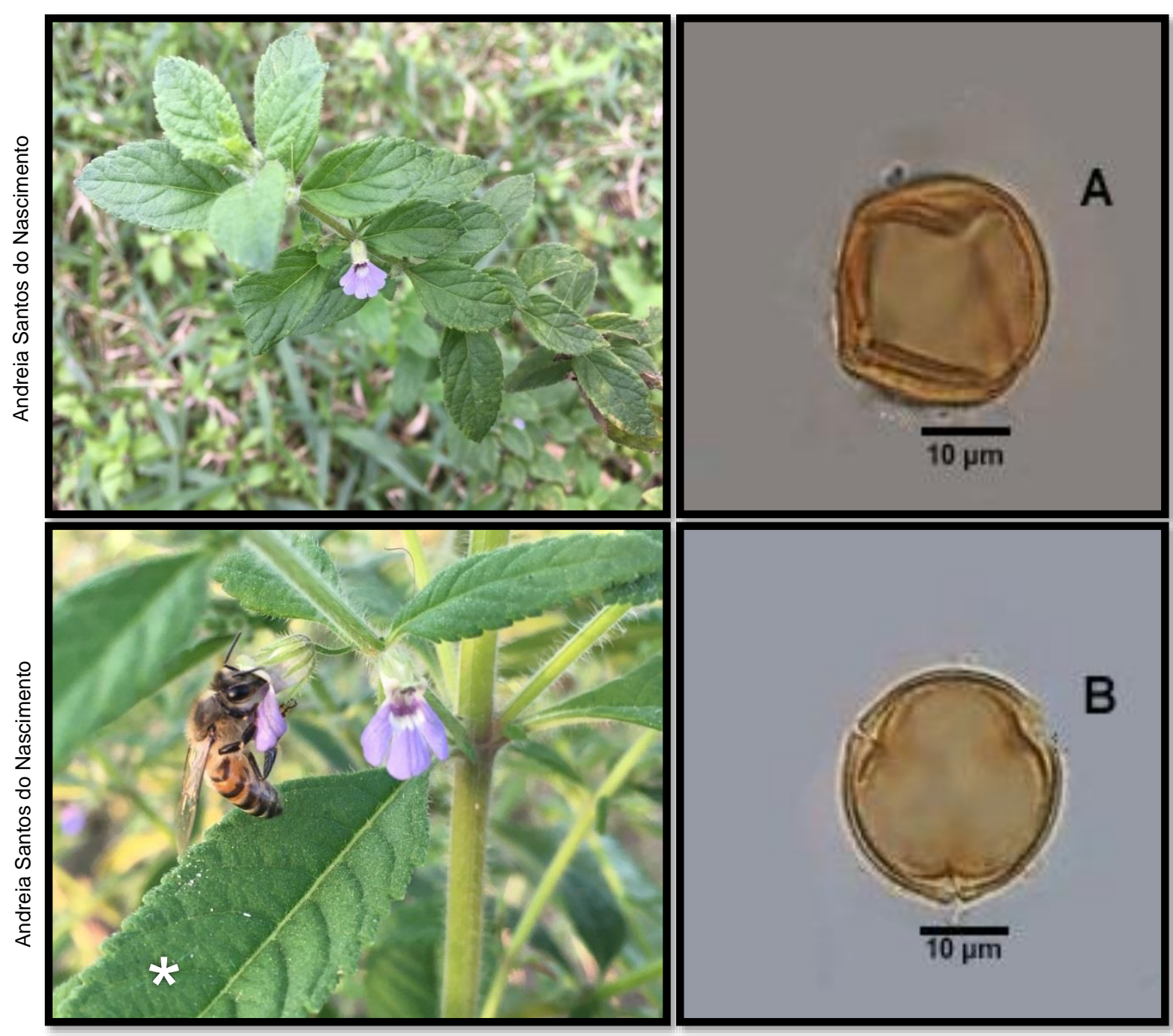

Descrição polínica: $A=$ vista equatorial e $B=$ vista polar, grão de pólen com simetria radial, isopolar, nômade, âmbito subtriangular, abertura polínica do tipo colporo, exina microrreticulada, tamanho muito médio, forma prolata esferoidal, eixo polar $=26,36 \mu \mathrm{m}$; eixo equatorial $=25,54 \mu \mathrm{m} ; \mathrm{P} / \mathrm{E}=1,03 \mu \mathrm{m}$.

*Abelha visitante floral: Apis mellifera Linnaeus, 1758. 


\section{Plumbaginaceae}

Espécie: Plumbago auriculata Lam.

Nome comum: Jasmim-azul

Hábito de crescimento: herbáceo

Fonte de recurso trófico: néctar/pólen

Período de Floração: março a julho

No Palinoteca: NAS22

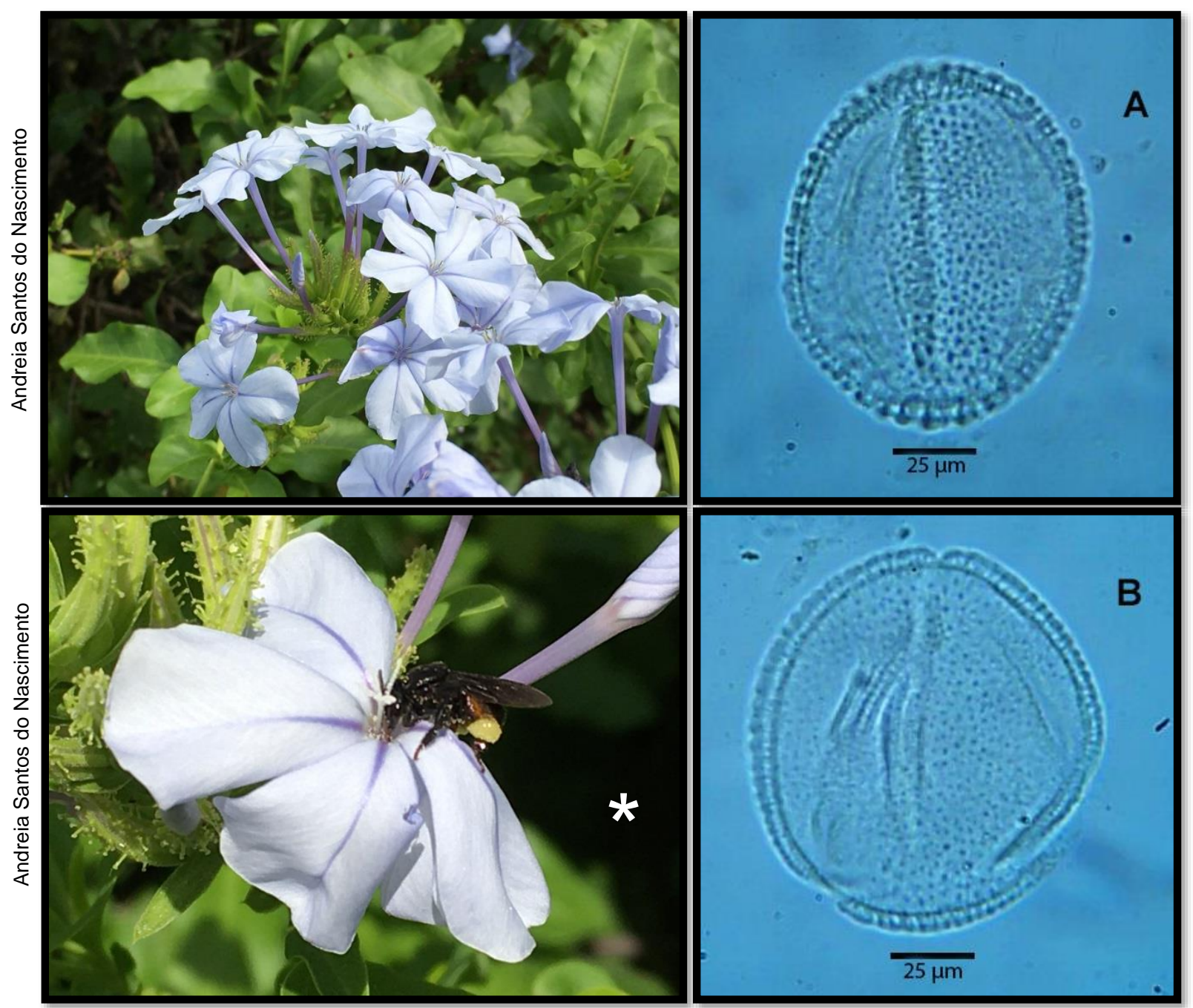

Descrição polínica: $A-B=$ vista equatorial, grão de pólen com simetria radial, isopolar, nômade, âmbito subtriangular, abertura polínica do tipo colpo, exina, reticulada/heterobrocada, tamanho muito grande, forma prolata esferoidal, eixo polar $=124,03 \mu \mathrm{m}$; eixo equatorial $=108,52 \mu \mathrm{m} ; \mathrm{P} / \mathrm{E}=1,14 \mu \mathrm{m}$.

*Abelha visitante floral: Trigona spinipes Fabricius, 1793. 


\section{Poaceae}

Espécie: Sorghum bicolor (L.) Moench

Nome comum: Sorgo

Hábito de crescimento: gramínea

Fonte de recurso trófico: pólen

Período de Floração: março a junho

No Palinoteca: PA 101
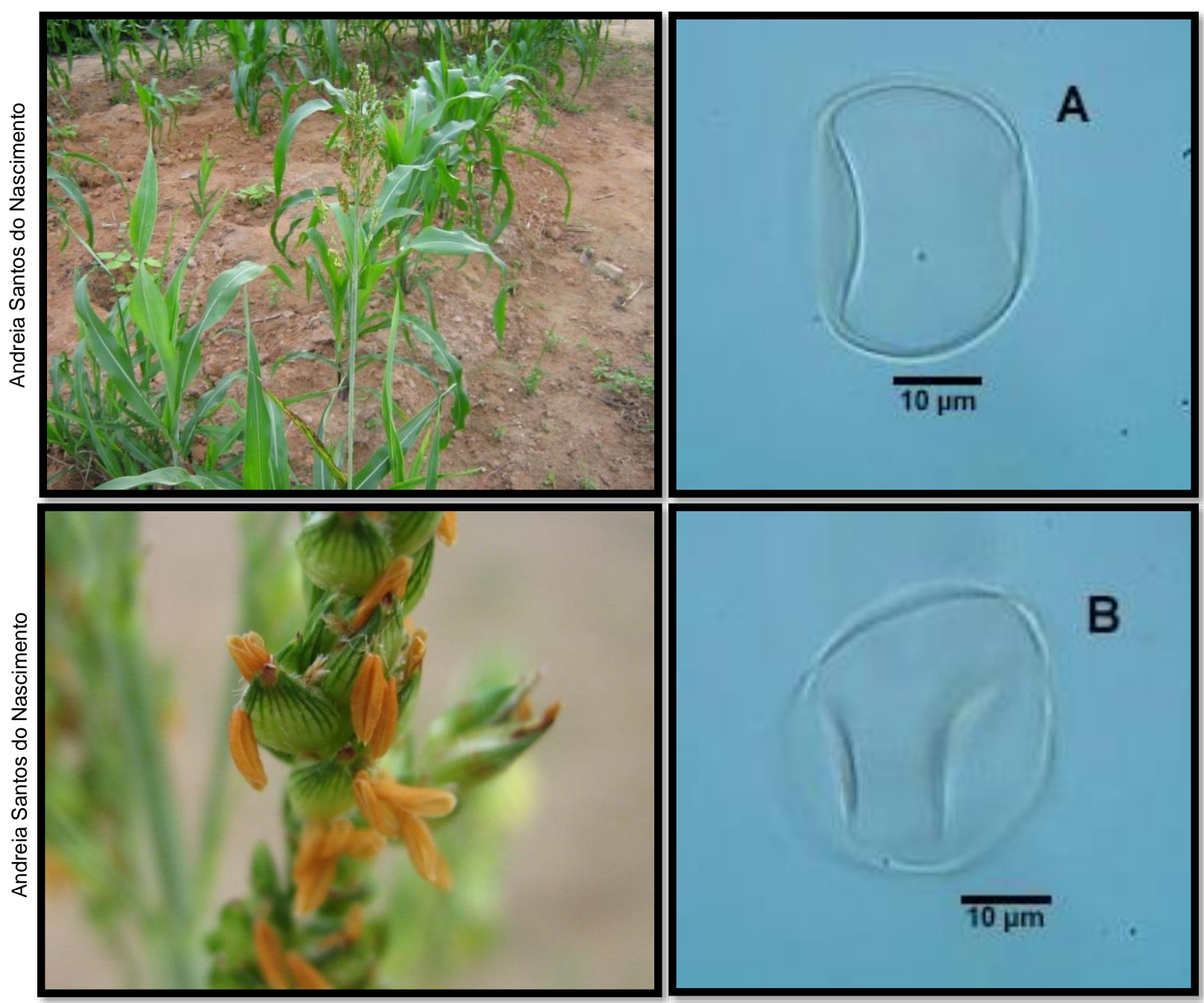

Descrição polínica: A-B = vista polar, grão de pólen com simetria radial, heteropolar, nômade, âmbito circular, abertura polínica do tipo poro, exina microequinada, tamanho médio, forma esferoidal, diâmetro do eixo polar $=37,57 \mu \mathrm{m}$; diâmetro do eixo equatorial $=37,27 \mu \mathrm{m} ; \mathrm{P} / \mathrm{E}=1,00 \mu \mathrm{m}$. 


\section{Poaceae}

Espécie: Zea mays L.

Nome comum: Milho

Hábito de crescimento: gramínea

Fonte de recurso trófico: pólen

Período de Floração: março a junho

No Palinoteca: PA 155

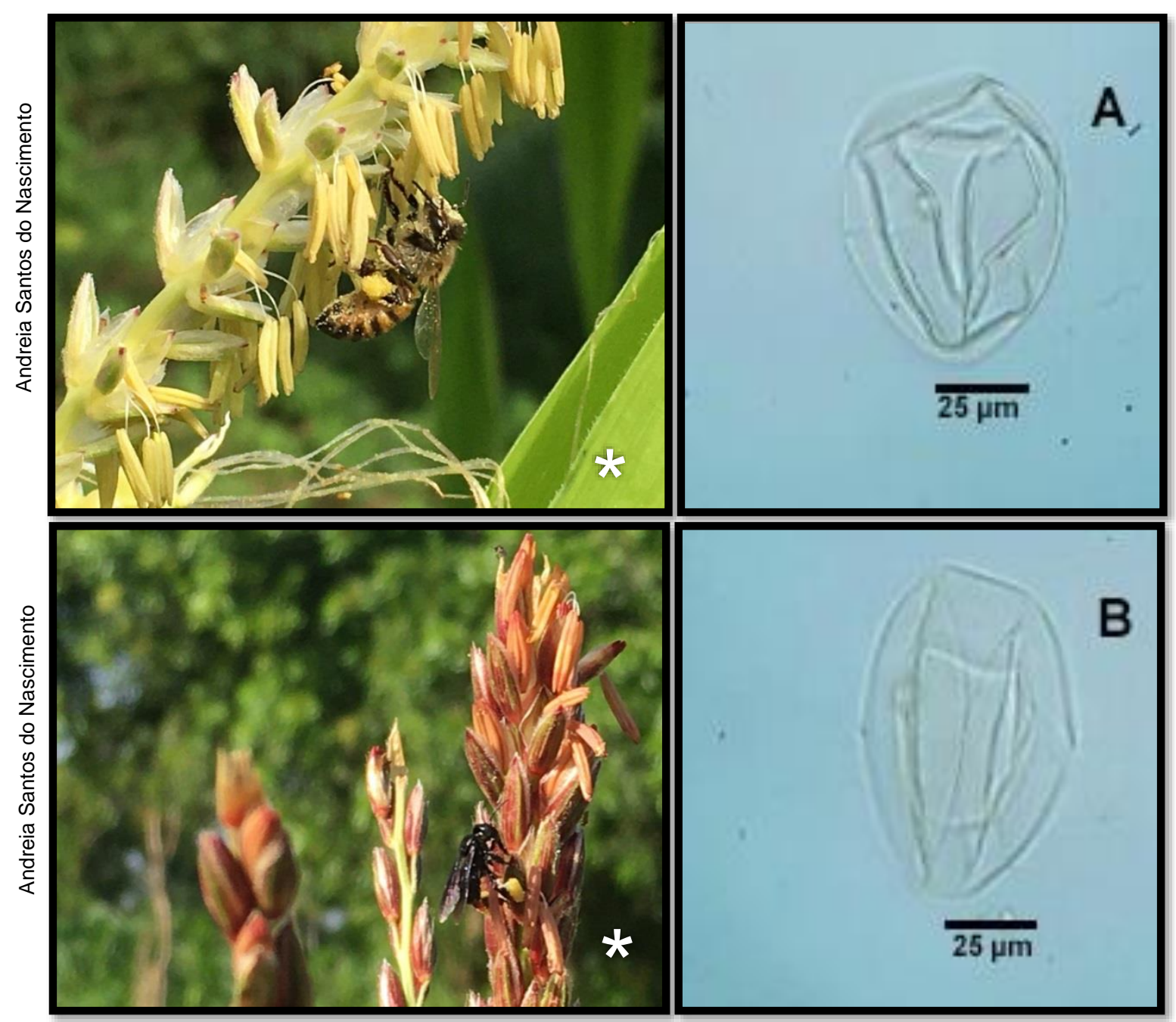

Descrição polínica: A-B = vista polar, grão de pólen com simetria radial, heteropolar, nômade, âmbito circular, abertura polínica do tipo poro, exina microequinada, tamanho muito grande, forma esferoidal, eixo polar $=103,01 \mu \mathrm{m}$; eixo equatorial $=$ $102,32 \mu \mathrm{m} ; \mathrm{P} / \mathrm{E}=1,00 \mu \mathrm{m}$.

*Abelha visitante floral: Apis mellifera Linnaeus, 1758 e Trigona spinipes Fabricius, 1793. 


\section{Polygonaceae}

Espécie: Antigonon leptopus Hook. \& Arn.

Nome comum: Mimo-do-céu

Hábito de crescimento: liana

Fonte de recurso trófico: pólen

Período de Floração: janeiro a dezembro

No Palinoteca: PA 13
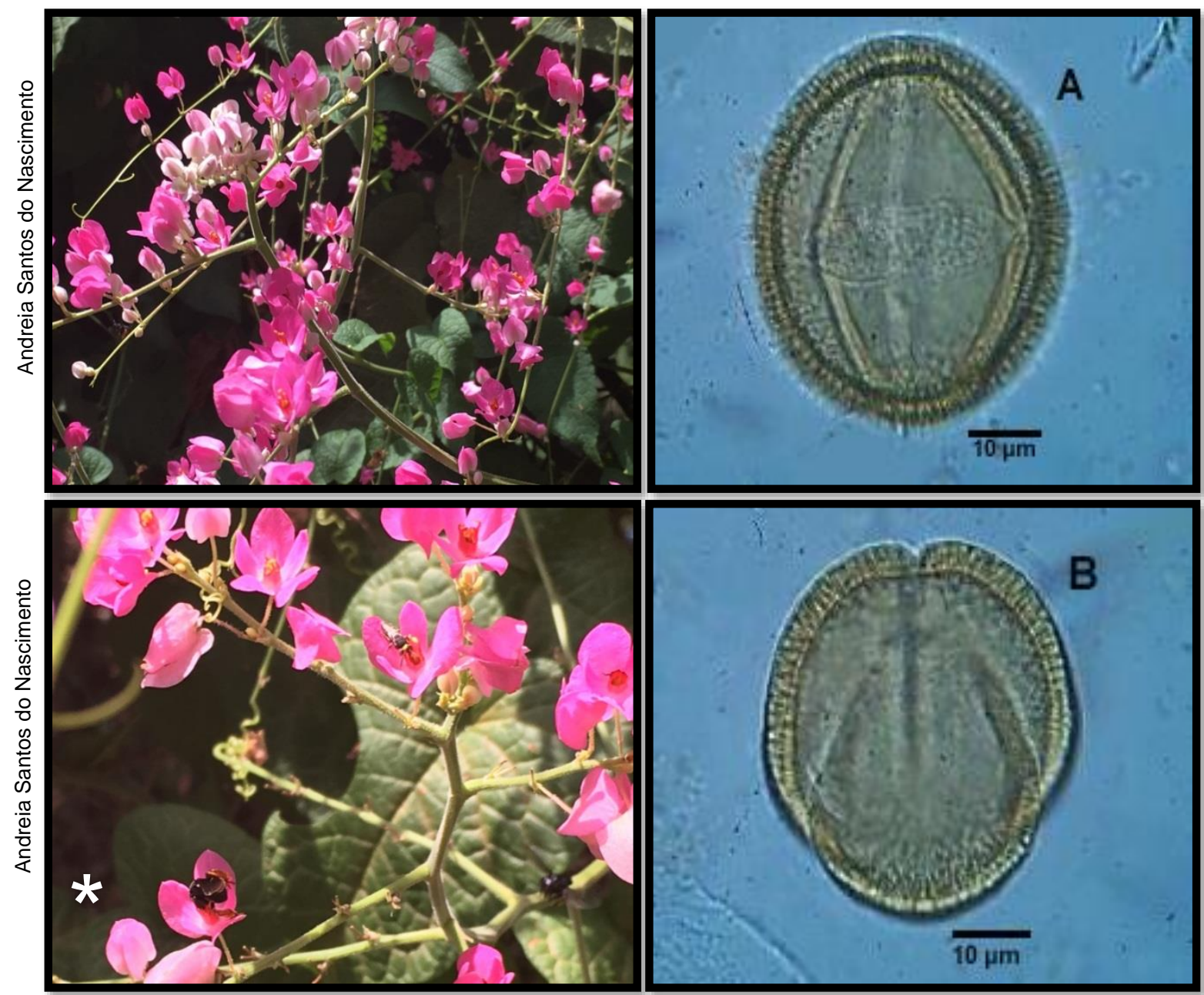

Descrição polínica: $A-B=$ vista equatorial, grão de pólen com simetria radial, isopolar, nômade, âmbito subtriangular, abertura polínica do tipo colporo, exina reticulada, tamanho grande, forma prolata esferoidal, eixo polar $=51,81 \mu \mathrm{m}$; eixo equatorial $=47,27 \mu \mathrm{m} ; \mathrm{P} / \mathrm{E}=1,09 \mu \mathrm{m}$.

*Abelha visitante floral: Trigona spinipes Fabricius, 1793. 


\section{Portulacaceae}

Espécie: Portulaca oleracea L.

Nome comum: Beldroega

Hábito de crescimento: herbáceo

Fonte de recurso trófico: pólen

Período de Floração: março a junho

No Palinoteca: PA 16

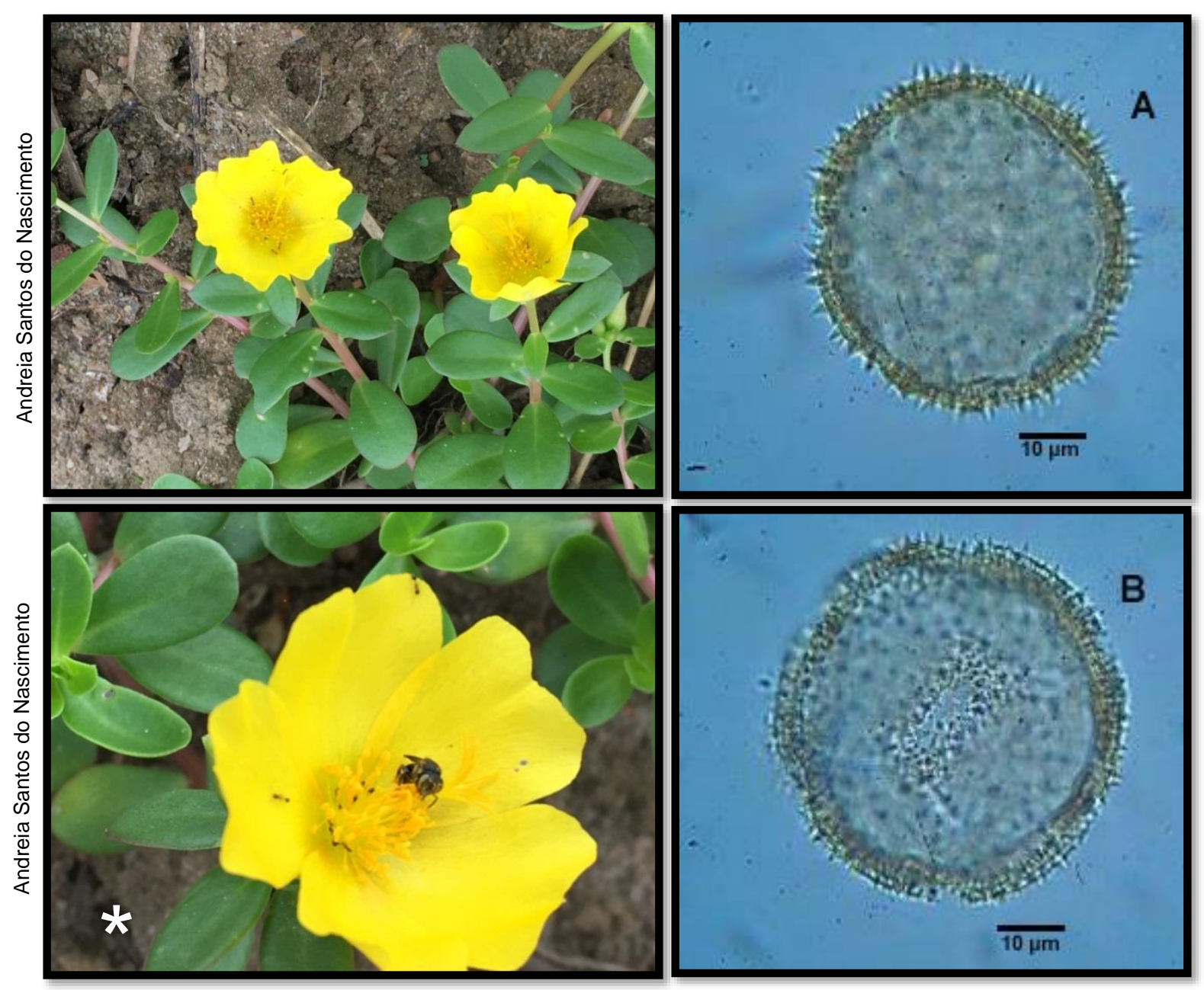

Descrição polínica: A-B = vista polar, grão de pólen com simetria radial, apolar, nômade, âmbito circular, abertura polínica do tipo colpo, exina equinada, tamanho grande, forma esferoidal, diâmetro do eixo polar $=51,21 \mu \mathrm{m}$; diâmetro do eixo equatorial $=51,51 \mu \mathrm{m} ; \mathrm{P} / \mathrm{E}=1,00 \mu \mathrm{m}$.

${ }^{*}$ Abelha visitante floral: Nannotrigona testaceicornis Lepeletier, 1836. 


\section{Rhamnaceae}

Espécie: Ziziphus joazeiro Mart.

Nome comum: juazeiro

Hábito de crescimento: arbóreo

Fonte de recurso trófico: pólen/néctar

Período de Floração: novembro e dezembro

No Palinoteca: NAS28
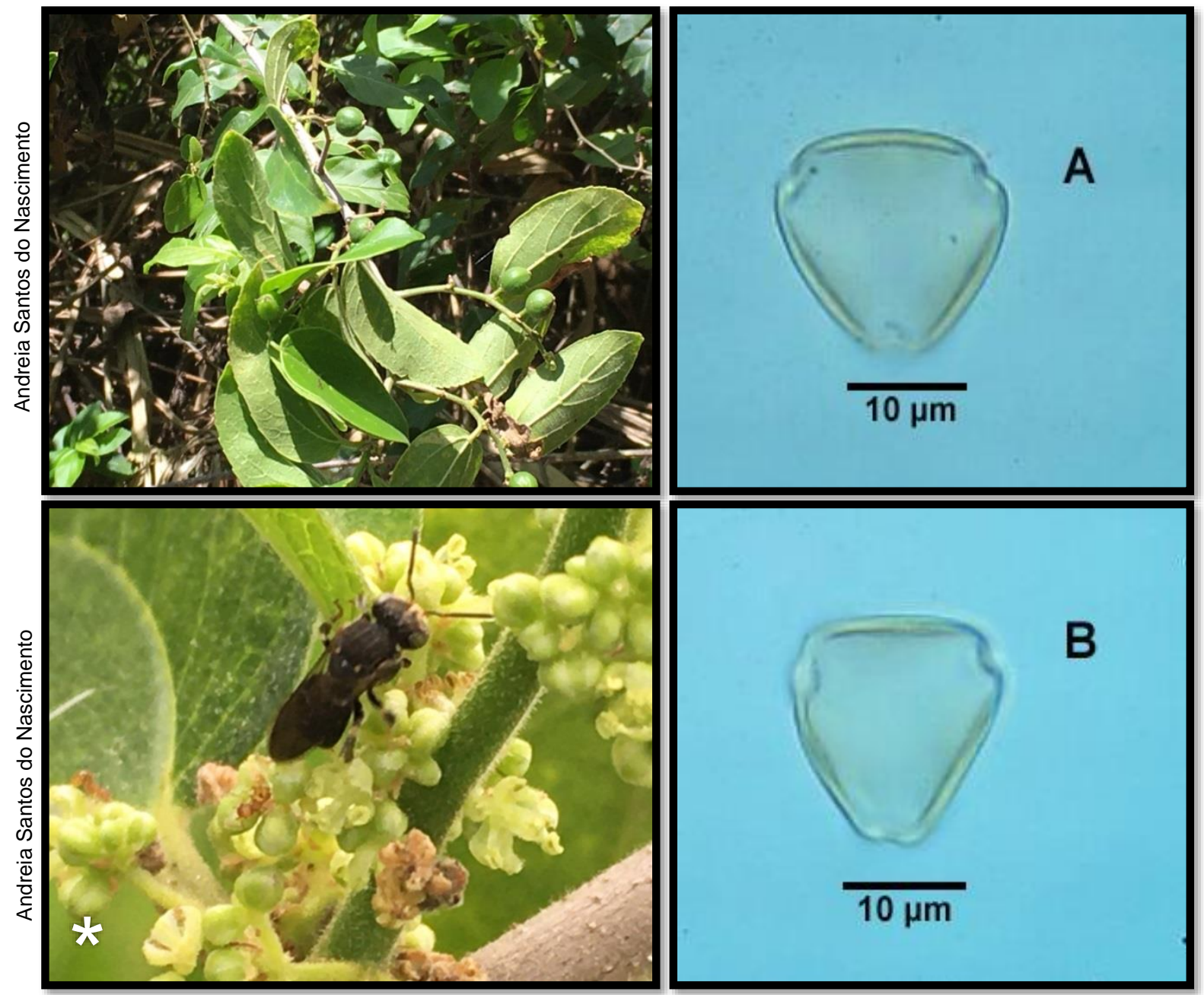

Descrição polínica: $A-B=$ vista polar, grão de pólen com simetria radial, isopolar, nômade, âmbito triangular, abertura polínica do tipo colporo, exina escabrada, tamanho pequeno, forma suboblata, diâmetro da área polar $=14,84 \mu \mathrm{m}$; diâmetro equatorial em vista polar $=19,09 \mu \mathrm{m} ; \mathrm{P} / \mathrm{E}=0,77 \mu \mathrm{m}$.

*Abelha visitante floral: Nannotrigona testaceicornis Lepeletier, 1836. 


\title{
Rubiaceae
}

\author{
Espécie: Borreria scabiosoides Cham. \& Schltdl. \\ Nome comum: Cabeça-de-velho \\ Hábito de crescimento: herbáceo \\ Fonte de recurso trófico: néctar \\ Período de Floração: maio a agosto \\ No Palinoteca: NAS24
}

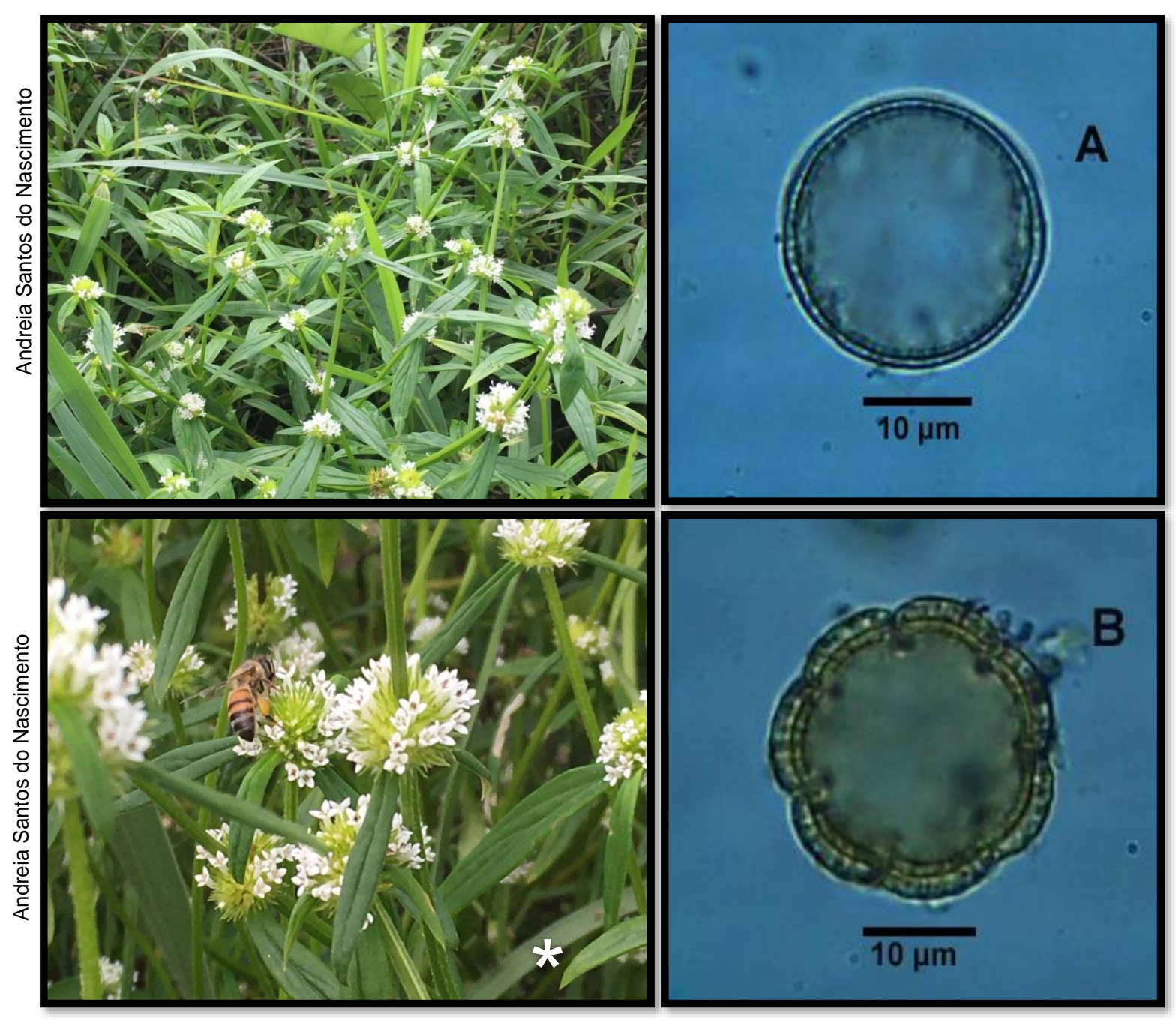

Descrição polínica: $A=$ vista equatorial e $B=$ vista polar, grão de pólen com simetria radial, isopolar, nômade, âmbito circular, abertura polínica do tipo colpo, exina microrreticulada, tamanho médio, forma oblata esferoidal, diâmetro do eixo polar $=38,18 \mu \mathrm{m}$; diâmetro do eixo equatorial $=38,48 \mu \mathrm{m} ; \mathrm{P} / \mathrm{E}=0,99 \mu \mathrm{m}$.

${ }^{*}$ Abelha visitante floral: Apis mellifera Linnaeus, 1758. 


\section{Rubiaceae}

Espécie: Borreria suaveolens G.Mey.

Nome comum: Vassourinha

Hábito de crescimento: herbáceo

Fonte de recurso trófico: néctar

Período de Floração: maio a agosto

No Palinoteca: PA 47
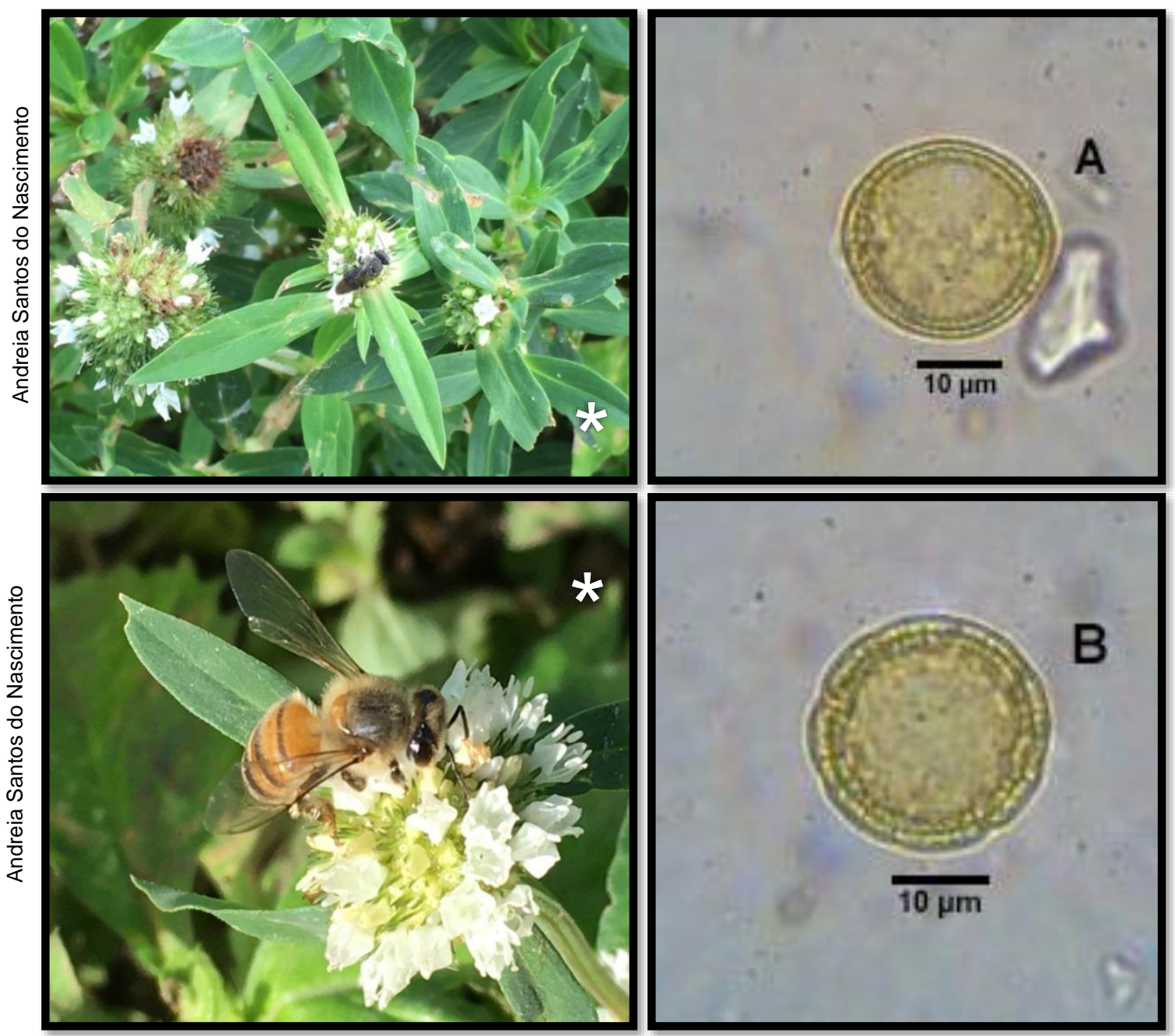

Descrição polínica: $A$ = vista equatorial e $B$ = vista polar, grão de pólen com simetria radial, isopolar, nômade, âmbito circular, abertura polínica do tipo colpo, exina microrreticulada, tamanho médio, forma oblata esferoidal, diâmetro do eixo polar $=$ $28,48 \mu \mathrm{m}$; diâmetro do eixo equatorial $=29,09 \mu \mathrm{m} ; \mathrm{P} / \mathrm{E}=0,97 \mu \mathrm{m}$.

*Abelha visitante floral: Nannotrigona testaceicornis Lepeletier, 1836

e Apis mellifera Linnaeus, 1758. 


\section{Rubiaceae}

Espécie: Borreria verticillata (L.) G.Mey.

Nome comum: Vassourinha-de-botão

Hábito de crescimento: herbáceo

Fonte de recurso trófico: néctar

Período de Floração: maio a agosto

No Palinoteca: PA 49
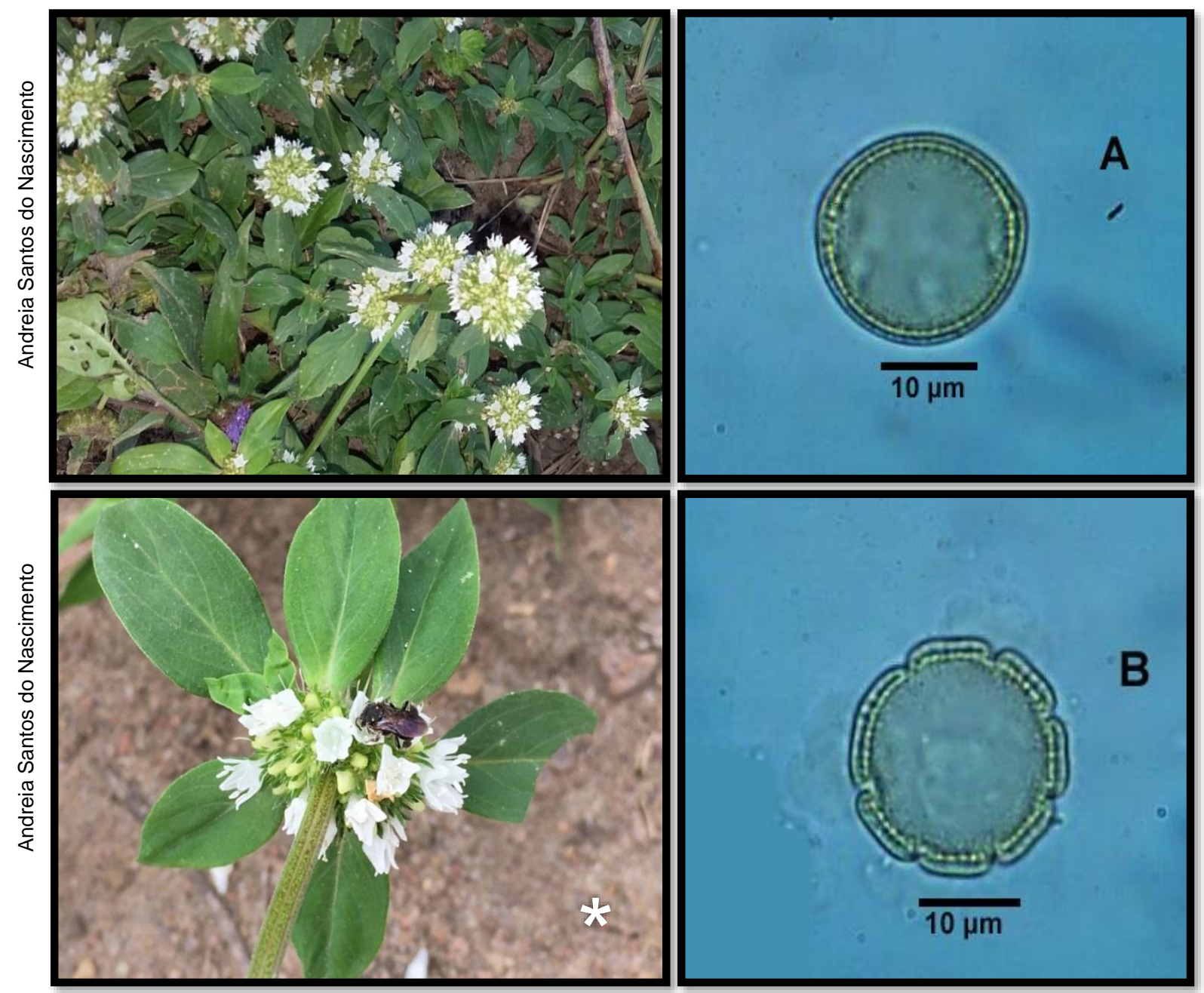

Descrição polínica: $A$ = vista equatorial e $B=$ vista polar, grão de pólen com simetria radial, isopolar, nômade, âmbito circular, abertura polínica do tipo colpo, exina microrreticulada, tamanho médio, forma oblata esferoidal, diâmetro do eixo polar $=28,18 \mu \mathrm{m}$; diâmetro do eixo equatorial $=28,87 \mu \mathrm{m} ; \mathrm{P} / \mathrm{E}=0,97 \mu \mathrm{m}$.

*Abelha visitante floral: Nannotrigona testaceicornis Lepeletier, 1836. 


\section{Rubiaceae}

Espécie: Diodia teres Walter

Nome comum: Poaia

Hábito de crescimento: herbáceo

Fonte de recurso trófico: néctar

Período de Floração: maio a agosto

$\mathrm{N}^{\circ}$ Palinoteca: NAS25

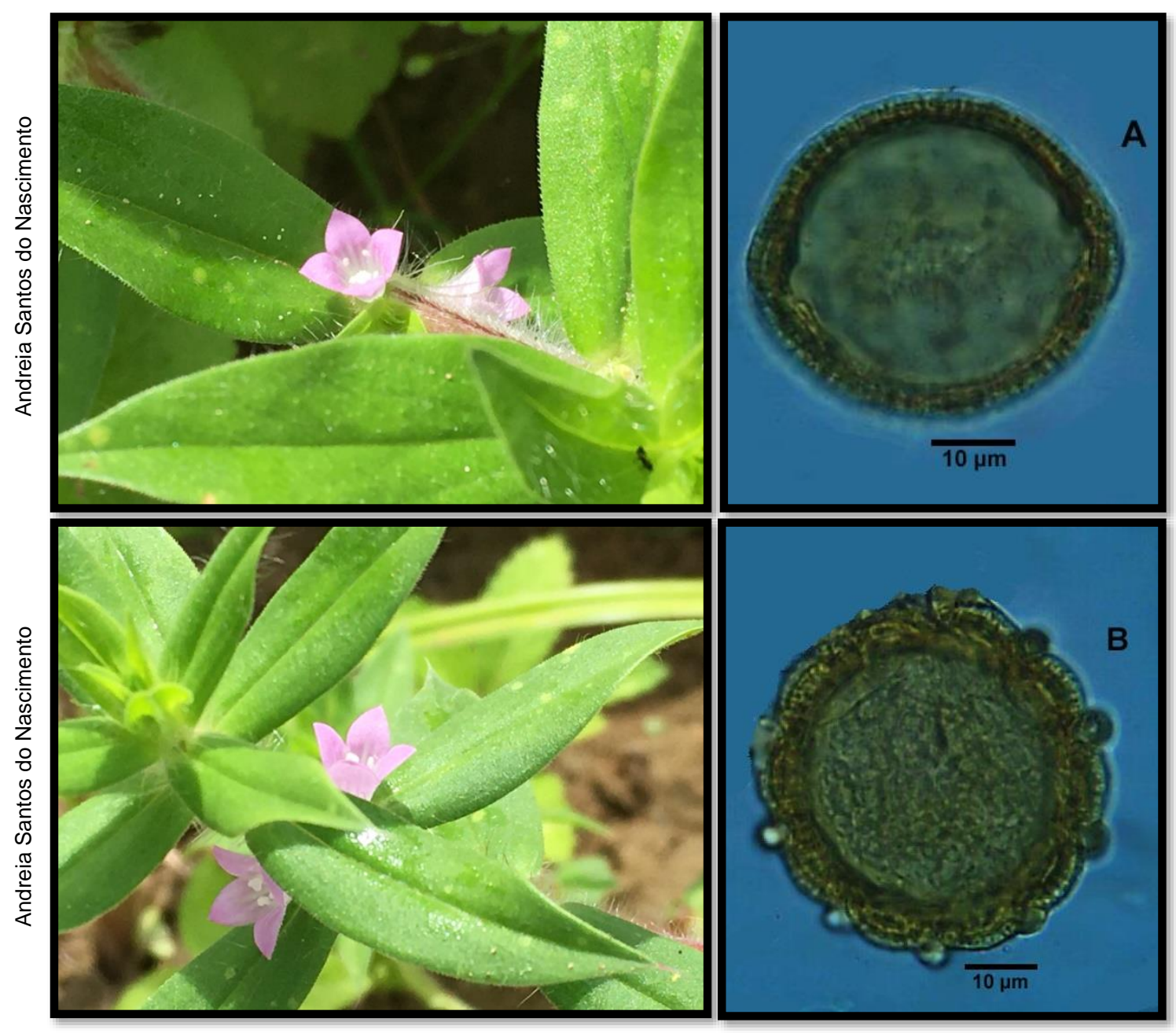

Descrição polínica: $A$ = vista equatorial e $B$ = vista polar, grão de pólen com simetria radial, isopolar, nômade, âmbito circular, abertura polínica do tipo colpo, exina microrreticulada, tamanho grande, forma oblata esferoidal, diâmetro do eixo polar $=64,24 \mu \mathrm{m}$; diâmetro do eixo equatorial $=65,45 \mu \mathrm{m} ; \mathrm{P} / \mathrm{E}=0,98 \mu \mathrm{m}$. 


\section{Rubiaceae}

Espécie: Richardia brasiliensis Gomes

Nome comum: Ervanço

Hábito de crescimento: herbáceo

Fonte de recurso trófico: néctar

Período de Floração: maio a agosto

No Palinoteca: PA 29

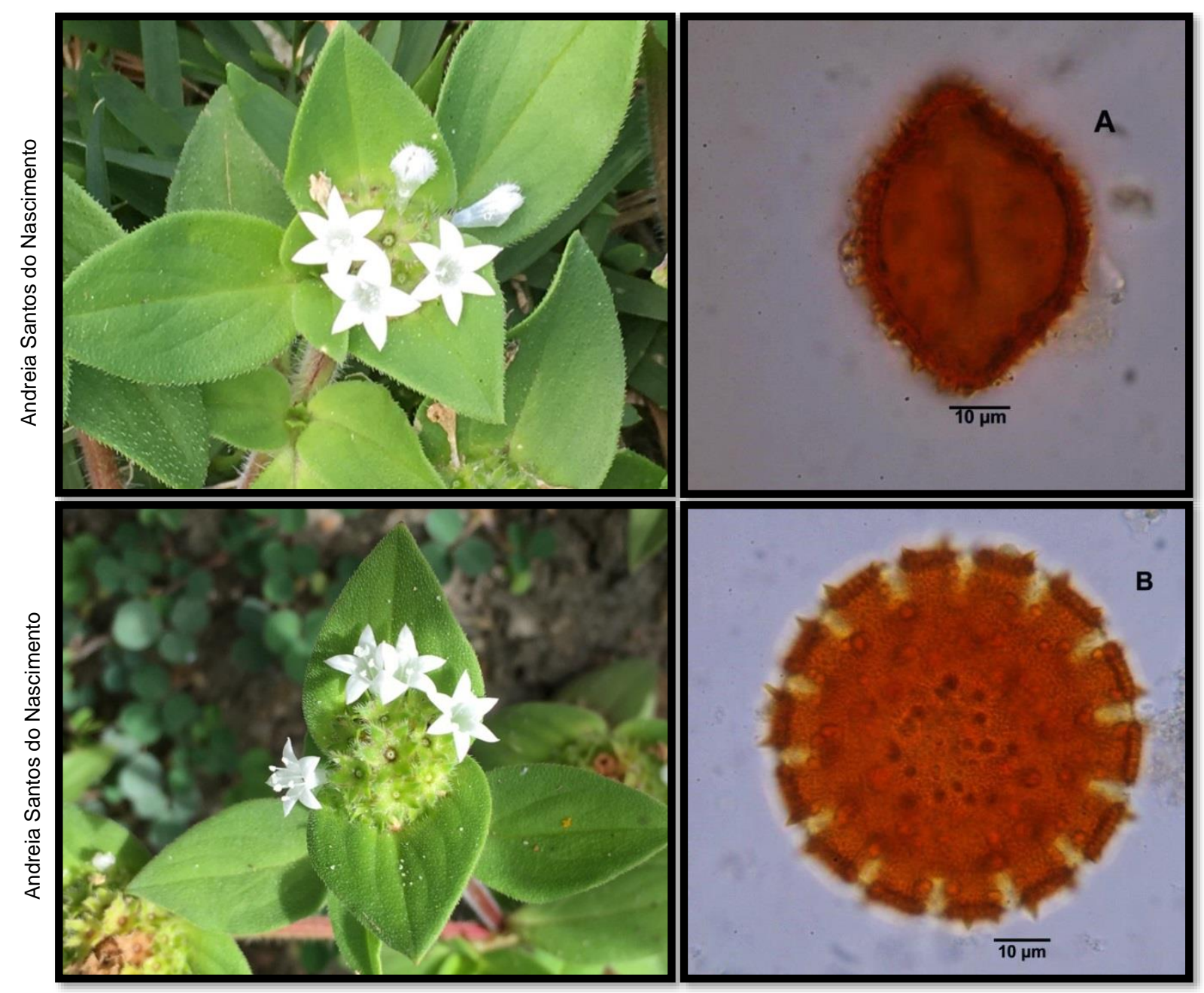

Descrição polínica: A-B = vista polar, grão de pólen com simetria radial, isopolar, nômade, âmbito circular, abertura polínica do tipo colpo, exina equinada, tamanho grande, forma esferoidal, diâmetro do eixo polar $=62,72 \mu \mathrm{m}$; diâmetro do eixo equatorial $=62,72 \mu \mathrm{m} ; \mathrm{P} / \mathrm{E}=1,00 \mu \mathrm{m}$. 


\section{Rubiaceae}

Espécie: Richardia grandiflora (Cham. \& Schltdl.) Steud.

Nome comum: Ervanço

Hábito de crescimento: herbáceo

Fonte de recurso trófico: néctar

Período de Floração: maio a agosto

No Palinoteca: PA 01
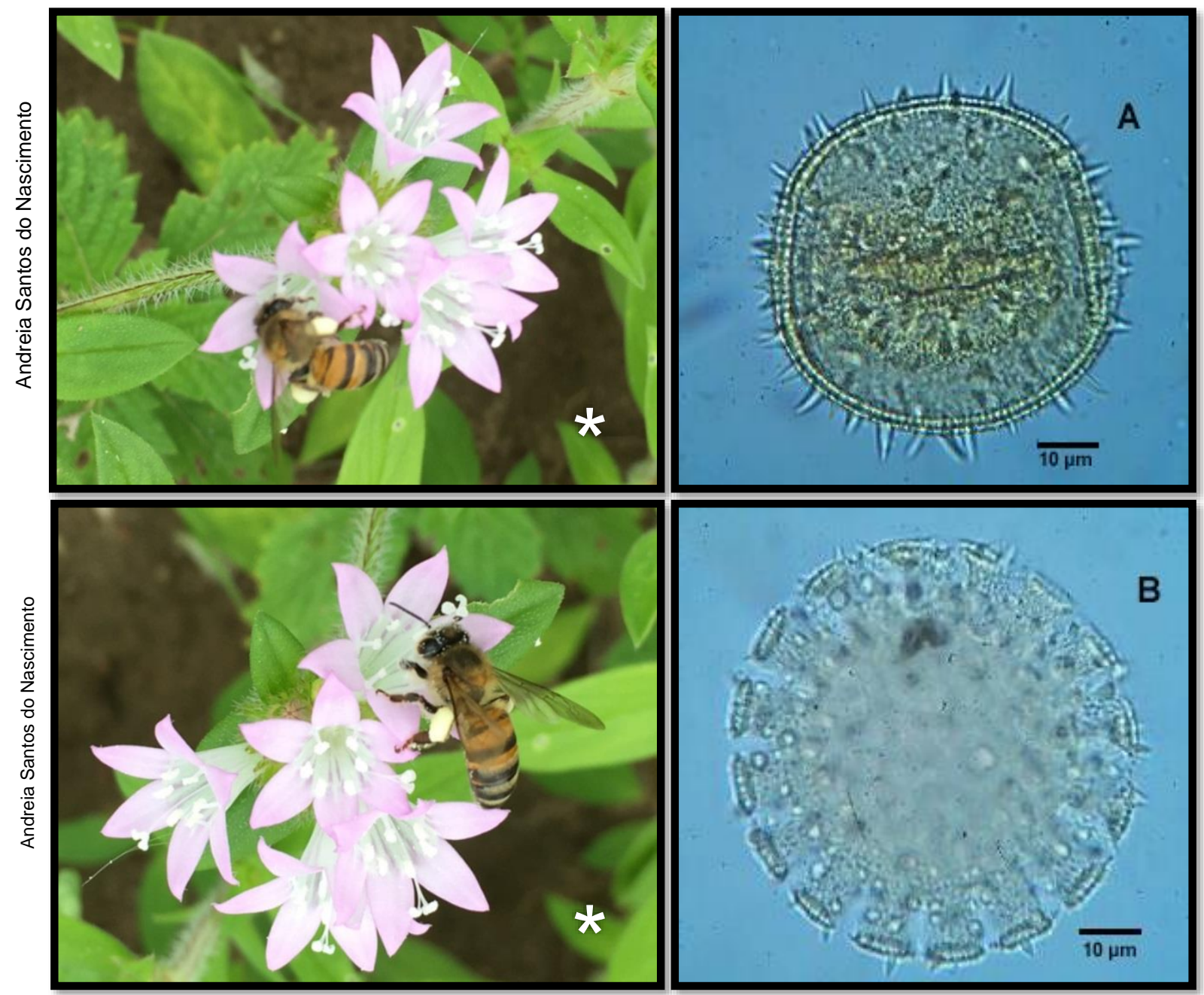

Descrição polínica: A-B = vista polar, grão de pólen com simetria radial, isopolar, nômade, âmbito circular, abertura polínica do tipo colpo, exina equinada, tamanho grande, forma esferoidal, diâmetro do eixo polar $=64,84 \mu \mathrm{m}$; diâmetro do eixo equatorial $=64,84 \mu \mathrm{m} ; \mathrm{P} / \mathrm{E}=1,00 \mu \mathrm{m}$.

${ }^{*}$ Abelha visitante floral: Apis mellifera Linnaeus, 1758. 


\section{Rutaceae}

Espécie: Citrus latifolia Tanaka

Nome comum: Limão-Tahiti

Hábito de crescimento: arbustivo

Fonte de recurso trófico: néctar

Período de Floração: março a abril; agosto a outubro

No Palinoteca: NAS26
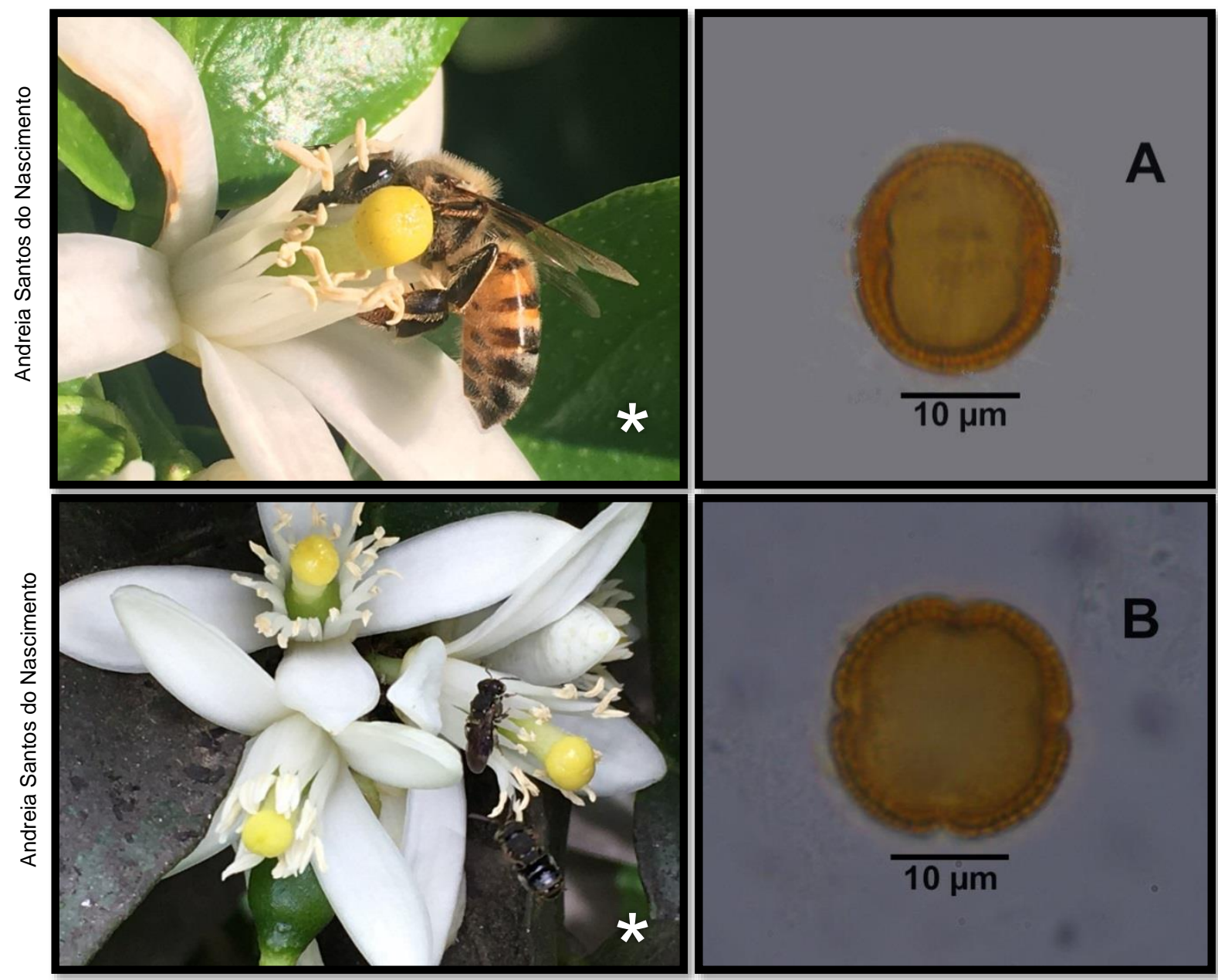

Descrição polínica: $A=$ vista equatorial e $B=$ vista polar, grão de pólen com simetria radial, isopolar, nômade, âmbito circular, abertura polínica do tipo colporo, exina reticulada, tamanho médio, forma prolata esferoidal, eixo polar $=26,66 \mu \mathrm{m}$; eixo equatorial $=23,93 \mu \mathrm{m} ; \mathrm{P} / \mathrm{E}=1,11 \mu \mathrm{m}$.

*Abelha visitante floral: Apis mellifera Linnaeus, 1758 e Nannotrigona testaceicornis Lepeletier, 1836. 


\section{Rutaceae}

Espécie: Citrus limonia Osbeck

Nome comum: Limão-cravo

Hábito de crescimento: arbustivo

Fonte de recurso trófico: néctar

Período de Floração: março a abril; agosto a outubro

No Palinoteca: PA 89
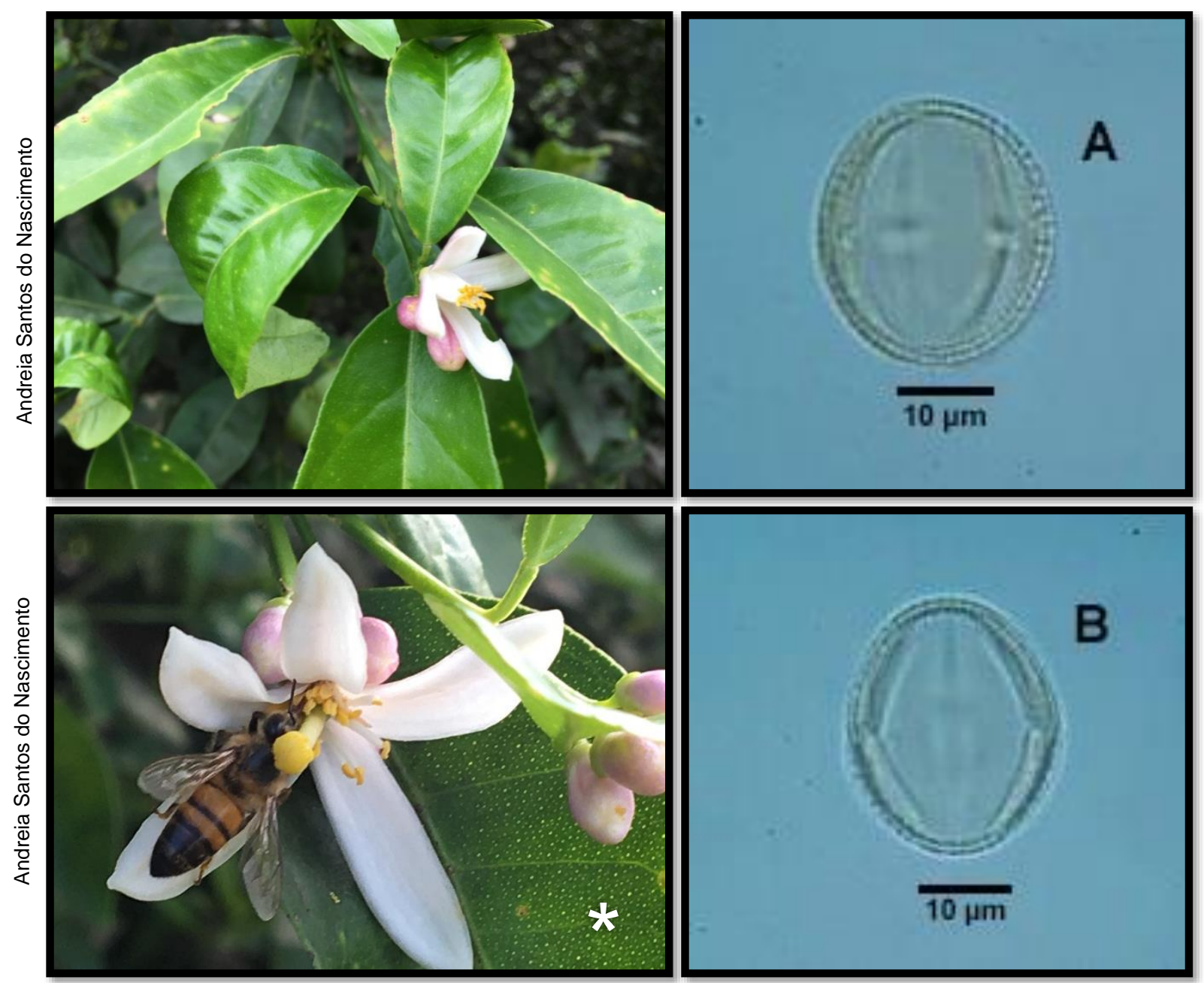

Descrição polínica: $A-B=$ vista equatorial, grão de pólen com simetria radial, isopolar, nômade, âmbito circular, abertura polínica do tipo colporo, exina reticulada, tamanho médio, forma prolata esferoidal, eixo polar $=28,78 \mu \mathrm{m}$; eixo equatorial $=$ $25,75 \mu \mathrm{m} ; \mathrm{P} / \mathrm{E}=1,11 \mu \mathrm{m}$.

*Abelha visitante floral: Apis mellifera Linnaeus, 1758. 


\section{Rutaceae}

Espécie: Citrus sinensis (L.) Osbeck

Nome comum: Laranja

Hábito de crescimento: arbustivo

Fonte de recurso trófico: néctar

Período de Floração: março a abril; agosto a outubro

No Palinoteca: NAS23

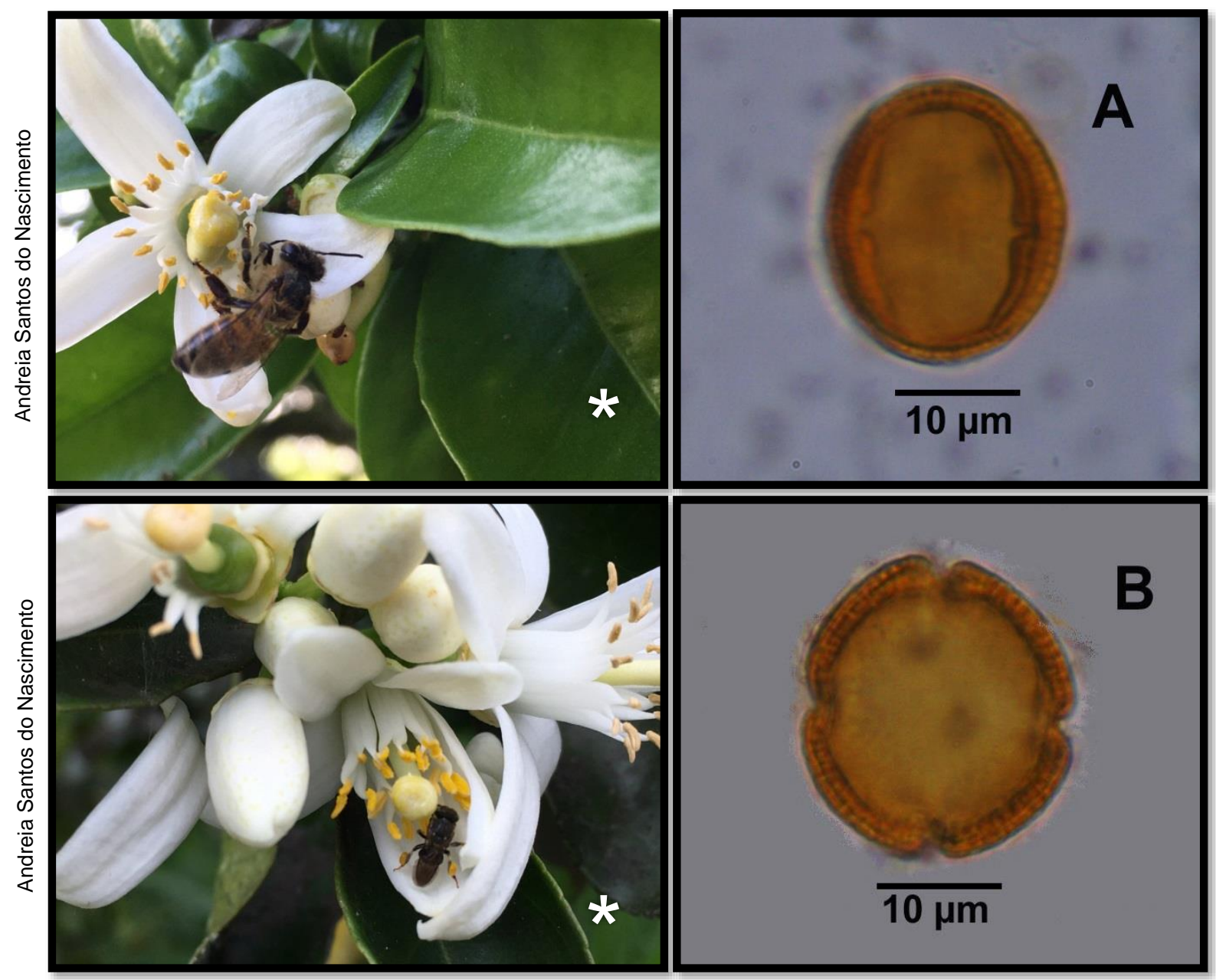

Descrição polínica: $A$ = vista equatorial e $B$ = vista polar, grão de pólen com simetria radial, isopolar, nômade, âmbito circular, abertura polínica do tipo colporo, exina reticulada, tamanho médio, forma prolata esferoidal, eixo polar $=25,45 \mu \mathrm{m}$; eixo equatorial $=22,72 \mu \mathrm{m} ; \mathrm{P} / \mathrm{E}=1,12 \mu \mathrm{m}$.

*Abelha visitante floral: Apis mellifera Linnaeus, 1758 e Nannotrigona testaceicornis Lepeletier, 1836. 


\section{Sapindaceae}

Espécie: Cardiospermum corindum L.

Nome comum: Balãozinho

Hábito de crescimento: liana

Fonte de recurso trófico: néctar

Período de Floração: julho a setembro

No Palinoteca: PA 187
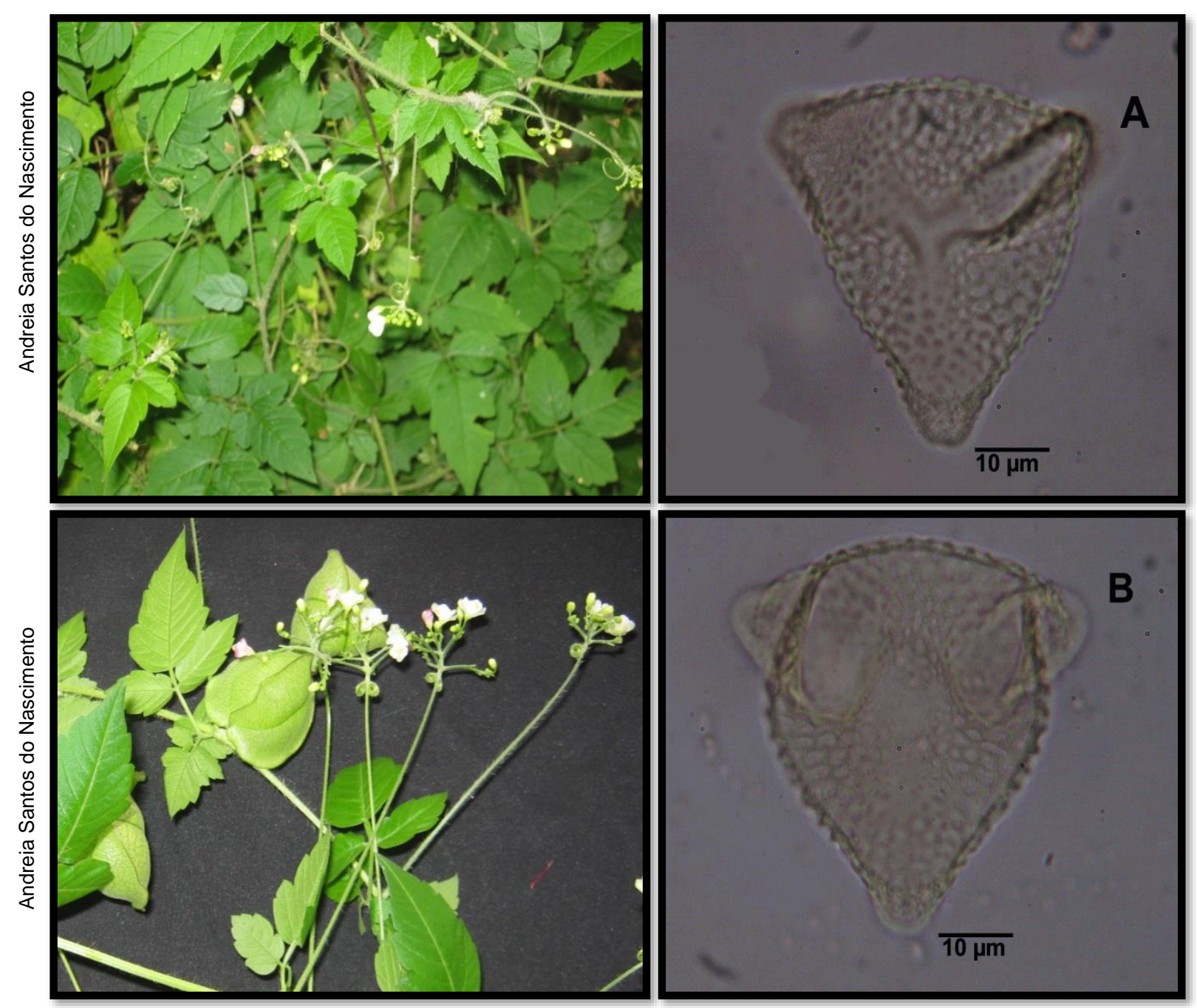

Descrição polínica: A-B = vista polar, grão de pólen com simetria radial, isopolar, nômade, âmbito quadrangular/triangular, abertura polínica do tipo poro, exina heterobrocada/reticulada, tamanho grande, forma suboblata, diâmetro da área polar $=41,51 \mu \mathrm{m}$; diâmetro do eixo equatorial em vista polar $=52,42 \mu \mathrm{m} ; \mathrm{P} / \mathrm{E}=0,79 \mu \mathrm{m}$. 


\title{
Sapindaceae
}

\author{
Espécie: Serjania pernambucensis Radlk. \\ Nome comum: Cipó-uva \\ Hábito de crescimento: trepadeira \\ Fonte de recurso trófico: néctar \\ Período de Floração: julho a setembro \\ No Palinoteca: PA 68
}
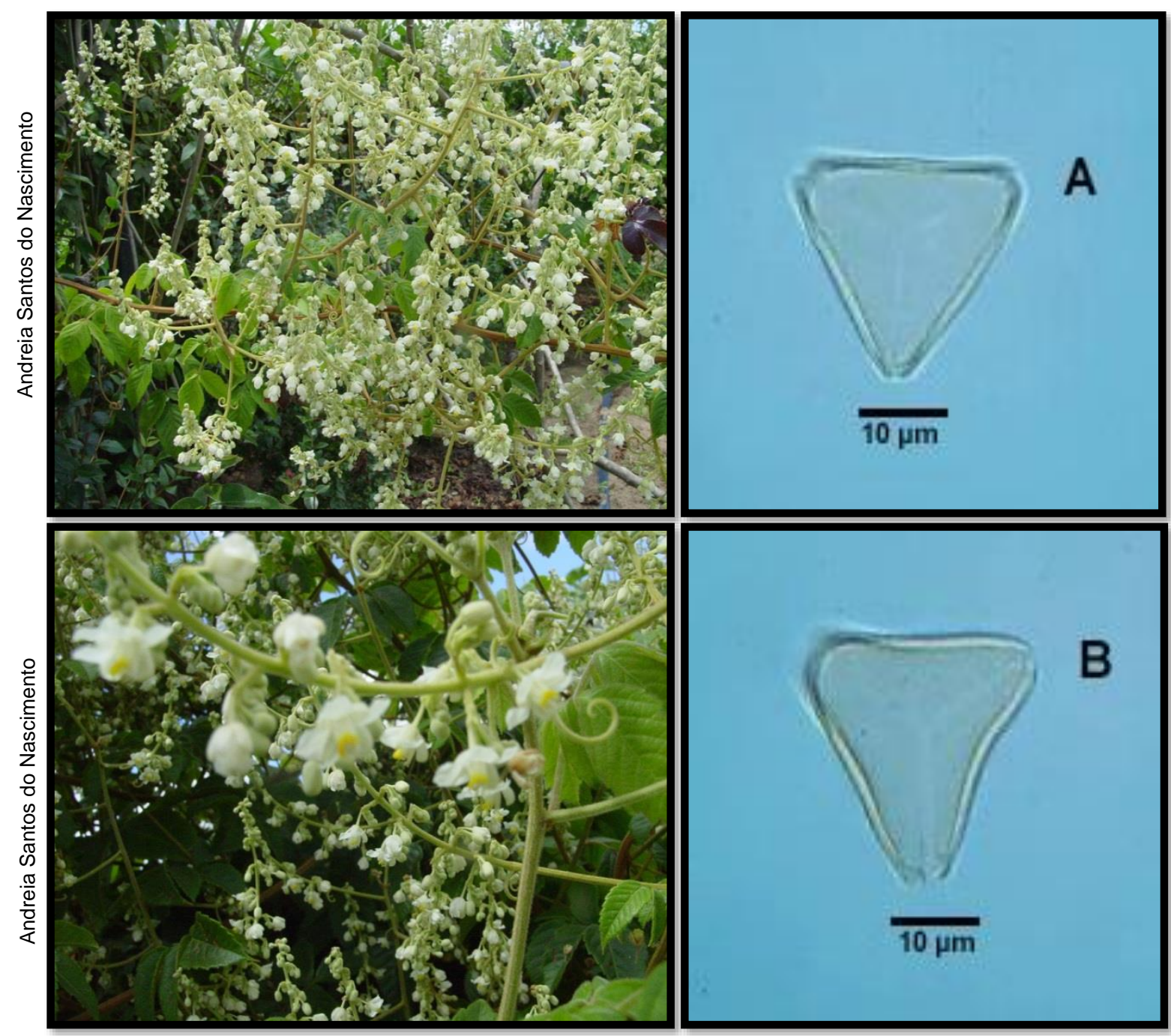

Descrição polínica: A-B = vista polar, grão de pólen com simetria radial, isopolar, nômade, âmbito triangular, abertura polínica do tipo poro, exina heterobrocada/reticulada, tamanho médio, forma suboblata, diâmetro da área polar $=21,51 \mu \mathrm{m}$; diâmetro do eixo equatorial em vista polar $=26,96 \mu \mathrm{m} ; \mathrm{P} / \mathrm{E}=0,79 \mu \mathrm{m}$. 


\section{Solanaceae}

Espécie: Cestrum laevigatum Schltdl.

Nome comum: Quarana

Hábito de crescimento: arbustivo

Fonte de recurso trófico: pólen

Período de Floração: novembro a outubro

No Palinoteca: PA 116

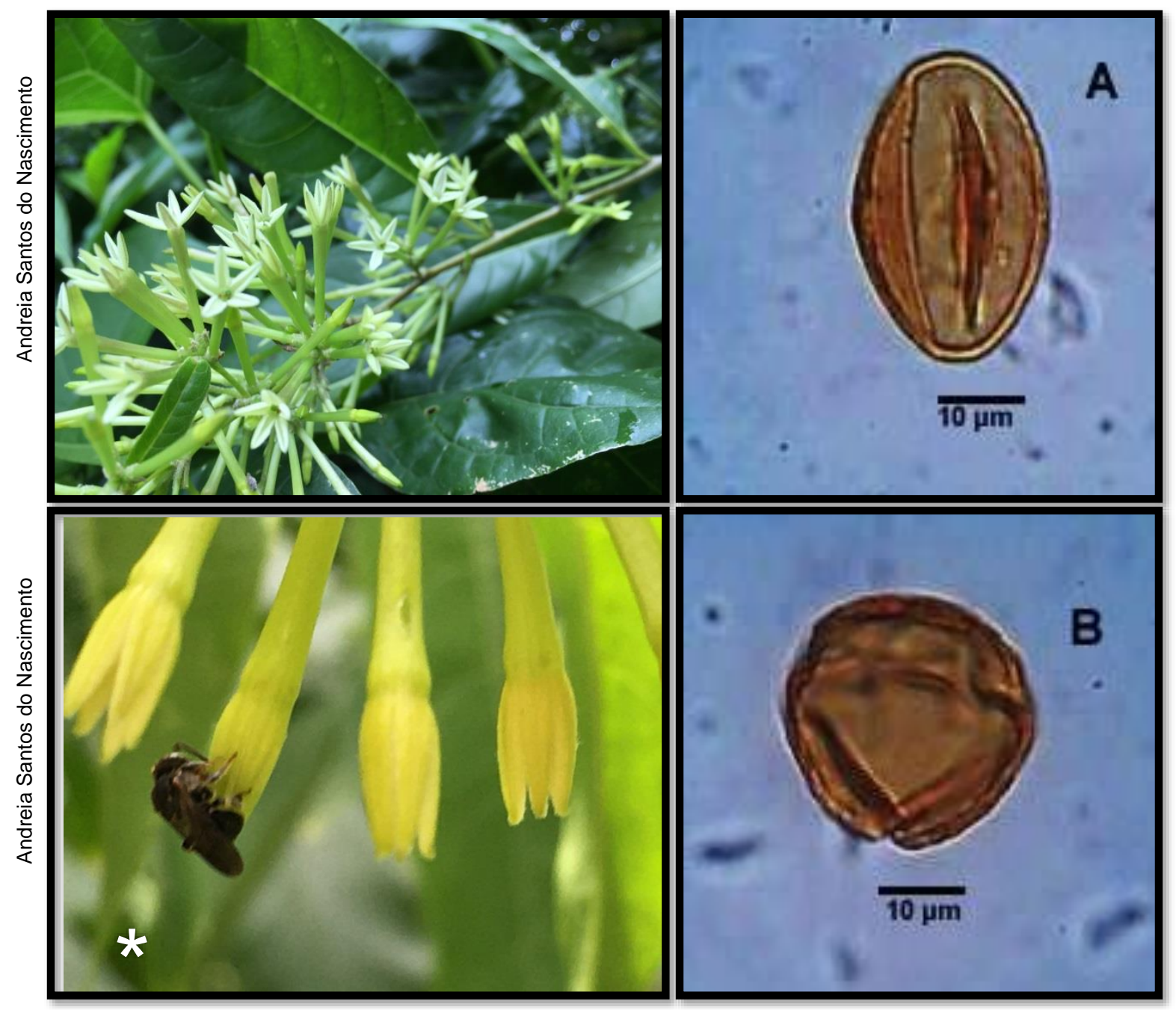

Descrição polínica: $A$ = vista equatorial e $B$ = vista polar, grão de pólen com simetria radial, isopolar, nômade, âmbito subtriangular, abertura polínica do tipo colporo, exina microrreticulada, tamanho médio, forma subprolata, eixo polar $=33,63 \mu \mathrm{m}$; eixo equatorial $=25,45 \mu \mathrm{m} ; \mathrm{P} / \mathrm{E}=1,32 \mu \mathrm{m}$.

*Abelha visitante floral: Nannotrigona testaceicornis Lepeletier, 1836. 


\section{Solanaceae}

Espécie: Nicotiana tabacum L.

Nome comum: Fumo

Hábito de crescimento: herbáceo

Fonte de recurso trófico: pólen

Período de Floração: agosto a novembro

No Palinoteca: PA 15
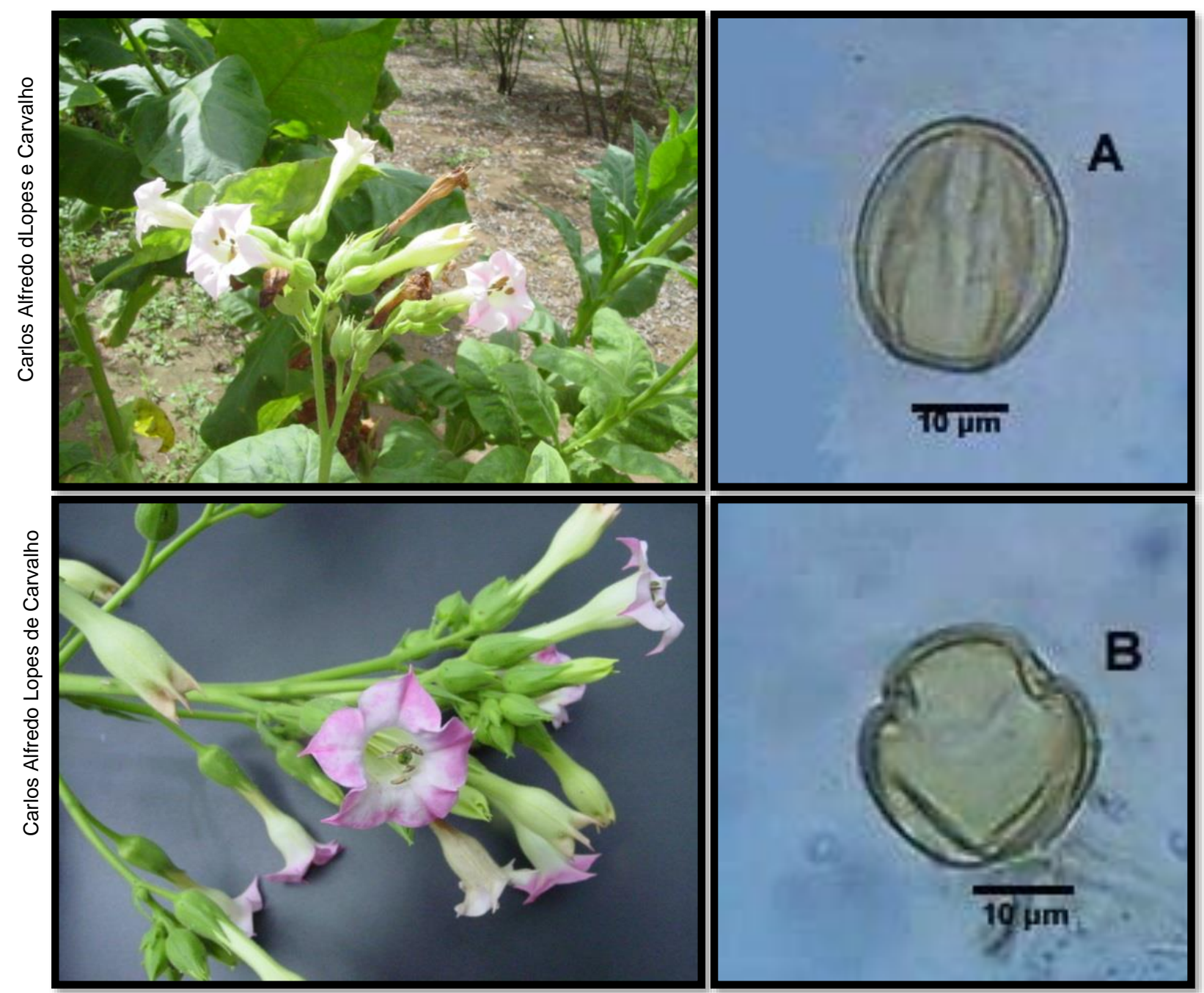

Descrição polínica: $A$ = vista equatorial e $B$ = vista polar, grão de pólen com simetria radial, isopolar, nômade, âmbito subtriangular, abertura polínica do tipo colporo, exina microrreticulada, tamanho pequeno, forma subprolata, eixo polar $=24,84 \mu \mathrm{m}$; eixo equatorial $=19,69 \mu \mathrm{m} ; \mathrm{P} / \mathrm{E}=1,26 \mu \mathrm{m}$. 


\section{Solanaceae}

Espécie: Physalis pubescens L.

Nome comum: Camapú

Hábito de crescimento: herbáceo

Fonte de recurso trófico: pólen

Período de Floração: maio a julho

No Palinoteca: PA 132

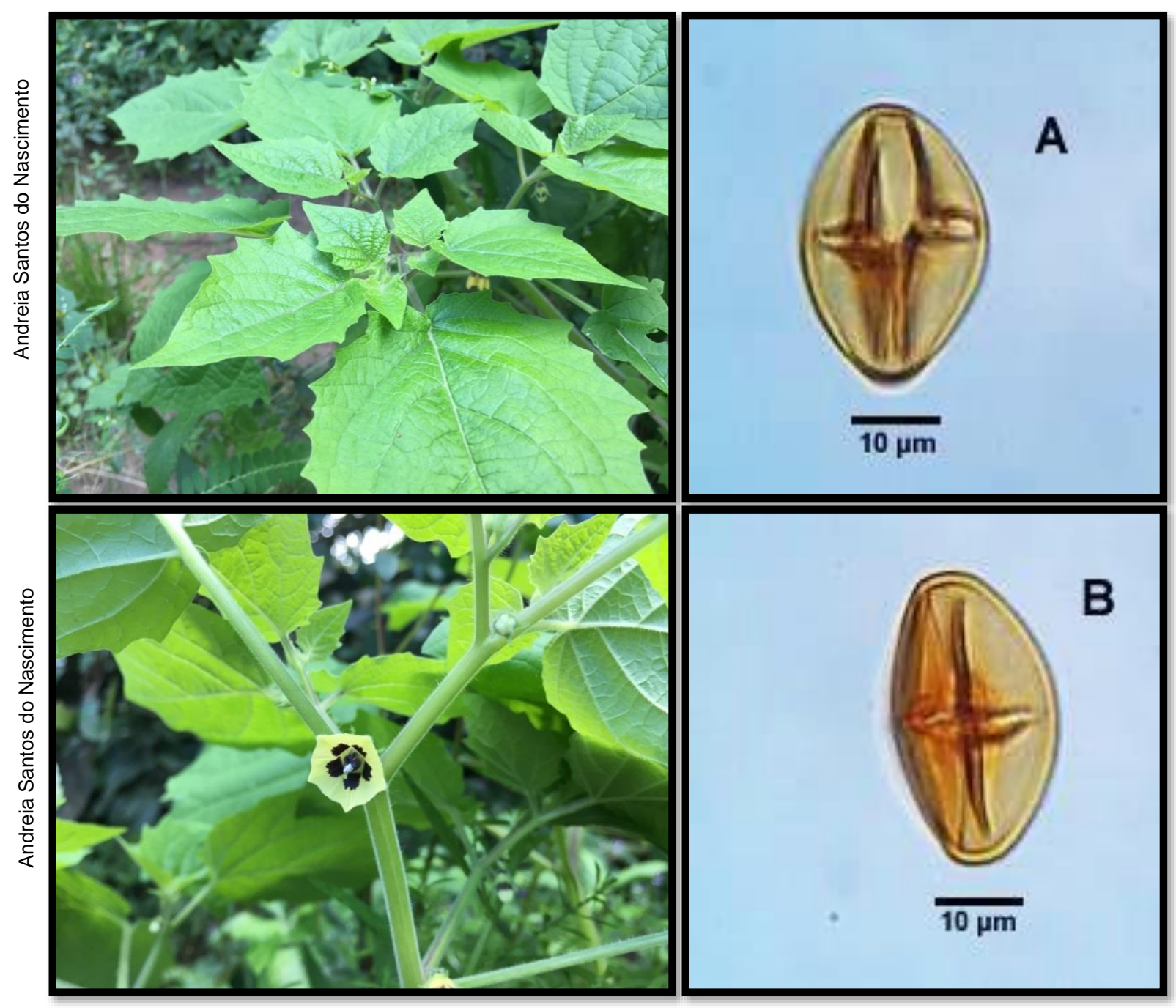

Descrição polínica: $A$ = vista equatorial e $B$ = vista polar, grão de pólen com simetria radial, isopolar, nômade, âmbito subtriangular, abertura polínica do tipo colporo, exina psilada, tamanho médio, forma prolata, eixo polar $=26,06 \mu \mathrm{m}$; eixo equatorial $=17,57$ $\mu \mathrm{m} ; \mathrm{P} / \mathrm{E}=1,48 \mu \mathrm{m}$. 


\section{Solanaceae}

Espécie: Solanum americanum Mill.

Nome comum: Maria-preta

Hábito de crescimento: herbáceo

Fonte de recurso trófico: pólen

Período de Floração: maio a julho

No Palinoteca: PA 62

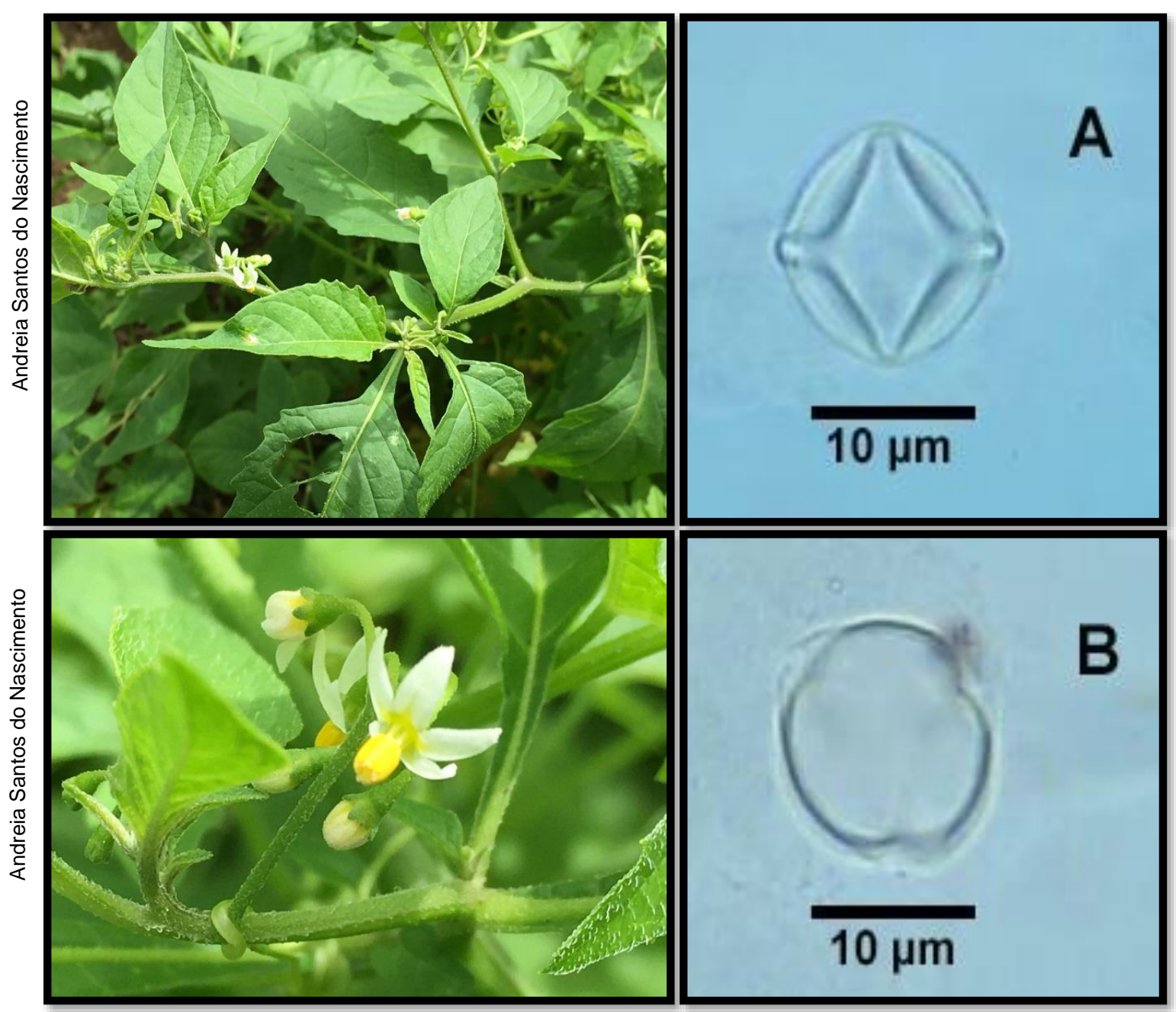

Descrição polínica: $A=$ vista equatorial e $B=$ vista polar, grão de pólen com simetria radial, isopolar, nômade, âmbito subtriangular, abertura polínica do tipo colporo, exina psilada, tamanho pequeno, forma prolata esferoidal, eixo polar = $13,93 \mu \mathrm{m}$; eixo equatorial $=13,03 \mu \mathrm{m} ; \mathrm{P} / \mathrm{E}=1,06 \mu \mathrm{m}$. 


\section{Solanaceae}

Espécie: Solanum erianthum D.Don.

Nome comum: Caiçara

Hábito de crescimento: herbáceo

Fonte de recurso trófico: pólen

Período de Floração: maio a julho

No Palinoteca: PA 97

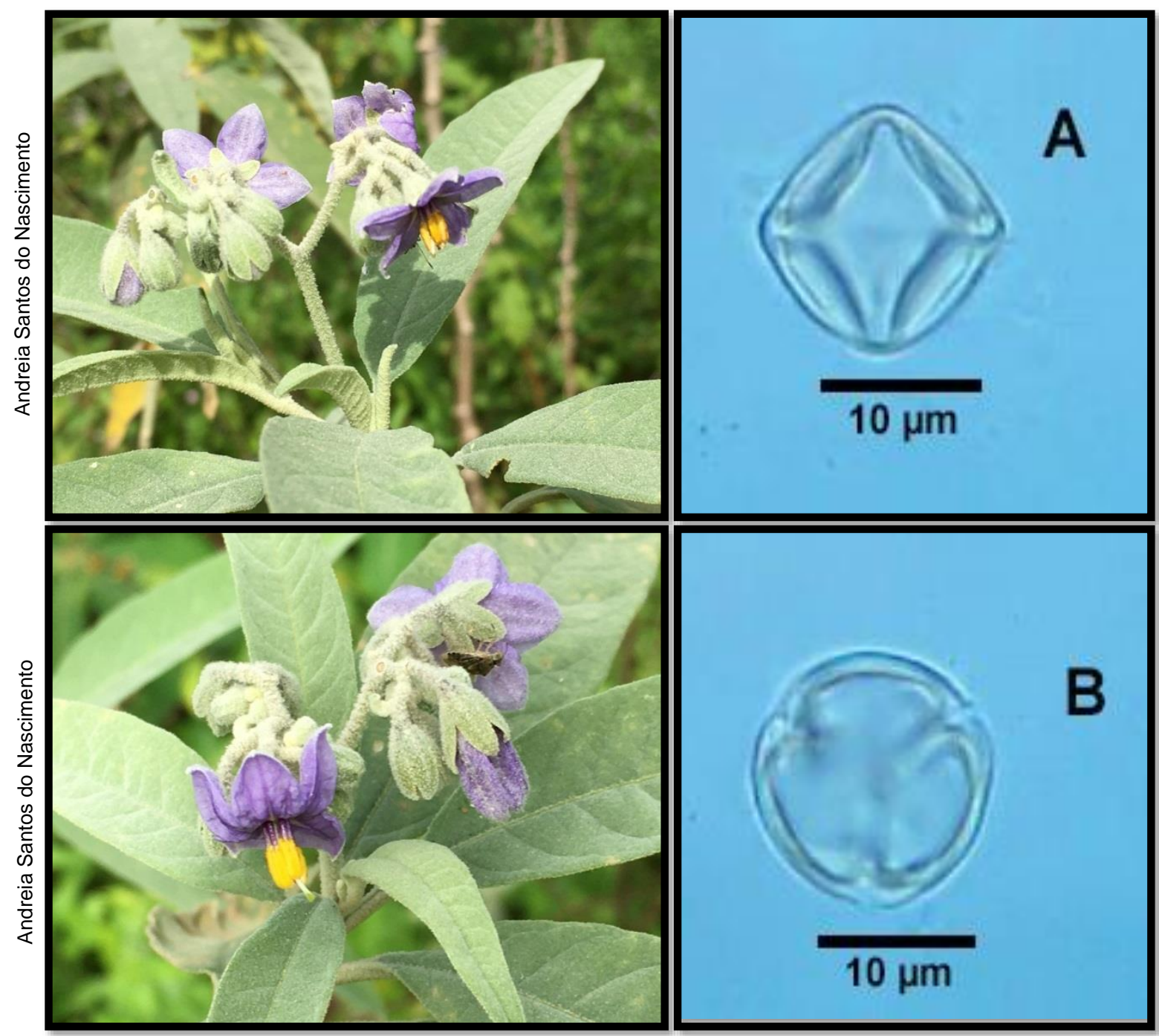

Descrição polínica: $A$ = vista equatorial e $B=$ vista polar, grão de pólen com simetria radial, isopolar, nômade, âmbito subtriangular, abertura polínica do tipo colporo, exina psilada, tamanho pequeno, forma prolata esferoidal, eixo polar $=14,84 \mu \mathrm{m}$; eixo equatorial $=14,24 \mu \mathrm{m} ; \mathrm{P} / \mathrm{E}=1,04 \mu \mathrm{m}$. 


\section{Solanaceae}

Espécie: Solanum palinacanthum Dunal

Nome comum: Melancia-do-mato

Hábito de crescimento: herbáceo

Fonte de recurso trófico: pólen

Período de Floração: maio a julho No Palinoteca: PA 99
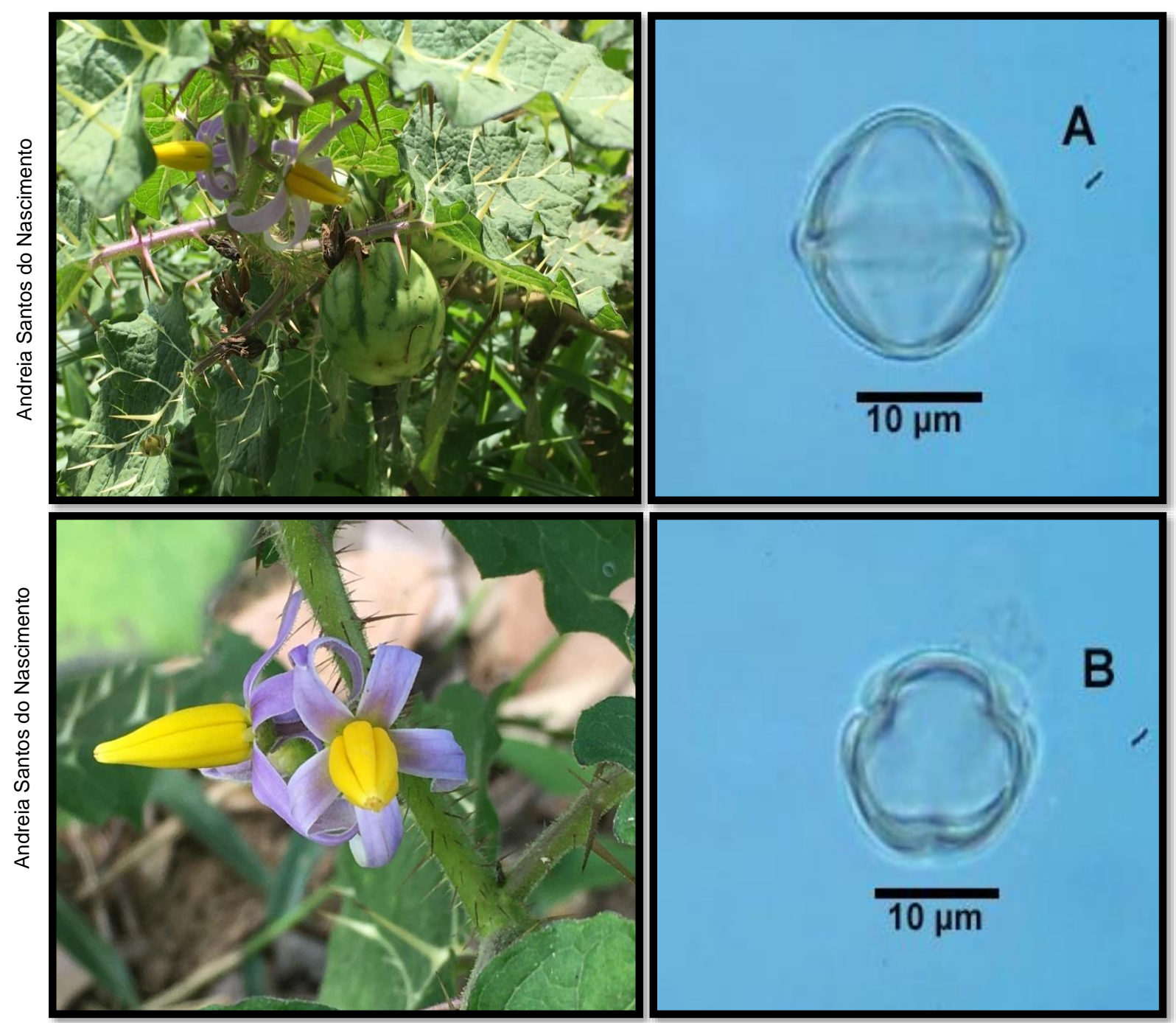

Descrição polínica: $A$ = vista equatorial e $B$ = vista polar, grão de pólen com simetria radial, isopolar, nômade, âmbito subtriangular, abertura polínica do tipo colporo, exina psilada, tamanho pequeno, forma prolata esferoidal, eixo polar $=18,48 \mu \mathrm{m}$; eixo equatorial $=16,36 \mu \mathrm{m} ; \mathrm{P} / \mathrm{E}=1,12 \mu \mathrm{m}$. 


\section{Solanaceae}

Espécie: Solanum paniculatum L.

Nome comum: Jurubeba

Hábito de crescimento: herbáceo

Fonte de recurso trófico: pólen

Período de Floração: maio a julho

No Palinoteca: PA 98

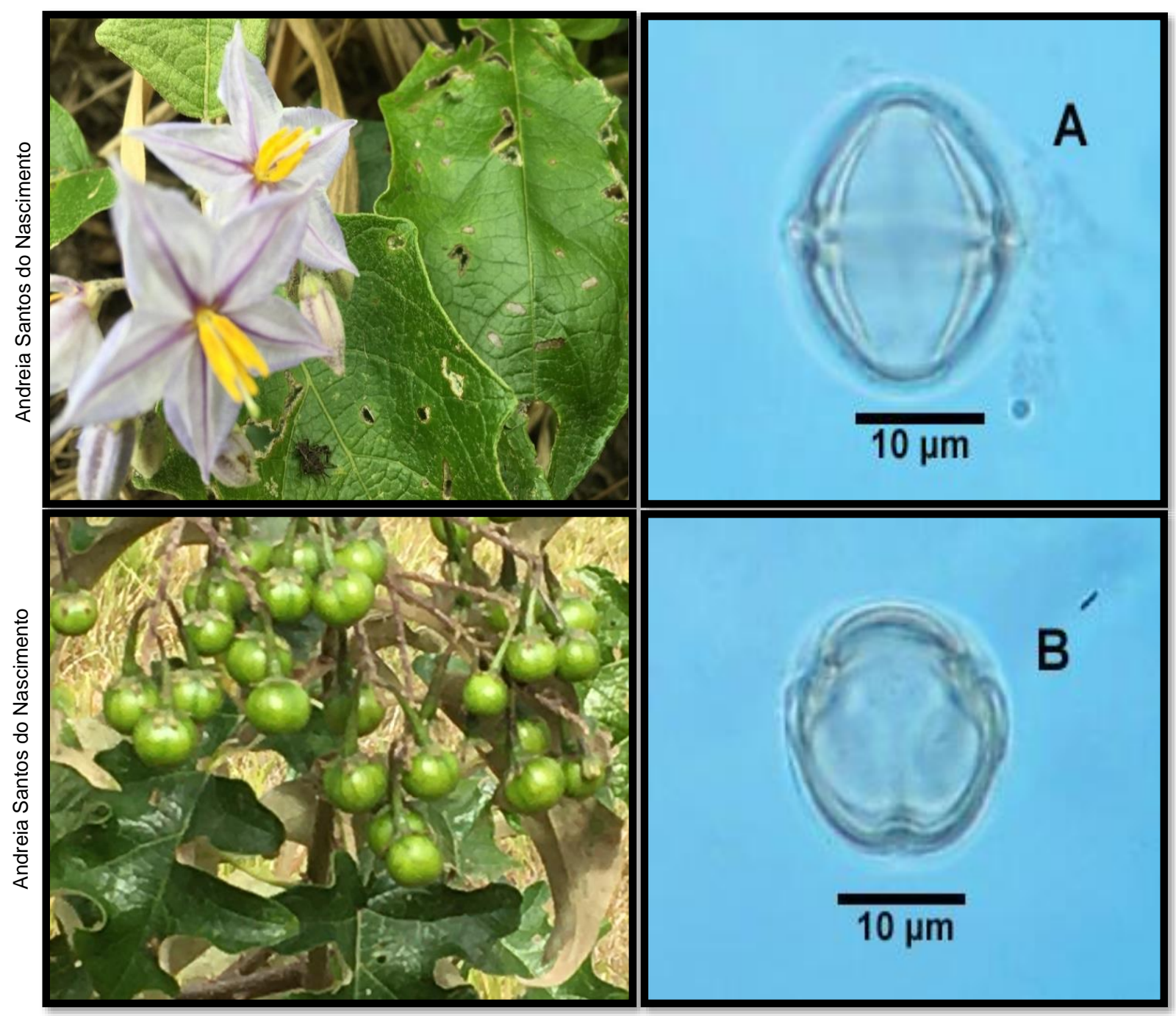

Descrição polínica: $A$ = vista equatorial e $B=$ vista polar, grão de pólen com simetria radial, isopolar, nômade, âmbito subtriangular, abertura polínica do tipo colporo, exina psilada, tamanho pequeno, forma prolata esferoidal, eixo polar $=20,30 \mu \mathrm{m}$; eixo equatorial $=17,87 \mu \mathrm{m} ; \mathrm{P} / \mathrm{E}=1,13 \mu \mathrm{m}$. 


\section{Talinaceae}

Espécie: Talinum patens Will.

Nome comum: Língua-de-vaca

Hábito de crescimento: herbáceo

Fonte de recurso trófico: pólen

Período de Floração: março a julho No Palinoteca: PA 11
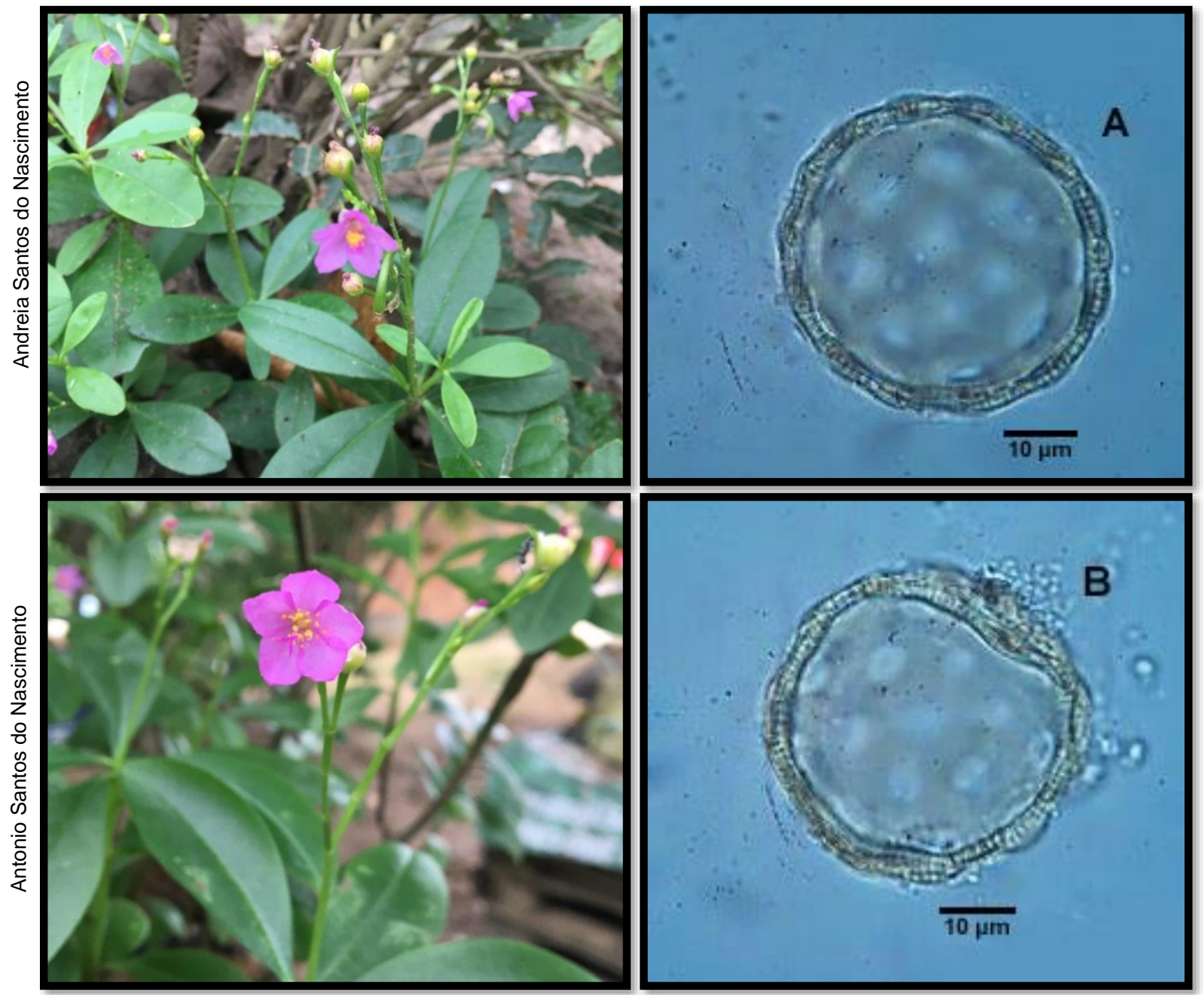

Descrição polínica: $A-B$ = vista polar, grão de pólen com simetria radial, apolar, nômade, âmbito circular, abertura polínica do tipo poro, exina microrreticulada, tamanho grande, forma esferoidal, diâmetro do eixo polar $=55,75 \mu \mathrm{m}$; diâmetro do eixo equatorial $=55,45 \mu \mathrm{m} ; \mathrm{P} / \mathrm{E}=1,00 \mu \mathrm{m}$. 


\section{Turneraceae}

Espécie: Piriqueta cistoides (L.) Griseb.

Nome comum: Malva amarela

Hábito de crescimento: herbáceo

Fonte de recurso trófico: néctar/pólen

Período de Floração: março a junho

$N^{\circ}$ Palinoteca: PA 30
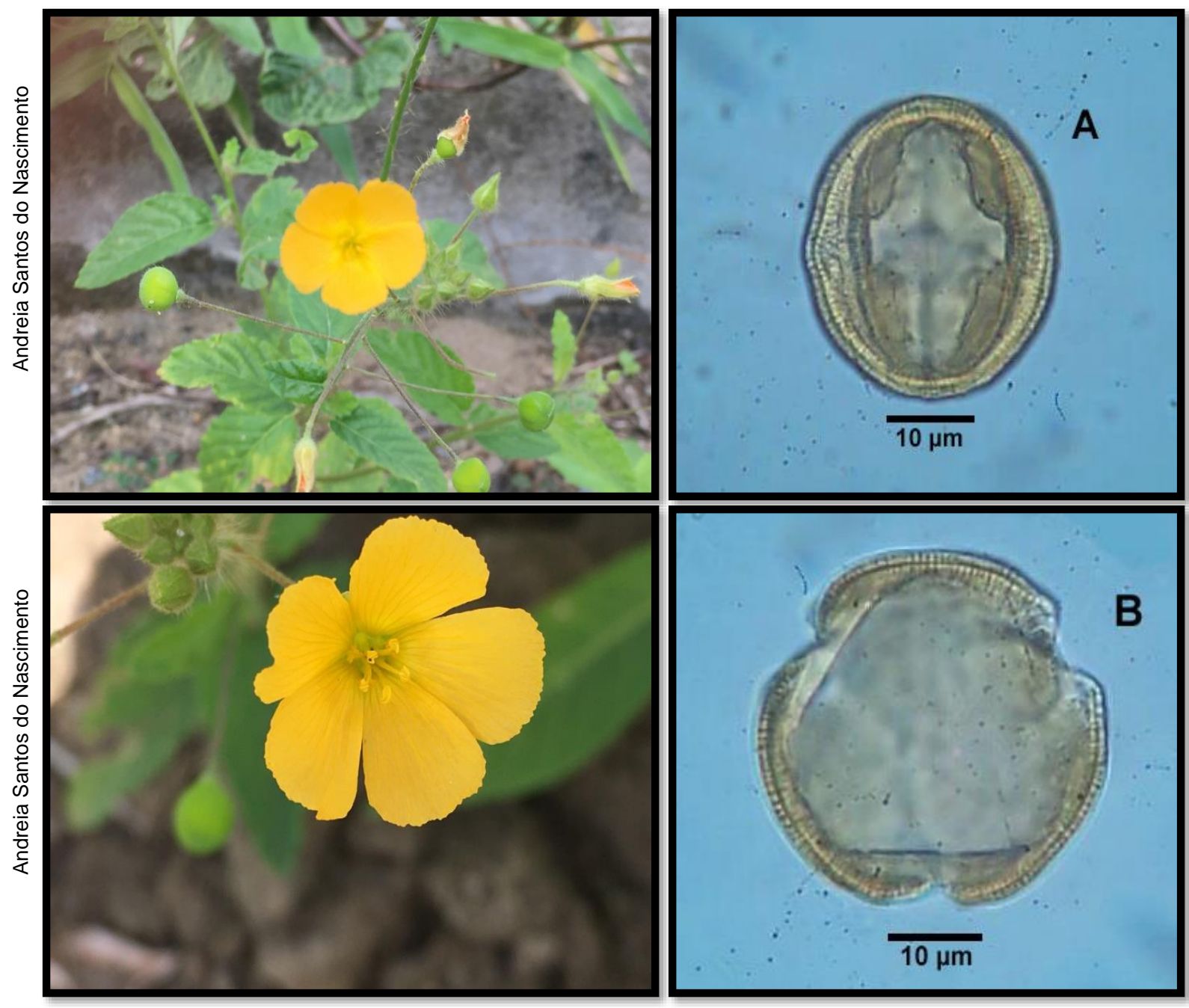

Descrição polínica: $A$ = vista equatorial e $B$ = vista polar, grão de pólen com simetria radial, isopolar, nômade, âmbito subtriangular, abertura polínica do tipo colporo, exina reticulada, tamanho médio, forma subprolata, eixo polar $=35,75 \mu \mathrm{m}$; eixo equatorial $=29,69 \mu \mathrm{m} ; \mathrm{P} / \mathrm{E}=1,20 \mu \mathrm{m}$. 


\section{Turneraceae}

Espécie: Piriqueta viscosa Griseb.

Nome comum: Malva rosa

Hábito de crescimento: herbáceo

Fonte de recurso trófico: néctar/pólen

Período de Floração: março a junho No Palinoteca: PA 33
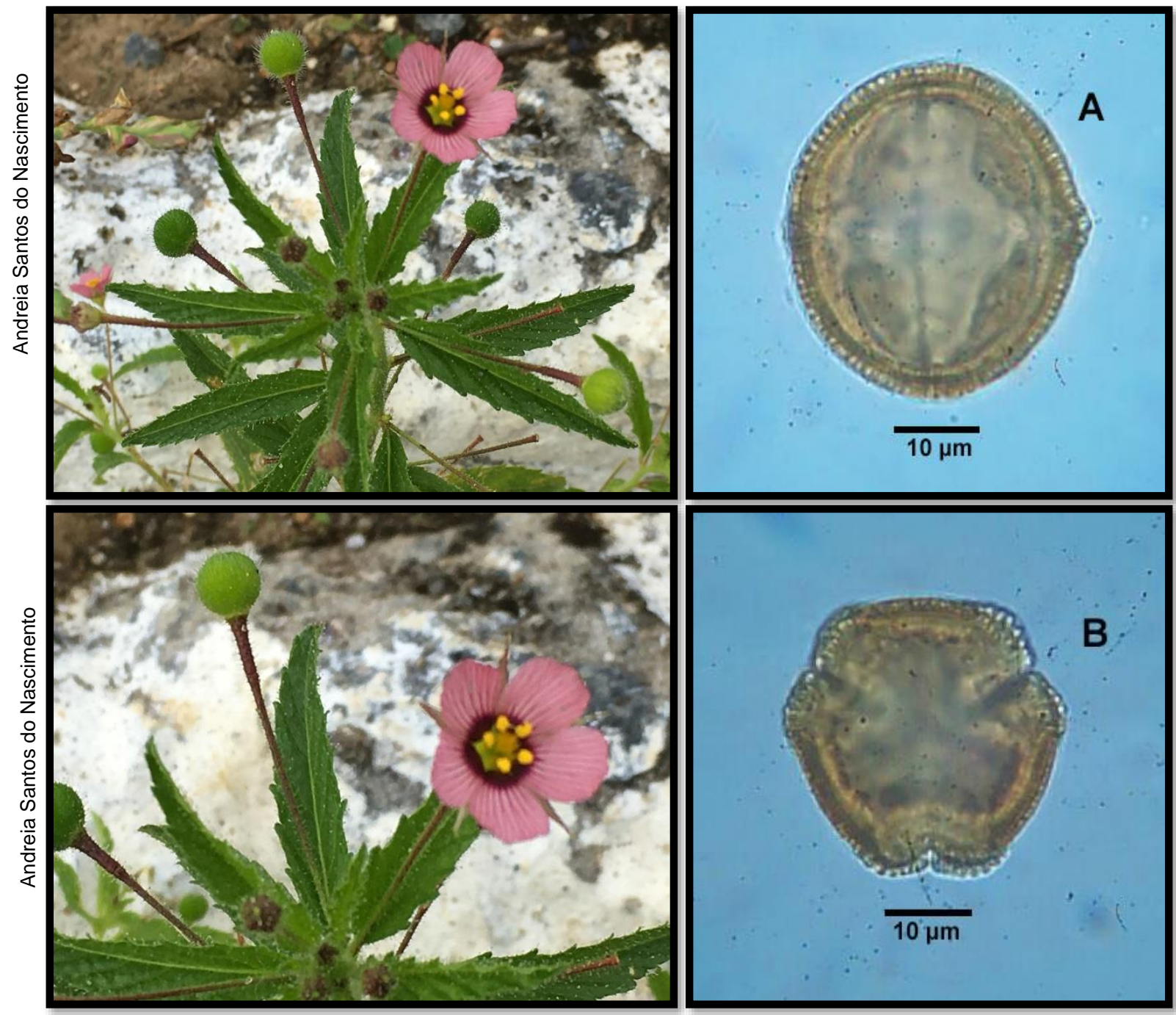

Descrição polínica: $A=$ vista equatorial e $B=$ vista polar, grão de pólen com simetria radial, isopolar, nômade, âmbito subtriangular, abertura polínica do tipo colporo, exina reticulada, tamanho médio, forma subprolata, eixo polar $=35,75 \mu \mathrm{m}$; eixo equatorial $=32,72 \mu \mathrm{m} ; \mathrm{P} / \mathrm{E}=1,09 \mu \mathrm{m}$. 


\section{Turneraceae}

Espécie: Turnera chamaedrifolia Cambess.

Nome comum: Chanana

Hábito de crescimento: herbáceo

Fonte de recurso trófico: néctar/pólen

Período de Floração: março a junho

No Palinoteca: PA 178
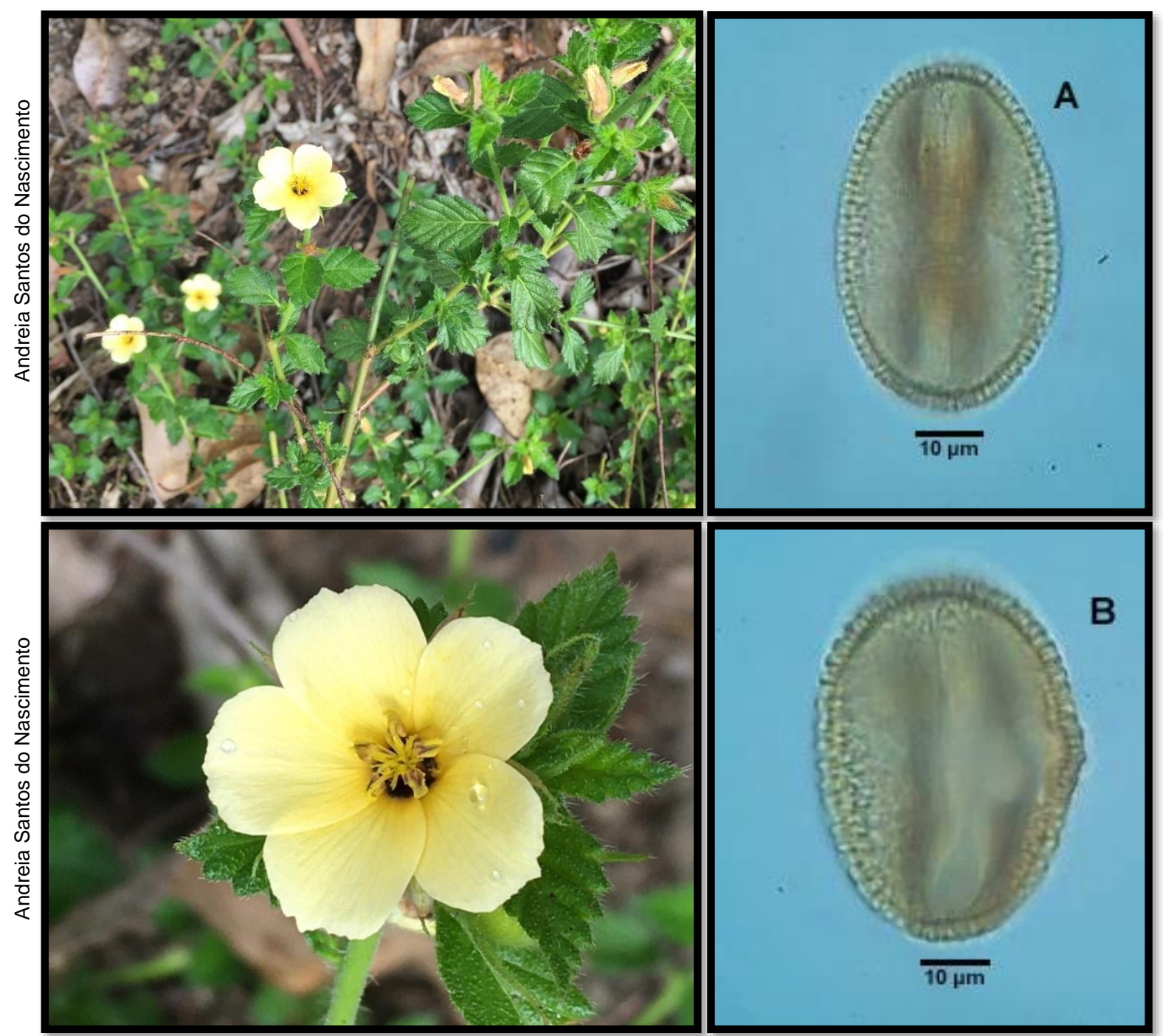

Descrição polínica: $A-B=$ vista equatorial, grão de pólen com simetria radial, isopolar, nômade, âmbito subtriangular, abertura polínica do tipo colporo, exina reticulada, tamanho grande, forma subprolata, eixo polar $=62,12 \mu \mathrm{m}$; eixo equatorial $=47,57 \mu \mathrm{m} ; \mathrm{P} / \mathrm{E}=1,30 \mu \mathrm{m}$. 


\section{Turneraceae}

Espécie: Turnera subulata Sm.

Nome comum: Onze horas

Hábito de crescimento: herbáceo

Fonte de recurso trófico: néctar/pólen

Período de Floração: março a junho

No Palinoteca: PA 20
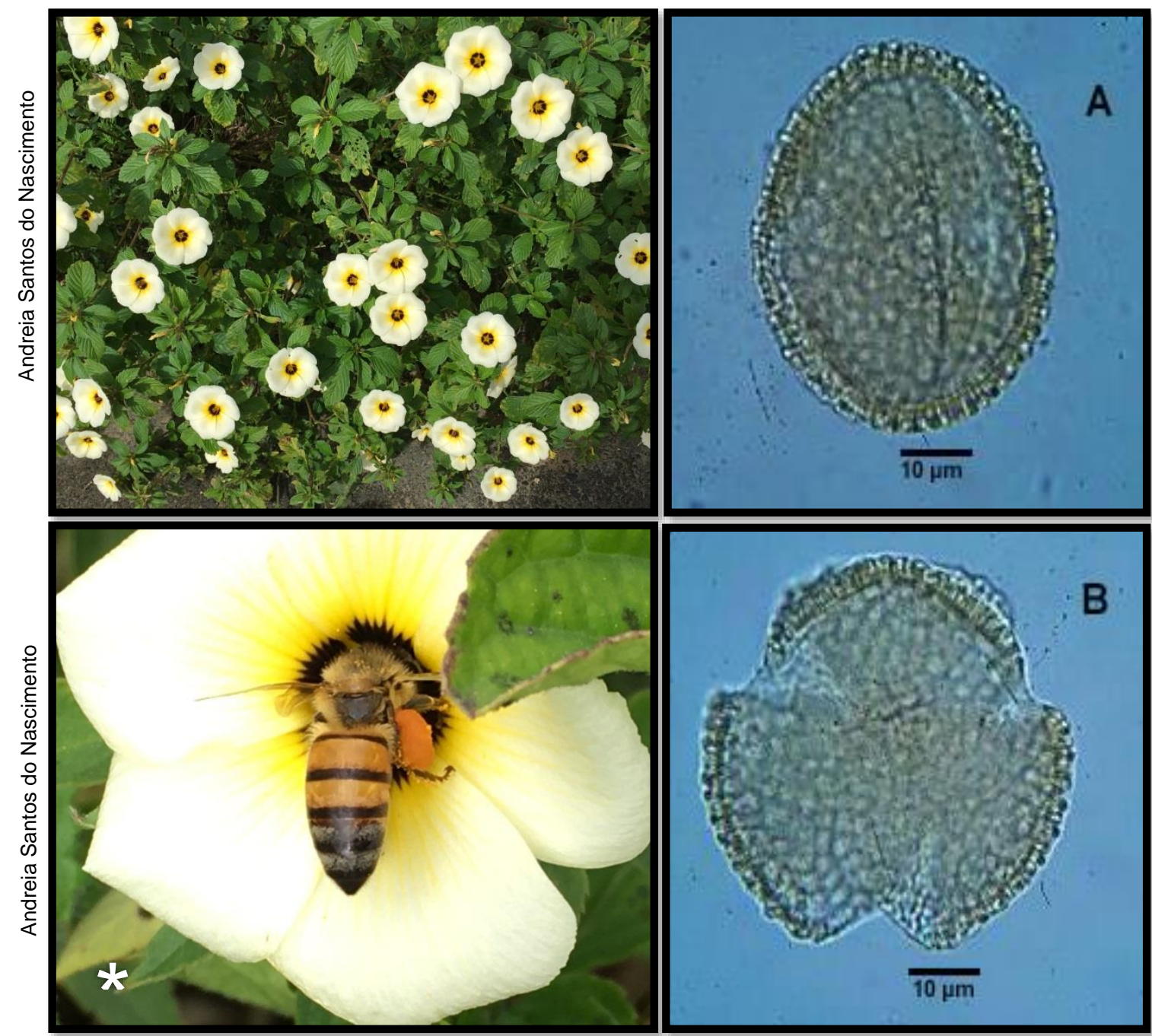

Descrição polínica: $A$ = vista equatorial e $B=$ vista polar, grão de pólen com simetria radial, isopolar, nômade, âmbito subtriangular, abertura polínica do tipo colporo, exina reticulada, tamanho grande, forma prolata, eixo polar $=63,03 \mu \mathrm{m}$; eixo equatorial $=$ 46,66 $\mu \mathrm{m} ; \mathrm{P} / \mathrm{E}=1,35 \mu \mathrm{m}$.

${ }^{*}$ Abelha visitante floral: Apis mellifera Linnaeus, 1758. 


\section{Turneraceae}

Espécie: Turnera ulmifolia L.

Nome comum: Chanana

Hábito de crescimento: herbáceo

Fonte de recurso trófico: néctar/pólen

Período de Floração: março a junho

No Palinoteca: PA 135
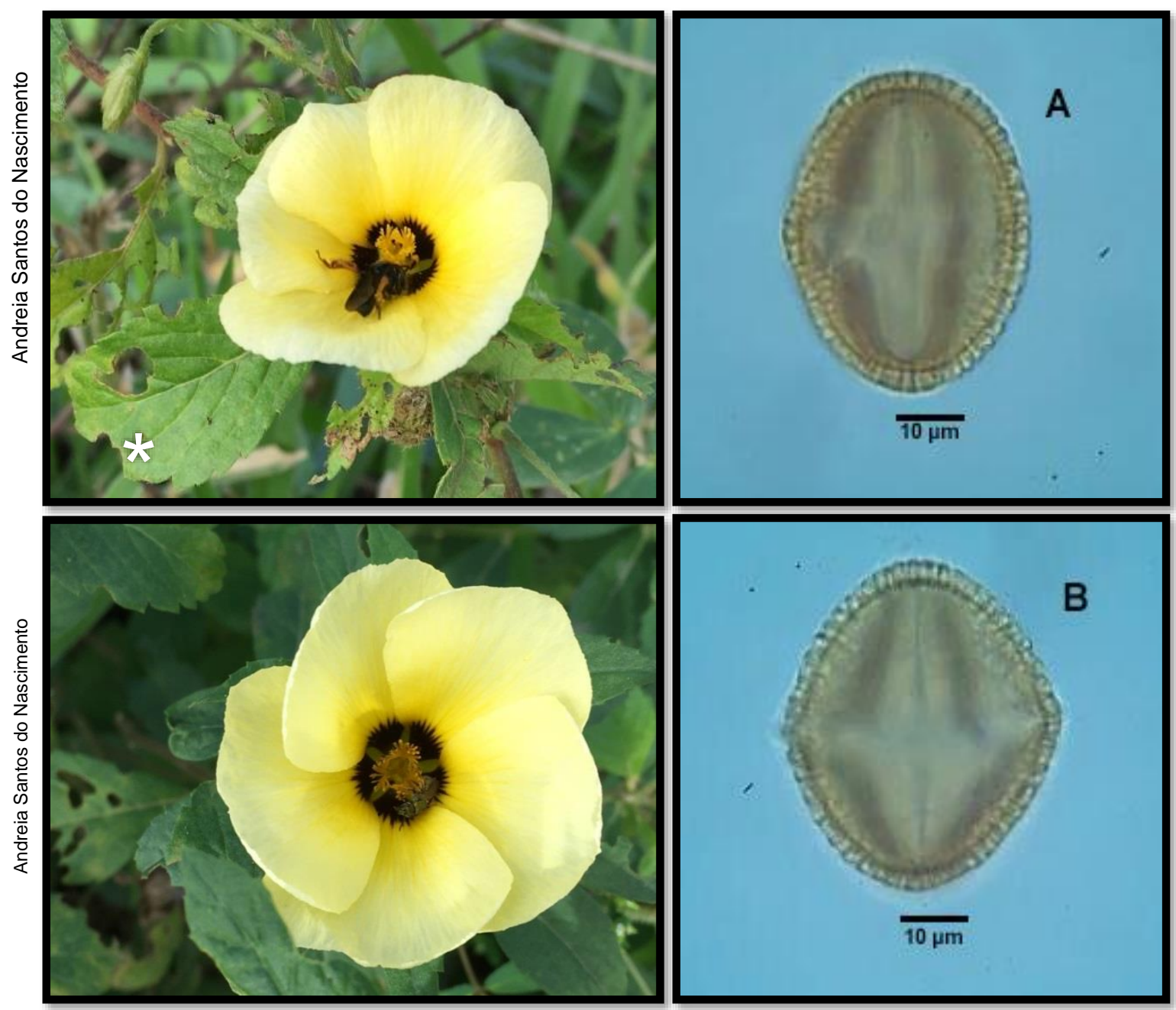

Descrição polínica: $A-B=$ vista equatorial, grão de pólen com simetria radial, isopolar, nômade, âmbito subtriangular, abertura polínica do tipo colporo, exina reticulada, tamanho médio, forma prolata, eixo polar $=48,48 \mu \mathrm{m}$; eixo equatorial $=$ $36,96 \mu \mathrm{m} ; \mathrm{P} / \mathrm{E}=1,31 \mu \mathrm{m}$.

*Abelha visitante floral: Nannotrigona testaceicornis Lepeletier, 1836. 


\section{Verbenaceae}

Espécie: Aloysia gratissima (Gillies \& Hook.) Tronc.

Nome comum: Alfazema

Hábito de crescimento: arbustivo

Fonte de recurso trófico: néctar

Período de Floração: agosto a janeiro

No Palinoteca: PA 57
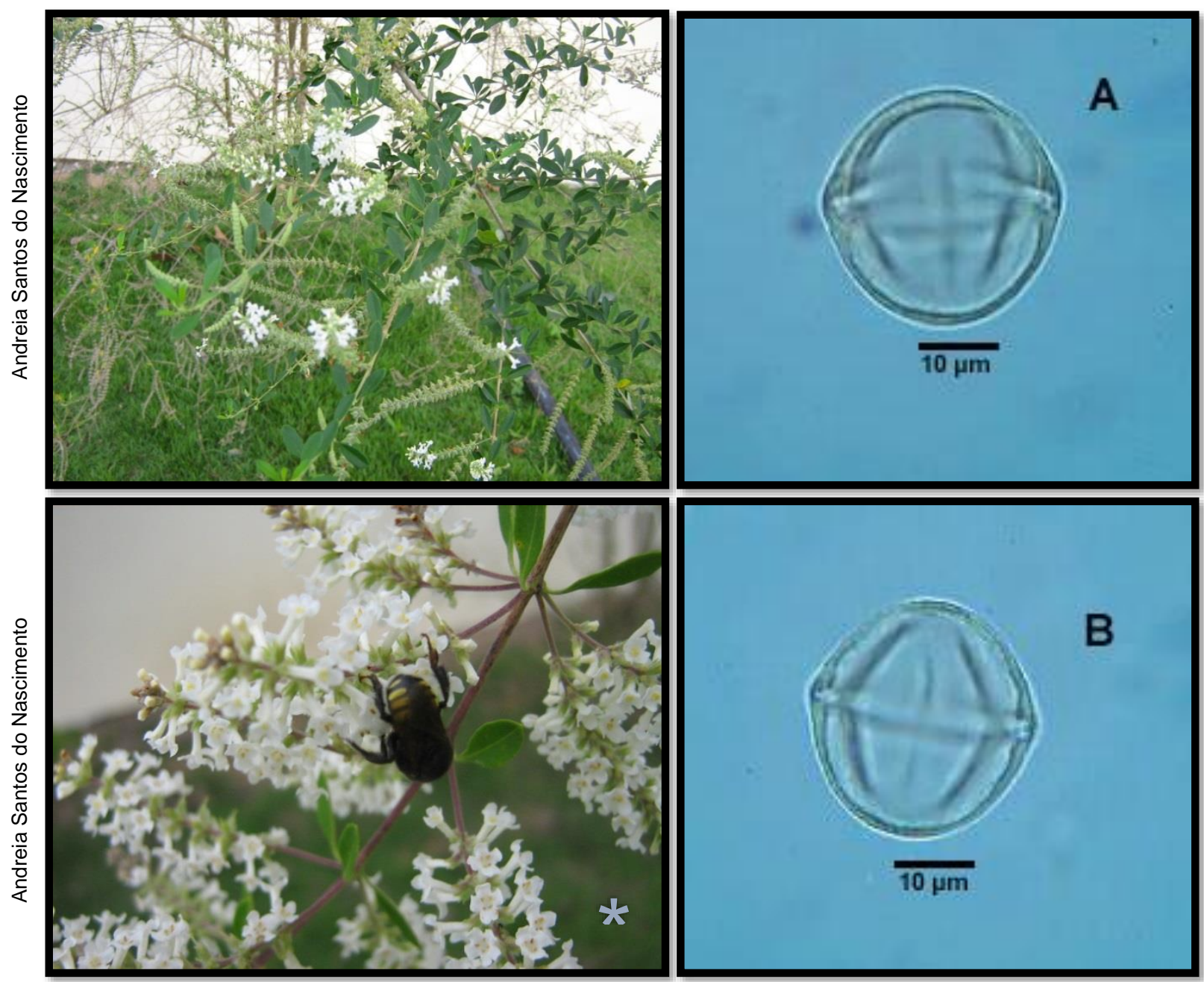

Descrição polínica: $A-B=$ vista equatorial, grão de pólen com simetria radial, isopolar, nômade, âmbito subtriangular, abertura polínica do tipo colporo, exina microrreticulada, tamanho médio, forma prolata esferoidal, eixo polar $=25,45 \mu \mathrm{m}$; eixo equatorial $=24,24 \mu \mathrm{m} ; \mathrm{P} / \mathrm{E}=1,04 \mu \mathrm{m}$.

*Abelha visitante floral: Melipona quadrifasciata anthidioides Lepeletier, 1836. 


\section{Verbenaceae}

Espécie: Aloysia virgata (Ruiz \& Pav.) Juss.

Nome comum: Lixa

Hábito de crescimento: arbustivo

Fonte de recurso trófico: néctar

Período de Floração: outubro a novembro

No Palinoteca: PA 185
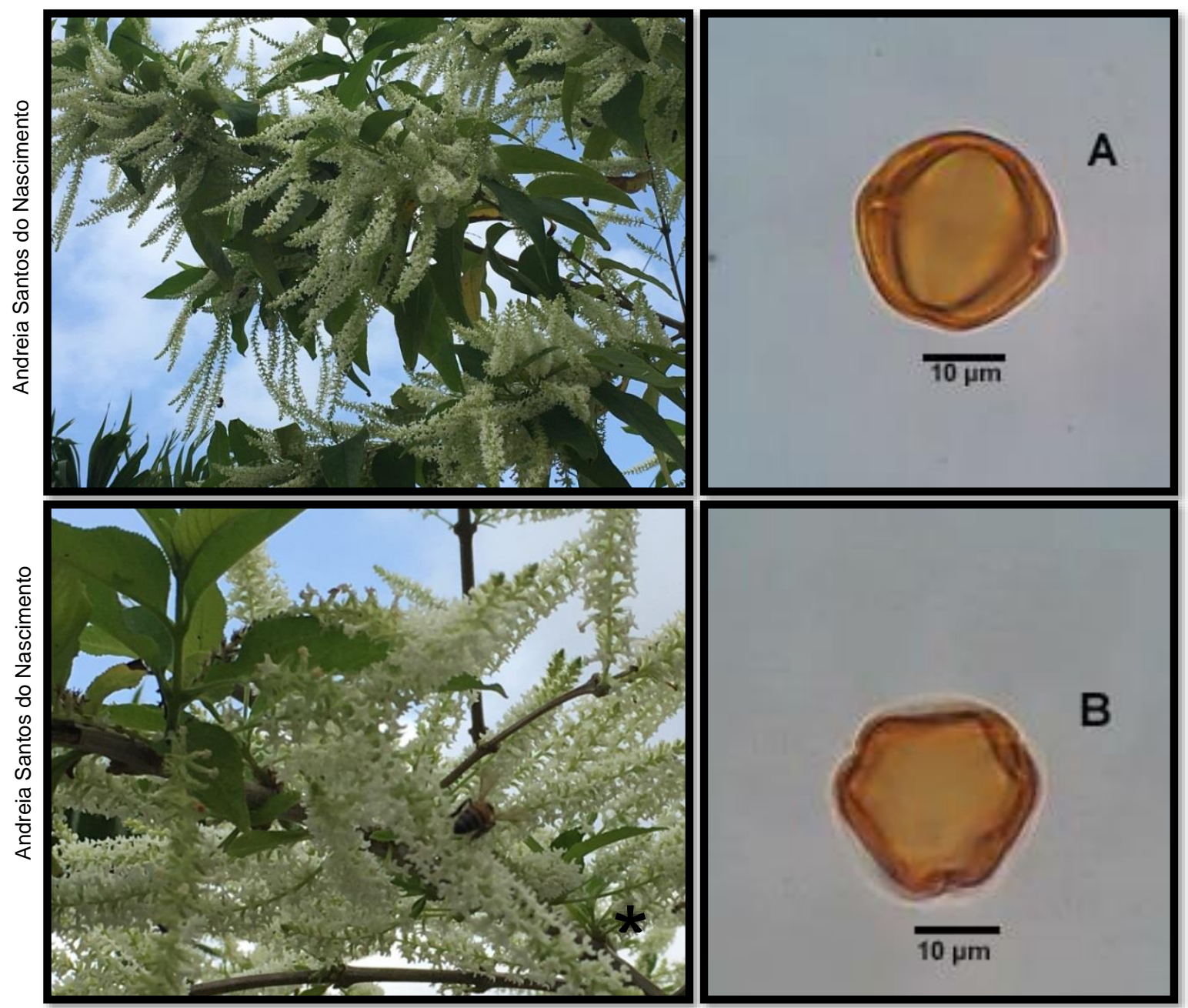

Descrição polínica: $A$ = vista equatorial e $B$ = vista polar, grão de pólen com simetria radial, isopolar, nômade, âmbito subtriangular, abertura polínica do tipo colporo, exina microrreticulada, tamanho pequeno, forma prolata esferoidal, eixo polar $=23,63 \mu \mathrm{m}$; eixo equatorial $=22,72 \mu \mathrm{m} ; \mathrm{P} / \mathrm{E}=1,04 \mu \mathrm{m}$.

*Abelha visitante floral: Apis mellifera Linnaeus, 1758. 


\section{Verbenaceae}

Espécie: Duranta repens L.

Nome comum: Pingo-de-ouro

Hábito de crescimento: arbustivo

Fonte de recurso trófico: néctar

Período de Floração: maio a julho No Palinoteca: PA 54

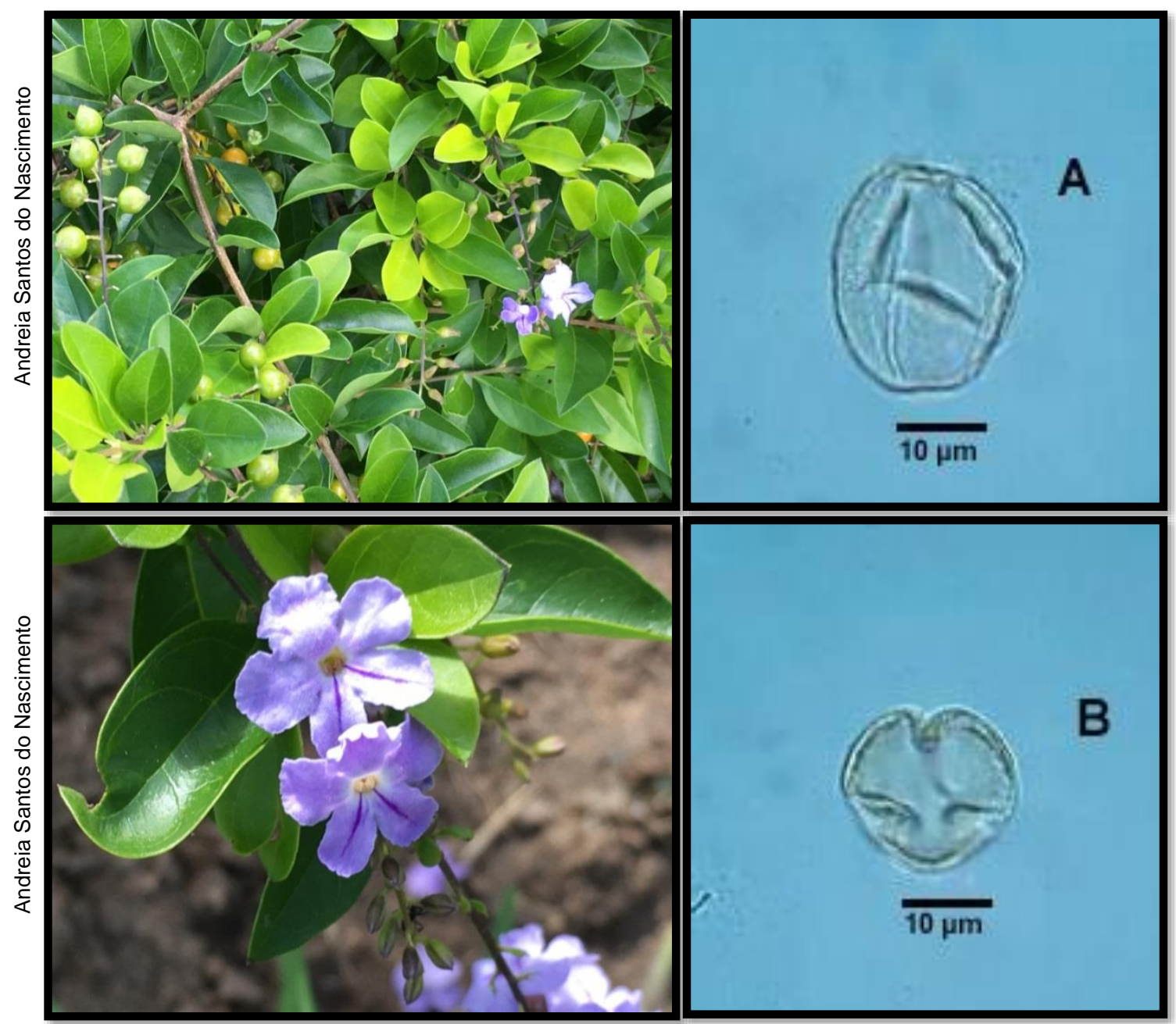

Descrição polínica: $A$ = vista equatorial e $B$ = vista polar, grão de pólen com simetria radial, isopolar, nômade, âmbito subtriangular, abertura polínica do tipo colporo, exina microrreticulada, tamanho médio, forma prolata esferoidal, eixo polar $=27,87$ $\mu \mathrm{m}$; eixo equatorial $=26,06 \mu \mathrm{m} ; \mathrm{P} / \mathrm{E}=1,06 \mu \mathrm{m}$. 


\section{Verbenaceae}

Espécie: Gmelina arborea Roxb.

Nome comum: Teca

Hábito de crescimento: arbóreo

Fonte de recurso trófico: néctar

Período de Floração: abril a junho

No Palinoteca: PA 128
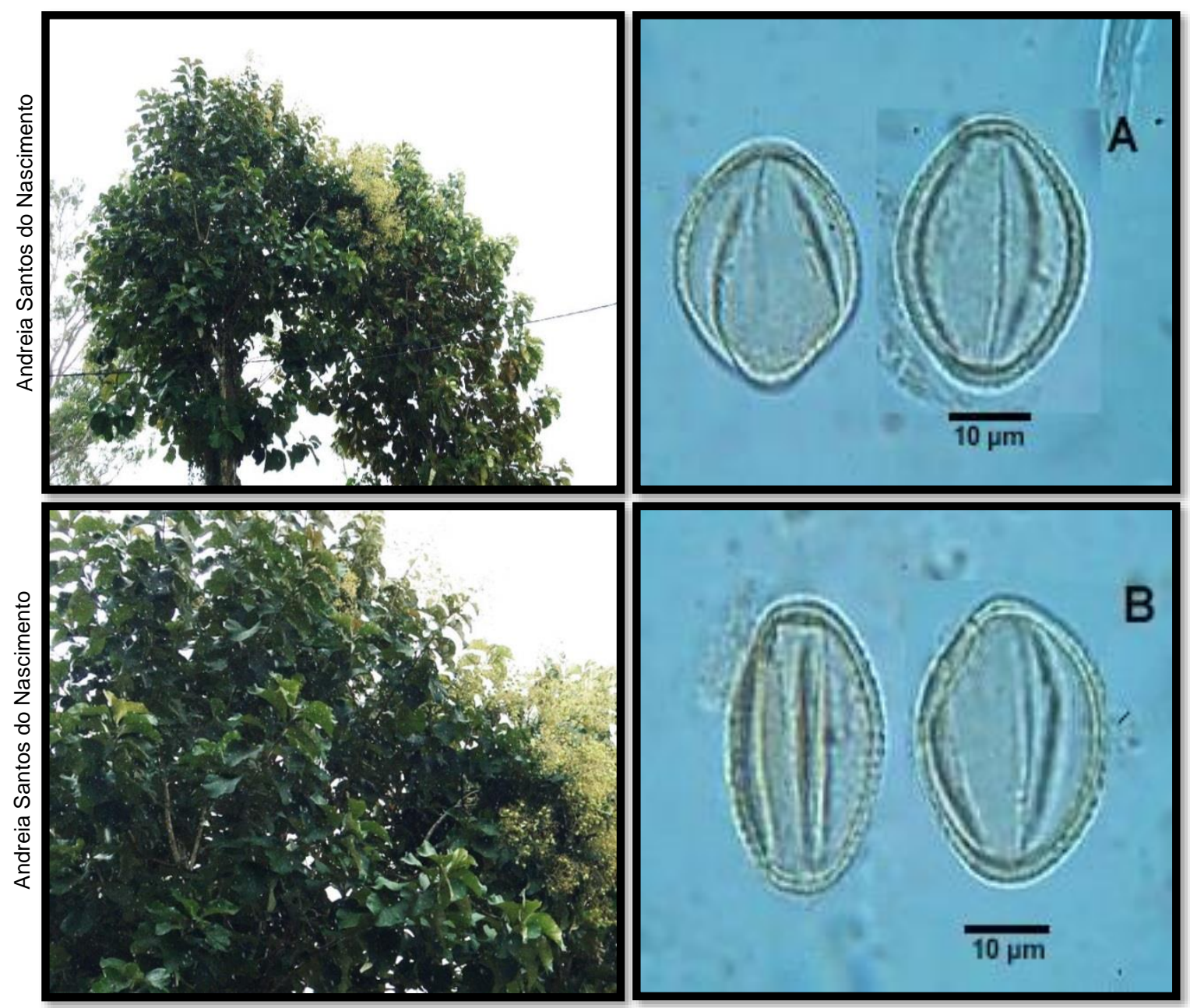

Descrição polínica: $A-B=$ vista equatorial, grão de pólen com simetria radial, isopolar, nômade, âmbito subtriangular, abertura polínica do tipo colporo, exina reticulada, tamanho médio, forma prolata, eixo polar $=30,90 \mu \mathrm{m}$; eixo equatorial $=$ $21,51 \mu \mathrm{m} ; \mathrm{P} / \mathrm{E}=1,43 \mu \mathrm{m}$. 


\section{Verbenaceae}

\section{Espécie: Lantana camara L.}

Nome comum: Cambara

Hábito de crescimento: arbustivo

Fonte de recurso trófico: néctar

Período de Floração: janeiro a dezembro

No Palinoteca: PA 09
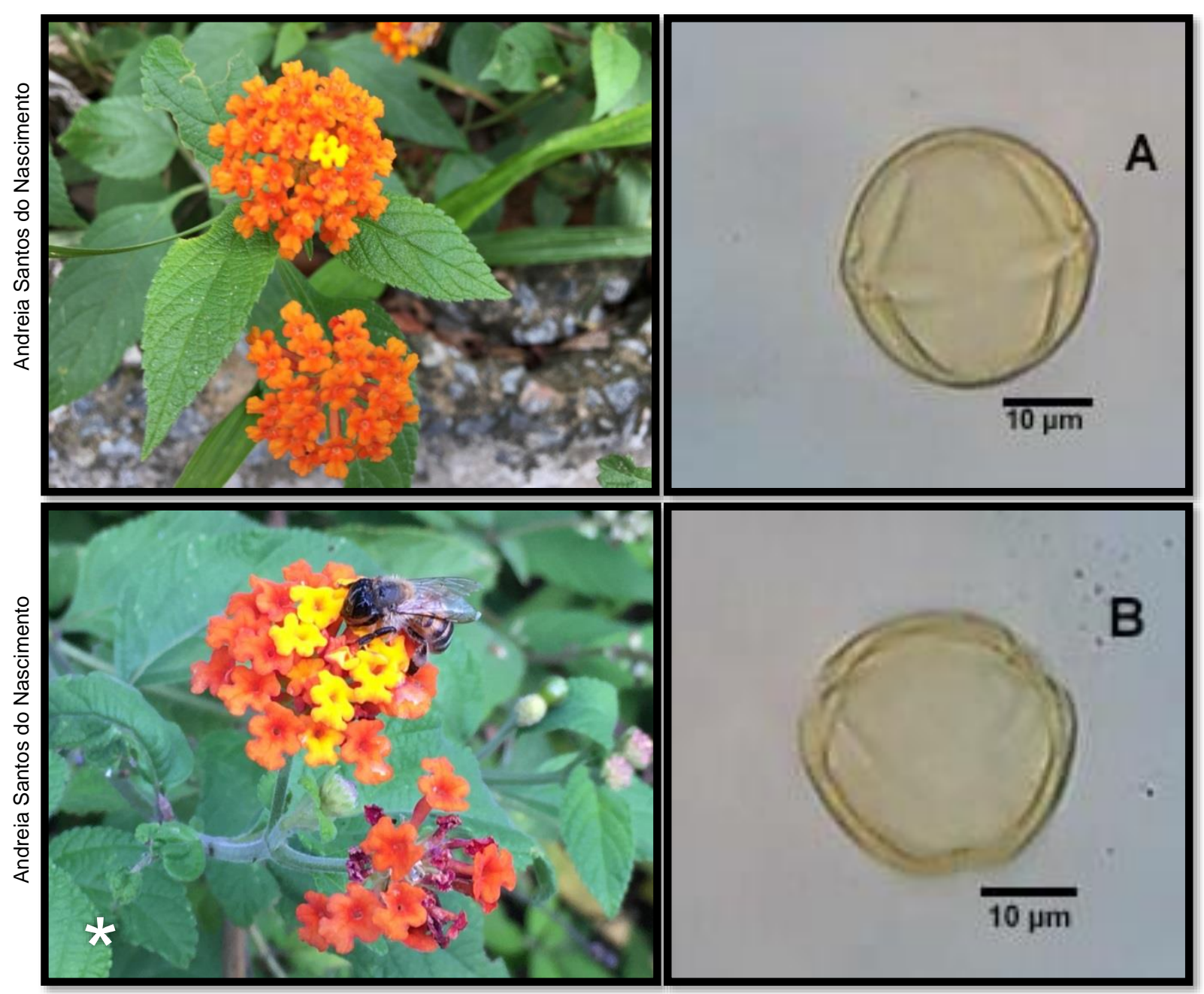

Descrição polínica: $A$ = vista equatorial e $B$ = vista polar, grão de pólen com simetria radial, isopolar, nômade, âmbito subcircular, abertura polínica do tipo colporo, exina regulada, tamanho médio, forma prolata esferoidal, eixo polar $=26,63 \mu \mathrm{m}$; eixo equatorial $=26,36 \mu \mathrm{m} ; \mathrm{P} / \mathrm{E}=1,01 \mu \mathrm{m}$.

*Abelha visitante floral: Apis mellifera Linnaeus, 1758. 


\section{Verbenaceae}

Espécie: Lantana fucata Lindl.

Nome comum: Cambara-rosa; casadinha-branca

Hábito de crescimento: arbustivo

Fonte de recurso trófico: néctar

Período de Floração: janeiro a dezembro

No Palinoteca: PA 05
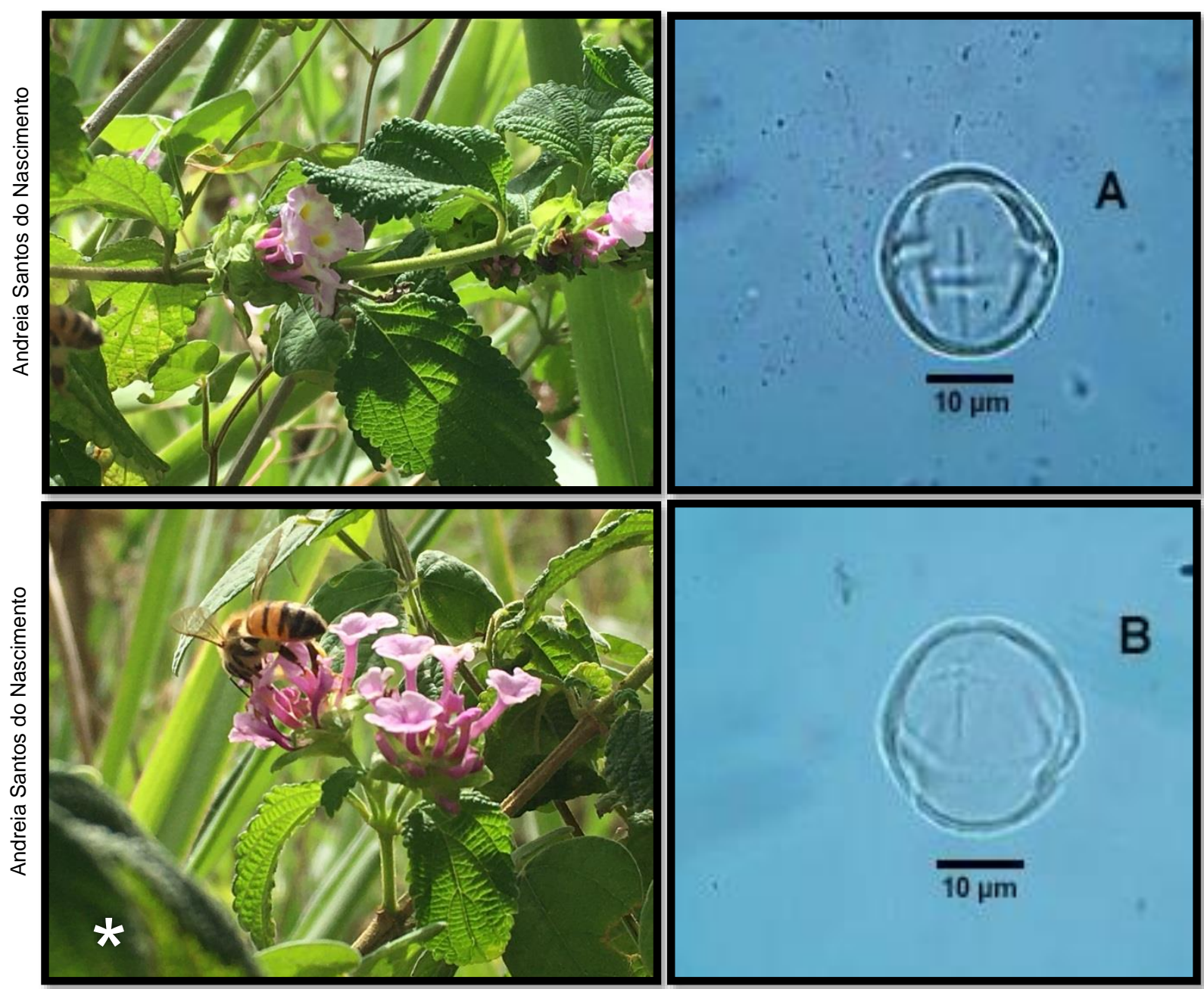

Descrição polínica: $A$ = vista equatorial e $B$ = vista polar, grão de pólen com simetria radial, isopolar, nômade, âmbito subcircular, abertura polínica do tipo colporo, exina regulada, tamanho pequeno, forma prolata esferoidal, eixo polar $=23,63 \mu \mathrm{m}$; eixo equatorial $=22,42 \mu \mathrm{m} ; \mathrm{P} / \mathrm{E}=1,05 \mu \mathrm{m}$.

*Abelha visitante floral: Apis mellifera Linnaeus, 1758. 


\section{Verbenaceae}

Espécie: Lippia alba (Mill.) N.E. Brown

Nome comum: Erva-cidreira

Hábito de crescimento: arbustivo

Fonte de recurso trófico: néctar

Período de Floração: janeiro a agosto No Palinoteca: PA 76
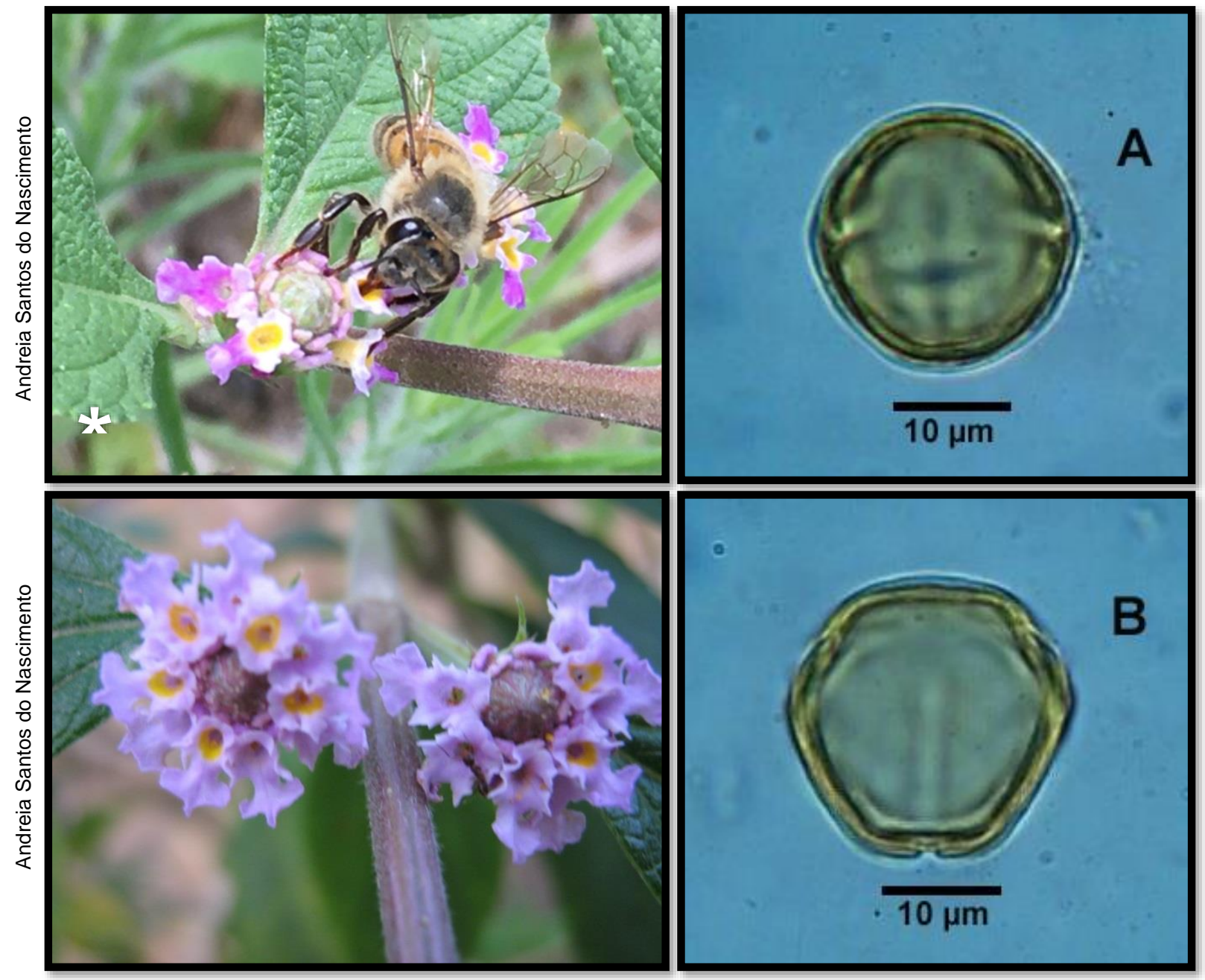

Descrição polínica: $A$ = vista equatorial e $B$ = vista polar, grão de pólen com simetria radial, isopolar, nômade, âmbito subcircular, abertura polínica do tipo colporo, exina microrreticulada, tamanho médio, forma prolata esferoidal, eixo polar $=25,75 \mu \mathrm{m}$; eixo equatorial $=25,45 \mu \mathrm{m} ; \mathrm{P} / \mathrm{E}=1,01 \mu \mathrm{m}$.

*Abelha visitante floral: Apis mellifera Linnaeus, 1758. 


\section{REFERÊNCIAS}

ABEMEL - Associação Brasileira de Exportadores de Mel. Dados estatísticos do mercado de mel: 2016-2020. 13 p. 2020. Disponível em:

https://www.brazilletsbee.com.br/Dados\%20Estat\%C3\%ADsticos\%20do\%20Mercado\%20de \%20Mel_2016_a_2019_11nov2020.pdf. Acesso em: 15 nov. 2020.

ADAMCHUK, L. et al. Methods for determining the botanical origin of honey. Potravinarstvo Slovak Journal of Food Sciences, Eslováquia, v. 14, p. 483-493, 2020.

AGOSTINI, K.; SAZIMA, M. Plantas ornamentais e seus recursos para abelhas no campus da Universidade Estadual de Campinas, Estado de São Paulo, Brasil. Bragantia, Campinas, v. 62 , n. 3, p. 335-343, 2003.

ALMEIDA, D. et al., Plantas visitadas por abelhas e polinização. Piracicaba: ESALQ, 2003. 40 p. (Série Produtor Rural, Edição Especial).

ALOTAIBI, S. S. et al., Pollen molecular biology: applications in the forensic palynology and future prospects: a review. Saudi Journal of Biological Sciences, Riad, v. 27, n. 5, p. 1185-1190, 2020.

ANDRADE, B. R. et al. Pollen spectrum and trophic niche width of Melipona scutellaris Latreille, 1811 (Hymenoptera: Apidae) in highly urbanized and industrialized sites.

Sociobiology, Feira de Santana, v. 66, n. 2, p. 279-286, 2019.

ANDRADE, J. P. et al., Perfil polínico do mel de Melipona scutellaris Latreille, 1811

(Hymenoptera: Apidae) proveniente de colônias instaladas em área de agricultura familiar na Bahia. Revista Brasileira de Agroecologia, Dois Vizinhos, v. 4, n. 2, p. 636-640, 2009.

AZEVEDO, R. L. et al., Abelhas (Hymenoptera: Apoidea) visitantes das flores do feijão guandu no Recôncavo Baiano, Brasil. Ciência Rural, Santa Maria, v. 37, n. 5, p. 1453-1457, 2007.

BARROS, T. F. et al., Abelhas visitantes de flores de Pimpinella anisum L.. Magistra, Cruz das Almas, v. 14, n. 1, p. 55-60, 2002.

BARTH, O. M. O pólen no mel brasileiro. Rio de Janeiro: Luxor, 1989. 150 p.

BARTH, O. M. Pollen analysis and the vegetation. Anuário do Instituto de Geociências, Rio de Janeiro, v. 36, n. 1, p. 112-118, 2013.

BARTH, O. M.; BARBOSA, A. F. Catálogo sistemático dos polens das plantas arbóreas do Brasil Meridional XV - Myrtaceae. Memórias do Instituto Oswaldo Cruz. Rio de Janeiro, v. 70, n. 4, p. 467-476, 1972.

BARTH, O. M.; MELHEM, T. S. Glossário ilustrado de palinologia. Campinas: UNICAMP, 1988. $75 \mathrm{p}$.

BELL, A. D. Plant from: an illustrated guide to flowering plant morphology. Oxford University Press: New York, 1991. 341 p.

BOSCO, L. B.; LUZ, C. F. P. da. Pollen analysis of atlantic forest honey from the Vale do Ribeira region, state of São Paulo, Brazil. Grana, Stockholm, v. 57, n. 1-2, p. 144-157, 2018. 
BRIZOLA-BONACINA, A. K. et al., Bee visitors of quaresmeira flowers (Tibouchina granulosa Cogn.) in the Region of Dourados (MS-Brasil). Sociobiology, Feira de Santana, v. 59, n. 4, p. 1253-1267, 2012.

BRYANT, V. The science of using pollen to study honey. Bee Culture, 2018. Disponível em: https://www.beeculture.com/melissopalynology/. Acesso em: 12 maio. 2020.

CARVALHO, C. A. L. de; MARCHINI, L.C. Plantas visitadas por Apis mellifera L. no vale do rio Paraguaçu, Município de Castro Alves, Bahia. Brazilian Journal of Botany, São Paulo, v. 22, n. 2, p. 333-338, 1999.

CARVALHO, C. A. L. de et al., Pollen spectrum of honey of "uruçu" bee (Melipona scutellaris Latreille, 1811). Revista Brasileira de Biologia, São Carlos, v. 61, n.1, p. 63-67, 2001.

CARVALHO, C. A. L. de et al., Fontes nectaríferas e poliníferas utilizadas por Melipona quadrifasciata (Hymenoptera: Apidae) no Recôncavo Baiano. Magistra, Cruz das Almas, v. 18, n. 4, p. 249-256, 2006.

CARVALHO, C. A. L. de et al., Abelhas (Hymenoptera: Apoidea) visitantes das flores de gliricídia no Recôncavo Baiano. Ciência e Agrotecnologia, Lavras, v. 33, n. 2, p. 606-610, 2009.

ÇELEMLI, O. G. et al., Melissopalynological analysis for geographical marking of Kars honey. Kafkas Universitesi Veteriner Fakultesi Dergisi, [s. I.], v. 24, n. 1, p. 53-59, 2018.

CORREIA, F. C. S.; FRANCISCO, R. S.; PERUQUETTI, R. C. Palinologia e a interação planta-abelha: revisão de literatura. Arquivos de Ciências Veterinárias e Zoologia da UNIPAR, Umuarama, v. 20, n. 4, p. 247-251, 2017.

COSTA, S. N. et al., Perfil polínico da carga de pólen transportada por Melipona scutellaris Latreille, 1811 (Hymenoptera: Apidae) proveniente de colônias instaladas em áreas de agricultura familiar na Bahia. Revista Brasileira de Agroecologia, Dois Vizinhos, v. 4, n. 2, p. 1804-1807, 2009.

EBENEZER, I. O.; OLUGBENGA, M. T. Pollen characterisation of honey samples from north central Nigeria. Journal of Biological Sciences, Dubai, v. 10, n. 1, p. 43-47, 2010.

ERDTMAN, G. Pollen morphology and plant taxonomy. Angiosperms, Stockholm: Almqvist \& Wiksell; Waltham, Mass.: Chronica Botanica Co. 1952. 539 p.

ERDTMAN, G. The acetolysis method. A revised description. Svensk Botanisk Tidskrift, Uppsala, v. 39, n. 4, p. 561-564, 1960.

ESTEVINHO, L. M. et al., Characterization of Lavandula spp. honey using multivariate techniques. Plos One, San Francisco, v. 11, n. 9, e0162206 p. 1-15, 2016.

EVALDT, A. C. P.; PAZ, F. R.; BAUERMANN, S. G. Laboratório de Palinologia da Universidade Luterana do Brasil (ULBRA). Boletín de la Asociación Latinoamericana de Paleobotánica y Palinología, Porto Alegre, n. 14, p. 95-101, 2014.

FELLER-DEMALSY, M. J.; PARENT, J.; STRACHAN, A. A. Microscopic analysis of honeys from Saskatchewan, Canada. Journal of Apicultural Research, Londres, v. 26, n. 4, p. 247-254, 1987. 
FERRI, M. G. Botânica: morfologia externa das plantas (Organografia). 15. ed. São Paulo: Nobel, 1983. 149 p.

JONES, G. D.; BRYANT JR., V. M. The use of ETOH for the dilution of honey. Grana, Stockholm, v. 43, n. 3, p. 174-182, 2004.

LABOURIAU, M. L. S. Contribuição à palinologia dos Cerrados. Rio de Janeiro: Academia Brasileira de Ciências, 1973. 291 p.

LINS, L. Palma-de-Manila, a festa das abelhas. OxeRecife, 2020. Disponível em: http://oxerecife.com.br/2020/06/02/palmeira-de-manila-a-festa-das-abelhas/. Acesso em: 23 maio. 2020.

LOUVEAUX, J.; MAURIZIO, A.; VORWOHL, G. Methods of Melissopalynology. Bee World, Londres, v. 59, n. 4, p. 139-157, 1978.

MACHADO, C. S.; CARVALHO, C. A. L. de. Abelhas (Hymenoptera: Apoidea) visitantes dos capítulos de girassol no recôncavo baiano. Ciência Rural, Santa Maria, v. 36, n. 5, p. 14041409, 2006.

MAGALHÃES, E. O. et al., Própolis: estudo da origem do exsudado resinoso vermelho no caule de Dalbergia ecastophyllum. Mensagem Doce, São Paulo, n. 110, artigo 5, 2011.

Disponível em: https://www.apacame.org.br/mensagemdoce/110/artigo5.htm. Acesso em: 10 abr. 2020.

MAJEWSKA, E.; DRUŻYŃSKA, B.; WOŁOSIAK, R. Determination of the botanical origin of honeybee honeys based on the analysis of their selected physicochemical parameters coupled with chemometric assays. Food Science and Biotechnology, Gangnam-gu, v. 28, n. 5, p. 1307-1314, 2019.

MATOS, V. R. M.; SANTOS, F. A. R. Pollen in honey of Melipona scutellaris L. (Hymenoptera: Apidae) in an Atlantic rainforest area in Bahia, Brazil. Palynology, Stockholm, v. 41, n. 1, p. 144-156, 2017.

MORETI, A. C. de C. C. et al., Espectro polínico de amostras de mel de Apis mellifera L., coletadas na Bahia. Bragantia, Campinas, v. 59, n.1, p. 1-6, 2000.

NASCIMENTO, A. S. do et al. Recursos nectaríferos e poliníferos explorados por Melipona quadrifasciata anthidioides em Cruz das Almas, Bahia. Magistra, Cruz das Almas, v. 21, n. especial, p. 25-29, 2009.

NASCIMENTO, A. S. et al. Honey from stingless bee as indicator of contamination with metals. Sociobiology, Feira de Santana, v. 65, n. 4, p. 727-736, 2018.

NASCIMENTO, A. S.; CARVALHO, C. A. L. de; MARTINS, M. L. L. Plants visited by Apis mellifera L. (Hymenoptera: Apidae) in Recôncavo Baiano, State of Bahia, Brazil. Revista de Agricultura, Piracicaba, v. 89, n. 2, p. 97-116, 2014.

NASCIMENTO, A. S.; CARVALHO, C. A. L. de; SODRÉ, G. da S. The pollen spectrum of Apis mellifera honey from Reconcavo of Bahia, Brazil. Journal of Scientific Research and Reports, Chhattisgarh, v. 6, n. 6, p. 426-438, 2015. 
NASCIMENTO, A. S.; NASCIMENTO, A. S. do; CARVALHO, C. A. L. de. Honey: the main product of Brazilian beekeeping activity and its quality requirements. In: PEREIRA, A. I. A. (ed.). Coletânea nacional sobre entomologia 2. Ponta Grossa: Atena, 2020, cap. 7, p. 7888.

NASCIMENTO, A.S. do; CARVALHO, C. A. L. de. Pollen morphology of Myrtaceae visited by social bees. Plant Science Today, [s. I.], v. 6, n.2, p. 98, 2019.

NEVES, C. M. de L. et al., Pollen consumed by the solitary bee Tetrapedia diversipes (Apidae: Tetrapediini) in a tropical agroecosystem. Grana, Stockholm, v. 53, n. 4, p. 1-7, 2014.

NORDI, J. C.; BARRETO, L. M. R. C. Flora apícola e polinização. São Paulo: Cabral, 2016. $80 \mathrm{p}$.

OLIVEIRA, D. de J. et al., Botanical origin, microbiological quality and physicochemical composition of the Melipona scutellaris pot-pollen (samburá) from Bahia (Brazil) Region. Journal of Apicultural Research, Londres, v. 59, p. 1-13, 2020.

OLIVEIRA, G. A. de; CARVALHO, C. A. L. de; AONA, L. Y. S. Biologia Floral de Cardiospermum corindum L. f. parviflorum (A. St.-Hil., A. Juss. \& Cambess.) Radlk.

(Sapindaceae) no Recôncavo da Bahia, Brasil. Magistra, Cruz das Almas, v. 25, n. 1, p. 6372, 2013.

OSTERKAMP, I. C.; JASPE, A. Análise palinológica em méis da região do vale do Taquari, Rio Grande do Sul, Brasil: ferramenta para a definição de origem botânica. Revista Destaques Acadêmicos, Lajeado, v. 5, n. 3, p. 111-119, 2013.

PAREDES, R.; BRYANT, V. M. Pollen analysis of honey samples from the Peruvian Amazon. Palynology, Stockholm, v. 44, n. 2, p. 344-354, 2020.

PUNT, W. et al. Glossary of pollen and spores terminology. Review of Palaeobotany and Palynology, Amsterdam, v. 143, p. 1-81. 2007.

QUEZADA-EUÁN, J. J. G. The Past, present, and future of meliponiculture in Mexico. In: QUEZADA-EUÁN, J. J. G. (ed.), Stingless bees of Mexico. New York: Springer International Publishing, 2018. p. 243-269.

RAMALHO, M.; SILVA, M. D.; CARVALHO, C. A. L. Dinâmica de uso de fontes de pólen por Melipona scutellaris Latreille (Hymenoptera: Apidae): uma análise comparativa com Apis mellifera L. (Hymenoptera: Apidae), no Domínio Tropical Atlântico. Neotropical Entomology, Londrina, v. 36, p. 38-45, 2007.

RIBEIRO, G. S.; ALVES, E. M.; CARVALHO, C. A. L. de. Biology of pollination of Citrus sinensis variety 'pera rio'. Revista Brasileira de Fruticultura, Jaboticabal, v. 39, p. e-033, 2017.

RICCIARDELLI, D. G.; GALARINI, R.; RICCIARDELLI, D. M. Mediterranean Melissopalynology. 2020. Disponível em:

http://www.izsum.it/Melissopalynology/index.htm?8. Acesso em: 10 out. 2020. 
ROUBIK, D. W.; MORENO, J. E. P. Pollen and Spores of Barro Colorado Island. [St. Louis]: Missouri Botanical Garden, v. 36, 1991. 268 p.

SANFORD, M. T.; TEW J. E. Apiculture (beekeeping). In: Capinera J. L. (eds.). Encyclopedia of entomology. p. 147-158. Dordrecht: Springer, 2004. p. 215-229.

SANT'ANA, R. S. et al., Characterization of honey of stingless bees from the Brazilian semiarid region. Food Chemistry, Bruxelas, v. 327, article 127041, p. 1-6, 2020.

SANTANA, A. L. A. et al., Experiências com oficinas sobre plantas apícolas e meliponícolas com agricultores familiares do território do Recôncavo Baiano. Revista Brasileira de Agroecologia, Dois Vizinhos, v. 4, n. 1, p. 1455-1458, 2009.

SANTOS, A. M. V. et al., Pollen spectrum of the honey of Apis mellifera L. collected in the period of honey production. Scientific Electronic Archives, Rondonópolis, v. 12, n. 6, p. 6976, 2019.

SANTOS, F. A. R. et al., Grupos de uso e as espécies prioritárias: espécies melíferas. In: CORADIN, L.; CAMILLO, J.; PAREYN, F. G. C. (ed.). Espécies nativas da flora brasileira de valor econômico atual ou potencial: plantas para o futuro: região Nordeste. Brasília: MMA, 2018, cap. 5, p. 969-1010.

SANTOS, F. A. R. Identificação botânica do pólen apícola. Magistra, Cruz das Almas, v. 23, n. especial. p. 5-9, 2011.

SANTOS, P. C. et al., Pollen spectrum of honey of Apis mellifera L. and stingless bees (Hymenoptera: Apidae) from the semi-arid region of Bahia State, Brazil. Grana, Stockholm, v. 59 , n. 5 , p. 377-388, 2020.

SEI - Superintendência de Estudos Econômicos e Sociais da Bahia. Novos limites dos 20 municípios do Recôncavo são fechados com consenso. 2020. Disponível em: https://www.sei.ba.gov.br/index.php?option=com_content\&view=article\&id=2289\&ltemid=26. Acesso em: 14 out. 2020.

SILVA, A. P. C.; SANTOS, F. A. R. Pollen diversity in honey from Sergipe, Brazil. Grana, Stockholm, v. 53, n. 2, p. 159-170, 2014.

SILVA, C. I. et al., Catálogo polínico das plantas usadas por abelhas no campus da USP de Ribeirão Preto. Ribeirão Preto: Holos, 2014. 153 p.

SILVA, I. P. et al., Antioxidants activity and physicochemical properties of honey from social bees of the Brazilian semiarid region. Journal of Apicultural Research, Londres, v. 2020, p. 1- 11, 2020.

SILVA, M. L. da et al., As abelhas de Santa Catarina, Brasil, possuem apenas DNA mitocondrial africano. Arquivo Brasileiro de Medicina Veterinária e Zootecnia, Belo Horizonte, v. 64, n. 2, p. 518-520, 2012.

SNIDERMAN, J. et al., Pollen analysis of Australian honey. Plos One, San Francisco, v. 13, n. 5, e0197545, p. 1-24, 2018. 
UFRB - Universidade Federal do Recôncavo da Bahia. Recôncavo da Bahia. 2020.

Disponível em: https://www2.ufrb.edu.br/chave-plant-aq/index.php/reconcavo-da-bahia. Acesso em: 12 out. 2020.

VILLAS-BÔAS, J. Aproveitamento integral dos produtos das Abelhas nativas sem ferrão. 2 ed. Brasília: ISPN, 2018. 212 p. 
Agência Brasileira ISBN

ISBN: 978-65-86230-68-0 

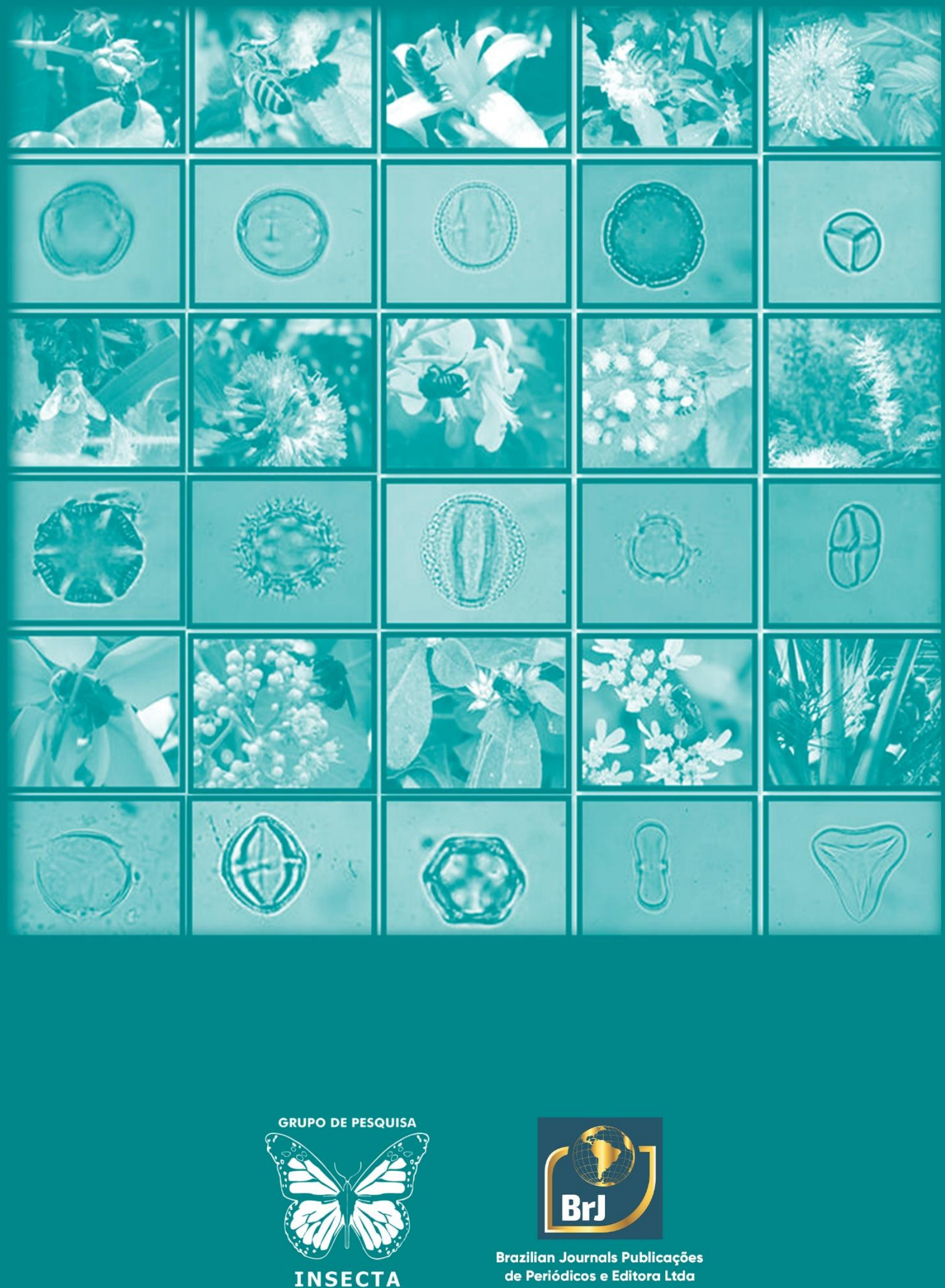

ISBN: 978-65-86230-68-0 